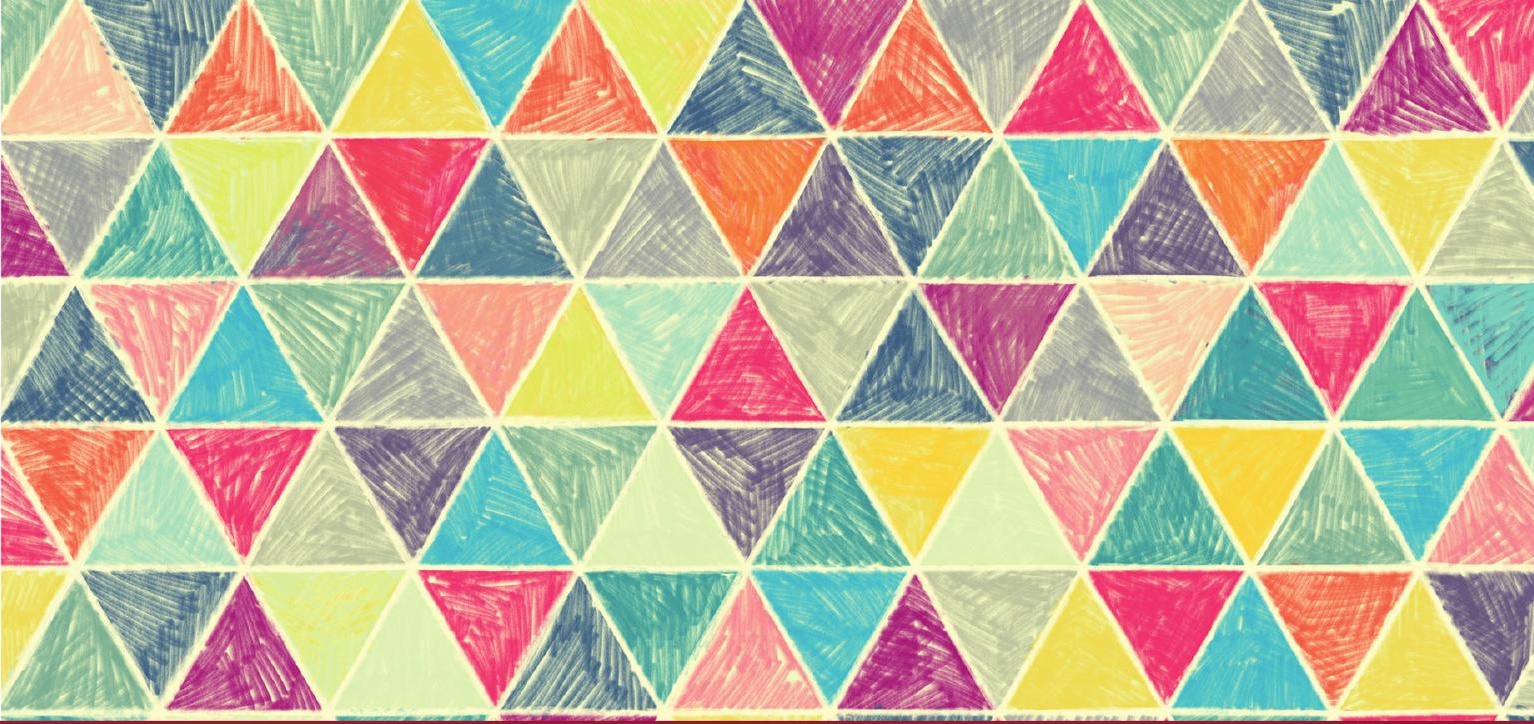

Routledge Studies in Media, Communication, and Politics

\title{
HATE SPEECH AND POLARIZATION IN PARTICIPATORY SOCIETY
}

Edited by

Marta Pérez-Escolar and

José Manuel Noguera-Vivo

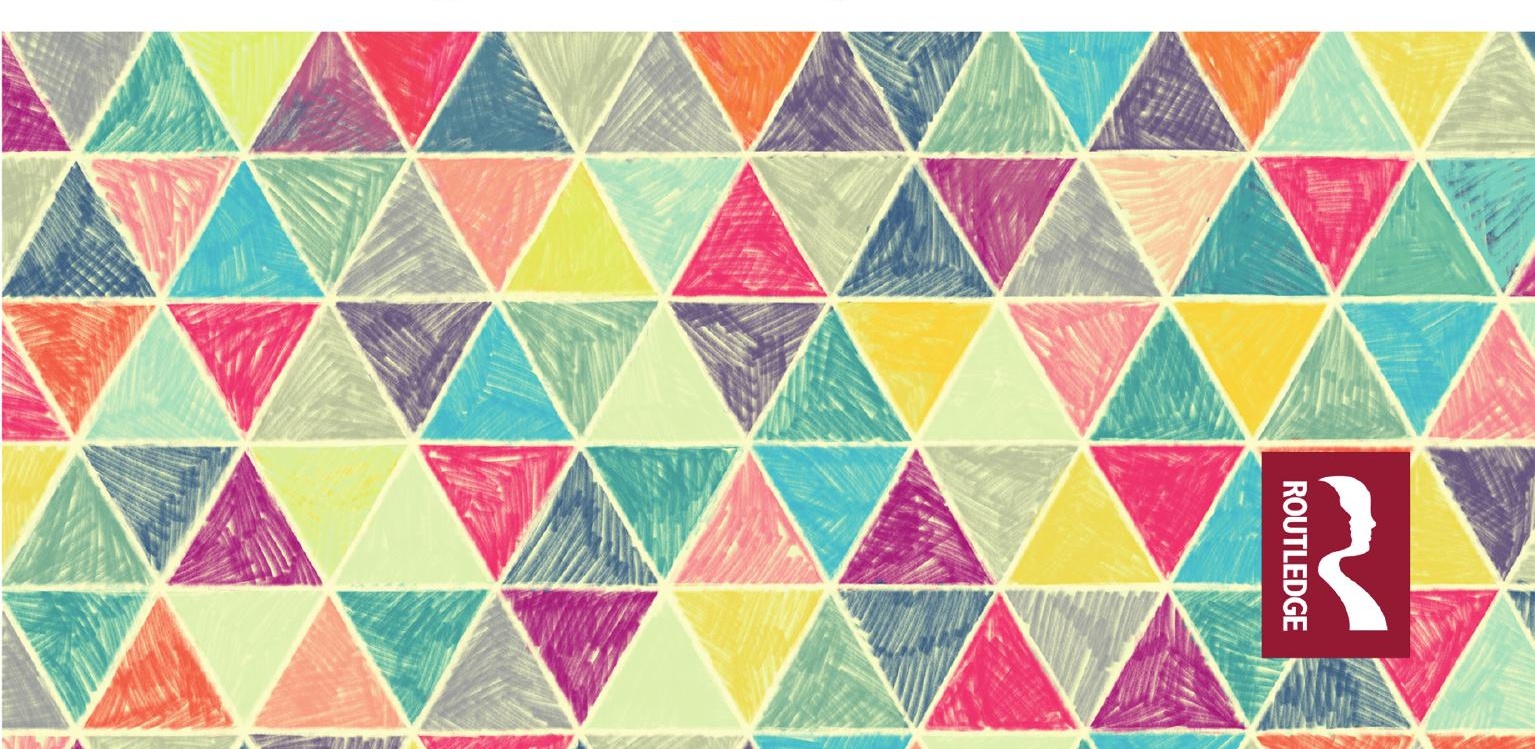


This volume brings a whole range of colours in the black-and-white debate on technologies and participatory society. Both the cyber-optimistic views about a brave new Internet fuelled participatory democracy and the simplistic techno-fatalist criticism solely focused on data-driven corporations contribute to misguide the understanding of the complex social process that characterises media in the 21st century. Between these two extremes there is a necessary room for a rich comprehension of the entanglements amongst the new connectivities, the new flows of information and the social configurations that come along them. The state-of-the-art analyses included in this volume definitely contribute to relocate the discussion on hate speech and disinformation in the open, wide frame its complexity demands.

Juan Miguel Aguado, Full Professor of Media and

Communication, Mobile Media Research Lab, School of Information and Media Studies, University

of Murcia, Spain

Hate Speech and Polarization in Participatory Society provides a timely perspective on core issues of contemporary society and culture. The lineup of authors is admirable and delivers a truly multi-national approach on the many facets and contexts of hate speech and polarization. Although hate speech is often practiced under the guise of free speech, it can in fact be used to impede deliberation and freedom of speech of others - these phenomena are not only dark sides of peer-to-peer social media, but exist also in political and media representations. The volume thus assembles a rich and many-sided perspective on hate speech and polarization, adopting realistic connotations of the potentials of participatory society.

Mikko Villi, Professor of Journalism Studies, Department of Language and Communication Studies, University of Jyväskylä, Finland

This book is an astute volume that challenges preconceptions and informs perspectives on one of the most pressing issues of our time. Hate speech and polarization have significant consequences for society if they are left misunderstood and misrepresented. Cognizant that hate speech and polarization are global challenges, Hate Speech and Polarization in Participatory Society brings together a broad range of leading scholars from across the world to provide shrewd insights from diverse contexts. The edited collection is a nuanced intervention that unpacks the potential, promise and peril of participatory media.

Alfred Hermida, Professor of Journalism, Writing, and Media, University of British Columbia, Canada 

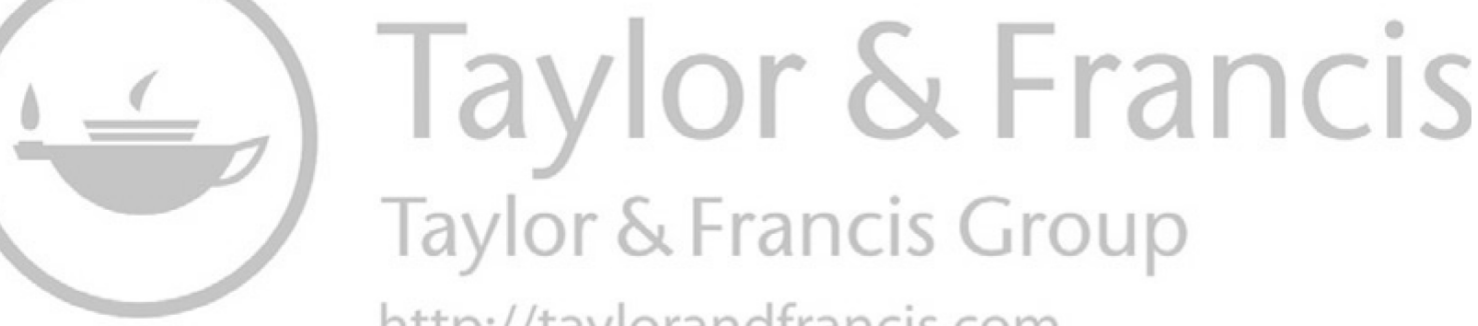
http://taylorandfrancis.com 


\section{Hate Speech and Polarization in Participatory Society}

This timely volume offers a comprehensive and rigorous overview of the role of communication in the construction of hate speech and polarization in the online and offline arena.

Delving into the meanings, implications, contexts and effects of extreme speech and gated communities in the media landscape, the chapters analyse misleading metaphors and rhetoric via focused case studies to understand how we can overcome the risks and threats stemming from the past decade's defining communicative phenomena. The book brings together an international team of experts, enabling a broad, multidisciplinary approach that examines hate speech, dislike, polarization and enclave deliberation as cross axes that influence offline and digital conversations. The diverse case studies herein offer insights into international news media, television drama and social media in a range of contexts, suggesting an academic frame of reference for examining this emerging phenomenon within the field of communication studies.

Offering thoughtful and much-needed analysis, this collection will be of great interest to scholars and students working in communication studies, media studies, journalism, sociology, political science, political communication and cultural industries.

Marta Pérez-Escolar is an assistant professor in the Department of Communication at Loyola University (Sevilla, Spain). She received the Civic Participation, Transparency and Good Governance PhD Extraordinary Award in 2018, awarded by the Region of Murcia (Spain). Her main lines of research are focused on civic participation, public opinion, political communication and information disorders.

José Manuel Noguera-Vivo is an associate professor of Journalism at UCAM, Spain, where he also is head of Sciences Communication Department. His research emerges from the synergy of society, tech, and journalism. He is responsible of Spanish division of Online News Association and Science Communication Manager of the European project Interactive Narrative Design for Complexity Representations. 


\section{Routledge Studies in Media, Communication, and Politics}

Human Rights, Iranian Migrants, and State Media

From Media Portrayal to Civil Reality

Shabnam Moinipour

Threat Communication and the US Order after 9/11

Medial Reflections

Edited by Vanessa Ossa, David Scheu and Lukas R.A. Wilde

Rhetoric, Fantasy, and the War on Terror

Vaheed Ramazani

Generational Gaps in Political Information Use and Civic Engagement From Baby Boomers to Generation Z

Kim Andersen, Jakob Ohme, Camilla Bjarnøe, Mats Joe Bordacconi, Erik Albce, and Claes de Vreese

Solidarity in the Media and Public Contention over Refugees in Europe Edited by Manlio Cinalli, Hans-Joerg Trenz, Verena Brändle, Olga Eisele and Christian Labusen

Populist Disinformation in Fragmented Information Settings Understanding the Nature and Persuasiveness of Populist and Post-factual Disinformation Michael Hameleers

Hate Speech and Polarization in Participatory Society Edited by Marta Pérez-Escolar and José Manuel Noguera-Vivo

For more information about this series, please visit: https://www.routledge.com 


\section{Hate Speech and Polarization in Participatory Society}

Edited by

Marta Pérez-Escolar and

José Manuel Noguera-Vivo

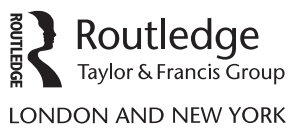


First published 2022

by Routledge

2 Park Square, Milton Park, Abingdon, Oxon OX14 4RN

and by Routledge

605 Third Avenue, New York, NY 10158

Routledge is an imprint of the Taylor \& Francis Group, an informa business

(C) 2022 selection and editorial matter, Marta Pérez-Escolar and

José Manuel Noguera-Vivo; individual chapters, the contributors

The right of Marta Pérez-Escolar and José Manuel Noguera-

Vivo to be identified as the authors of the editorial material, and

of the authors for their individual chapters, has been asserted in accordance with sections 77 and 78 of the Copyright, Designs and

Patents Act 1988.

All rights reserved. No part of this book may be reprinted or reproduced or utilised in any form or by any electronic, mechanical, or other means, now known or hereafter invented, including photocopying and recording, or in any information storage or retrieval system, without permission in writing from the publishers.

Trademark notice: Product or corporate names may be trademarks or registered trademarks, and are used only for identification and explanation without intent to infringe.

British Library Cataloguing-in-Publication Data

A catalogue record for this book is available from the British Library

Library of Congress Cataloging-in-Publication Data

A catalog record has been requested for this book

ISBN: 9780367625986 (hbk)

ISBN: 9780367626013 (pbk)

ISBN: 9781003109891 (ebk)

DOI: $10.4324 / 9781003109891$

Typeset in Sabon

by codeMantra 


\section{Contents}

Lists of illustrations $\quad \mathrm{xi}$

List of contributors xiii

Preface xvii

Original Preface in Spanish xxi

Acknowledgements $\quad$ xxv

1 Introduction to the dilemmas and struggles of participatory society

MARTA PÉREZ-ESCOLAR AND JOSÉ MANUEL NOGUERA-VIVO

\section{PART I}

Contextualizing the participatory society: Metaphors for polarization and hate speech

2 How did we get here? The consequences of deceit in addressing political polarization

MARTA PÉREZ-ESCOLAR AND JOSÉ MANUEL NOGUERA-VIVO

3 Echo chambers? Filter bubbles? The misleading metaphors that obscure the real problem

AXEL BRUNS

4 Hate speech and deliberation: Overcoming the

"words-that-wound" trap 
viii Contents

PART II

Political and ideological polarisation

5 There ain't no rainbow in the 'rainbow nation':

A discourse analysis of racial conflicts on twitter

hashtags in post-apartheid South Africa

ALLEN MUNORIYARWA

6 Blessed be the fight: Misogyny and anti-feminism in

The Handmaid's Tale

LAURA CORTÉS-SELVA AND SUSANA MARTÍNEZ-GUILLEM

7 Discursive construction of affective polarization in Brexit Britain: Opinion-based identities and out-group differentiation

MONIKA BRUSENBAUCH MEISLOVÁ

8 The public debate on Twitter in the Iberian sphere:

Comparative analysis of the characteristics in

Portugal and Spain

JUAN ANTONIO MARÍN ALBALADEJO AND JOÃO FIGUEIRA

9 Towards a new left-populist rhetoric in Turkey: Discourse analysis of İmamoğlu's campaign

GÜLÜM ŞENER, HAKAN YÜCEL AND UMUR YEDIKARDEŞ

10 Anti-immigrant hate speech as propaganda: A comparison between Donald Trump and Santiago Abascal on Twitter

ANA I. BARRAGÁN-ROMERO AND MARÍA ELENA VILLAR

11 Hate speech and social polarization in Brazil: From impeachment to Bolsonaro

GISELLA MENEGUELLI AND CARME FERRÉ-PAVIA

PART III

Hate speech in the social, traditional and community media

12 Countering the stigma of homeless people: The Swedish street paper Situation Sthlm as a counter-hegemonic voice for the rehumanisation of homeless people 
13 Hate speech as a media practice: The portray of haters and polarization in The Internet Warriors

ALEJANDRO BARRANQUERO AND SUSANA MORAIS

14 The asylum-seeker discourse fed by political polarization in Turkey: A Twitter-based analysis

NURCAN TÖRENLI AND ZAFER KIYAN

15 Orientalism and the mass media-a study of the representation of Muslims in Southern European TV fiction: The case of Spanish prime-time TV series

CRISTINA ALGABA, BEATRIZ TOMÉ-ALONSO

AND GIULIA CIMINI

16 Sports and hate speech messages on Instagram: The case of Seville FC in the Spanish league

ALBERTO MONROY-TRUjILlo, GRACIELA PADILLA-CASTILLO AND FRANCISCO CABEZUELO-LORENZO

Index 

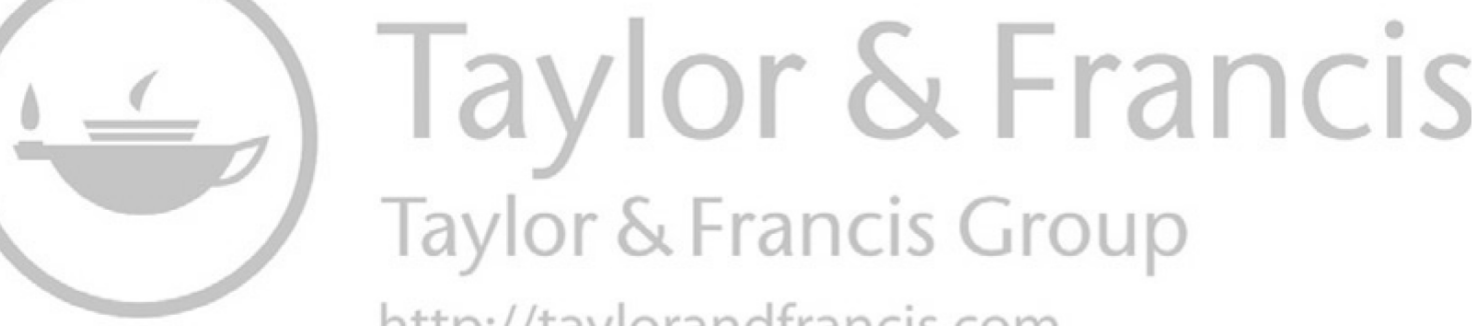
http://taylorandfrancis.com 


\section{Illustrations}

\section{Figure}

4.1 Forms of Interaction on SNS. Source: Author's own presentation based on Neuberger (2014)

\section{Tables}

4.1 Hate Speech as Communicative Actions. Source: Author's own presentation based on General Recommendation No. 35 of the Committee on the Elimination of Racial Discrimination (CERD), 2013

4.2 Subcategories of Hate Speech in Digital Conversations. Source: Author's own presentation based on Matsuda (1989); Brown (2017); Waldron (2010); Benesch (2013)

4.3 Hate Speech in Digital Objects. Source: Author's own presentation based on Langlois \& Elmer (2013) 59

7.1 Speech Corpus. Source: Author's own 101

8.1 Actors Analysed. Source: Author's own 120

8.2 Message Orientation of Political Leaders by Country. Source: Author's own

10.1 Frames and Related Themes. Source: Author's own 156

13.1 Identification of The Internet Warriors. Source: own elaboration

14.1 Tweet Examples (Referential/Nomination). Source: Author's own

14.2 Tweet Examples (Argumentation). Source: Author's own 214

14.3 Example Tweets (Perspectivization). Source: Author's own 215

14.4 Example Tweets (Intensification). Source: Author's own 216

15.1 Orientalist Framework. Source: Author's own based on Tomé-Alonso \& Ferreiro Prado (2019) 225

16.1 List of Questions for the Survey. (Source: Authors' own) 238 
xii Illustrations

16.2 Sample of Some of the Most Popular Teams, Players, and Politicians in Spain in 2019 on Instagram. (Source: Authors' own)

16.3 Categories in Comments and Insults. (Source: Authors' own) 245

16.4 Most Repeated Insults. (Source: Authors' own) 


\section{Contributors}

Ali İhsan Akbaş is a PhD candidate in the Department of Political Science at Bilkent University, Turkey.

Juan Antonio Marín Albaladejo is a professor in the Department of Journalism at Catholic University of Murcia, Spain.

Cristina Algaba is a PhD student in the Interuniversity Doctoral Program in Communication jointly with the Universities of Sevilla, Málaga, Huelva and Cádiz (Spain) and research fellow of IDECO, research group in Political Communication, Ideology and Propaganda at Universidad de Sevilla, Spain.

Ana I. Barragán-Romero is an associate professor at the School of Communication, Universidad de Sevilla, Spain.

Alejandro Barranquero is an assistant professor in the Department of Journalism and Audiovisual Communication at Universidad Carlos III de Madrid, Madrid, Spain.

Axel Bruns is a professor in the Digital Media Research Centre at Queensland University of Technology in Brisbane, Australia, and a chief investigator in the ARC Centre of Excellence for Automated Decision-Making and Society.

Monika Brusenbauch Meislová is an assistant professor in the Department of International Relations and European Studies at Masaryk University, Brno, Czech Republic.

Francisco Cabezuelo-Lorenzo is a full-time lecturer and researcher in the Department of Journalism and Global Communication at Complutense University, Madrid, Spain.

Nico Carpentier is an extraordinary professor in the Institute of Communication Studies and Journalism, Charles University, Czech Republic. He is also an associate professor in the Department of Communication Studies, Vrije Universiteit Brussel (VUB), Belgium. 


\section{xiv Contributors}

Giulia Cimini is a post-doctoral researcher in the Department of Political and Social Sciences with a Fellowship supported by the Gerda Henkel Foundation, University of Bologna, Italy.

Laura Cortés-Selva is an associate professor of Media Studies in the Department of Social Sciences and Humanities, Universidad Miguel Hernández, Spain.

Vaia Doudaki is an associate professor in the Institute of Communication Studies and Journalism, Charles University, Czech Republic.

Carme Ferré-Pavia is a senior lecturer in Communication at the Media, Communication and Culture Department, Autonomous University of Barcelona, Spain.

João Figueira is an assistant professor in the Department of Philosophy, Communication and Information, University of Coimbra, Portugal.

Zafer Kiyan is a research assistant at the Faculty of Communication, Ankara University, Turkey.

Susana Martínez-Guillem is an associate professor in the Department of Communication, University of New Mexico, USA.

Gisella Meneguelli is an independent researcher and Executive Secretary of the Institutional Evaluation Board at the Federal University of Juiz de Fora, Brasil.

Alberto Monroy-Trujillo is a Master of Social Sciences by the Tampere University. He is currently a pre-doctoral researcher at Complutense University of Madrid.

Susana Morais is a researcher at RICCAP (Research Network on Alternative and Participatory Community Communication), Madrid, Spain.

Allen Munoriyarwa is a post-doctoral research fellow and lecturer in the Department of Journalism, Film and Television, University of Johannesburg, Republic of South Africa.

José Manuel Noguera-Vivo is an associate professor of Journalism at UCAM, Spain, where he also is head of Communication Sciences Department. His research emerges from the synergy of society, tech and journalism. He is responsible of Spanish division of Online News Association and Science Communication Manager of the European project Interactive Narrative Design for Complexity Representations.

Graciela Padilla-Castillo is full-time lecturer and coordinator of the BA programme in Journalism of the School of Mass Media and Communication Studies at the Universidad Complutense, Madrid, Spain. She is also editor of the scientific journal Investigaciones Feministas (Instituto de Investigaciones Feministas, Universidad Complutense de Madrid). 
Marta Pérez-Escolar is an assistant professor in the Department of Communication at Loyola University (Sevilla, Spain). She received the Civic Participation, Transparency and Good Governance PhD Extraordinary Award in 2018, awarded by the Region of Murcia (Spain). Her main lines of research are focused on civic participation, public opinion, political communication and information disorders.

Gülüm Şener is an associate professor, 15 November Cyprus University, Faculty of Communication, Turkish Republic of Northern Cyprus.

Liriam Sponholz is a post-doctoral research fellow at the German Centre for Integration and Migration Research (DeZIM-Institut) in Berlin, Germany.

Beatriz Tomé-Alonso is a lecturer in the Department of International Studies, Universidad Loyola Andalucía (Seville, Spain), and an associate research fellow in the Study Group on Arab and Muslim Societies (GRESAM) at Universidad Castilla La Mancha, Spain.

Nurcan Törenli is a professor at the Faculty of Communication, Ankara University, Turkey.

Maria Elena Villar is an associate professor at the School of Communication and Journalism, Florida International University.

Tianyi Wang is an independent scholar, formerly affiliated to the Department of Informatics and Media, Faculty of Social Sciences, Uppsala University, Uppsala, Sweden.

Umur Yedikardeş is an MA student at Mimar Sinan University, Department of Urban Planning, Istanbul, Turkey.

Hakan Yücel is an assistant professor, Galatasaray University, Faculty of Political Sciences, Istanbul, Turkey. 

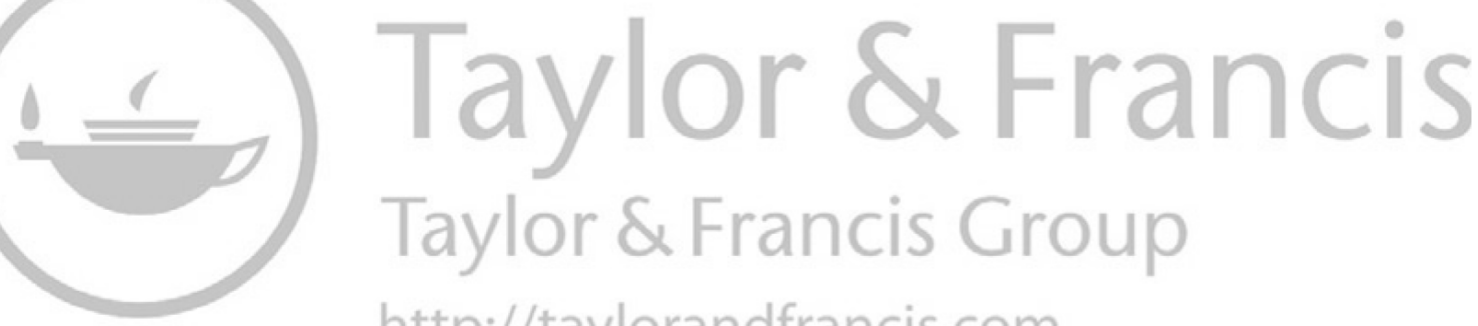
http://taylorandfrancis.com 


\title{
Preface
}

\author{
"I hate, therefore I am somebody"1
}

Fernando Iwasaki ${ }^{2}$

THE STUDIES GATHERED by José Manuel Noguera-Vivo and Marta Pérez-Escolar for this book imply both a diagnosis of political malaise and a serious warning for all seafarers, since it is not possible to separate the evil nature of the tumor from the inexorable metastasis one glimpses after reading each of the contributions collected in Hate Speech and Polarization in Participatory Society.

In reality, the political vocation of the research in this work is not oblivious to the shamelessness upon which hatred has been crowned in contemporary society, thanks to what Hannah Arendt referred to as the "banality of evil." With regard to the topic that concerns us, it results not only in an obscene exhibition of hatred but also in the desperate hunger of many people for attracting haters to their social networks, with the same or greater desire than when they sought fans or followers in the past. Why should we be surprised that politics spread hate when the current school, university, professional, artistic, familiar and conjugal coexistence are nothing more exemplary, nor calmer? However, the novelty is not the hatred. Rather, the novelty is the statute of hate in the contemporary world.

In 1936, after publishing the clandestine edition of Story of the Eye (1928) - comprising barely 134 signed copies under the pseudonym Lord Auch-George Bataille founded Acéphale, a secret society formed by the Friends of Human Sacrifices, whose anagram was a headless man. For the presentation into society of this secret community, Bataille and other members invited and called people to witness a live execution. Unfortunately, none of the founding partners offered to act as executioner, in spite of the numerous members willing to let themselves have their heads cut off during the opening ceremony. I cannot imagine a coterie more modest than those Friends of Human Sacrifices, who were unable to deprive themselves, even in the most absolute clandestinity. Would the same thing happen today? Not at all, because our era has found out that executions are performances, 
and that the difference between zombie executions on television and real victims just depends on the prime time.

Naturally, we are very concerned about hatred in politics, but why are treachery, malice and ferocity costless, excessive and pornographic in contemporary fictions? Because after centuries of concealed wickedness and cruelty, hatred is no longer hidden and does not embarrass the people who practice it. Nowadays, hate is part of the show, and thus one of the fine arts that triumphs in series, movies and novels. What do Breaking Bad, Nefando, Amores Perros and The Sopranos have in common? An Ars Malefica, an Ars Delendi and an Ars Maligna. Thanks to the hegemony of spectacle, vileness and abjectness have abolished-as Guy Debord suspected-the boundaries between what is possible and what is allowed, so that hatred has turned into another expression of the spectacular. And due to contemporary politics having also evolved into a spectacle, hate is one of their consubstantial ingredients.

Alejandro Barranquero and Susana Morais' chapter about the documentary The Internet Warriors comes to mind, and I perceive that the topic swings from the analysis of racist tweets conducted by Ana Barragán-Romero and María Elena Villar, to the evidence of misogyny that Laura Cortés-Selva and Susana Martínez-Guillem find in the series The Handmaid's Tale; not to mention the image of the "other" Muslim that Cristina Algaba, Beatriz Tomé-Alonso and Giulia Cimini have elucidated through their analysis of Spanish series. Nevertheless, hatred in fictions also floods the political sphere in social networks, as the contributions from Axel Bruns, Monika Brusenbauch, João Figueira, Juan Antonio Marín Albadalejo, Marta Pérez-Escolar and José Manuel Noguera-Vivo show; however racial and ideological hate speeches-analyzed by Liriam Sponholz, Allen Munoriyarwa, Gisella Menguelli, Carma Ferré-Paria, Nurkan Törenli, Zafer Kiyan, Güllüm Şener, Hakan Yücel, Umor Yedikardeş, Niko Carpentier, Vaia Doudaki, Ali Ihsan Akbaş, Tiany Wang, Alberto Monroy-Trujillo, Graciela Padilla-Castillo and Francisco Cabezuelo-Lorenzo-are those that overfill the measure of hatred as an agent of dehumanization.

Indeed, "in hatred there is no place for compassion," because the fantasy of hate-filled people lies in destroying the object of their hate (Castilla del Pino, 2000, pp. 292-296), and thus, in the hate speech spread on social networks and audiovisual media, the absence of negativity of the "other" dehumanizes, ${ }^{3}$ and then denigrates, destroys and erases, because hatred thrives thanks to anonymity and impunity in social networks. ${ }^{4}$ Therefore, the "digital hitman" is actually someone because they hate.

The classical philosopher Carlos García Gual reflected on hatred in the Iliad, since from the first verse the poem announces the rage of Achilles, who was blind with anger due to Patroclus' death. Devastated by the hatred, the Achaean hero kills all the Trojans that come his way with icy cruelty, until he meets Hector, who, aware of the imminence of his death, asks him to respect his corpse and allow his family to bury him. But Achilles hates 
him so much that he denies Hector his humanity with a terrible threat: "the dogs and birds of prey will divide your body." However, the poem has an unexpected ending, because the gods protect Hector's corpse and allow King Priam to come to the tent of his son's slayer, to beg him, hugging his knees, to allow him to take the corpse:

The pathetic force of the epic, on which Homer has imposed a tragic idea, reaches its most impressive moment in the torn tears of Achilles and Priam, embraced for a few moments. Hatred yields there to the vision of the respective humanity. At a deeper level than the enmity of the warriors, both kings have discovered in their mutual pain, the common humanity, precisely what Achilles wanted to deny Hector, precisely what old Priam did not expect to find in the bloodthirsty murderer of so many of his children. The overcoming of hatred is thus offered as a magnificent climax to a cruel tale of revenge in that emotional end of our Iliad.

(García Gual, 2002, p. 164)

The reading of Hate Speech and Polarization in Participatory Society should have as its objective the restoration of the human dimension as an antidote against polarization and hate speech, because many times academic bronze also demands the loss of the wax of humanity, in name of the index or rankings. That is why I unite with the authors of this book to rescue the human condition from the clutches of hatred, although not at all to celebrate authors' funerals or perform an autopsy, but to be human and enthrone humanity.

\section{Notes}

1 Günther Anders deconstructed the famous Descartes precept-cogito ergo sum-into three distressing sayings- "I hate, therefore I am" (Ich hasse, als bin ich); "I hate, therefore I am me" (Ich hasse, also bin ich ich), and "I hate, therefore I am Somebody" (Ich hasse, also bin ich wer) - to reinforce that the third expression means "self-affirmation and self-constitution through the denial and annihilation of the other" (Anders, 2019, pp. 34-35).

2 Fernando Iwasaki is a Peruvian writer of El descubrimiento de España (1996), Somos libros, seámoslo siempre (2014) and Ajuar funerario (2014). To learn more about the author, please visit his personal website: www.fernandoiwasaki.com

3 "Digital media is much more disembodied than letters. Calligraphy is still a bodily sign. All digital alphabets look alike. Digital media and what the other has to the contrary. They really deprive us of the ability to think about the man who is far away and to touch a man who is near" (Han, 2017, p. 85).

4 "Respect is bound to name. Anonymity and respect are mutually exclusive. Anonymous communication, which is promoted by digital media, massively destroys respect" (Han, 2019, p. 15). 

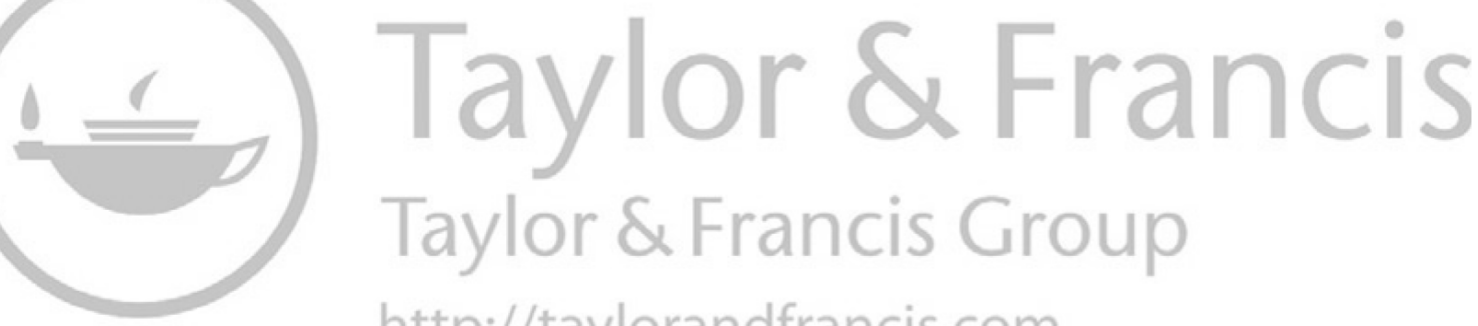
http://taylorandfrancis.com 


\section{Original Preface in Spanish}

«Odio, por lo tanto, soy Alguien» ${ }^{1}$

Fernando Iwasaki ${ }^{2}$

Ódiame, por piedad, yo te lo pido.

Ódiame, sin medida ni clemencia.

Odio quiero más, que indiferencia, pues el rencor hiere menos que el olvido

Canción popular latinoamericana ${ }^{3}$

LAS INVESTIGACIONES REUNIDAS en esta obra por José Manuel Noguera-Vivo y Marta Pérez Escolar, constituyen al mismo tiempo un diagnóstico del malestar político y un serio aviso de navegantes, pues no es posible disociar la naturaleza maligna del tumor, de la inexorable metástasis que uno entrevé al concluir la lectura de cada una de las contribuciones compiladas en Hate Speech and Polarization in Participatory Society.

En realidad, la vocación política de los estudios de la presente obra no es ajena a la impudicia con que el odio se ha entronizado en la sociedad contemporánea, gracias a lo que Hanna Arendt denominó la «banalidad del mal», y que en el tema que nos ocupa se traduce no sólo en la exhibición obscena del odio, sino en la angurria de muchas personas por atraer haters hacia sus redes sociales, con la misma o mayor avidez con la que antes buscaban fans o followers. ¿Por qué debería extrañarnos que la política siembre el odio, si la convivencia escolar, universitaria, profesional, artística, familiar y conyugal de nuestros días no es ni más ejemplar ni más bonancible? Sin embargo, la novedad no es el odio. Más bien, lo novedoso es el estatuto del odio en el mundo contemporáneo.

Hacia 1936 y después de haber publicado Historia del ojo (1928) en una edición clandestina de apenas 134 ejemplares firmados bajo el seudónimo de Lord Auch, Georges Bataille fundó "Acéphale», una sociedad secreta de Amigos de los Sacrificios Humanos, cuyo anagrama era un hombre decapitado y que para su presentación en sociedad convocó a los interesados 
a presenciar una ejecución en vivo. Por desgracia, ninguno de los socios fundadores se ofreció a ejercer de verdugo, a pesar de los numerosos afiliados dispuestos a dejarse cortar la cabeza durante la ceremonia inaugural. No puedo imaginar cenáculo más pudoroso que aquellos Amigos de los Sacrificios Humanos incapaces de sacrificarse entre ellos, incluso en la clandestinidad más absoluta. ¿Ocurriría lo mismo en nuestros días? De ninguna manera, porque nuestra época ha descubierto que las degollaciones son performances, y que la diferencia entre las decapitaciones televisivas de zombis y víctimas verdaderas sólo depende del prime time.

Nos preocupa el odio en la política, por supuesto, ¿pero por qué en las ficciones contemporáneas la alevosía, lo canalla y la ferocidad son gratuitas, excesivas y pornográficas? Porque después de siglos de maldad y crueldad disimuladas, el odio ya no se oculta y no avergüenza a quienes lo ejercen. El odio en nuestros días es parte del espectáculo y -por lo tantouna de las bellas artes que arrasa en series, películas y novelas. ¿Qué tienen en común Breaking Bad, Nefando, Amores Perros y Los Soprano? Un Ars Malefica, un Ars Delendi y un Ars Maligna. Gracias a la hegemonía del espectáculo, la vileza y la abyección han abolido -como intuyó Guy Debord- las fronteras entre lo posible y lo permitido, de forma que el odio se ha convertido en otra expresión de lo espectacular. Y como la política contemporánea también ha devenido espectáculo, el odio es uno de sus ingredientes consustanciales.

Pienso en el artículo de Alejandro Barranquero y Susana Morais sobre el documental The Internet Warriors, y veo que el tema oscila entre el análisis de los tuits racistas realizado por Ana Barragán-Romero y María Elena Villar, y las evidencias de misoginia que Laura Cortés-Selva y Susana Martínez-Guillem hallaron en la serie El cuento de la criada, por no hablar de la imagen del «otro» musulmán que Cristina Algaba, Beatriz ToméAlonso y Giulia Cimini han dilucidado a través de las series españolas. No obstante, el odio de las ficciones anega también la esfera política de las redes sociales, como lo demuestran las contribuciones de Axel Bruns, Monika Brusenbauch, João Figueira, Juan Antonio Marín Albadalejo, Marta Pérez Escolar y José Manuel Noguera-Vivo, aunque los discursos del odio racial e ideológico -analizados por Liriam Sponholz, Allen $\mathrm{Mu}$ noriyarwa, Gisella Menguelli, Carma Ferré-Paria, Nurkan Törenli, Zafer Kiyan, Güllüm Şener, Hakan Yücel, Umor Yedikardeş, Niko Carpentier, Vaia Doudaki, Ali Ihsan Akbaş, Tiany Wang, Alberto Monroy-Trujillo, Graciela Padilla-Castillo y Francisco Cabezuelo-Lorenzo- son los que colman la medida del odio como agente de la deshumanización.

En efecto, "en el odio no hay lugar para la compasión”, porque la fantasía del odiador consiste en la destrucción del objeto de su odio (Castilla del Pino, 2000, pp. 292-296) y así, en los discursos del odio a través de las redes y los medios audiovisuales, la ausencia de negatividad del "otro» deshumaniza ${ }^{4}$ y luego denigra, destruye y borra, porque el odio prospera 
gracias al anonimato y la impunidad en las redes ${ }^{5}$. Por lo tanto, el «sicario digital» realmente es Alguien porque odia.

El filólogo clásico Carlos García Gual, reflexionó acerca del odio en la Ilíada, pues desde su primer verso el poema anuncia la cólera de Aquiles, ciego de ira por la muerte de Patroclo. Arrasado por el odio, el héroe aqueo mata con glacial crueldad a todos los troyanos que le salen al paso hasta que se encuentra con Héctor, quien consciente de la inminencia de su muerte le pide que respete su cadáver y permita que su familia lo sepulte, pero Aquiles lo odia tanto que le niega la humanidad con una terrible amenaza: "los perros y las aves de rapiña se repartirán tu cuerpo". Sin embargo, el poema tiene un final inesperado, porque los dioses protegen el cadáver de Héctor y permiten que el rey Príamo llegue hasta la tienda del matador de su hijo, para suplicarle abrazado a sus rodillas que le permita llevarse el cadáver:

La fuerza patética de la epopeya, a la que Homero ha impuesto una idea trágica, alcanza su momento más impresionante en el llanto desgarrado de Aquiles y Príamo, abrazados por unos instantes. El odio cede ahí ante la visión de la humanidad respectiva. A un nivel más profundo que el de la enemistad de los guerreros, ambos reyes han descubierto en su recíproco dolor, la humanidad común, justamente lo que Aquiles quería negarle a Héctor, justamente lo que el viejo Príamo no esperaba encontrar en el sanguinario asesino de tantos hijos suyos. La superación del odio se ofrece así como un magnífico colofón para una cruel historia de venganza en ese emotivo final de nuestra Ilíada (García Gual, 2002, p. 164).

La lectura de Hate Speech and Polarization in Participatory Society, debe tener como objetivo la restauración de la dimensión humana como antídoto contra la polarización y los discursos del odio, porque muchas veces el bronce académico también exige la pérdida de la cera de la humanidad, en nombre del índice h o los rankings. Por eso me conjuro con los autores de este libro para rescatar de las garras del odio la condición humana, aunque en ningún caso para celebrar sus funerales o practicarle la autopsia, sino para ser humanos y entronizar la humanidad.

\section{Notes}

1 Günther Anders deconstruyó la célebre máxima de Descartes -cogito ergo sumen tres desoladoras sentencias - «odio, por lo tanto, soy» (Ich hasse, als bin ich); «odio, por lo tanto, yo soy yo» (Ich hasse, also bin ich ich), y "odio, por lo tanto, soy Alguien» (Ich hasse, also bin ich wer)- para hacer hincapié en cómo la tercera expresión supone "la autoafirmación y la autoconstitución por medio de la negación y la aniquilación del otro" (Anders, 2019, pp. 34-35).

2 Fernando Iwasaki autor de El descubrimiento de España (1996), Somos libros, seámoslo siempre (2014) y Ajuar funerario (2014). Para saber más sobre el autor, consulte su página web personal: www.fernandoiwasaki.com

3 La autoría de Ódiame se la atribuyen poetas y músicos de Colombia, Ecuador y Perú, pues unos dicen que el autor fue el colombiano Guillermo Valencia (1873-1943) y otros aseguran que fue el peruano Federico Barreto (1886-1929), 


\section{xxiv Original Preface in Spanish}

aunque el dúo ecuatoriano Martínez-Dougard la grabó en 1913 con melodía de pasillo en Lima y Sebastián Rosado volvió a grabarlo como pasillo en 1914 en Guayaquil. Sin embargo, en 1945 el peruano Rafael Otero López la registró como un vals de su autoría, y así fue reconocido en los créditos cuando «Los tres reyes» de México la grabaron en 1959. Con todo, el ecuatoriano Julio Jaramillo volvió a popularizar la canción como pasillo en la década de los 60 y la polémica no ha cesado, porque reivindicar la cuna de Ódiame se ha convertido en una cuestión nacional.

4 "Los medios de comunicación digital son mucho más incorpóreos que las cartas. La caligrafía es todavía un signo corporal. Todos los alfabetos digitales se parecen . Los medios digitales lijan lo que el otro tiene de contrario. Nos privan realmente de la capacidad de pensar en el hombre que está lejos y de tocar a un hombre que está cerca" (Han, 2017, p. 85).

5 "El respeto va unido al nombre. Anonimato y respeto se excluyen entre sí. La comunicación anónima, que es fomentada por el medio digital, destruye masivamente el respeto" (Han, 2019, p. 15).

\section{References}

Anders, G. (2019). La obsolescencia del odio. Valencia, Spain: Pre-Textos.

Castilla del Pino, C. (2000). Teoría de los sentimientos. Barcelona: Tusquets.

García Gual, C. (2002). Los estragos del odio. Algunos ejemplos del mundo griego.

En C. Castilla del Pino (Ed), El odio (pp. 149-183) Barcelona: Tusquets.

Han, B. C. (2017). La expulsión de lo distinto. Barcelona: Herder.

Han, B. C. (2019). En el enjambre. Barcelona: Herder. 


\section{Acknowledgements}

This book represents a journey of exploration and learning that all of usboth, the authors and the editors-undertake for the purpose of seeking solutions to political and social problems being faced in many parts of the world nowadays. During this adventure, some marvelous people helped us do so.

We would like to thank the reviewers for their outstanding contributions to our edited book. We really appreciate their time and efforts in helping to improve the quality of our chapters. Their feedback, as well as their critical and thoughtful discussions, has provided us with joyful debates that have certainly enriched this experience.

We also would like to thank Suzanne Richardson-editor in the Communication Studies section-and the Routledge team for their unwavering support. This journey would not have even started without their confidence and trust. Thank you for this opportunity.

We would like to take this page as a way to remember our beloved friends and colleagues who sadly passed away these last two years-during the publication process of this volume. We all will miss their very much appreciated insights and critiques to this book.

Finally, we particularly want to acknowledge the excellent work that the authors of this book have carried out. Their level of commitment and the rigor of their studies have exceeded all expectations. Thank you so much for your kind and encouraging words in every single email we have shared. In this line, we are especially grateful to Fernando Iwasaki for agreeing to write the preface of this book. It is a great honor and privilege to include his words and reflexions in this volume. Thanks to Fernando, the prolegomenon of this book is, definitely, the best welcome a reader could receive.

Lastly, thank you to our families and authors' families. They are always such a support to all of us, since they helped us to direct and discuss our worries.

Hope we can meet again in the future and collaborate on further projects. 

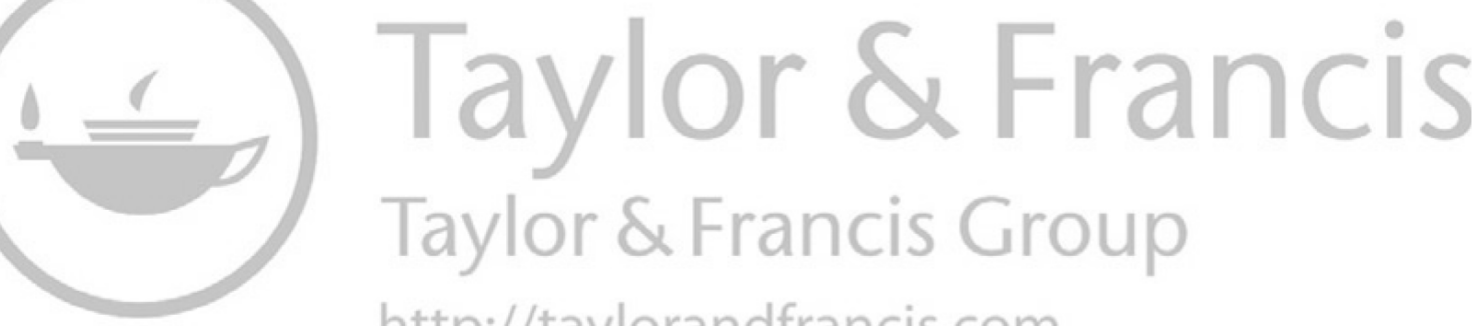
http://taylorandfrancis.com 


\title{
1 Introduction to the dilemmas and struggles of participatory society
}

\author{
Marta Pérez-Escolar and José Manuel \\ Noguera-Vivo
}

\section{Tracing complex realities}

The term 'participatory society' has traditionally had positive connotations and has even been associated with a more democratic, fair and equal civilization. Drawing upon the cyber-optimistic perspective (Dahlgren, 2000, 2005, 2011, 2012; Rheingold, 2000, 2002; Sánchez, 2001; Davis, Elin \& Reeher, 2002; Lévy, 2004; Surowiecki, 2005; Siedschlag, 2007; Mossberger et al., 2008; Castells, 2010, 2013; Borge \& Cardenal, 2011; Sampedro \& Sánchez, 2011; Jenkins, Ford \& Green, 2013; Herreros, 2013; Vilché, 2015; Jenkins, 2016), the digital realm offers new forms of participation in such a way that contributes to the progress of society and the evolution of citizenship; individuals have the power to change the current landscape positively by encouraging sustainable practices and empathic behaviors. However, participation is also a tricky empowerment tool, since a participatory society does not always represent an open democratic model, but could also serve as a catalyst for reinforcing hate speech, increasing ideological polarization and spreading disinformation.

Multiple authors have already warned about the disadvantages that arise in participatory society due to the peculiarities and traits of online scenarios: Van Alstyne and Brynjolfsson (1996) proposed the term 'cyberbalkanization' to describe the fragmentation of the internet into special interest groups. Users interact with only like-minded others and "thereby close themselves off from ideological opposition, alternative understandings, and uncomfortable discussions" (Brainard, 2009, p. 598). According to Putnam (2001), "real world interactions often force us to deal with diversity, whereas the virtual world may be more homogeneous, not in demographic terms, but in terms of interest and outlook. Place-based communities may be supplanted by interest-based communities" (Putnam, 2001, p. 178). This strong ideological polarization (Stroud, 2007, 2008) favors the growth of communication cyber-ghettos in which users tend to support their own points of view and criticize opposing ones (Johnson, Bichard \& Zhang, 2009). 


\section{Marta Pérez-Escolar and José Manuel Noguera-Vivo}

Thus, the current digital environment is creating a spiral of selective attention (Neuman, Bimber \& Hindman, 2011, p. 34): users actively seek out information that supports their opinions and beliefs and avoid interacting with people who challenge their existing convictions (Redlawsk, 2002; Taber \& Lodge, 2006). The 'selective exposure' theory (Festinger, 1957) also describes this online phenomenon as a way to reduce dissonance in online communities: individuals select news, information, interactions and relations that reinforce their existing attitudes and mindset, and reject dissident, alternative or opposing speeches (Zillmann \& Bryant, 1985; Chaffee et al., 2001; Mutz \& Martin, 2001; Best, Chmielewski \& Krueger, 2005; Stroud, 2007, 2008; Cinelli et al., 2020; Johnson et al., 2020; Parmelee \& Roman, 2020; Stier et al., 2020).

Similarly, Thompson (2008) argues that "if the participants are mostly like-minded or hold the same views before they enter into the discussion, they are not situated in the circumstances of deliberation" (p. 502). When like-minded people simply follow the beliefs provided by the members of the same deliberating group and only have discussions with one other, then these polarized communities are engaged in 'enclave deliberation' (Sunstein, 2000, 2008, 2009), where disinformation, misinformation, rumors and hate speech may be amplified due to the lack of contrary evidence (Grönlund, Herne \& Setälä, 2015) and by groups of users living in 'echo chambers' (Sunstein, 2008). This results in an increased ideological polarization, extremist behaviors and a deep information bias.

One of the most representative and recent examples of the dark side of participatory society was the attack on the US Capitol at the beginning of January 2021. After the 2020 presidential elections, Donald Trump repeated false claims of electoral fraud, stating that he had won the 'legal vote'. This conspiracy theory pushed thousands of pro-Trump extremists to carry out a violent invasion of one of the most iconic American buildings, seeking to fight against the election of Joe Biden. The mob of Donald Trump's supporters was mainly made up of members of different right-wing nationalist extremist groups, like the Proud Boys, Qanon or 'rednecks', among others, who firmly believed Trump's false statements and rejected evidence or proof that challenged their existing convictions outright.

For that reason, when polarized ideological ghettos magnify information disorders (Wardle \& Derakhshan, 2017) and reinforce outrageous behaviors, like the assault on the US Capitol, it is essential to start counterattacking the falsehood, combating hate speech and breaking up social segregation and political fragmentation. Twitter, for example, has permanently suspended the official account of Donald Trump (@realDonaldTrump) "due to the risk of further incitement of violence" (Twitter, 2021) as well as the great amount of misleading information he disseminated. According to Newtral, a Spanish fact-checking media, Donald Trump has spread 29,508 false or deceitful statements in 1,386 days (Baeza, 2021). In addition, Parler - the social network used by pro-Trump extremists to spread 
hatred - went offline after Amazon suspended it from its server hosting; Google Play and Apple both also decided to remove the social media platform from their app stores. Furthermore, Wikipedia has just published the Universal Code of Conduct to provide a baseline of behavior based on mutual respect, civility, collegiality, mutual support and good citizenship, thus condemning harassment, abuse of power, privilege, influence, content vandalism and abuse of the projects (Wikipedia, 2021).

In the same spirit of these initiatives, the main contribution of this book is to offer a context whereby it is understood that the democratizing and empowering functions of the digital realm are being exaggerated and a more realistic perspective is needed to face the communicative, social, cultural and political problems of our era. This book is written for anyone with academic or professional interests in media representations of polarization and hate speech, as well as their consequences in many different international contexts. The studies included in this volume confirm that it is relevant to adopt a cyber-realistic perspective when we discuss the revolutionary and emancipatory potential participatory society has for changing the current landscape. Thus, by drawing on different theoretical concepts, focusing on various methods and meeting a broad range of research problems, the chapters included here shape the nature and the character of contemporary participatory society. More precisely, the book is structured according to three perspectives on the complex world of hate speech, ideological polarization and their consequences: contextualizing participatory society: metaphors for polarization and hate speech; political and ideological polarization; and hate speech in social, traditional, and community media.

\section{Contextualizing participatory society: metaphors for polarization and hate speech}

The perspective of the authors in the first section of this book is the widest because they tackle broad aspects of participatory society. The chapters in this section encompass different approaches to the complex connections in participatory society, and the particular linkages forged between ideological polarization, disinformation and hate speech. By placing their analyses in the political context of Spain, Marta Pérez-Escolar and José Manuel Noguera-Vivo evaluate in the first chapter some of the most popular Spanish political leaders' false statements. The authors conclude that fabricated contents - misinformation or disinformation - nourish the diversification of opinions, because citizens only perceive a frame of reality that is distorted and divides people into multiple polarized groups. As a consequence, the act of lying increases what the authors call diversification of polarization, which refers to people becoming isolated in multiple bubble cyber-ghettos depending upon the nature of the issue under debate (e.g. inequality between sexes, climate change, immigration issues, the high prices of rent or the Catalonian independence movement, among others). 
Therefore, diversification of polarization increases the number of enemies and reduces the possibilities of achieving consensus. As a consequence, the diversification of polarization increasingly hinders the possibilities for raising a collective understanding, as well as weakening the values of a democracy based on mutual respect, tolerance and equality.

In the following chapter, Axel Bruns critically argues that 'echo chambers' and 'filter bubbles' principally constitute an unfounded moral panic that presents a convenient technological scapegoat for a much more critical, fundamentally human-made problem: growing social and political polarization. Bruns affirms that the 'echo chamber' and 'filter bubble' metaphors are doing us a fundamental disservice by misdirecting our attention to online platforms as the root cause of these problems. The rise of hyperpartisan, populist and illiberal ideological agitators and propagandists from the fringes of the political spectrum, and their rejection of established democratic principles and processes, is not principally a phenomenon related to the communications technologies they use; it is, centrally, a societal problem. For that reason, the author conveys that our continuing debate about ill-considered metaphors such as 'echo chambers' and 'filter bubbles' is a distraction that we can no longer afford, because it keeps us from confronting far more important matters head-on. Therefore, the central question now is what they do with such information when they encounter it. This is the debate we need to have: not a proxy argument about the impact of platforms and algorithms, but a meaningful discussion about the complex and compound causes of political and societal polarization. The 'echo chamber' and 'filter bubble' metaphors have kept us from pursuing that debate and must now be put to rest.

Liriam Sponholz provides a taxonomy of hate speech in digital conversations, allowing an identification of how hate speech manifests in online conversations, how these forms can be assessed empirically and what differentiated effects they have on online deliberation. Her findings suggest that different subsets of hate speech incorporated in different digital objects also have differentiated consequences for deliberative processes. For example, hateful speech may affect how respectfully participants deal with each other in digital conversations, while in the case of hate-fueled speech, 'true believers' may justify assertions and validity claims by packaging their group-libeling positions in argumentation processes. Hatred-inciting speech provokes debates where speakers submit the worthiness of human beings to processes of argumentation. Sponholz conveys that online hate speech poses a specific threat to democracy, created by both social action and the media logic of digital platforms, particularly social networking sites. With regard to media logic, these forms of hate speech manifest themselves not only in content, but first and foremost in the form of digital objects. More generally, the theoretical framework she provides in her chapter is an attempt to assess hate speech in a way that goes beyond 'words-that-wound' in online comments. The main objective of Sponholz's work is to address a 
digital threat that not only targets groups that are systematically discriminated against but also affects everybody by undercutting one of the pillars of participatory societies: deliberation.

\section{Political and ideological polarization}

The second section includes studies conducted from the perspective of political polarization. The chapters in this section consider the troubles and tensions between political aims, decision-making and political fragmentation on the one hand, and social consequences on the other. In the fifth chapter, Allen Munoriyarwa examines what sort of discourses emerged from the hashtag \#Penny Sparrow and \#VickyMomberg, both referring to two racist incidents that were trendy topics between 2016 and 2017. The selected hashtags juxtaposed both anti-black and anti-white discourses that were equally vitriolic. The author concludes that the Twittersphere has amplified and escalated racial tensions in post-apartheid South Africa. In showing this, Munoriyarwa argues that Twitter discourses have shattered the hopes of a 'rainbow nation' by promoting exclusionary discourses that advance - hate and polarizing - narratives of in-groups and out-groups.

Laura Cortés-Selva and Susana Martínez-Guillem focus on the Handmaid's movement and reflect on the misogynistic and anti-feminist content present in the fictitious Republic of Gilead. Toward this end, the authors analyze a set of audiovisual codes featured through the mise en scene, comparing them to those acquired by women activists in the real world. The authors conclude that Atwood's warning message urging women to resist and fight against extreme and hateful speech, through action and voice, has firmly influenced and shaped the current feminist movement.

Monika Brusenbauch Meislová explores which topics, discursive strategies and linguistic devices have been employed by British politicians to construct Leave and Remain identities in a sense of out-group antagonism(s) in contra-distinction to the given in-group. By looking at how Leavers and Remainers discursively construct the 'other', the author provides an empirical example of (a part of) collective identity formation and meaning-making in the process of Brexit and adds to the literature on growing affective polarization along Brexit lines in the United Kingdom. Meislová concludes that the political discourse of both Leavers and Remainers is continually and abundantly replete with references to the out-groups, which are constructed not in terms of similarities, but in terms of differences. With people on both sides of the Leave-Remain divide engaging vigorously in discursive tugs-ofwar with each other, the analysis demonstrates their readiness to exclude the others from their in-group as the constructed collective and to debase (and even demonize) them. In both cases, the deployed 'us versus them' narratives and the various assertions of out-group hate/outrage effectively draw attention to opinion-based group differences, pit one group against another and create inter-group tension. 


\section{Marta Pérez-Escolar and José Manuel Noguera-Vivo}

Juan Antonio Marín Albaladejo and João Figueira offer a comparative approach to the political, media and citizen discourses within Twitter in the two Iberian countries, Spain and Portugal. In particular, Marín Albaladejo and Figueira's work analyzes the tweets posted by journalists or political commentators and party leaders, as well as the topics that generate the greatest interest on media accounts and the users' replies to information related to political issues. The authors' findings suggest that although the polarization and the hostile tone of journalistic discourse are lower than in Spain, the ideological alignment and high doses of criticism focused on certain parties are also observed in the accounts of Portuguese journalists. Notwithstanding the differences in journalistic and political speeches, a negative tone and offensive language or messages that contain accusations and promote prejudice and intolerance appear with a similar frequency in the interventions of citizens in both countries. According to Marín Albaladejo and Figueira, although this behavior is not representative of the majority among users, it offers a sample of the significant hostility against dissenting positions in this environment. This convergent trend between the citizen speeches reveals that the radicalism of public debate on Twitter seems to be homogeneous and independent of the political and media cultures of each country.

Gülüm Şener, Hakan Yücel and Umur Yedikardeş reconsider the potential of left populism to overcome polarization created by authoritarian populist politics. In an extremely polarized political climate, Ekrem İmamoğlu, the candidate of the CHP, the main opposition party in Turkey, won the local elections on June 23, 2019, and became the new mayor of Istanbul by defeating the ruling party AKP, which lost control of Istanbul for the first time since 1994. The authors argue that his election campaign provided important clues on how to fight authoritarian populist politics and overcome political and social polarization. From Şener, Yücel and Yedikardeş' point of view, İmamoğlu's campaign matches left-wing populism embracing inclusive, pluralist and egalitarian discourses; democratic values; and social democrat projects. The unification of 'the People' against polarization, the politics of hope against politics of fear of the AKP, an emphasis on democratic values and institutions, the recognition of subaltern identities created by neoliberal politics, and the inclusion of various identities are the prominent populist discourses of his campaign. The inclusion of all segments of society and the portrayal of 'the People' as a plural and heterogeneous collective subject are in contrast with the exclusionary and polarizing populism of the AKP.

Ana I. Barragán-Romero and María Elena Villar observe two politicians, Trump (US) and Abascal (Spain), and the hate speech that circulates through analysis of their official Twitter accounts. Specifically, they focus on the messages related to immigrants, the scapegoats of these new political leaders. The authors conclude that Abascal and Trump both use social media as a way to promote negative feelings against immigrants, framing 
them as threats and implying that they are responsible for crisis, crimes and violent acts. This fits with the goal of propaganda to oversimplify a common enemy. In terms of propaganda types, Trump was more preoccupied with advancing his agenda than putting down opposition agenda, although he still used negating or reaction propaganda. In contrast, the majority of Abascal's tweets focused on the opposition's ideas by criticizing or contrasting them with his. The analysis of themes conducted by Barragán-Romero and Villar leads to the conceptualization of frames that extend beyond those previously identified around immigration: Law and Defense and Preserving Values.

Finally, Gisella Meneguelli and Carme Ferré-Pavia study the sociopolitical course that enabled the rise of Jair Bolsonaro in the context of political hate speech. Their findings show the leading role of traditional Brazilian media in building a social-discursive imaginary that circulated hate speech to further weaken agitations that had already been underway in Brazil since 2013. Hate speech gave a sense of legitimacy to Rousseff's impeachment and to all the following chapters of Brazil's recent sociopolitical history. Meneguelli and Ferré-Pavia conclude that the discourse that led to polarization was circulated largely through the media as part of a political game that had been defined in the 2014 election. Some rightwing parties were unsatisfied with the election results; thus, the media and judicial support gave legitimacy not only to the organization of Rousseff's impeachment, but to the creation of a character who would fit the role whose script was ready: Jair Bolsonaro.

\section{Hate speech in social, traditional and community media}

The third section tackles questions related to the nature of hate speech. The chapters in this last part of the present volume examine how and the degree to which hate speech influences social, traditional and community media. Focusing on the Swedish street paper Situation Sthlm, Nico Carpentier, Vaia Doudaki, Ali İhsan Akbaş and Tianyi Wang demonstrate not only how Situation Sthlm counters polarization and stigmatization, but also what the limits of these counter-hegemonic strategies are. The authors acknowledge that homeless people are constructed as an out-group through the centrality of the home as a site of civilization, the removal of social agency and the denial of citizenship. However, street papers, publications that are distributed, and in a modest way co-produced, by homeless people, attempt to counter this hegemonic stigma by re-humanizing homeless people. Carpentier, Doudaki, Akbaş and Wang's findings suggest that street papers invite a reconfiguration of the representation of marginalized and stigmatized social groups in ways that reverse the state of polarization that has left the homeless in the position of an out-group.

Alejandro Barranquero and Susana Morais investigate the complex narrative strategies of the testimonial documentary The Internet Warriors 
(2017), which aims at understanding the motivations and social contexts behind the people who confront the internet daily regarding identities, political beliefs or religious values. The documentary ultimately states that we are all subject to hate, since hatred is usually introjected from masters to victims, and the latter may paradoxically turn to it if they feel offended or discriminated against. The authors conclude that online hate speech is a dialectic process that confronts victims and prosecutors, who may also become hate mongers when they feel challenged and need to defend their beliefs. In other words, hate mongers are not an amorphous mass of trolls and false identities, since hate may also be produced by identified and ordinary people like the spectator.

Nurcan Törenli and Zafer Kiyan determine the extent to which individuals' proximity to the governing party or the opposition affects their discourse on Syrian asylum seekers in a highly polarized Turkey. Their findings showed that a sample of Twitter users acted in alignment with the political party that they felt close to. Accordingly, while Twitter users close to the party with a negative attitude toward Syrian asylum seekers created a negative discourse, those close to the party with a positive attitude created a positive discourse. Törenli and Kiyan recognize that the tension between the asylum seekers and indigenous population in Turkey is not a new situation, since the country has experienced many major population movements throughout history. What is new is that the language of politics is increasingly fed by this tension between the asylum seekers and local people, escalating the polarization at the individual level. The authors conclude that politics is the source of positive and negative discourses on Syrian asylum seekers. Then, the responsibility of ending the racist and exclusionary discourse against asylum seekers falls primarily on the actors of institutional politics.

Aiming to contribute to the accumulative knowledge about stereotypes and distorted images disseminated by mass media, Cristina Algaba, Beatriz Tomé-Alonso and Giulia Cimini attempt to study the representation of the Muslim world in prime-time TV series broadcast in Spain, a country with a long-established Muslim population and a strategic migratory destination. Specifically, the narratives the authors have chosen are constructed to offer a deliberate image of Muslim characters. For this purpose, Algaba, ToméAlonso and Cimini analyze two TV series that have had a special impact on Spanish audiences: El tiempo entre costuras (Antena 3, 2013-2014) and El principe (Telecinco, 2014-2016). Their findings suggest that the orientalist representation of Muslim 'others' contributes to the differentiation between their space and the Spanish/Western one. In this sense, the authors conclude that these cultural artifacts help reinforce national identities and highlight the common traits that countries like Spain, as a 'peripheral' Southern European region, share with other EU Member States.

Finally, Alberto Monroy-Trujillo, Graciela Padilla-Castillo and Francisco Cabezuelo-Lorenzo argue that hate speech is one of the most important 
scourges users must live with nowadays, particularly in the case of soccer. Therefore, in this chapter, the authors study several issues, such as the theory of the Internet, social media and hate speech with a longitudinal analysis of the bibliography in this field and data, legislation and examples of sentences that illustrate hate speech. In addition, to explore the hate speech phenomenon, the authors also analyze the specific case of the Seville Football Club (@sevillafc) Instagram account.

\section{References}

Baeza, L. (2021, 17 January). Los datos de la desinformación en el mandato de Donald Trump: 29.508 declaraciones falsas o engañosas en 1.386 días. Newtral. https://bit.ly/2Vtf9jS

Best, S. J., Chmielewski, B. \& Krueger, B. S. (2005). Selective exposure to online foreign news during the conflict with Iraq. Harvard International Journal of Press/Politics, 10(4), 52-70.

Borge, R. \& Cardenal, A. (2011). Surfing the net: A pathway to participation for the politically uninterested? Policy \& Internet, 3(1), 1-2.

Brainard, L. A. (2009). Cyber-communities. In H. K. Anheier \& S. Toepler (Eds.), International encyclopedia of civil society (pp. 587-600) New York, NY: Springer Science \& Business Media.

Castells, M. (2010). Comunicación y poder. Madrid: Alianza.

Castells, M. (2013). Redes de indignación y esperanza. Madrid: Alianza Editorial.

Chaffee, S. H., Saphir, M. N., Graf, J., Sandvig, C. \& Hahn, K. S. (2001). Attention to counter-attitudinal messages in a state election campaign. Political Communication, 18 (3), 247-272.

Cinelli, M., Quattrociocchi, W., Galeazzi, A., Valensise, C. M., Brugnoli, E., Schmidt, A. L., Zola, P., Zollo, F. \& Scala, A. (2020). The COVID-19 social media infodemic. Scientific Report, 10(16598). https://doi.org/10.1038/s41598020-73510-5

Dahlgren, P. (2000). The internet and the democratization of civic culture. Political Communication, 17, 335-340.

Dahlgren, P. (2005). The internet, public spheres, and political communication: dispersion and deliberation. Political Communication, 22(2), 147-162.

Dahlgren, P. (2011). Jóvenes y participación política. Los medios en la Red y la cultura cívica. Telos, (89), 12-22.

Dahlgren, P. (2012). Mejorar la participación: la democracia y el cambiante entorno de la web. In D. Innerarity \& S. Champagne (Eds.), Internet y el futuro de la democracia (pp. 45-67). Barcelona: Paidós.

Davis, S., Elin, L. \& Reeher, G. (2002). Click on Democracy. The Internet's Power to Change Political Apathy into Civic Action. Colorado: Westview Press.

Festinger, L. (1957). A Theory of Cognitive Dissonance. Stanford, CA: Stanford University Press.

Grönlund, K., Herne, K. \& Setälä, M. (2015). Does Enclave Deliberation Polarize Opinions? Political Behavior, 37, 995-1020. https://doi.org/10.1007/ s11109-015-9304-x

Herreros, P. (2013). El poder de las personas. Madrid: Léeme Editorial. 
Jenkins, H. (2016). Youth voice, media, and political engagement: introducing the core concepts. In H. Jenkins, S. Shresthova, L. Gamber-Thompson, N. Kligler-Vilenchik \& A. Zimmerman (Eds.), By Any Media Necessary. The New Youth Activism (pp. 1-60). Nueva York: NY University Pres

Jenkins, H., Ford, S. \& Green, J. (2013). Spreadable media: Creating value and meaning in a networked culture. Nueva York: New York University Press.

Johnson, N. F., Velásquez, N., Restrepo, N. J., Leahy, R., Gabriel, N., El Oud, S., Zheng, M., Manrique, P., Wuchty, S. \& Lupu, Y. (2020). The online competition between pro- and anti-vaccination views. Nature, 582, 230-233. https:// doi.org/10.1038/s41586-020-2281-1

Johnson, T., Bichard, S. \& Zhang, W. (2009). Communication communities or "CyberGhettos?": A path analysis model examining factors that explain selective exposure to blogs. Journal of Computer-Mediated Communication, 15(1), $60-82$.

Lévy, P. (2004). Ciberdemocracia. Ensayo sobre filosofía política. Barcelona: Editorial UOC.

Mossberger, K., Tolbert, C. J., McNeal, R. S., \& McDonald, J. (2008). The benefits of society online: Civic engagement. In K. Mossberger, C. J. Tolbert \& R. S. McNeal (Eds.), Digital Citizenship: The Internet, Society, and Participation (pp. 47-66). Cambridge, MA: The MIT Press.

Mutz, D. C. \& Martin, P. S. (2001). Facilitating communication across lines of political difference: The role of mass media. American Political Science Review, 95(1), 97-114.

Neuman, R., Bimber, B. \& Hindman, M. (2011). The Internet and four dimensions of citizenship. In L. R. Jacobs \& R. Y. Shapiro, The Oxford Handbook of American Public Opinion and the Media (pp. 22-42). Oxford: Oxford University Press.

Parmelee, J., \& Roman, N. (2020). The strength of no-tie relationships: Political leaders' Instagram posts and their followers' actions and views. First Monday, 25(9). https://doi.org/10.5210/fm.v25i9.10886

Putnam, R. D. (2001). Bowling Alone. New York: Simon and Schuster.

Redlawsk, D. P. (2002). Hot cognition or cool consideration? Journal of Politics, 64(4), 1021-1044.

Rheingold, H. (2000). The Virtual Community: Homesteading on the Electronic Frontier. Massachusetts: MIT Press.

Rheingold, H. (2002). Smart Mobs: The Next Social Revolution. Cambridge: Perseus Books Group.

Sampedro, V. \& Sánchez, J. M. (2011): A modo de epílogo. 15-M. La red era la plaza. In V. Sampedro (eds.), Cibercampaña. Cauces y diques para la participación. Las Elecciones Generales de 2008 y su proyección tecnopolitica (pp. 237-242). Madrid: Editorial Complutense.

Sánchez, J. (2001). Internet como instrumento de participación: conclusiones. In J. Font (eds.), Ciudadanos y decisiones públicas (pp. 150-152). Barcelona: Ariel. Siedschlag, A. (2007). Digital democracy and its application to the international arena - From 'deliberation' to 'Decision'. In M. Dunn Cavelty, S. F. KrishnaHensel \& V. Mauer (eds.), The Resurgence of the State: Trends and Processes in Cyberspace Governance (pp. 35-58). Hampshire: Ashgate Publishing.

Stier, S., Kirkizh, N., Froio, C., \& Schroeder, R. (2020). Populist attitudes and selective exposure to online news: A cross-country analysis combining web 
tracking and surveys. The International Journal of Press/Politics, 25(3), 426446. https://doi.org/10.1177/1940161220907018

Stroud, N. J. (2007). Media effects, selective exposure, and Fahrenheit 9/11. Political Communication, 24(4), 415-432.

Stroud, N. J. (2008). Media use and political predispositions: Revisiting the concept of selective exposure. Political Behavior, 30(3), 341-366.

Sunstein, C. R. (2000). Deliberative trouble? Why groups go to extremes. The Yale Law Journal, 110(1), 71-119.

Sunstein, C. R. (2008). Neither Hayek nor Habermas. Public Choice, 134, 87-95. https://doi.org/10.1007/s11127-007-9202-9

Sunstein, C. R. (2009). Republic.com 2.0. Princeton, NJ: Princeton University Press.

Surowiecki, J. (2005). The Wisdom of Crowds. New York: Random House.

Taber, C. S. \& Lodge, M. (2006). Motivated skepticism in the evaluation of political beliefs. American Journal of Political Science, 50(3), 755-769.

Thompson, D. F. (2008). Deliberative democratic theory and empirical political science. Annual Review of Political Science, 11, 497-520.

Twitter (2021, January 8). Permanent suspension of @ realDonaldTrump. https:// bit.ly/35Y3Wtr

Van Alstyne, M. \& Brynjolfsson, E. (1996). Could the Internet Balkanize Science? Science, 274(5292), 1479-1480. 10.1126/science.274.5292.1479

Vilché, M. (2015). El empoderamiento de los ciudadanos Internet. Revista Internacional de Pensamiento Político, 10, 85-10.

Wardle, C., \& Derakhshan, H. (2017). Information disorder. Toward an interdisciplinary framework for research and policymaking. Strasbourg: Council of Europe. https://bit.ly/2OsHEHY.

Wikipedia (2021). Universal Code of Conduct. https://bit.ly/3xQxZiO

Zillmann, D. \& Bryant, J. (1985). Selective Exposure to Communication. Routledge. 

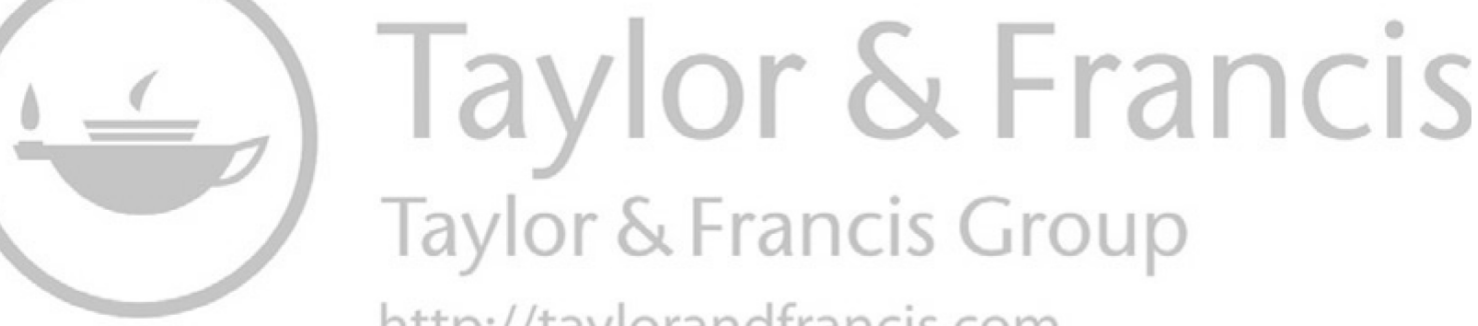
http://taylorandfrancis.com 


\section{Part I}

\section{Contextualizing the participatory society}

Metaphors for polarization and hate speech 

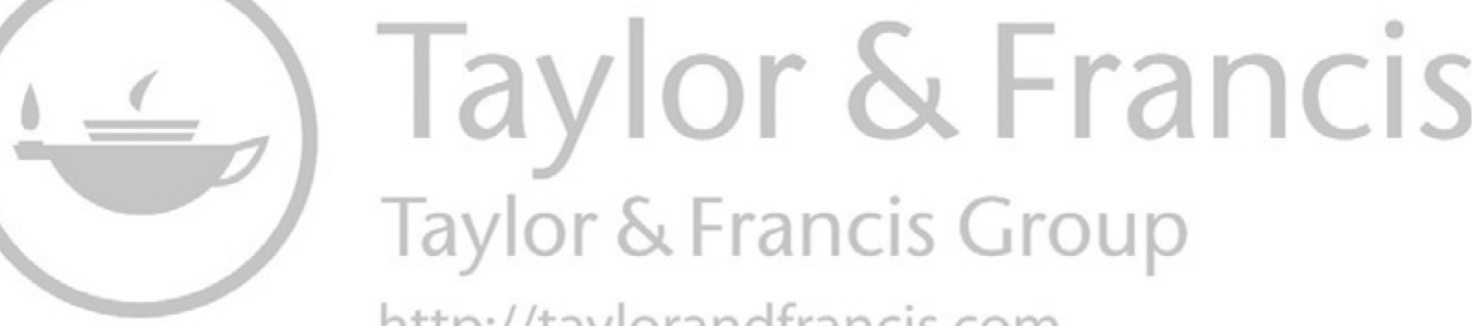
http://taylorandfrancis.com 


\title{
2 How did we get here? The consequences of deceit in addressing political polarization
}

\author{
Marta Pérez-Escolar and José Manuel \\ Noguera-Vivo
}

\section{Introduction}

Trust and truth have both turned into prized assets in democratic societies. Bok (1978) already suggested that "whatever matters to human beings, trust is the atmosphere in which it thrives" (p. 31). In the same line of thought, Macleod (2015) maintains that trust is needed in any civilization, since it has an "enormous instrumental value and [...] intrinsic value"; in turn, MacKenzie and Bhatt (2020) argue that lies are harmful "to those who have legitimate claims to know the facts, to democracy, to anyone who values truth and honesty" (p. 12). For that reason, in this new digital era characterized by information disorders, apprehension and disbelief, trust and truth are now more relevant for combating deceit than ever before.

In the Spanish context, these values are increasingly essential. After the last Spanish general election in 2019, the political landscape transformed from a primarily bipartisan system - led by the left-wing PSOE $^{1}$ party and the right-wing $\mathrm{PP}^{2}$ party - into a pluralist and heterogeneous system. In this case, PSOE obtained the most seats - 120 - but they needed the support of other parties if Pedro Sánchez - PSOE candidate - was to be sworn in as prime minister.

Hence, the new Spanish government is a left-wing coalition government, ${ }^{3}$ between PSOE and the leftist party Unidas Podemos ${ }^{4}$ - the left-wing alliance between Podemos and United Left (IU for its initials in Spanish) who obtained 35 seats. Meanwhile, the far-right party Vox gained prominence and gained 52 deputies in parliament. The conservative People's Party (PP) won 88 seats, and the right-leaning party Ciudadanos ${ }^{5}$ was seriously affected and attained a mere 10 seats. Nowadays, Pedro Sánchez (PSOE) is the Prime Minister of Spain. The Council of Ministers is structured into four Deputy Prime Ministers - three women from PSOE and the leader of the Unidas Podemos party, Pablo Iglesias - and 22 ministries. The current opposition political parties are integrated forming a sort of right-wing bloc comprised by PP, Ciudadanos and Vox.

All these political incidents have shed light on the importance of trusting political parties' and politicians' rhetoric, since they seem to be focused 
on reinforcing their identities and power, by undermining the credibility of the opposition and refuting the accusations made by other parties. This situation is emphasized when media and journalists act as representatives of concrete ideological positions or political parties, using the power of mass media to damage the reputation of opponents as a political strategy (Mazzoleni, 2010). As a consequence, the current Spanish scenario is more of a battlefield, where it is difficult to discern truth from falsehood, than a democratic debate characterized by critical thinking.

Therefore, drawing upon this political context, the main objective of this chapter is to explore the role played by Spanish political parties in sustaining polarized groups - or ghettos - and fueling radical behaviors, by spreading false content. We hypothesize that the distribution of fabricated stories contributes to an increased political polarization and enhances extremist and intolerant attitudes. With regard to the political polarization that makes individuals more defenseless and exposed to misinformation and disinformation, we aim to examine the potential impact of both political polarization and deceitful news in undermining the quality of the Spanish democracy. Using the case study method, this research describes five representative examples - the most popular political parties in Spain: PSOE, PP, Vox, Unidas Podemos and Ciudadanos - that illustrate how Spanish political parties shape political polarization, while inflaming radical behaviors, by spreading lies and false content on the Internet.

\section{Ideological polarization}

There are several dynamics in the digital media landscape that help the spread of controversial statements, while making it hard to find spaces for moderated content, dialogue or consensus. Some of these mechanisms are related to the new media role of social platforms and to the use of social media by politicians. In a time where most politicians are delivering their official statements through these platforms, a single piece of mis/disinformation will rapidly become an instrument for ideological polarization used by allies and enemies. Despite the hypothesis of the "End of Ideology" (Dalton, 2006), which posits that social modernization could moderate ideological polarization, with more centrism and moderate debates, it seems like the new digital landscape is providing exactly the opposite. It seems to be the case that the more polarized the message is, the more dissemination and visibility it gets.

Disinformation has always existed throughout history, through different channels, means and formats, but the level of ideological polarization we have nowadays is a consequence of media infrastructures being influenced by social platforms, which have become media themselves. In November 2018 the founder of Facebook, Mark Zuckerberg, explained his main strategy to fight against disinformation and fake news, by underlining a key issue, "What content should be distributed and what should be blocked?" 
(Zuckerberg, 2018). This question was noteworthy because it sheds light upon the kind of knowledge Facebook has about the flows of information with better engagement. In his article, Zuckerberg explained how Facebook knows that "borderline content" - referring to content that lies on the limits of prohibited content - is the one that gets more engagement from users and is closely related with misinformation, fake news, hate speech and polarization. Therefore, the policies of the platform that limit - or not the reach of borderline content are key to understand some of the defining principles of the digital ecosystem, such as viral content, click-baiting and "user-distributed content" (Villi, Khaldarova \& Matikainen, 2016). Thus, a question arises: How can one fight against hate speech when even the users - who want to defeat this content - are helping to spread it?

The role of the new mediators, meaning social media, is key in this process. Facebook has been connected and repeatedly linked to misinformation and political influence, even before the 2016 election, but also afterward and in a more intense way because, as Madrigal (2017) pointed out, "things we thought we understood ... have had to be reinterpreted in light of Donald Trump's surprising win as well as the continuing questions about the role that misinformation and disinformation played in his election" (p. 1). Meanwhile, Twitter has launched many initiatives to clean its image, around the idea of becoming a better environment for the dissemination of reliable information. In early February 2020, Twitter announced that starting on March 5, tweets containing manipulated content with the intention of misleading the public would be labeled, and their visibility and relevance would be filtered. This action can be added to many others such as the "hide replies" feature, launched in July 2019.

In this unbalanced relation between users and social platforms, media have to assume their responsibility within this growing tension: how to manage media content outside media. But it is important to note that there is no more outside media. Everything is media content - even personal content - because every platform is a medium and turns each user into a potential one. Everything is media-related in the same way that everything is digital communication: "Digital communication is the air we breathe. It has become harder to separate social life from digital technologies. Digitalization has reorganized virtually every domain of social life as communication and media infrastructures" (Waisbord, 2019, p. 78). Media infrastructures assume a greater significance with the new media landscape, where many of the digital platforms seem to operate as infrastructures themselves (Plantin \& Punathambekar, 2018). And there is the asymmetry: social platforms turn into media while media do not turn into social systems.

On one side, the new mediators are making decisions in order to portray a media role, by offering media content to users who are in platforms where they do not expect just news and other kinds of media content. Filter bubbles, algorithmic filtering and echo chambers are influencing media consumption as well as editorial lines, but sometimes with unexpected effects. 
These factors need to be studied further in order to confirm that social sites, such as Facebook, also depolarize when promoting specific flows of information (Beam, Hutchens \& Hmielowski, 2018).

But on the other side, a huge polarization problem is taking place $u n$ der the radar of public online communication, in the action of sharing political news in private messaging networks (Noguera-Vivo, 2019) but also through other closed spaces such as private Facebook groups (Reuters Institute, 2019, pp. 18-19). It is true that a new media industry based on fact-checking is living sort of a golden age - in countries like Spain - but a common problem for these fact-checkers is the way in which the verified message hardly gets the same amplification and dissemination than the original, viral - and fake - message. Another example of the limitations of verification is false information that is extensively disseminated through online private communication - WhatsApp - but fact-checked at a lower level than in public online platforms - Twitter, Facebook, etc. - where polarization does not let the controversial messages merge in order to be compared.

A new problem is added when false information is initiated from the political elites themselves - parties and politicians - in a conscious way. In this case, social networks have been an emergent tool for politicians to discredit media, as Trump has done every time he points to the traditional media landscape as a source of fake news (Lakoff \& Duran, 2018).

\section{Deceitful news and debunking journalism}

False information is truly a global problem nowadays, due to the emergence of several incidents that have shaken the credibility of politicians and the media (Bharali \& Lahkar, 2018). However, fake contents have always existed throughout history (Moore, 2017; Tandoc, Lim \& Ling, 2018), but in recent years they have grown as a consequence of a new era of Internet hoaxes (LaGarde \& Hudgins, 2018). Pal and Banerjee (2019) suggest that fabricated stories have become a "social problem" for the digital society, and, therefore, it is urgent to combat online falsehood.

According to Wardle and Derakhshan (2017), the term "fake news" is not the most accurate concept "to describe the complex phenomena of information pollution" (p. 5). Moreover, multiple research studies (Basson, 2017; UNESCO, 2017; Wardle, 2017; Wardle \& Derakhshan, 2017; Ireton $\&$ Posetti, 2018) also suggest that this concept undermines journalism and all news. For these reasons, it is more convenient to describe the three types of falseness, identified by Wardle and Derakhshan (2017), in order to examine information disorder (p. 5):

- Misinformation is when false information is shared, but no harm is meant.

- Disinformation is when false information is knowingly shared to cause harm. 
- Malinformation is when genuine information is shared to cause harm, often by moving information designed to stay private into the public sphere - i.e. leaks, harassment, hate speech.

Focusing on the political landscape, fabricated stories have a substantial impact on public opinion and behaviors; for example, according to some journalists and researchers (Dewey, 2016; Parkinson, 2016; Read, 2016; Allcott \& Gentzkow, 2017), Donald Trump "would not have been elected president were it not for the influence of fake news" (Allcott \& Gentzkow, 2017, p. 212). Voters are exposed to a great number of hoaxes, untrue information and unsupported beliefs that boost political misperceptions (Flynn, Nyhan \& Reifler, 2017) and influence political convictions (Taber \& Lodge, 2006; DiFonzo \& Bordia, 2007; Berinsky, 2017; De keersmaecker \& Roets, 2017; Pennycook \& Rand, 2019; Bago, Rand \& Pennycook, 2020).

Similarly, one of the examples of phenomena that has influenced the massive dissemination of deceitful news - misinformation, disinformation or malinformation - is ideological polarization (Spohr, 2017). Whereas many authors (Benkler, 2006; Obendorf et al., 2007; Goel, Mason \& Watts, 2010; Goel, Hofman \& Sirer, 2012; Messing \& Westwood, 2012) affirm that the digital scenario increases exposure to diverse ideas and perspectives, changing media consumption patterns by giving individuals more choices of content; other researchers (Garrett, 2009; Iyengar \& Hahn, 2009; Sunstein, 2009; Munson \& Resnick, 2010; Pariser, 2011; Bakshy, Messing \& Adamic, 2015; Flaxman, Goel \& Rao, 2016; Gentzkow, Shapiro \& Stone, 2016) warn that such a situation could bring the risk of increasing segregation in online consumption which deepens the ideological distance between individuals. This apocalyptic approach entails dangerous implications in the political context, as several researchers (Bishop, 2008; Gentzkow, 2016; Sphor, 2017; Duell \& Valasek, 2019; Herrero-Diz, Pérez-Escolar \& Plaza Sánchez, 2020) have already observed, leading to the conclusion that intolerance and hostile feelings towards individuals with different political opinions have increased nowadays.

Drawing upon this uncertain and disorderly context, in which "information falls into one of two categories-true or false-"(LaGarde \& Hudgins, 2018, p. 29) and where discerning real facts from lies is increasingly harder, the role of journalism becomes more necessary now than ever before (Silverman, 2015). This situation also gives rise to an important question: Are we facing a new form of specialized journalism?

On the one hand, the fact-checking process has always been part of journalistic routines. Before the appearance of muckraking journalism in the early 1900s, Time magazine already had its own fact-checking department in the 1930s, comprised by women whose obligation was "to check articles for accuracy before publication" (Fabry, 2017). Therefore, fact-checking is not a new phenomenon, since verifying information has always been one of the main journalists' responsibilities. 
On the other hand, many authors (Kovach \& Rosenstiel, 2007; Hermida, 2012; Graves, 2013; Shirky, 2014; Graves, Nyhan \& Reifle, 2015; LoteroEcheverri, Romero-Rodríguez \& Pérez-Rodríguez, 2018) claim that verification journalism is a new business model because it implies a new type of professional practice, new rhythms of work - due to the great speed at which hoaxes and false content spread in the digital scene - new forms of narration, etc. Dobbs (2011) and Graves and Cherubini (2016) ensure that the background of this professional profile - debunker - goes back to the presidency of Ronald Reagan, when journalists began checking his speeches for inaccuracies. Nowadays, debunking journalism has evolved by becoming part of mainstream media in the form of in-house fact-checking units dedicated to unmasking false content - i.e. Newtral in Spain (La Sexta), New York Times Fact Checks in the United States (The New York Times), El Polígrafo in Chile (El Mercurio) or CNN Fact First in the United States (CNN), among others. On the other hand, specialized newsrooms oriented towards reporting lies, rumors and hoaxes have also emerged (Lowrey, 2017). Some of these include Maldito Bulo in Spain, PolitiFact in the United States, GhanaFact in Africa or Pagella Politica in Italy, among others. Hence, debunking journalism not only involves informing individuals, but it is also a professional practice that includes monitoring, spotting and disproving misinformation and disinformation.

Nonetheless, Graves (2017) wonders whether journalists can objectively evaluate the truthfulness of political claims. As other authors stated before (Kinsley, 2016; Graves, 2017), the efficacy of fact-checking is still unclear, since some of these new forms of dedicated fact-checking journalism "are openly partisan" (Graves, 2013, p. 2). On the one hand, the left-leaning Media Matters is focused on monitoring and combating "claims made by Republican pundits and politicians" (Graves, 2013, p. 2). On the other hand, the right leaning NewsBusters is a "conservative media watchdog group" that controls and refutes statements made by their political opponents (Graves, 2013, p. 2).

In spite of these facts, Graves (2017) firmly defends that "journalists must do their best to debunk false claims" (p. 519) as well. In the same line of thought, Graves, Nyhlan and Reifler (2016) conclude that debunking journalism must embrace the objectivity norms that dominates the mainstream media in order to avoid ideological, political and economic influences.

\section{Case study description: politicians as a source of mis- and disinformation in Spain}

The main objective of this chapter is to illustrate how Spanish political elites - parties and politicians - feed radical ghettos and polarized groups, when distributing lies and fabricated stories on the Internet. For this purpose, we have applied a qualitative methodology, consisting of the case study method, to understand the potential impact of both - political polarization 
and false content - on the weakened quality of the Spanish democracy. The selected cases include the most popular political parties in Spain: PSOE, PP, Vox, Unidas Podemos and Ciudadanos. These five cases will enable an understanding of how these political actors shape political polarization in Spanish society, by spreading fake information in different online scenarios.

Political parties and candidates play "an outsized role in the spread of polarising content” (Tucker et al., 2018, p. 5). Specifically, Humanes (2016) concludes that Spanish society is becoming increasingly more polarized because of the characteristics of political information and the behavior of the media. Other authors agree on connecting the rise of deceitful news and polarizing groups with the fact that individuals are frequently more guided by feelings and emotions. In this sense, "it is also important to bear in mind that anger and hate have always been used as political tactics" (Gerbaudo, 2018, p. 94). In this regard, Tucker et al. (2018) point out that "anger makes people less likely to distrust inaccurate information that support their views, and more likely to distribute it" (p. 40). In the same line of thought, Weeks (2015) also states that anger makes misinformation more likely to be believed due to an individual's political ideology. Then, according to these authors, anger is more likely to emerge in hoaxes or false stories than in real news.

Drawing upon these statements, the selected cases describe how lies and fake information, spread by these five parties in Spain, have a role in political polarization.

\section{The President of the Government (PSOE) lies about the increase in convictions for sexual crimes in Spain}

The leader of left-leaning PSOE party and President of the Government, Pedro Sánchez, stated on January 4, 2020, during the investiture debate: "The number of people convicted for sexual crimes has increased $10 \%$ every year since 1998". In order to understand the relevance of this claim, it is important to understand that in the Spanish context sexual crimes are in front pages almost daily, and Sánchez tried to explain - with this argument - the need to fight harder against gender violence and most specifically, violence against women.

The two main Spanish fact-checkers, Newtral ${ }^{6}$ and Maldito Bulo, ${ }^{7}$ proved that the data were false. Also, a historic personal blog focused on fact-checking in Spain, MalaPrensa, ${ }^{8}$ maintained by Professor Josu Mezo, collaborated with Maldito Bulo during the verification process. As published by Maldito Bulo, in 9 out of the 20 years mentioned by Sánchez, the number of convictions decreased when compared to the year before.

About setting media agendas, a huge problem here is the way in which some media publish statements that bypass any kind of fact-checking process, maybe because of the pressure to break news and broadcast live. In this sense, a big news agency like Europa Press published the same quote 


\section{Marta Pérez-Escolar and José Manuel Noguera-Vivo}

without corrections: "He [Pedro Sánchez] stressed that the number of people convicted of sex crimes in Spain have increased by 10 percent each year since 1998". 9

As Maldito Bulo stressed, the source of Sánchez's mistake was possibly the media itself, mainly an article published by El País on July 30, 2019. In that case the title is almost the same sentence uttered by Sánchez during the investiture debate: "The number of prisoners for sexual crimes has increased by $10 \%$ every year since $1998 \% .{ }^{10}$ But the fact is that this article was wrong, and it was edited later with a slightly different new title: "The number of prisoners for sexual crimes has doubled in 20 years". ${ }^{11}$ When the source of incorrect data is a political actor we can hope for a correction by the media, but when the media themselves are the source of this inaccurate information... Who would think that it will be fixed by politicians?

\section{The PP denies the severity of pollution in Madrid: "Nobody has died because of contamination"}

Isabel Díaz Ayuso, President of the Community of Madrid, gave the following response during an interview for Cadena SER, on January 1, 2020: "Nobody has died due to contamination. I mean, I do not want to create a public health alarm, because we are not at that level". The phrase was uttered in response to a question by a journalist about "the balance between people who want to visit Madrid and the ones who live in Madrid (...) and do not want to die due to pollution".

Ayuso's claim appeared in all the front pages of the Spanish media, and members of the party stated that the answer was taken out of context. But according to the European site EU fact-check ${ }^{12}$ there are many scientific reports about the relationship between pollution and the rise of deaths, and all these sources show how this statement is completely false. Just at the European level, EHJ (European Heart Journal) estimated 790.000 premature deaths because of air pollution in Europe. In terms of Ayuso's claim, there is a 2018 report by DKV ("The air you breathe: atmospheric pollution in cities") calculating that 16.000 deaths are directly related to air pollution in Madrid.

The statement by Ayuso created a huge controversy in Spain. According to the site Trending-topics.co, "Díaz-Ayuso" was the first Trending Topic on Twitter on January 1, 2020, in Spain for more than 5 hours, from 3.42 $\mathrm{pm}$ to $8.42 \mathrm{pm}$., and many members of her party were forced to support her because of the well-known party discipline. The mayor of the city of Madrid, José Luis Martínez-Almeida, said that left-leaning parties took Ayuso's statement out of context, in order to position her as a climate change denier. Moreover, a different right-leaning political party, Ciudadanos stated that they no longer agree with Ayuso because there are clear and proven correlations between air pollution and deaths. With this example we can see how a political lie becomes the root of many reactions and media consequences. In the media landscape, the first effect is reflected in the 
agenda setting for several hours, by hiding other topics. Meanwhile, many other politicians take positions with statements clearly aimed at wearing out the adversary, rather than helping find solutions to citizens' concerns.

\section{Far-right Vox party promotes racist acts by lying about the "insecurity" generated by unaccompanied foreign minors}

The far-right party Vox commonly aims its political messages towards vilifying and condemning immigration from Muslim countries. This attitude has been associated with an increase in racist behaviors, such as those observed in Seville in November 4, 2019, when Rocío Monasterio - Vox's leader in Madrid - visited a center for unaccompanied foreign minors in La Macarena neighborhood. ${ }^{13}$ Once there, she denounced that unaccompanied foreign minors generate "insecurity" and cause "huge problems" for neighbors, while creating an "unsustainable" situation in the area.

According to Newtral, ${ }^{14}$ her statements were false, since La Macarena is not a suburb. In fact, this district is quite popular with tourists. However, immigrants have established roots and created their families there, and they have been part of the Spanish community for quite a long time. Moreover, the Regional Government of Andalusia informed that just $0.52 \%$ of unaccompanied foreign minors have been involved, in some manner, with delinquency. This is not the first time Vox blasted attacks on immigrants, in a previous instance during the 2019 electoral campaign, the far-right party spread false articles, videos and images on social networks against this minority group. For that reason, Maldito Bulo began gathering all the hoaxes Vox has disseminated about immigration. ${ }^{15}$

Despite the fact that some traditional media - both at the national and local levels - and specialized fact-checking media - Maldito Bulo and Newtral - debunked Rocío Monasterio's lies, her speech promoted xenophobic behaviors in some neighborhoods in Seville, and in other Spanish regions, where migrant populations reside. The last UNICEF report ${ }^{16}$ warned that unaccompanied foreign minors have been targets of fake news in Spain; this situation is particularly worrisome given that false content promotes hatred and rejection towards children.

Nowadays, the Office of the Prosecutor is conducting an investigation to determine whether or not Rocío Monasterio's statements constituted an offence of incitement to racial hatred. ${ }^{17}$

\section{The leftist group Unidas Podemos creates confusion about an alleged property speculator and publicly blames an innocent citizen}

The Congressional spokesperson for the leftist group Unidas Podemos, Irene Montero, tweeted the name and surnames of a - female - alleged property speculator on October 22, 2019. According to Montero, the supposed speculator, Esther Argerich, decided to increase the price of the flat 


\section{Marta Pérez-Escolar and José Manuel Noguera-Vivo}

she was renting by $30 \%$ - from $1000 €$ to $1300 €$ - forcing the tenants, Livia and Juan, to find another more affordable flat to live. ${ }^{18}$ People started googling the name of the alleged property speculator, Esther Argerich, discovering she also owned a rural house. Almost immediately, she became the target of fierce criticism and users began to attack her on social networks.

This situation became worrisome, not only because a politician was publicly blaming a citizen, but because the identity of the woman Irene Montero accused was not correct; in other words, Irene Montero tweeted a misleading and questionable piece of information about this individual. Fortunately, Spanish digital media platforms such as El Confidencial, ${ }^{19}$ contacted Esther Argerich by telephone, to find out that she was just a victim who had the same name and same first surname as a real property speculator, but the second surname of both women was different. Whereas it was true that the victim owned a rural house, she is not a property speculator. As soon as digital media platforms started debunking Irene Montero's statements, users on Twitter and on other social media began to show their support to the victim by sharing news and comments that disproved the false statements.

Moreover, three days after Irene Montero's tweet, a user profile was created on Twitter using the name Esther Argerich - @Esther06081626. We were unable to confirm the identity behind this username, mostly because there is no biographical information available. However, its first tweet was quite reveling:

I do not belong to any political party. I just defend a flat that is mine, but it scares me to think that some people, with political representation, can engage in this kind of behaviour and enable associations to harass homeowners. WE ARE NOT IN DEMOCRACY. ${ }^{20}$

Esther Argerich's account was dedicated to her experience during this intimidating situation. The last tweet was published on December 22, 2019 the account was active for two months.

It is paradoxical that although many Spanish digital media denounced Irene Montero's tweet and were concerned about bringing the real story to light, other specialized media, like Maldito Bulo or Newtral, did not report this fake news item. Irene Montero has not yet apologized for publishing such deceptive content that enraged individuals and fostered bullying behaviors towards an innocent citizen.

\section{The right-leaning party Ciudadanos contributes to deepening the gap separating pro-independence citizens and the rest of citizens by spreading distorted information}

The ex-leader of the right-leaning party Ciudadanos, Albert Rivera, tweeted, ${ }^{21}$ in August 26, 2018, that an elderly man had been attacked - in the presence of his grandson - by Catalonian pro-independence citizens, 
due to his criticism of a poster about the separatist politicians who had been accused/charged in the Catalan independence referendum in 2017. Indeed, Albert Rivera's tweet included a news item published by $A B C$, a newspaper that is part of the Spanish traditional media industry. ${ }^{22}$ The tweet became viral and users started sharing the information Albert Rivera posted, as a way to portray how the independence movement is disturbing the peace in Spain. For many people, this tweet reinforced the idea that Catalonian pro-independence citizens are violent and do not respect people with different ideologies. In terms of political polarization, this example sparked a heated debate that created further divisions between Catalonian citizens and the rest of the Spanish population. It has also deepened the gap between separatists and people who want to suppress the independence movement.

Whereas, some digital media ${ }^{23}$ and Twitter users began to claim that the incident described by Albert Rivera was completely distorted, while specialized media, like Maldito Bulo or Newtral, disregarded this piece of disinformation and related content. In reality, the facts did not happen in Catalonia, but at the Figatell Sound concert, that took place in the town of Olivia - Valencia, Spain. According to a report filed by local police, the elderly man was the one who started the fight when musicians displayed a sign that said, "Aggressors out, feminist self-defence". The man, who was a British national, was accompanied by his daughter and he reacted by punching the musicians in the face. Despite these evidences, Albert Rivera's tweet has not been deleted and $A B C$ has not rectified the reported information.

In general, these selected cases are representative examples that illustrate and portray political polarization in Spain, regarding different types of topics: gender and inequality between sexes (in the case of PSOE), climate change (in PP's example), immigration issues (in the case of Vox), the high cost of rent (concerning Unidas Podemos) and the Catalonian independence movement (in the case of Ciudadanos). This mapping enables a deeper understanding of the processes that make falsehood such a ubiquitous phenomenon that crosses partisan lines and is not limited to single ideologies.

\section{Discussion and conclusions}

How did we get here? is a tricky and usual question that makes us wonder when something is too complex to be understood holistically. Here refers to a public environment which is tainted by a variety of information disorders, and where the metrics of relevance - shares, likes, follows, visibility, etc. seem more important than reality itself. Moreover, here describes the convoluted media landscape where official sources are mixed with the interests of users - citizens - mass media - brands - institutions - government - and journalists - professionals - creating a dangerous cocktail. But here is also the problem we deal with when falsehood is commonly adopted and accepted by society. Hence, the real dilemma lies on the variety in the types of here we face in current democratic configurations. 
The main contribution of this chapter is the central role information disorders play in political polarization. This occurs in the dissemination of polarizing content that appeals to emotions rather than reason. As we have demonstrated, political parties in Spain spread both misinformation and disinformation. On the one hand, misinformation implies sharing false or inaccurate information without intent to cause harm. This was the case of PSOE and PP. The President of the Government, and leader of the leftleaning PSOE party Pedro Sánchez, provided erroneous information about the increase in the number of convicted people for sexual crimes in Spain. Similarly, Isabel Díaz Ayuso, the President of the Community of Madrid and a member of right-leaning PP party, also misspoke when stating that "no one has ever died of pollution". In neither case did the political figure seek to cause harm, but both shared misleading contents publicly, these were then spread as if they were true, affecting unwary citizens.

On the other hand, disinformation refers to false information shared with an intent to harm, found in examples from the far-right party Vox, the leftist group Unidas Podemos and the right-leaning party Ciudadanos. In the case of far-right Vox's Rocío Monasterio, she spoke out against immigrants by stating that most of them are criminals that generate insecurity and huge problems in Spanish neighborhoods. Moreover, Irene Montero - from the leftist group Unidas Podemos - posted a deceptive tweet to criticize an alleged property speculator. Lastly, the former leader of the right-wing Ciudadanos party, Albert Rivera, also shared a deceitful message, on Twitter, demonizing the independence movement of Catalonia.

However, in these specific case studies, the traditional political parties in Spain - PSOE and PP - are more conservative in distributing inaccurate content, which is evidenced by the presence of misinformation in their speeches - meaning that no harm is meant. On the other hand, the rhetoric of the newest political parties, like Vox, Unidas Podemos and Ciudadanos, is more radical, since they use disinformation - intentionally causing harm as a political strategy as part of their messages. However, it would be necessary to analyze more case studies in order to prove the approach presented.

Regarding the hypothesis of this study, we confirm that political parties contribute to increase political polarization when they spread fabricated stories. This results in what we call diversification of polarization, which refers to people becoming isolated in multiple bubble cyber-ghettos (Pariser, 2011) depending upon the nature of the issue under debate, i.e. inequality between sexes, climate change, immigration issues, the high prices of rent or the Catalonian independence movement, among other examples. Therefore, these types of fabricated content - misinformation, disinformation or malinformation - nourish the diversification of opinions, because citizens only perceive a frame of reality which is distorted, and divide people into multiple polarized groups.

In general, this chapter describes how lies have become a common resource. Specifically, when the sources of lies are the political actors and 
institutions. Hence, the objective of this research is to illustrate how easy it is to find deceptive information in the discourse of political parties in Spain; in other words, the source of deceit is usually at the top of the democratic system - political parties and their representatives. Unfortunately, it is not uncommon to see how often manipulation originates from the political institutions. In March 2020, the first video tagged by Twitter as having "manipulated media" was published by the White House. It cited a sentence by Joe Biden. The original statement was "Excuse me. We can only reelect Donald Trump if in fact we get engaged in this circular firing squad here. It's gotta be a positive campaign", and they only published "we can only reelect Donald Trump...”.

Not surprisingly, trust in journalists has also been undermined, whereas trust in scientists has been strengthened (Edelman, 2020, p. 9). Moreover, confidence in politicians is no better than the trust placed in journalists, since political debates and speeches usually contain false and misleading information. As a consequence, the act of lying increases the diversification of polarization; in other words, it increases the number of enemies and reduces the possibilities of achieving consensus. For that reason, the diversification of polarization is increasingly hindering the possibilities for raising a collective understanding, as well as weakening the values of a democracy based on mutual respect, tolerance and equality.

\section{Funding information}

This work was supported by the Catholic University of Murcia (Spain) under Grant PMAFI-10/19_University Research Plan 2018-2019.

\section{Notes}

1 Partido Socialista Obrero Español-Spanish Socialist Workers' party.

2 Partido Popular - People's party.

3 This new coalition is the first in the Spanish's political history since the restoration of democracy in 1977.

4 Unidas Podemos - United We Can.

5 Ciudadanos - Citizens.

6 Available at https://www.newtral.es/.

7 Available at https://maldita.es/malditobulo/.

8 Available at http://www.malaprensa.com/.

9 Available at https://bit.ly/2InhPpi.

10 Available at https://bit.ly/38t4ztQ.

11 Available at https://bit.ly/2wzhywJ.

12 Available at https://eufactcheck.eu.

13 Available at https://bit.ly/2wsKJ4T.

14 Available at https://bit.ly/2VLfuwf.

15 Available at https://bit.ly/2Iz47Qx.

16 Available at https://bit.ly/2xeVmbR.

17 Available at https://bit.ly/2wuynsP.

18 Available at https://bit.ly/3cALmda. 


\section{Marta Pérez-Escolar and José Manuel Noguera-Vivo}

19 Available at https://bit.ly/2TGjwn1.

20 This tweet got around 1,800 likes and 886 retweets. It is available at https://bit. $1 \mathrm{y} / 2 \mathrm{vOdMQr}$.

21 This tweet got around 3,100 likes and 1,900 retweets. It is available at https:// bit.ly/38GhCs3.

22 Available at https://bit.ly/2U1sDyK.

23 Available at https://bit.ly/33hby8s.

\section{References}

Allcott, H. \& Gentzkow, M. (2017). Social Media and Fake News in the 2016 Election. Journal of Economic Perspectives, 31(2), pp. 211-236. doi: 10.1257/ jep.31.2.211

Bago, B., Rand, D. G. \& Pennycook, G. (2020). Fake News, Fast and Slow: Deliberation Reduces Belief in False (But Not True) News Headlines. Journal of Experimental Psychology: General. doi: 10.1037/xge0000729

Bakshy, E., Messing, S. \& Adamic, L. A. (2015). Exposure to Ideologically Diverse News and Opinion on Facebook. Science, 348(6239), pp. 1130-1132. doi: 10.1126/science.aaa1160

Basson, A. (2017, July 6). If It's Fake, It's Not News. News24. Available at https:// bit.ly/2RZHHwZ

Beam, M., Hutchens, M. \& Hmielowski, J. (2018). Facebook News and (de)Polarisation: Reinforcing Spirals in the 2016 US Election. Information, Communication \& Society, 21(7), pp. 940-958. doi: 10.1080/1369118X.2018.1444.783

Benkler, Y. (2006). The Wealth of Networks: How Social Production Transforms Markets and Freedom. New Haven, CT: Yale University Press.

Berinsky, A. J. (2017). Rumors and Health Care Reform: Experiments in Political Misinformation. British Journal of Political Science, 47(2), pp. 241-262. doi: 10.1017/S0007123415000186

Bharali, B. \& Anupa, L. G. (2018). Fake News: Credibility, Cultivation Syndrome and the New Age Media. Media Watch, 9(1), pp. 118-130. doi: 10.15655/ $\mathrm{mw} / 2018 / \mathrm{v} 9 \mathrm{i} 1 / 49277$

Bishop, B. (2008). The Big Sort: Why The Clustering of Like-minded America is Tearing Us Apart. New York: Mariner Books.

Bok, S. (1978). Lying: Moral Choice in Public and Private Life. New York: Vintage.

Dalton, R. J. (2006). Social Modernization and the End of Ideology Debate: Patterns of Ideological Polarisation. Japanese Journal of Political Science, 7(1), pp. 1-22.

De keersmaecker, J. \& Roets, A. (2017). 'Fake News': Incorrect, But Hard To Correct. The Role of Cognitive Ability on the Impact of False Information on Social Impressions. Intelligence, 65, pp. 107-110. doi: 10.1016/j.intell.2017.10.005

Dewey, C. (2016, November 17). Facebook Fake-News Writer: 'I Think Donald Trump Is in the White House because of Me'. Washington Post. Available at https://wapo.st/3bhohLN

DiFonzo, N. \& Bordia, P. (2007). Rumor Psychology: Social and Organizational Approaches. Washington, DC: American Psychological Association.

Dobbs, M. (2011). The Rise of Political How Reagan Inspired a Journalistic Movement: A Reporter's Eye View. Washington, DC: New America Foundation. Available at https://bit.ly/3bl7cAI 
Duell, D. \& Valasek, J. (2019). Political Polarisation and Selection in Representative Democracies. Journal of Economic Behavior and Organization, 168, pp. 132-165. doi: 10.1016/j.jebo.2019.10.004

Edelman, R. (2020). 2020 Edelman Trust Barometer: Special Report Trust and the Coronavirus. Edelman.com. Available at https://bit.ly/39eDHOG

Fabry, M. (2017, August 24). Here's How the First Fact-Checkers Were Able to Do Their Jobs before the Internet. Time. Recuperado de https://bit.ly/ 35FEdnA

Flaxman, S., Goel, S. \& Rao, J. M. (2016). Filter Bubbles, Echo Chambers, and Online News Consumption. Public Opinion Quarterly, 80(S1), pp. 298-320. doi: $10.1093 / \mathrm{poq} / \mathrm{nfw} 006$

Flynn, D. J., Nyhan, B. \& Reifler, J. (2017). The Nature and Origins of Misperceptions: Understanding False and Unsupported Beliefs about Politics. Advances in Political Psychology, 38(S1), pp. 127-150. doi: 10.1111/pops.12394

Garrett, R. K. (2009). Echo Chambers Online? Politically Motivated Selective Exposure among Internet News Users. Journal of Computer-Mediated Communication, 14(2), pp. 265-285. doi: 10.1111/j.1083-6101.2009.01440.x

Gentzkow, M. (2016). Polarisation in 2016. Stanford University. Available at https://stanford.io/31wlud4

Gentzkow, M., Shapiro, J. M. \& Stone, D. F. (2016). Media Bias in the Marketplace: Theory. In S. Anderson, J. Waldofgel \& D. Stromberg (eds.), Handbook of Media Economics, vol. $1 B$ (pp. 623-645). Oxford: Elsevier.

Gerbaudo, P. (2018). Fake News and All-Too-Real Emotions: Surveying the Social Media Battlefield. Brown Journal of World Affairs, 25(1), pp. 85-100. Available at https://bit.ly/2vr88D4

Goel, S., Hofman, J. M. \& M. Sirer, M. I. (2012). Who Does What on the Web: A LargeScale Study of Browsing Behavior. Proceedings of the Sixth International AAAI Conference on Weblogs and Social Media (pp. 130-137). Ireland: Trinity College Dublin.

Goel, S., Mason, W. \& Watts, D. J. (2010). Real and Perceived Attitude Agreement in Social Networks. Journal of Personality and Social Psychology, 99(4), pp. 611-621.doi: 10.1037/a0020697

Graves, L. (2013). Deciding What's True: Fact-Checking Journalism and the New Ecology Of News [Doctoral dissertation]. New York: Columbia University. doi: 10.7916/D8XG9Z7C

Graves, L. (2017). Anatomy of a Fact Check: Objective Practice and the Contested Epistemology of Fact Checking. Communication, Culture \& Critique, 10, pp. 518-537. doi: 10.1111/cccr.12163

Graves, L. \& Cherubini, F. (2016). The Rise of Fact-Checking Sites in Europe. Digital News Publication. Available at https://bit.ly/389KzNw

Graves, L., Nyhan, B. \& Reifle, J. (2015). The Diffusion of Fact-checking: Understanding the Growth of a Journalistic Innovation. Available at https://bit. ly/2TEp8Qg

Graves, L., Nyhlan, B. \& Reifler, J. (2016). Understanding Innovations in Journalistic Practice: A Field Experiment Examining Motivations for Fact-Checking. Journal of Communication, 66, pp. 102-138. doi: 10.1111/ jcom. 12198

Hermida, A. (2012). TWEETS AND TRUTH Journalism as a Discipline of Collaborative Verification. Journalism Practice, 6(5-6), pp. 659-668. 
Herrero-Diz, P., Pérez-Escolar, M. \& Plaza Sánchez, J.F. (2020). Gender Disinformation: Analysing Hoaxes on Maldito Feminismo. ICONO 14, Revista de comunicación y tecnologías emergentes, 18(2), pp. 188-215. Available at https:// bit.ly/3q90Rzv

Humanes, M. L. (2016). Exposición selectiva, partidismo y polarización de las audiencias de los medios en España. En A. Casero-Ripollés (coord.), Periodismo $y$ democracia en el entorno digital (pp. 37-51). Salamanca: Sociedad Española de Periodística

Ireton, C. \& Posetti, J. (2018). Journalism, 'Fake News' \& Disinformation. Handbook for Journalism Education and Training. Paris, France: UNESCO Series on Journalism Education. Available at https://bit.ly/2GVAYxM

Iyengar, S. \& Hahn, K. S. (2009). Red Media, Blue Media: Evidence of Ideological Selectivity in Media Use. Journal of Communication, 59(1), pp. 19-39. doi: 10.1111/j.1460-2466.2008.01402.x

Kinsley, M. (2016, February 9). Ahead by a Nose. Vanity Fair, 58(3), pp. 146-147.

Kovach, B. \& Rosenstiel, T. (2007). The Elements of Journalism: What Newspeople Should Know and the Public Should Expect. New York: Three Rivers Press.

LaGarde, J. \& Hudgins, D. (2018). Fact vs. Fiction: Teaching Critical Thinking Skills in the Age of Fake News. Portland, OR: International Society for Technology in Education.

Lakoff, G. \& Duran, G. (2018, June 13). Trump Has Turned Words into Weapons. And He's Winning The Linguistic War, The Washington Post. Available at https://bit.ly/2TEfVGa

Lotero-Echeverri, G., Romero-Rodríguez, L. M. \& Pérez-Rodríguez, M. A. (2018). Fact-Checking vs. Fake News: Periodismo de confirmación como recurso de la competencia mediática contra la desinformación, index.comunicación, 8(2), pp. 295-316.

Lowrey, W. (2017). The Emergence and Development of News Fact-Checking Sites. Journalism Studies, 18(3), pp. 376-394. doi: 10.1080/1461670X.2015.1052537

MacKenzie, A. \& Bhatt, I. (2020). Lies, Bullshit and Fake News: Some Epistemological Concerns. Postdigital Science and Education, 2(1), pp. 9-13. doi: 10.1007/s42438-018-0025-4

MacLeod, C. (2015). Trust. Stanford Encyclopedia of Philosophy. Available at https://stanford.io/2HaUVRB

Madrigal, A. C. (2017, October 12). What Facebook Did to American Democracy. The Atlantic. Available at https://bit.ly/39tm66z

Mazzoleni, G. (2010). La comunicación politica. Madrid, Spain: Anaya.

Messing, S. \& Westwood, S. J. (2012). Selective Exposure in the Age of Social Media: Endorsements Trump Partisan Source Affiliation When Selecting News Online. Communication Research, 41(8), pp. 1042-1063, doi: 10.1177/00 93650212466406

Moore, M. (2017). Inquiry into Fake News. London: King's College London's Centre for the Study of Media, Communication and Power. Available at https://bit. ly/2SIDsuM

Munson, S. A. \& Resnick, P. (2010). Presenting Diverse Political Opinions: How and How Much. Proceedings of the Sigchi Conference on Human Factors in Computing Systems (pp. 1457-1466). Atlanta, GA: Association for Computing Machinery. https://doi.org/10.1145/1753326.1753543 
Noguera-Vivo, J. M. (2019). The (Private) News Sharing Report. Murcia: UCAM. Available at http://hdl.handle.net/10952/4179

Obendorf, H., Weinreich, H. Herder, E. \& Mayer, M. (2007). Web Page Revisitation Revisited: Implications of a Long-Term Click-Stream Study of Browser Usage. Proceedings of the 2007 Conference on Human Factors in Computing Systems, CHI (pp. 597-606). San Jose, CA: ACM. doi: 10.1145/1240624.1240719

Pal, A. \& Banerjee, S. (2019). Understanding Online Falsehood from the Perspective of Social Problem. In I. E. Chiluwa \& S. A. Samoilenko (eds.), Handbook of Research on Deception, Fake News, and Misinformation Online (pp. 1-17). Hershey, PA: IGI Global.

Pariser, E. (2011). The Filter Bubble: What the Internet is Hiding from You. London: Penguin UK.

Parkinson, H. J. (2016, November 14). Click and Elect: How Fake News Helped Donald Trump Win a Real Election. The Guardian. Available at https://bit. $1 \mathrm{y} / 2 \mathrm{H} 676 \mathrm{yN}$

Pennycook, G. \& Rand, D. G. (2019). Who Falls for Fake News? The Roles of Bullshit Receptivity, Overclaiming, Familiarity, and Analytic Thinking. Journal of Personality. 10.1111/jopy.12476

Plantin, J. C. \& Punathambekar, A. (2019). Digital Media Infrastructures: Pipes, Platforms, and Politics. Media, Culture \& Society, 41(2), pp. 163-174.

Read, M. (2016, November 9). Donald Trump Won because of Facebook. New York Magazine. Available at https://nym.ag/387wXTc

Reuters Institute. (2020). Digital News Report 2019, University of Oxford. Available at https://bit.ly/2TntXNs

Shirky, C. (2014). Truth without Scarcity, Ethics without Force. In K. McBride \& T. Rosenstiel (eds.), The New Ethics of Journalism (pp. 9-24). Thousand Oaks, CA: CQ Press.

Silverman, C. (2015). Lies, Damn Lies, and Viral Content. How News Websites Spread (and debunk) Online Rumors, Unverified Claims, and Misinformation. Columbia University: Tow Center for Digital Journalism. doi: 10.7916/ D8Q81RHH

Spohr, D. (2017). Fake News and Ideological Polarisation: Filter Bubbles and Selective Exposure on Social Media. Business Information Review, 34(3), pp. 150-160. doi: 10.1177/0266382117722446

Sunstein, C. R. (2009). Republic.com 2.0. Princeton, NJ: Princeton University Press.

Taber, C. S. \& Lodge, M. (2006). Motivated Skepticism in the Evaluation of Political Beliefs. American Journal of Political Science, 50(3), pp. 755-769. doi: 10.1111/j.1540-5907.2006.00214.x

Tandoc, E. C., Lim, Z. W. \& Ling, R. (2018). Defining “Fake News”. Digital Journalism, 6(2), pp. 137-153. doi: 10.1080/21670811.2017.1360143

Tucker, J. A., Guess A., Barberá, P., Vaccari, C., Siegel, A., Sanovich, S., Stukal, D. \& Nyhan, B. (2018). Social Media, Political Polarisation, and Political Disinformation: A Review of the Scientific Literature. Hewlett Foundation. Available at https://bit.ly/2Hjn9cJ

UNESCO. (2017, November 15). Solving "Fake News" Starts with Avoiding the Term. UNESCO. Available at https://bit.ly/3bgldzp

Villi, M., Matikainen, J. \& Khaldarova, I. (2016). Recommend, Tweet, Share: User-Distributed Content (UDC) and the Convergence of News Media and 


\section{Marta Pérez-Escolar and José Manuel Noguera-Vivo}

Social Networks. In A. Lugmayr \& C. Dal Zotto (eds.), Media Convergence Handbook-Vol. 1 (pp. 289-306). Berlin, Heidelberg: Springer.

Waisbord, S. (2019). Communication. A Post-Discipline. Cambridge, UK: Polity Press.

Wardle, C. (2017, February 16). Fake News. It's Complicated. First Draft. Available at https://bit.ly/387UN1a

Wardle, C. \& Derakhshan, H. (2017). Information Disorder. Toward an Interdisciplinary Framework for Research and Policymaking. Strasbourg: Council of Europe. Available at https://bit.ly/2OsHEHY

Weeks, B. E. (2015). Emotions, Partisanship, and Misperceptions: How Anger and Anxiety Moderate the Effect of Partisan Bias on Susceptibility to Political Misinformation. Journal of Communication, 65(4), pp. 699-719. doi: 10.1111/ jcom.12164

Zuckerberg, M. (2018, November 15). A Blueprint for Content Governance and Enforcement, Facebook Notes. Available at https://bit.ly/2uW2TeJ 


\title{
3 Echo chambers? Filter bubbles? The misleading metaphors that obscure the real problem
}

\author{
Axel Bruns
}

\section{Introduction}

Following the surprise victories of Brexit and Trump in 2016, even outgoing U.S. President Barack Obama (2017) warned in his farewell speech that "it's become safer to retreat into our own bubbles", thereby linking increased electoral volatility and ideological polarization with concepts such as "echo chambers" (Sunstein, 2001a) and "filter bubbles" (Pariser, 2011). The politicians, journalists and scholars who support these concepts suggest that, with online and social media as the primary sources of information for a growing percentage of the public (Newman et al., 2016), echo chambers and filter bubbles are chiefly responsible for the emergence of communities that espouse contrarian and counterfactual perspectives and ideologies, and for their disconnection from mainstream public debates.

Echo chambers are said to enable these groups to reinforce their views by connecting with like-minded others; filter bubbles to shield them from encountering contrary perspectives. Such disconnection from and ignorance of alternative perspectives is assumed to result from a combination of individual choice, in selecting the news sources to consult or the social media accounts to follow, and the algorithmic shaping of such choices, as news portals, search engines and social media platforms highlight and recommend some sources over others. As platform algorithms learn from the users' choices, and users make those choices predominantly from the options promoted by the algorithms, a self-reinforcing feedback loop gradually curtails choice to an increasingly narrow and homogeneous set of options.

Rigorous empirical evidence for the operation of such processes is sorely lacking, however. Building on empirical studies that show no significant evidence of filter bubbles or echo chambers in search or social media, this chapter argues that echo chambers and filter bubbles principally constitute an unfounded moral panic that presents a convenient technological scapegoat (search and social platforms and their affordances and algorithms) for a much more critical problem: growing social and political polarization. But this is a problem that has fundamentally social and societal causes, and therefore cannot be solved by technological means alone. 


\section{The metaphors we communicate by}

At their core, 'echo chambers' and 'filter bubbles' are highly evocative yet unfortunately ill-defined metaphors; their apparently commonsensical nature explains both their considerable appeal in scholarly and mainstream media debate, and their conceptual vagueness. Introduced and popularized by legal scholar Cass Sunstein in a series of books since the early 2000s (Sunstein, 2001a, 2001b, 2009, 2017), the 'echo chamber' concept builds explicitly on Nicholas Negroponte's mid-1990s vision of the Daily Me (Negroponte, 1995): a Web 2.0-enabled, personalized news portal that would serve only those news items that are of relevance to the known interests of its user, and would therefore vary significantly across individual users. While Negroponte's (1995) own vision of this service was largely positive, Sunstein took a considerably more dystopian view and saw the Daily Me and similar services as leading to a fragmentation and atomization of society that would mean that there was no longer a guarantee that all citizens participating in democratic processes would do so on the basis of a shared and broadly comparable information diet; in particular, he viewed the deep political divisions revealed in the disputed U.S. presidential election race between George W. Bush and Al Gore in 2000 , and in its acrimonious aftermath, as a clear sign of such coming societal disintegration. Subsequently, Sunstein's focus has shifted away from Web-based news platforms and towards the role played by social media services and their algorithms; here, too, the personalization of content feeds to suit the interests of individual users is seen as a driver of fragmentation. However, critics point out that the exact meaning of the concept has remained vague even after nearly two decades: for example, David Weinberger (2017) writes in a review of Sunstein's 2017 book \#Republic that "despite his frequent use of the term ..., Sunstein never defines echo chambers" (Sunstein, 2017, n.p.).

Similar critiques can be mounted for the related 'filter bubble' concept. Developed and promoted predominantly by the tech entrepreneur and activist Eli Pariser, it builds fundamentally on an anecdote Pariser recounts in his 2011 book The Filter Bubble: What the Internet Is Hiding from You:

in the spring of 2010, while the remains of the Deepwater Horizon oil rig were spewing crude oil into the Gulf of Mexico, I asked two friends to search for the term "BP." They're pretty similar - educated white left-leaning women who live in the Northeast. But the results they saw were quite different. One of my friends saw investment information about BP. The other saw news. For one, the first page of results contained links about the oil spill; for the other, there was nothing about it except for a promotional ad from BP.

(Pariser, 2011, p. 2) 
The 'filter bubble' metaphor suggests, then, that if such divergent patterns result systematically from the customization of search results for individual users, each user will come to be enclosed in a "personalized universe of information" (Pariser, 2015, n.p.) that may share very few overlaps with the information universes of others; again, the metaphor suggests that societal fragmentation eventually results from this disintegration of shared informational environments amongst citizens. However, Pariser, too, fails to adequately define his central concept beyond such anecdotes; indeed, like Sunstein he has pivoted in his subsequent writings from a concern with search engines as the driver of filter bubble formation to a focus on social media platforms and their algorithms, suggesting, for example, that "the Facebook news feed algorithm in particular will tend to amplify news that your political compadres favour" (Pariser, 2015, n.p.).

As both echo chambers and filter bubbles have therefore remained somewhat moving targets in both public discourse and scholarly inquiry, one result has been the gradual conflation of the two. Even as a growing number of research projects have sought to provide evidence for or against the existence of echo chambers and/or filter bubbles, the two terms have been used increasingly interchangeably; indeed, some scholarly publications openly use language such as "filter bubbles (aka 'echo chambers')" (OrellanaRodríguez \& Keane, 2018). Such confusion is thoroughly understandable, given the lack of interest in providing more concrete definitions that has been shown by the terms' primary proponents - but it does not aid our ability to develop methodologically sound and empirically rigorous tests for the existence and strength of echo chambers or filter bubbles.

Indeed, at what point should diverging information diets between individual users be considered to constitute echo chambers or filter bubbles, rather than merely expressions of differing personal interests? After all, well before the introduction of our current online and social media platforms indeed, well before any form of electronic media - different groups in society have always already informed themselves from different sources that suited their specific informational interests, needs or literacies, and have formed communities of interest, professional associations, learned societies or political parties to further that information exchange amongst the cognoscenti. If such diverging information diets predate the Internet and its various communication forms, have the echo chambers and filter bubbles that these new technologies are supposed to have caused always existed? Given that society and democracy have persisted nonetheless, should we even worry about them? Or do the proponents of these new metaphors argue that contemporary search engines and social media and their personalization algorithms have measurably worsened communicative disconnects and dysfunctions in society, and continue to do so? Put simply, what is new here, and how is it different from before?

From this perspective, we need to develop measures that assess the level of dysfunction, possibly against a normative ideal: these would determine 
how severely individuals and groups are disconnected from the available diversity of information, and set one or more threshold points at which mere interest in specific fields and types of information (preferential attachment) turns to an active rejection of other material (selective avoidance) - in simple terms, such measures would create a scale from 'balanced information diet' through 'informational specialization' to 'dysfunctional disconnection'. At some point along that scale, individuals or groups may then be assessed to have entered echo chambers or filter bubbles, yet where that point lies must remain unclear for now: there is little agreement amongst the users of these metaphors about whether a 'true' echo chamber or filter bubble would require the hermetic severance of all informational ties with the outside, or whether less complete disruptions to the flow of information into and out of the space are already problematic enough to warrant the use of these terms. Here, again, the metaphors we use are obstructing our progress: the image of 'chambers' and 'bubbles' seems to suggest an entirely disconnected space that is both inescapable and impermeable, yet some of the existing literature begins to speak of echo chambers and filter bubbles already in the context of far less significantly constricted flows of information and communication that leave their participants connected to the outside world.

\section{The unbearable sameness of search}

While much of the subsequent discussion will focus on social media platforms as the proposed locus of echo chambers and filter bubbles, let us first briefly consider these concepts in the context of search, since both Sunstein's and Pariser's early work - and indeed Pariser's foundational anecdote for the 'filter bubble' metaphor - reference search engines as important drivers of informational fragmentation.

A series of recent studies have largely debunked such claims. Working at different scales, across several countries, with a focus on both Google Search and Google News, and variously using made-up user profiles, human clickworkers recruited via Amazon's Mechanical Turk service, and data donations generated by thousands of everyday users installing a browser plugin, studies by Haim, Graefe and Brosius (2018), Nechushtai and Lewis (2019), and Krafft, Gamer and Zweig (2018) each found the very opposite of the experience reported by Pariser: different users searching for the same search terms were served very similar information, and in $5-10 \%$ of all cases saw identical search results "even in the same order" (Krafft, Gamer \& Zweig, 2018, p. 30; my translation). Substantial differences occurred, not unexpectedly, only for users based in different countries and/or using their browsers in different languages.

Very much in contrast to the picture painted by the filter bubble metaphor, therefore, this evidence shows "only minor effects of personalization on content diversity", if any (Haim, Graefe \& Brosius, 2018, p. 339); as a 
result, Krafft, Gamer and Zweig (2018) go as far as to categorically "deny the algorithmically based development and solidification of isolating filter bubbles" (Haim, Graefe \& Brosius, 2018, p. 53; my translation). Indeed, in their discussion of the findings for their U.S.-based study, Nechushtai and Lewis (2019) even express the concern that, "despite the platform's algorithmic capability of constructing a much more diverse and/or tailored news experience" (Nechushtai \& Lewis, 2019, p. 302), Google News provides not enough personalization, and instead directs its users predominantly to the same four or five prominent mainstream media news sources. While this should not be misunderstood as an explicit call for the construction of filter bubbles, it nonetheless points to the fact that some degree of personalization - to address the individual user's interests, geographic location, socioeconomic context and levels of news and media literacy - may in fact be desirable, and beneficial to their ability to realize their full potential as an informed citizen.

These findings show that if there are echo chambers or filter bubbles in search at all, they appear to encapsulate entire national populations rather than divide them into separate groups. But in reality this stretches these metaphors beyond breaking point, since they were originally introduced explicitly to address apparent dysfunctions within contemporary societies; instead, what these studies of search results appear to have uncovered is the fact that in spite of the considerable transformations experienced by national and international media ecologies since the widespread adoption of digital media, the afterimages of national public spheres that are sustained by a handful of leading mainstream media outlets continue to linger.

\section{Echo chambers and filter bubbles in social media}

Even before the emergence of this comprehensive evidence against echo chambers or filter bubbles in search, much of the debate about these metaphors had shifted towards social media, where a number of studies claim to have found genuine evidence for the existence of communicative fragmentation and dysfunction. Here, too, the thorough empirical evaluation of these concepts has been frustrated by the lack of clear definitions, however; 'echo chamber' and 'filter bubble' are often used interchangeably, and there are wildly varying thresholds for when a mild preferential attachment to other communication partners on social media platforms (that is, the formation of communities of interest or clusters in the network) is seen as turning into an exclusionary detachment from and selective avoidance of mainstream discourse.

Elsewhere, in order to address some of these shortcomings in the current scholarship, I have proposed new and more explicit definitions for 'echo chamber' and 'filter bubble' that are better suited to their study in social media contexts (Bruns, 2019); in particular, these distinguish between patterns of connection and practices of communication on these platforms. 
While there is no space to discuss these definitions in detail in the present chapter, this central distinction maps well onto the affordances of leading social media platforms such as Facebook and Twitter: using these definitions, the 'echo chamber' metaphor then addresses the structure of Facebook friendship or Twitter follower networks, while the 'filter bubble' metaphor focuses on the actual networks of communication that may or may not follow these connection structures (on both platforms, it remains possible to communicate with other users who are not friends or followers). Further, under this definition echo chambers and filter bubbles would amplify each other if the dysfunctional connection and communication structures overlap closely with each other - that is, if individuals and groups are both connecting and communicating only with their chosen in-group, and information flows to and from the outside are thus entirely severed. Finally, these new definitions also make it possible to assess more systematically exactly how disconnected the denizens of such suspected echo chambers or filter bubbles really are: most simply, it would be possible to use network metrics such as the E-I Index (Krackhardt \& Stern, 1988) to compare their volume of connection and communication with others external or internal to the group (cf. Bruns [2017] and Bruns \& Enli [2018] for applications of this approach to the Australian and Norwegian Twitterspheres).

This repurposing of echo chambers and filter bubbles from loose commonsensical metaphors to empirically verifiable concepts is already foreshadowed in some much earlier work. Focusing on the previous generation of social media - blogs - in their influential study of interconnection patterns amongst political blogs during the 2004 U.S. presidential election, Adamic and Glance (2005) famously found significant preferential attachment amongst partisan blogs on either side of the major political divide in the United States: Democrats were more likely to link to other Democrats, and Republicans more likely to link to other Republicans, than they were to connect to the other side. Nonetheless, there were some connections between them that linked to ideologically divergent content, even if perhaps only to criticize and attack such opposing views. The study therefore described the progressive and conservative blog networks it uncovered only "as mild echo chambers" (Adamic \& Glance, 2005, p. 41), yet without further qualifying or explaining that term; the obvious question that flows from this classification is whether such 'mild' preferential attachment tendencies should be considered to be echo chambers in the fuller sense of the term at all, or whether they simply reflect the diverging ideological orientations amongst different partisan groups that should be expected in any election campaign, but which are not in themselves damaging to society. Indeed, an even more interesting question is perhaps whether such partisanship amongst social media participants has become measurably more severe in subsequent U.S. elections.

Studies of such connection and communication patterns within the current generation of mainstream social media have provided a similarly mixed 
picture. Amongst a multitude of such studies (see Bruns [2019] for a more detailed review of the current state of the field), the research by Williams et al. (2015) into the structure of participant communities in discussions about climate change on Twitter serves as a useful example for such work: the authors examined connection (via follower relations) and communication (via @mentions and retweets) patterns amongst the lead participants in a number of relevant hashtags that variously reflected an acceptance of the scientific consensus, a neutral stance or an outright denial of the science. In the definition sketched out above, therefore, they tested for both echo chambers (connection) and filter bubbles (communication), across a range of ideological contexts. Their findings are decidedly mixed: follower networks are often polarized, yet not entirely bifurcated (indicating perhaps a mild to more severe tendency towards echo chamber formation, depending on the hashtag); retweet networks show similar patterns; yet @mentions generally see partisans from all sides of the debate interact freely with each other (undermining any suggestion of ideologically determined filter bubbles amongst them). The researchers see this as evidence for both "open forums" and "echo chambers" (Williams et al., 2015, p. 137), even within the same hashtags.

Such potentially contradictory findings - which are also documented by a number of other studies, across a wide range of issues and topics - are further complicated by the fact that such studies often only investigate communication patterns within selected Twitter hashtags or Facebook pages, and like Williams et al. (2015) often only focus on the most active and most persistent contributors within these spaces. Further, these communicative spaces are often selected specifically because they represent controversies known to engender strong partisanship - for instance, Smith and Graham (2017) examine anti-vaccination pages on Facebook, while Garimella et al. (2018) explore divisive hashtags such as \#obamacare, \#guncontrol and \#abortion on Twitter. That such spaces are often highly polarized, and that their most committed participants also show the greatest levels of partisanship, is hardly surprising - yet similar patterns are not evident when these studies also consider inherently non-political cases for comparison: for Garimella et al. (2018), this includes hashtags such as \#gameofthrones or \#foodporn. Here, there appears to be no appreciable tendency towards the formation of echo chambers or filter bubbles, or towards any form of polarization, amongst the participant communities.

\section{Busting the bubble}

Indeed, even the apparent echo chamber or filter bubble tendencies that some of these studies claim to have observed in highly polarized Facebook pages or Twitter hashtags must be relativized if we consider that the very platform affordances that such research studies - pages and hashtags - are designed to connect users and make their communicative contributions 
visible to each other. Even if participants from different sides of an ideological divide choose neither to follow nor engage with their antagonists within such a space, each will still see the posts made by the opposite side, and the accounts that posted them, if they follow the page or hashtag feed (and here especially the posts made by those most active and potentially most ideologically orthodox lead users on either side). Only if - through spiral of silence effects (Noelle-Neumann, 1974) and similar mechanisms oppositional voices have been entirely purged from a given communicative space can such environments be considered as genuine echo chambers or filter bubbles.

Such exclusionary processes are more likely to occur in cases where membership in such a space can be controlled by the community or its leaders this is impossible for Twitter hashtags, which may be created and used by any user at any time, but more likely for Facebook pages and especially Facebook groups. The members of such spaces could seek to deliberately cut themselves off from the broader communicative environment around them, in order to perpetuate their in-group narratives without fear of disruption or contradiction. But in order to form 'hard' echo chambers or filter bubbles, they would then also have to refrain from using any of the other affordances of these platforms, to avoid connecting and communicating with non-orthodox outsiders even serendipitously. To do so is not impossible, but would require almost cultish levels of devotion and rigor, as O'Hara and Stevens argue (2015, p. 416).

By contrast, even if they are members of one or more of such closed, ideologically orthodox social media spaces, most ordinary social media users would also continue to use the same platforms for a variety of other purposes ranging from everyday social interaction to following current developments and discussions across various non-political interests. Through such activities, they remain likely to be exposed serendipitously to a wide range of participants and views that will diverge from and thereby counteract the ideological monoculture they may be experiencing in their closed spaces. In fact, as Helberger (2011) notes, "even Sunstein concedes that unexpected exposures may help to 'promote understanding' and open-mindedness, and thereby also advance democratic goals" (p. 454). Here, it is therefore crucial to adopt a more holistic perspective on the various connective and communicative affordances and processes that a given user is likely to encounter on a social media platform over the course of an ordinary day, and indeed also to understand the social media platform itself only as one waypoint in their navigation of a much more complex media environment that incorporates multiple analogue as well as digital channels, from face-to-face encounters to electronic messaging (Dubois \& Blank, 2018). Unfortunately, the echo chamber and filter bubble metaphors tend to misrepresent the connective and communicative patterns they describe as symptomatic of users' entire experience of social media platforms, rather than as only one aspect of a much more diverse range of encounters. 
Each of the components of this complex and interwoven media ecology offers different affordances that variously close off or open out avenues for deliberate or serendipitous encounters with sameness and difference. Even within a single platform such as Facebook, we may argue that while its groups can indeed serve as engines of homophily, enabling like-minded users to connect and communicate with each other and exclude the outside world, its personal profiles serve as engines of context collapse (Marwick $\&$ boyd, 2011), where contacts from the many facets of the user's personal life - family, friends, acquaintances, workmates and others - connect and communicate with each other in an unruly and often uncontrollable mêlée. Whatever orthodox information diets participation in the former might have sought to create, these are thoroughly undone for most users of such a platform by the serendipitous "wild flows of messages" (Habermas, 2006, p. 415) across the latter.

Even the platforms' recommendation and filtering algorithms, often presented as a significant culprit in channeling such wild flows into monocultural feeds, cannot undo this diversity, even if they do affect it. Eli Pariser is simply and fundamentally wrong in his assessment that "the Facebook news feed algorithm in particular will tend to amplify news that your political compadres favour" (Pariser, 2015, n.p.), which we encountered earlier, for the basic fact that the users of Facebook and other mainstream social media platforms do not select their friends and followers on these platforms simply because they are 'political compadres'. Rather, as research by the Pew Center found even in the context of the exceptionally divisive 2016 U.S. presidential election, "a notable proportion of users simply don't pay much attention to the political characteristics of the people in their networks" (Duggan \& Smith, 2016, p. 9), and as a result are indeed often surprised and frustrated by the amount of political content they encounter in their networks that does not align with their own ideological views. Yet such cross-ideological connectivity can also be highly beneficial for these users' information diets: data gathered for the Reuters Institute's Digital News Report demonstrate that with the help of the habitual newssharing (Bruns, 2018a) performed by the friends and followers in their network, social media users generally encounter a greater diversity of news sources than non-users do (Fletcher \& Nielsen, 2018, p. 2459). Far from the concerns of the proponents of the echo chamber and filter bubble metaphors, in order words, mainstream social media platforms and practices enrich rather than impoverish their users' information diets.

This does not rule out that extreme hyperpartisans on the fringes of the political spectrum will display highly divergent communication practices, and will indeed only connect with their own political compadres on these platforms, or even communicate only on the smaller niche platforms specifically designed to cater to particular ideological groups. Yet in order to complete their enclosure in a self-selected echo chamber and/or filter bubble, even such political extremists would then need to abstain altogether 
from also engaging with more mainstream platforms (for instance, to maintain social connections with their non-political friends or family), and even from using mainstream media services altogether. Given the very hyperpartisan nature of their ideological stance, however, such cultish disconnection from the ordinary world would be inherently counterproductive: in order to shore up their own ideological worldview against outside challenge, to evangelize for new converts to their ideological orthodoxies and to be able to attack the perceived flaws in the arguments put forward by their opponents, it is critical for these hyperpartisans to also maintain their presence in mainstream social media conversations and to continue to monitor mainstream and opposition media content (Garrett, Carnahan \& Lynch, 2013, p. 131). As a result, those users frequenting the most extremely partisan conservative sites in the United States have been found also to be more likely than ordinary Internet users to visit the centrist New York Times, for instance (Gentzkow \& Shapiro, 2011, p. 1823).

From this whole-of-system perspective, then, it appears exceptionally unlikely that ordinary social media users would find themselves entirely enclosed in connective echo chambers or communicative filter bubbles, even if they actively pursue homophilous connections with like-minded others in the context of specific interests or activities: on the mainstream social media platforms themselves, and even more so across the contemporary media ecology as a whole, the forces of context collapse in a complex and thoroughly interconnected mediasphere are simply too powerful. This is borne out by studies that attempt to take a more comprehensive perspective: a major study of overlaps in the Facebook page likes amongst supporters of different political parties ahead of the 2017 German federal election showed significant shared interests even in spite of diverging ideological views, except for the neo-fascist AfD party (Brunner \& Ebitsch, 2017; Rietzschel, 2017), while comprehensive analyses of the follower network structures in the Australian and Norwegian Twitterspheres (Bruns et al., 2017; Bruns \& Enli, 2018), and of interaction patterns amongst Australian Twitter accounts (Bruns, 2017) detected clear tendencies to form network clusters around shared interests, but saw no evidence of active disconnection from other groups.

Such findings remain in line with earlier studies of online news use in the United States, which found that "exposure to highly partisan political information ... does not come at the expense of contact with other viewpoints" (Garrett, Carnahan \& Lynch, 2013, p. 132): the overall picture that emerges here is that online and social media do of course make it easier for individuals to pursue their interests, and to preferentially connect and communicate with like-minded others in doing so, but that this does not mean that they also withdraw from engaging with other contacts as a result. An element of homophily in one's online interactions does not mean an equal and opposite element of heterophobia at the same time, therefore; preferential attachment around political and other interests does not inevitably damage the user's overall information diet. 


\section{Conclusion: the dumbest metaphor on the Internet}

This detaches the echo chamber and filter bubble concepts, which we have redefined as empirically measurable divergences in connection and communication patterns from an idealized, cluster- and community-free network structure, from the inherently negative consequences - chiefly, societal and ideological fragmentation - that Sunstein and Pariser have attached to these metaphors. In many online and social media environments, mild or more severe tendencies towards homophily may well exist, for particular users and groups, across a wide range of contexts, and we could apply terms such as 'echo chamber' or 'filter bubble' to such patterns if we so choose, but it is not at all clear that this has any inevitable impact on these users' information diets or democratic participation. In light of the strongly negative connotations that these terms now have in both scholarly and mainstream discourses, however, it may be difficult to salvage them for future use as more value-neutral concepts.

Similarly, there no longer appears to be any direct and inescapable link between participants' involvement in such homophilous preferential attachment to like-minded others on the one side, and the digital media technologies they employ in pursuing it on the other side; this homophily, to the extent that it occurs, results in the first place from users' own personal, professional and political interests. By contrast, as O'Hara and Stevens (2015) observe, "the echo chamber argument seems to suggest that technology is a homogeneous influence on an individual whose social context is, if not fixed, at least not particularly multidimensional. Yet this does not accord with experience" (O'Hara \& Stevens, 2015, p. 412): it is the very complexity and multidimensionality of everyday life, experienced most viscerally at times of context collapse, that counteracts the homogenizing tendencies of preferential attachment to like-minded others in any one specific social context, online or offline. Even the organizing algorithms employed by search and social media platforms to channel and manage this complexity cannot counteract such fundamental human traits, although they are at times able to dampen and ease the rapid transitions between different social contexts.

In the face of such complexities, it is therefore difficult to see justifications for continuing our use of terms such as 'echo chamber' and 'filter bubble' other than in exceptional and extreme situations, and a growing chorus of scholars have come to take an explicitly critical view of these concepts. In a major review of the existing literature, for example, Zuiderveen Borgesius et al. (2016) come to the conclusion that "at present there is little empirical evidence that warrants any worries about filter bubbles" (Zuiderveen Borgesius et al., 2016, p. 1). But the concepts remain present in mainstream discourse, appearing even in presidential farewell speeches, and therefore continue to exert a significant influence on the popular understanding of contemporary digital media platforms; this is deeply problematic, and a symptom of a larger moral panic about the impacts of such 
new communication technologies on society, politics and democracy. As Weinberger put it as early as 2004 , the echo chamber "is a myth just waiting to concretize into common wisdom" (Weinberger, 2004, n.p.) - by now, the concrete has set, and this deeply flawed metaphor may well be used as a basis for political decision-making as further regulation of online communication platforms is developed.

This is concerning: "one lesson we should have learned from the past is that panic does not lead to sane policies" (Zuiderveen Borgesius et al., 2016, p. 11). Yet echo chambers and filter bubbles, and the platform affordances and algorithms that are said to be instrumental in their emergence, have been cast amongst the chief villains in the rise of populist and illiberal political movements in the Americas, Europe, the Asia-Pacific and elsewhere. This is sometimes done explicitly with an ulterior motive: the echo chamber "meme ... plays into the hands of those who are ready to misconstrue the Net in order to control it" (Weinberger, 2004, n.p.). But even in the absence of such more sinister motivations the echo chamber and filter bubble metaphors represent at the very least a technologically determinist fallacy that is likely to have consequences for how current crises are addressed: as Meineck (2018) puts it, these metaphors are "the desperate attempt to make technology responsible for ... societal problems. Whoever speaks of filter bubbles evidently sees the causes of radical users in algorithmic newsfeeds or monstrous online platforms that push their helpless visitors in despicable ways into bubbles of opinion” (Meineck, 2018, n.p.) an unacceptable oversimplification that fundamentally, cynically deprives users of their personal identity and agency. Meineck (2018) therefore calls the filter bubble "the dumbest metaphor of the Internet" (Meineck, 2018, n.p.; my translation), and this criticism is not unreasonable.

The fundamental problem, ultimately, is that the echo chamber and filter bubble metaphors both draw our attention to the specific technologies on which they focus: personalized content portals, search engines and - most recently and most forcefully - social media platforms. They correlate the emergence of the phenomena they decry with the widespread adoption of these tools by a mass userbase, and by extension suggest that similar patterns of homophily and heterophobia did not exist before their advent. But as we have seen, there are now both substantial challenges to the veracity of claims about the societal fragmentation and impoverished information diets that echo chambers and filter bubbles are supposed to cause, and significant questions about whether mere preferential attachment to others over shared interests is a particularly novel phenomenon, and in any way different from such tendencies even in offline environments.

If there are crucial and confronting challenges to societal cohesion in many nations of the developed and developing world at present, therefore - as there clearly are - the echo chamber and filter bubble metaphors are doing us a fundamental disservice by misdirecting our attention to online platforms as the root cause of these problems. This does not absolve the 
operators of these platforms from all culpability, of course: Facebook, Twitter and other major stakeholders could and should be doing a great deal more to militate against abuse and hate speech, suppress the circulation of mis-, dis- and malinformation, and deplatform extremists, and they should engage in a much more transparent manner with the scholarly community in finding social as well as technological solutions to these issues (Bruns, 2018b), rather than relying only on the limited expertise of their in-house teams. However, the rise of hyperpartisan, populist and illiberal ideological agitators and propagandists from the fringes of the political spectrum, and their rejection of established democratic principles and processes, is not principally a phenomenon related to the communications technologies they use: it is, centrally, a societal problem. Our continuing debate about ill-considered metaphors such as 'echo chambers' and 'filter bubbles' is a distraction that we can no longer afford, because it keeps us from confronting far more important matters head-on.

Even (indeed, perhaps especially) the most hyperpartisan users still encounter material that challenges their perspectives, and engage with others who represent opposing views (e.g. Garrett, Carnahan \& Lynch, 2013; Weeks, Ksiazek \& Holbert, 2016). The central question now is what they do with such information when they encounter it: do they dismiss it immediately as running counter to their own views? Do they engage in a critical reading, turning it into material to support their own worldview, perhaps as evidence for their own conspiracy theories? Do they respond by offering counter-arguments, by vocally and event violently disagreeing, by making ad hominem attacks or by knowingly disseminating all-out lies as 'alternative facts'? More important yet, why do they do so? What is it that has so entrenched and cemented their beliefs that they are no longer open to contestation? This is the debate we need to have: not a proxy argument about the impact of platforms and algorithms, but a meaningful discussion about the complex and compound causes of political and societal polarization. The 'echo chamber' and 'filter bubble' metaphors have kept us from pursuing that debate and must now be put to rest.

\section{Acknowledgments}

This research was supported by the Australian Research Council Future Fellowship project Understanding Intermedia Information Flows in the Australian Online Public Sphere and LIEF project TrISMA: Tracking Infrastructure for Social Media in Australia.

\section{References}

Adamic, L.A. \& Glance, N. (2005). The Political Blogosphere and the 2004 U.S. Election: Divided They Blog. In J. Adibi, M. Grobelnik, D. Mladenic, \& P. Pantel (Eds.), Proceedings of the 3rd International Workshop on Link Discovery (pp. 36-43). New York: ACM. doi:10.1145/1134271.1134277 
Brunner, K. \& Ebitsch, S. (2017, 2nd May). Von AfD bis Linkspartei - so politisch ist Facebook. Süddeutsche Zeitung. Available at https://bit.ly/2LdAb1e

Bruns, A. (2017, 15th September). Echo Chamber? What Echo Chamber? Reviewing the Evidence. Future of Journalism 2017. Available at https://bit.ly/3tezC8o

Bruns, A. (2018a). Gatewatching and News Curation: Journalism, Social Media, and the Public Sphere. New York: Peter Lang.

Bruns, A. (2018b). Facebook Shuts the Gate after the Horse Has Bolted, and Hurts Real Research in the Process. Internet Policy Review. Available at https://bit. ly/2MoCAqb

Bruns, A. (2019). Are Filter Bubbles Real? Cambridge, MA: Polity.

Bruns, A. \& Enli, G. (2018). The Norwegian Twittersphere: Structure and Dynamics. Nordicom Review, 39(1), pp. 129-148. doi :10.2478/nor-2018-0006

Bruns, A., Moon, B., Münch, F. \& Sadkowsky, T. (2017). The Australian Twittersphere in 2016: Mapping the Follower/Followee Network. Social Media + Society, 3(4), pp. 1-15. doi: 10.1177/2056305117748162

Dubois, E. \& Blank, G. (2018). The Echo Chamber Is Overstated: The Moderating Effect of Political Interest and Diverse Media. Information, Communication \& Society, 21(5), pp. 729-745. doi: 10.1080/1369118X.2018.1428656

Duggan, M. \& Smith, A. (2016). The Political Environment on Social Media. Washington, DC: Pew Research Center. Available at https://pewrsr.ch/36vP7PC

Fletcher, R. \& Nielsen, R.K. (2018). Are People Incidentally Exposed to News on Social Media? A Comparative Analysis. New Media \& Society, 20(7), pp. 2450-2468. doi: 10.1177/1461444817724170

Garimella, K., De Francisci Morales, G., Gionis, A. \& Mathioudakis, M. (2018). Political Discourse on Social Media: Echo Chambers, Gatekeepers, and the Price of Bipartisanship. In Proceedings of the 2018 World Wide Web Conference (pp. 913-922). Geneva: International World Wide Web Conferences Steering Committee. doi: 10.1145/3178876.3186139

Garrett, R.K., Carnahan, D. \& Lynch, E.K. (2013). A Turn toward Avoidance? Selective Exposure to Online Political Information, 2004-2008. Political Behavior, 35(1), pp. 113-134. doi: 10.1007/s11109-011-9185-9186.

Gentzkow, M. \& Shapiro, J.M. (2011). Ideological Segregation Online and Offline. The Quarterly Journal of Economics, 126, pp. 1799-1839. doi: 10.1093/qje/ qjr044

Habermas, J. (2006). Political Communication in Media Society: Does Democracy Still Enjoy an Epistemic Dimension? The Impact of Normative Theory on Empirical Research. Communication Theory, 16, pp. 411-426. doi: 10.1111/ j.1468-2885.2006.00280.x

Haim, M., Graefe, A. \& Brosius, H.-B. (2018). Burst of the Filter Bubble? Effects of Personalization on the Diversity of Google News. Digital Journalism, 6(3), pp. 330-343. doi:10.1080/21670811.2017.1338145

Helberger, N. (2011). Diversity by Design. Journal of Information Policy, 1, pp. 441-469. doi: 10.5325/jinfopoli.1.2011.0441

Krackhardt, D. \& Stern, R.N. (1988). Informal Networks and Organizational Crises: An Experimental Simulation. Social Psychology Quarterly, 51(2), pp. 123-140. doi: 10.2307/2786835

Krafft, T.D., Gamer, M. \& Zweig, K.A. (2018). Wer sieht was? Personalisierung, Regionalisierung und die Frage nach der Filterblase in Googles Suchmaschine. Kaiserslautern: Algorithm Watch. Available at https://bit.ly/3pDcL41 
Marwick, A.E. \& boyd, D. (2011). I Tweet Honestly, I Tweet Passionately: Twitter Users, Context Collapse, and the Imagined Audience. New Media \& Society, 13(1), pp. 114-133. doi:10.1177/1461444810365313

Meineck, S. (2018, 9th March). Deshalb ist 'Filterblase' die blödeste Metapher des Internets. Motherboard. Available at https://bit.ly/3cudwsB

Nechushtai, E. \& Lewis, S.C. (2019). What Kind of News Gatekeepers Do We Want Machines to Be? Filter Bubbles, Fragmentation, and the Normative Dimensions of Algorithmic Recommendations. Computers in Human Behavior, 90, pp. 298-307. doi: 10.1016/j.chb.2018.07.043

Negroponte, N. (1995). Being Digital. New York: Vintage.

Newman, N., Fletcher, R., Levy, D.A.L. \& Nielsen, R.K. (2016). Reuters Institute Digital News Report 2016. Oxford: Reuters Institute for the Study of Journalism. Available at https://bit.ly/3cyVeX9

Noelle-Neumann, E. (1974). The Spiral of Silence: A Theory of Public Opinion. Journal of Communication, 24(2), pp. 43-51. doi:10.1111/j.1460-2466.1974. tb00367.x

Obama, B. (2017, 10th January). President Obama's Farewell Address: Full Video and Text. New York Times. Available at https://nyti.ms/2NWnaKr

O’Hara, K. \& Stevens, D. (2015). Echo Chambers and Online Radicalism: Assessing the Internet's Complicity in Violent Extremism. Policy \& Internet, 7(4), pp. 401-422. doi:10.1002/poi3.88

Orellana-Rodríguez, C. \& Keane, M.T. (2018). Attention to News and Its Dissemination on Twitter: A Survey. Computer Science Review, 29, pp. 74-94. doi: 10.1016/j.cosrev.2018.07.001

Pariser, E. (2011). The Filter Bubble: What the Internet Is Hiding from You. London: Penguin.

Pariser, E. (2015, 7th May). Did Facebook's Big Study Kill My Filter Bubble Thesis? Wired. Available at https://bit.ly/36sLppJ

Rietzschel, A. (2017, 11th July). Wie es in Facebooks Echokammern aussieht - von links bis rechts. Süddeutsche Zeitung. Available at https://bit.ly/36yayPZ

Smith, N. \& Graham, T. (2017). Mapping the Anti-Vaccination Movement on Facebook. Information, Communication \& Society, 22(9), pp. 1310-1327. doi: 10.1080/1369118X.2017.1418406

Sunstein, C.R. (2001a). Echo Chambers: Bush v. Gore, Impeachment, and Beyond. Princeton, NJ: Princeton University Press.

Sunstein, C.R. (2001b). Republic.com. Princeton, NJ: Princeton University Press.

Sunstein, C.R. (2009). Republic.com 2.0. Princeton, NJ: Princeton University Press.

Sunstein, C.R. (2017). \#Republic: Divided Democracy in the Age of Social Media. Princeton, NJ: Princeton University Press.

Weeks, B.E., Ksiazek, T.B. \& Holbert, R.L. (2016). Partisan Enclaves or Shared Media Experiences? A Network Approach to Understanding Citizens' Political News Environments. Journal of Broadcasting \& Electronic Media, 60(2), pp. 248-268. doi: 10.1080/08838151.2016.1164170

Weinberger, D. (2004, 21st February). Is There an Echo in Here? Salon. Available at https://bit.ly/3cp7SIi

Weinberger, D. (2017, 20th July). Pointing at the Wrong Villain: Cass Sunstein and Echo Chambers. Los Angeles Review of Books. Available at https://bit. ly/2MNcPQb 


\section{Axel Bruns}

Williams, H.T.P., McMurray, J.R., Kurz, T. \& Lambert, F.H. (2015). Network Analysis Reveals Open Forums and Echo Chambers in Social Media Discussions of Climate Change. Global Environmental Change, 32, pp. 126-138. doi: 10.1016/j.gloenvcha.2015.03.006

Zuiderveen Borgesius, F.J., Trilling, D., Möller, J., Bodó, B., de Vreese, C.H. \& Helberger, N. (2016). Should We Worry about Filter Bubbles? Internet Policy Review, 5(1). doi:10.14763/2016.1.401 


\section{Hate speech and deliberation Overcoming the "words-that- wound" trap}

Liriam Sponholz

\section{Introduction}

The advent of social media in the 2000s raised huge hopes for the improvement of democracy. In the early 2010s, social media was seen through the lens of its emancipatory potential, as it enabled global movements such as the Arab Spring, Los Indignados, and Occupy (Kuehn \& Salter, 2020). However, the unanticipated electoral outcomes of 2016, which featured a U.S. presidential election and a U.K.-wide referendum on the country's withdrawal from the European Union ("Brexit"), shifted the focus from an emancipatory utopia to the digital threats posed by social media and its deliberative potential (Miller \& Vaccari, 2020).

This chapter focuses on one kind of digital threat, one that gives rise to conflict and that is nurtured by social media logic and generated by the communication of disparagement (Stone, 2000) against historically oppressed groups (Matsuda, 1989) or groups that are systematically discriminated against (Gelber, 2019). That is: hate speech. Since the critical race theorist Mari Matsuda coined the concept in a seminal article in 1989, it has been assessed in various communicative situations. However, online hate speech poses a specific threat to democracy because it is shaped by the media logic of digital platforms, particularly of social networking sites (SNS).

Such media logic turns hate speech from a matter of content into a matter of digital objects, performed not only by "words-that-wound" (Delgado \& Stefancic, 2004) and open, verbal threats, but by the possibilities of interaction provided by such platforms and by the networks they allow to be built online. As a consequence, understanding how online hate speech hijacks online deliberation requires the issue to be understood as more than merely a matter of bad words in online comments.

In line with this requirement, this chapter aims to provide a taxonomy of hate speech that integrates hate speech research and social media logic. Based on speech act theory (Searle, 1969) and on the theory of digital objects (Langlois \& Elmer, 2013), an integrative literature review was conducted in order to provide a taxonomy of hate speech in digital conversations, allowing an identification of how hate speech manifests in digital conversations, 
how these forms can be assessed empirically, and what differentiated effects they have on online deliberation.

\section{Theoretical framework: deliberative democracies and hate speech}

Deliberative democracies are characterized by the submission of political projects, positions, and evaluations to processes of argumentation in public debates. In such democracies, public debates are a means by which citizens ensure that society is governed by the will of the people rather than by arbitrariness. Deliberation is therefore the source of legitimation of such democracies (Dryzek, 1990) and one of the pillars of participatory societies (Hilmer, 2010, p. 57).

Deliberative models assume that public debates fulfil at least two basic requirements: reasoning against a common background and the pursuit of a general will or common good (Hilmer, 2010). For Habermas (2007), deliberation should also be free from constraints due to power and hierarchy. An "ideal deliberation" or, in his terms, an "ideal speech situation" should meet such criteria as (Habermas, 2007, p. 25):

- Open participation;

- Justification of assertions and validity claims;

- The common good;

- Respect towards groups, towards counterarguments, and towards demands;

- Constructive politics.

Consideration of Habermas's discourse ethics makes clear that deliberation is not purely a matter of putting forth arguments and of "empirical evidence," but also requires respect or "civility." Discourse cannot be uncivil and still have deliberative quality. The criteria do not necessarily go hand in hand. Putting forth arguments (justification), for example, does not preclude people from making uncivil (e.g. unrespectful) utterances (Coe, Kenski, \& Rains, 2014, p. 674).

Deliberative democratic theorists in general emphasize the importance of rational public deliberation among free and equal citizens about matters of common concern (Hilmer, 2010, p. 47). The most fundamental foundation is the idea of common good or general will as input and outcome of interaction, as Habermas (2007) explains:

In communicative action, the very outcome of interaction is even made to depend on whether the participants can come to an agreement among themselves on an inter-subjectively valid appraisal of their relations to the world. In this model of action, an interaction can succeed only if those involved arrive at a consensus among themselves. 


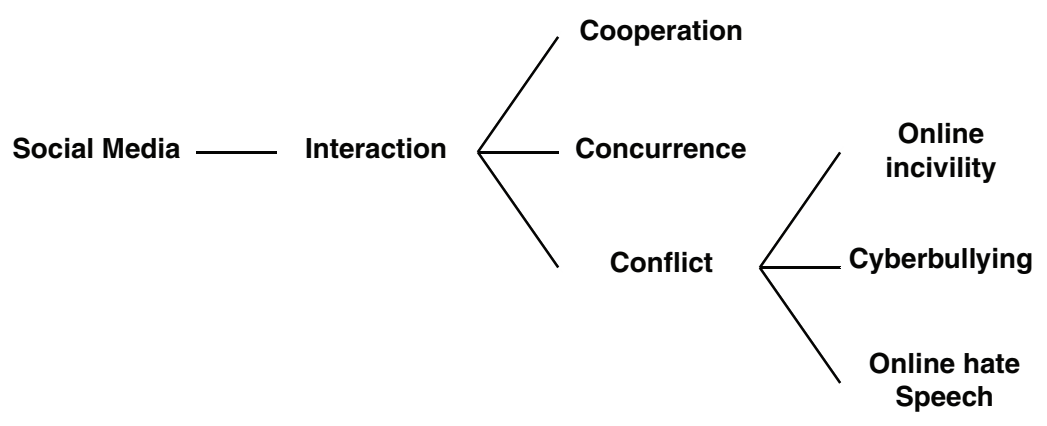

Figure 4.1 Forms of Interaction on SNS.

Source: Author's own presentation based on Neuberger (2014).

In short: deliberative processes are compatible with just one kind of interaction: cooperation. Cooperation corresponds to the pursuit of a common goal. In this kind of interaction, the participant relies on the expectation that the other will play according to the same (ethical) rules. However, social media triggers not only cooperation but conflicts. That is to say: interactions among new constellations of social actors that do not necessarily share the same background or pursue a "common good."

The media logic of SNS is built on the commodification of interactions (Van Dijck \& Poell, 2013), no matter what kind. By triggering interactions, social media not only opens the door to different voices, but also to different modes of interaction, such as cooperation, concurrence, and conflict (Neuberger, 2014).

In the case of concurrence, both parties pursue the same goal, but this goal cannot be achieved by both of them. In such an instance, there are no partners, only a goal. With conflicts, there are neither partners nor a common goal (Neuberger, 2014, p. 573; see Figure 4.1).

When hate speech meets deliberation in social media, old and new issues are raised. Coping with the problem requires at least two dimensions of analysis: (1) what forms hate speech can assume in digital conversations and how they specifically undermine the goals of deliberative democracy; and (2) how the media logic of SNS shapes digital conversations involving or prompted by hate speech.

\section{Hate speech}

Hate speech consists essentially of group libel or defamation (Brown, 2017; Waldron, 2010). "Group" in this context indicates a collective characteristic people can be associated with, such as race, colour, national origin, sex, disability, religion, or sexual orientation (Nockleby, 2000, p. 1277).

The "hate" in the name does not refer necessarily to affective action, but rather to hostility. There is an analogous use of the word in the phrase "hate 


\section{Liriam Sponholz}

crimes" (Brown, 2017; Waldron, 2010). Hate crimes receive this label not because they result from affective actions, but rather because the victim is chosen due to their membership of a particular group and actions are motivated by group hatred, prejudice, or hostility (Weston-Scheuber, 2012, p. 147).

The term "hate speech" was coined by a group of legal scholars from critical race theory in the late 1980s in the United States (Brown, 2017, p. 424). By their definition, hate speech cannot be said to occur against all groups. It affects only those people living in a situation that involves "chronic, pervasive, and intergenerational experiences of oppression that, over time, may be normalized, imposed, and internalized" into their daily lives (Burnette \& Figley, 2017, p. 37). As Delgado and Stefancic (2004) state:

Purely racial insults and name-calling (honky, cracker, whitey) directed against whites do not evoke and call up a specific oppressive history for the white majority.... On the other hand, words such as $\mathrm{ni}^{* * *} \mathrm{er}$, wop, spic, chink or kike do carry a historical message that often multiplies their impact.

The point here is that hate speech acts as a further layer in a long-standing process of subordination (Matsuda, 1989). This is the reason why "not everyone has known the experience of being victimized by racist, misogynist, or homophobic speech, and we do not share equally the burden of the societal harm it inflicts" (Lawrence III, 1993, p. 56).

By this definition, hate speech can be seen as the symbolic, communicative ring on a chain of manufacturing human inferiority (Sponholz, 2018, p. 48). By this kind of communication, antinomies between groups of people are intentionally activated. Such antinomies are not created initially by hate speech, but rather stored in social knowledge, where they remain in a latent situation until being activated; that is to say, thematized and brought to public attention (Marková, 2000, p. 444).

Although there is no single definition of "hate speech," diverse social actors have been applying the term with basically the same meaning: group libel. Recommendation No. R (97) 20 of the Council of Europe Committee of Ministers, for instance, states that:

the term "hate speech" shall be understood as covering all forms of expression which spread, incite, promote or justify racial hatred, xenophobia, anti-Semitism or other forms of hatred based on intolerance, including: intolerance expressed by aggressive nationalism and ethnocentrism, discrimination and hostility against minorities, migrants and people of immigrant origin.

(Weber, 2009, p. 3)

Social media has a similar understanding of the concept's core definition. The Facebook Company, for instance, applies the term as follows: 
We define hate speech as a direct attack on people based on what we call protected characteristics - race, ethnicity, national origin, religious affiliation, sexual orientation, caste, sex, gender, gender identity, and serious disease or disability. We protect against attacks on the basis of age when age is paired with another protected characteristic, and also provide certain protections for immigration status. We define attack as violent or dehumanizing speech, harmful stereotypes, statements of inferiority, or calls for exclusion or segregation.

(Facebook, 2020, para. 2)

In Twitter's (n.d.) "Hateful conduct policy," hate speech is defined like this:

You may not promote violence against or directly attack or threaten other people on the basis of race, ethnicity, national origin, sexual orientation, gender, gender identity, religious affiliation, age, disability, or serious disease. We also do not allow accounts whose primary purpose is inciting harm towards others on the basis of these categories.

(para. 1)

In the definition of racist hate speech in General Recommendation 35 (2013) of the Committee on the Elimination of Racial Discrimination (CERD) of the Office of the United Nations High Commissioner for Human Rights, hate speech consists of the dissemination and incitation of discrimination, calls for violence, the expressing of threats, insults, ridicule, or slander towards persons or groups due to a particular characteristic, and participation in organizations which promote and incite racial discrimination through means such as public denials of, or attempts to justify, crimes of genocide and crimes against humanity (Committee on the Elimination of Racial

Table 4.1 Hate Speech as Communicative Actions

(1) Incitement to

(2) Incitement through

(3) Threats

(4) Justification of

(5) Expressions of

(7) Participation in
Hatred

Contempt

Discrimination

Violence

Public denials of, or attempts to justify, crimes of genocide and crimes against humanity

Crimes of genocide

Crimes against humanity

Insults

Ridicule

Slander

Discriminatory ideas

Organizations and activities promoting and inciting discrimination

Source: Author's own presentation based on General Recommendation No. 35 of the Committee on the Elimination of Racial Discrimination (CERD), 2013. 
Discrimination [CERD], 2013). In a nutshell, hate speech involves an array of discriminatory actions performed via communication; that is to say, interaction around a message (Table 4.1).

This means that detecting hate speech requires various factors to be taken into account: the content and form of speech; the economic, social, and political climate; the position or status of the speaker in society; the audience to which the speech is directed; the reach of the speech; and the objectives of the speech (CERD, 2013). In brief, hate speech is not only about "wordsthat-wound" (Delgado \& Stefancic, 2004), but about the context in which symbolic, discriminatory actions acquire a sense. In this way, hate speech might be seen as speech acts; that is to say, actions performed by utterances (cf. Searle, 1969).

\section{Methods}

The objective of this chapter is to provide a theoretically founded and empirically applicable taxonomy which enables the identification of hate speech in digital conversation in its manifold forms and to assess what differences such forms make to online deliberation.

To this end, a review of texts on hate speech and on digital conversations was conducted. As an integrative literature review, this chapter aims "to overview the knowledge base, to critically review and potentially reconceptualize, and to expand on the theoretical foundation of the specific topic as it develops" (Snyder, 2019, p. 336). Studies were assessed and integrated in two major frameworks: speech act theory (Searle, 1969) and the theory of digital objects (Langlois \& Elmer, 2013).

"Hate speech" is not only a polysemic concept but also considered an essentially contested concept (Boromisza-Habashi, 2010). As a consequence, one cannot assume that the term has always been applied with the same meaning or that authors investigating this kind of group libel are calling their research object by the same name. This hinders a systematic literature review (Cooper, 1998; cf. also Snyder, 2019). In addition, this chapter does not aim to detect themes, theoretical perspectives, or common issues within a specific research discipline, as is the case with semi-systematic reviews.

As an integrative review, it "requires a more creative collection of data, as the purpose is usually not to cover all articles ever published on the topic but rather to combine perspectives and insights from different fields or research traditions" (Snyder, 2019, p. 336). In line with this idea, scientific literature (a) handling the original concept of hate speech from critical race theory and (b) providing theoretical approaches on subsets of hate speech was selected and systematized in the light of speech act theory. In a second step, empirical studies on digital communication that analyse research objects fitting (c) the original concept and (d) the subset of hate speech as theoretically developed in this chapter were purposively chosen in order to illustrate how hate speech can be empirically assessed in its manifold forms. 


\section{Online hate speech and speech acts}

As a speech act, hate speech is not necessarily dependent on the use of insulting words. It may be dependent on what is uttered (locutionary acts), what is intended by that (illocutionary acts), or what effect it has (perlocutionary acts). In line with this taxonomy, hate speech can be classified as hateful speech (Matsuda, 1989), hate-fuelled speech (Brown, 2017), hatredinciting speech (Waldron, 2010), or dangerous speech (Benesch, 2013; for an overview, see Table 4.2).

In the context of online deliberation (e.g. digital conversations), hateful speech (or hate-filled or hate-laden speech) manifests in online messages, such as user comments. This kind of hate speech carries forth, articulates, ${ }^{1}$ symbolizes, or represents the speaker's emotions, feelings, or attitudes of hate or hatred toward the subject of the speech (Brown, 2017, p. 449). As utterances of hateful or hate-filled speech express the state of mind of the speaker, they are often similar to swearing or insults. As a consequence, the form of the message - that is to say, the locutionary act - is pivotal for the identification of hateful speech.

The main advantage of the locutionary model for addressing such matters lies in its empirical operationalization, which enables the detection of hate speech in larger databases through automated content analysis. As a consequence, this model is particularly appropriate for community management. By applying automated content analysis to detect group-libelling language, organizations can filter such comments out of their Facebook walls and Twitter accounts.

In studies on digital conversations, this kind of hate speech has been analysed in terms of political incivility. The latter term refers to behaviour that counteracts the free and respectful exchange of different ideas (Stryker, Conway, \& Danielson, 2016, p. 539). Online incivility specifically means online comments or exchanges that (a) threaten democracy, (b) deny people their personal freedoms, or (c) stereotype groups (Papacharissi, 2004, p. 280). Hateful speech in this approach corresponds to uncivil comments stereotyp groups.

Empirical findings on online incivility, however, show that uncivil comments are the exception rather than the rule (Coe, Kenski, \& Rains, 2014; Rowe, 2015). Furthermore, stereotypes of groups do not constitute the commonest form of online incivility (Coe, Kenski, \& Rains, 2014; Papacharissi, 2004; Rowe, 2015).

Hateful speech is an exception not only according to studies on political incivility, but also within research on hate speech (Ben-David \& Matamoros Fernández, 2016; Gagliardone et al., 2015). Moreover, studies on so-called online hate groups have showed that such speakers intentionally avoid racial slurs, racist symbols, and other open, blatant forms of symbolic discrimination (Gerstenfeld, Grant, \& Chiang, 2003). Reducing hate speech to a matter of insults would mean coming to the conclusion that 


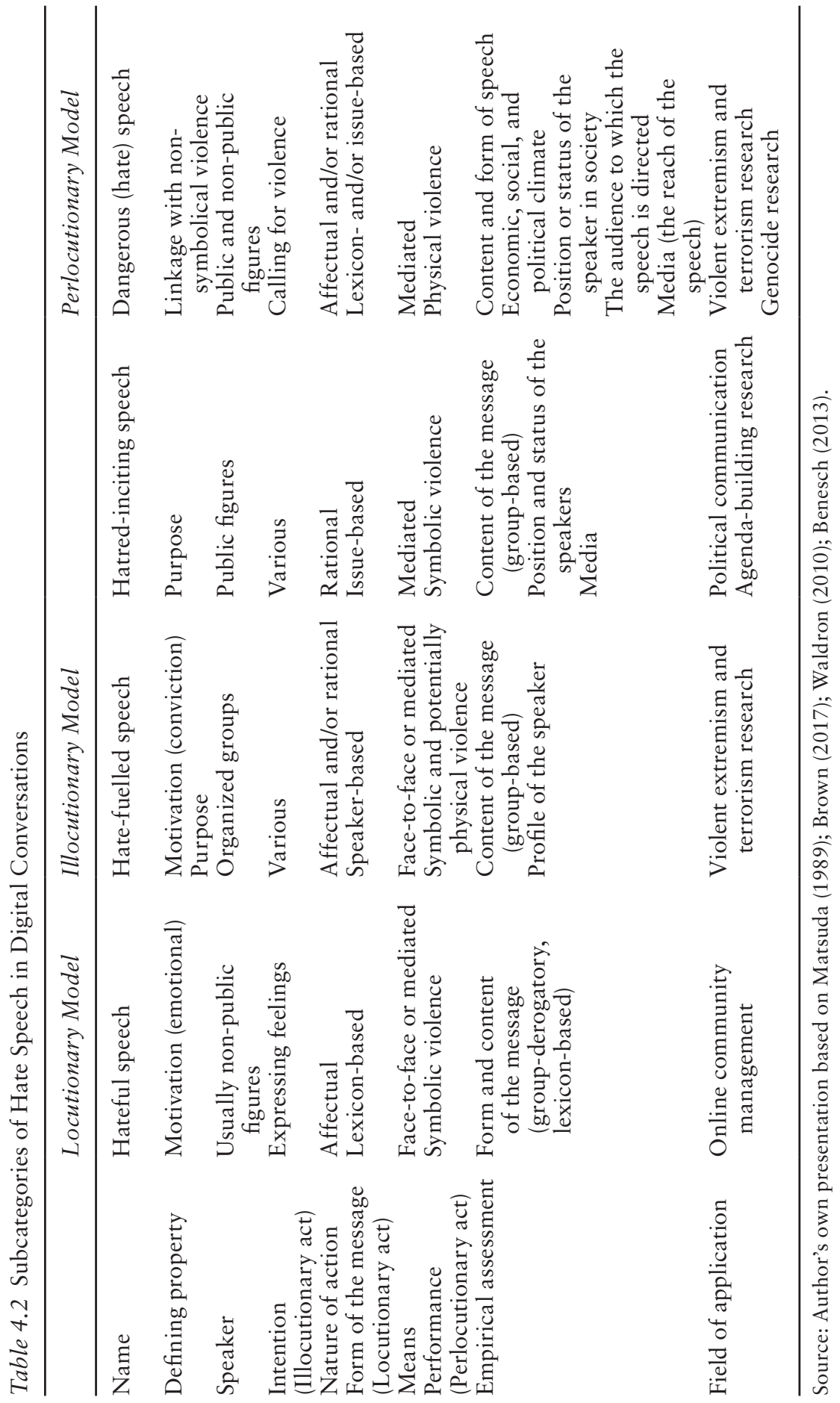


far-right racist groups are not libelling groups because they do not write the $\mathrm{N}$-word or display a swastika.

Such cases, where blatant forms of symbolic discrimination are often absent, present examples of hate-fuelled speech. Just like hateful speech, hate-fuelled speech is a matter of the speaker's motivation. The difference lies in the kind of motivation: While hateful speakers act in a moment of heightened emotion, hate-fuelled speakers act from a deep-seated conviction (Brown, 2017).

As such, hate-fuelled speech should not be put in the same category as hateful speech, particularly in view of online deliberation processes. As Meddaugh and Kay (2009) showed in the case of the website Stormfront, far-right speakers do not only express hatred. They also embed their views in sophisticated processes of argumentation. While hateful speakers are acting first and foremost expressively, hate-fuelled speakers justify their positions, acting by conviction. Furthermore, group libel by a far-right "true believer" also has a purpose: They are committed to inciting hatred. For these reasons, hate-fuelled speech is better seen as a form of hate speech characterized by both motivation (conviction, hatred) and purpose. This kind of hate speech can be identified by the content of the messages (group-targeting) and by the speakers (far-right speakers).

As the speakers are its defining property, this kind of hate speech requires narrow research designs, such as analysis of the online communications of far-right groups or parties (Kleinberg, Van der Vegt, \& Gill, 2020).

The third subcategory of hate speech consists of hatred-inciting speech. This kind of hate speech libels groups first and foremost in order to achieve a goal, and not to express feelings. The point here is not the motivation of the haters, as in the case of hateful (motivated by moments of emotion) or hate-fuelled speech (motivated by conviction), but the purpose of the speech (Waldron, 2010); that is to say, the illocutionary act.

As formulated by Waldron (2010) and Brown (2017), this kind of hate speech refers to situations in which inciting hatred against groups constitutes the primary purpose. A primary purpose or intention is particularly important for law scholars, since it provides a condition sine qua non for forbidding hate speech or for finding and condemning the offenders (Tsesis, 2013).

Such a focus, however, does not align with a communicative point of view. From the communicative point of view, it does not matter what the primary motive of the crime was. For media and communication science, what matters is if the message fulfils a purpose; that is, has an intention. In this context, it does not matter if inciting hatred is the primary purpose of hate speech or if it is only a subsidiary action intended to achieve other goals such as catching media attention or gaining votes (about intentionality and subsidiary action, cf. Searle, 1980).

In media communication, hatred-inciting speech is neither a matter of words nor necessarily of organized groups, but rather of issues, of 
agenda-building. This kind of speech intentionally places issues into the public agenda in which people due to a particular characteristic turn into a source of concern. The media is fundamental in the building of a public agenda and consequently for this form of hate speech. Further, building an agenda requires speakers to have media capital. This is why hatred-inciting speech requires public figures, such as politicians or public intellectuals. Because communication of discrimination in this case is intentional and goal-orientated, hatred-inciting speakers act rationally (zweckrational, cf. M. Weber, 1949), and not affectively as in the case of hateful speech.

This has consequences for empirical assessment: While hateful speech can be identified in the form of the message (for instance, racial slurs) and hate-fuelled speech is identified by the speaker ("true believers" such as racist groups), identifying hatred-inciting speech means focusing on what is at issue in an online debate, which public figures or other collective actors are involved in building a group-targeting agenda, and how the media is used by them to activate pre-existing grievances and fear towards the targeted group. Examples of hatred-inciting speech are provided by the online political communications of populist radical right parties (Wodak, 2015).

With regard to deliberation, the situation here is not of behaviour that counteracts the free and respectful exchange of different ideas through the utterance of group derogatory labels, as is the case with hateful speech/ political incivility. It is about making people a problem to be discussed in deliberation processes. When the discussion concerns whether Black people are less intelligent (Hunt-Grubbe, 2007) or whether Muslims deserve any respect (Sarrazin, 2010), the problem becomes something other than how the participants behave in a digital conversation. No matter how civilly participants behave, discussing the worthiness of people itself generates a situation of disparagement.

The illocutionary approach to the study of agenda-building has the potential to improve the understanding of incitement to hatred, discrimination, or contempt against groups, whether or not the speakers are extremists or the message contains racial slurs.

Last but not least, dangerous speech constitutes a subset of hate speech where the main feature lies in the perlocutionary effect: It unleashes or triggers physical violence (Benesch, 2013). Dangerous speech requires powerful speakers with a high degree of influence over the audience in order to legitimize violence and trigger conflicts. The speakers may behave affectively or act rationally, integrating processes of argumentation into their messages.

In order to mobilize people for the unleashing of physical violence against groups or individuals identified with those groups, the speakers usually also need some form of media outlet, which should be influential in itself and is often the sole or primary source of news for the relevant audience. The message does not need to be overt, but rather understood as a call to violence. Finally, dangerous speech requires a social or historical context that is propitious for violence, for any of a variety of reasons, including 
long-standing competition between groups for resources, lack of effort to solve grievances, and previous episodes of violence. The role of Facebook in the Myanmar genocide exemplifies this kind of hate speech (Fink, 2018). Genocide research has in fact been the main field of application for this approach. As dangerous speech exists far beyond the realm of deliberative processes, this subset of hate speech is not a focus of this chapter and will not be further discussed in relation to digital conversations.

\section{Hate speech in digital objects}

Digital conversations and online hate speech are not shaped solely by social actors but also by social media logic (Van Dijck \& Poell, 2013). SNS not only provide a platform for the publication of user content, but also determine the form in which content can be published, how people can interact with such content and with other users, and how they are kept in contact networks are built. Against this background, hate speech on SNS is not a social but a socio-technical process (cf. Matamoros-Fernández, 2017).

Table 4.3 Hate Speech in Digital Objects

\begin{tabular}{|c|c|c|c|}
\hline & Media Object & Network Object & Phatic Object \\
\hline Definition & Content & $\begin{array}{l}\text { Interface through which } \\
\text { different kinds of } \\
\text { informational economies } \\
\text { get attached to and } \\
\text { act within a specific } \\
\text { communicational context }\end{array}$ & $\begin{array}{l}\text { Networks establishing } \\
\text { one's position and } \\
\text { relationships within } \\
\text { an ecology of users } \\
\text { and digital objects }\end{array}$ \\
\hline \multirow[t]{6}{*}{ Forms } & Comments & Like-button & \multirow{6}{*}{$\begin{array}{l}\text { Like-network } \\
\text { Page-like-network }\end{array}$} \\
\hline & Pictures & Share-button & \\
\hline & Memes & Comment-button & \\
\hline & Videos & Hashtags & \\
\hline & GIFs & Page-like-button & \\
\hline & $\begin{array}{l}\text { Emojis, } \\
\text { Emoticons, } \\
\text { Stickers }\end{array}$ & $\begin{array}{l}\text { People-you-may-know- } \\
\text { button }\end{array}$ & \\
\hline \multirow[t]{2}{*}{$\begin{array}{l}\text { Empirical } \\
\text { assessment }\end{array}$} & $\begin{array}{l}\text { Web storytelling } \\
\text { analysis }\end{array}$ & $\begin{array}{l}\text { Human-computer } \\
\text { interaction research }\end{array}$ & \multirow[t]{2}{*}{$\begin{array}{l}\text { Social network } \\
\text { analysis }\end{array}$} \\
\hline & $\begin{array}{l}\text { Verbal and visual } \\
\text { content analysis }\end{array}$ & $\begin{array}{l}\text { Social media metrics } \\
\text { analysis }\end{array}$ & \\
\hline \multirow[t]{2}{*}{$\begin{array}{l}\text { Subset of hate } \\
\text { speech }\end{array}$} & Hateful speech & $\begin{array}{l}\text { Hatred-inciting speech } \\
\text { Hate-fuelled speech }\end{array}$ & \multirow{3}{*}{$\begin{array}{l}\text { Hatred-inciting } \\
\text { speech } \\
\text { Hate-fuelled speech } \\
\text { Geography of Hate } \\
\text { Map (Chaudhry } \\
\text { and Gruzd, 2019) }\end{array}$} \\
\hline & & & \\
\hline Example & $\begin{array}{l}\text { Pig emoticons in } \\
\text { Islamophobic } \\
\text { debates } \\
\text { (Matamoros- } \\
\text { Fernández, 2018) }\end{array}$ & $\begin{array}{l}\text { Hashtag \#stopislam (Poole, } \\
\text { Giraud, \& De Quincey, } \\
\text { 2019) }\end{array}$ & \\
\hline
\end{tabular}

Source: Author's own presentation based on Langlois and Elmer (2013). 
For this reason, a posting consists not only of the content on the computer monitor, but of a digital object, as Langlois and Elmer (2013) explain:

Digital objects ... are the elements that compose social media platforms in specific context: a "like" button is a digital object, for instance, as is a comment or any other kinds of text. Digital objects are also the results of invisible data processing that come back to us as personalized recommendations of all kinds. In doing so, the object of analysis is not simply the textual multimedia elements present on a user inter-face at a specific moment: it is also all the software elements that make textual elements visible, from formatting specifications to ranking algorithms.

Digital objects comprise (a) media objects such as memes, pictures, and comments; (b) network objects; that is to say, the affordances provided by the platform, such as the like-button; and (c) the phatic object, e.g. the networks of content and users resulting from liking and sharing (see Table 4.3).

The transformation of content in digital objects has large consequences for the forms hate speech can take in digital conversation. Media objects particularly enable the empirical assessment of hateful speech, which is detectable by the content. However, group libel on SNS is not restricted to comments (the main unit of analysis in studies on online incivility). Pig emoticons, for instance, have been intensively used in Islamophobic debates (Matamoros-Fernández, 2018). Thus, content analysis of hateful speech must also consider visual representations and the dynamics of Web storytelling on such sites.

Moreover, how users react to such content must also be taken into account. Uncivil comments might represent a small number of cases, but generate more likes or replies. This has consequences for counter-speech strategies. As Chaudhry and Gruzd (2019) showed, overt racist comments generate more user engagement. However, it is the counter-speakers rather than the racists who are responsible for this higher engagement. Such speakers are increasing social metrics for the racist comments by replying to them.

From a social perspective, such anti-racist users react as the deliberative model recommends: by submitting racist comments to a process of argumentation. From a technical point of view, they signal to platforms that hate speech triggers more interaction. This, in turn, generates data, the currency of SNS. The countering of hate speech may, therefore, have the dubious result of making hate speech a profitable phenomenon for the media outlets. Furthermore, social media metrics can increase the popularity of hate speakers (Van Dijck \& Poell, 2013).

In the case of network objects, these have been intentionally instrumentalized by organized groups (hate-fuelled speech) and other actors in order to build an agenda of group-targeting issues (hatred-inciting speech), as in the case of hashtags such as \#stopislam (Poole, Giraud, \& De Quincey, 2019).

Social media logic transforms interaction not only with regard to data, but also with regard to networks. This process results in phatic objects, 
which provide information about one's position and relationships within an ecology of users and digital objects (Langlois \& Elmer, 2013). Phatic objects are empirically assessed by social network analysis and may be applied to trace back networks built on group libel, as in the case of the "Geography of Hate Map" project (Chaudhry, 2015).

\section{Conclusions}

This chapter aimed to provide a taxonomy of hate speech that integrates hate speech research and social media logic. Based on an integrative literature review, different types of hate speech were identified according to the kind of speech act they perform (Searle, 1969) and to the digital object performing them (Langlois \& Elmer, 2013).

In order to unfold the best aims and possibilities of online deliberation, argumentation processes should fulfil such normative criteria as openness, justification, pursuit of a common good, respect, and constructive politics. However, online deliberation has been jeopardized by the media logic of SNS, which triggers not only cooperation, but also conflicts. In such cases, the most basic requirements for deliberation are often not met, so such conversations do not necessarily serve democratic purposes in a deliberative sense.

Online hate speech undermines deliberative purposes in different ways, according to the form the group libel assumes, with those forms including hateful speech, hate-fuelled speech, hatred-inciting speech, and dangerous hate speech. Online hateful speech refers to messages (such as user comments) whereby people are insulted or openly threatened in digital conversations on the basis of a collective characteristic, such as race, colour, national origin, sex, disability, religion, or sexual orientation. Hate-fuelled speech, meanwhile, involves groups or speakers libelling people by conviction on the basis of a collective characteristic. In the case of hatred-inciting speech, the problem lies neither in words nor in specific speakers, but in an agenda built by public figures such as politicians or public intellectuals that involves the problematizing of people on the basis of a collective characteristic.

Different subsets of hate speech incorporated in different digital objects also have differentiated consequences for deliberative processes. Hateful speech may affect how respectfully participants deal with each other in digital conversations, while in the case of hate-fuelled speech "true believers" may justify assertions and validity claims by packaging their grouplibelling positions in argumentation processes. Hatred-inciting speech provokes debates whereby speakers submit the worthiness of human beings to processes of argumentation.

Online hate speech poses a specific threat to democracy created by both social action and the media logic of digital platforms, particularly SNS. With regard to media logic, these forms of hate speech manifest themselves not only in content, but first and foremost in the form of digital objects.

Hateful speech turns from a matter of (swear-) words to a matter of memes, comments, emoticons, and so forth. Its empirical assessment 


\section{Liriam Sponholz}

requires content analysis. Network objects such as hashtags are strategically applied in order to build an agenda against people (hatred-inciting speech). This kind of hate speech requires not only an analysis of content, but also of social media metrics and affordances. Phatic objects, on the other hand, provide information about the networks behind online group libel, allowing the identification of organizations and activities by social network analysis (hate-fuelled speech).

The theoretical framework provided in this chapter is an attempt to assess hate speech in a way that goes beyond "words-that-wound" in online comments. It aims to address a digital threat that targets groups that are systematically discriminated against but also affects everybody by undercutting one of the pillars of participatory societies: deliberation.

\section{Note}

1 The term "hateful speech" was coined by the law scholar Mari Matsuda (1989). However, another law scholar, Alexander Brown, prefers the expressions "hatefilled" or "hate-laden" speech, finding the word "hateful" ambiguous, as it may be understood merely as a synonym for "detestable" rather than an indication that the speech is prompted by hate (Brown, 2017, p. 447).

\section{References}

Ben-David, A. \& Matamoros Fernández, A. (2016). Hate speech and covert discrimination on social media: Monitoring the Facebook pages of extreme-right political parties in Spain. International Journal of Communication, 10, pp. 1167-1193. Available at https://bit.ly/2NK92DN

Benesch, S. (2013). Dangerous speech: A proposal to prevent group violence. Available at https://bit.ly/36w3Ie1

Boromisza-Habashi, D. (2010). How are political concepts “essentially" contested? Language \& Communication, 30(4), pp. 276-284.

Brown, A. (2017). What is hate speech? Part 1: The myth of hate. Law and Philosophy, 36, pp. 419-468.

Burnette, C. E. \& Figley, C. R. (2017). Historical oppression, resilience, and transcendence: Can a holistic framework help explain violence experienced by indigenous people? Social Work, 62(1), pp. 37-44. https://doi.org/10.1093/sw/sww065

Chaudhry, I. (2015). \#Hashtagging hate: Using Twitter to track racism online. First Monday, 20(2). https://doi.org/10.5210/fm.v20i2.5450

Chaudhry, I. \& Gruzd, A. (2019). Expressing and challenging racist discourse on Facebook: How social media weaken the "spiral of silence" theory. Policy \& Internet, 12(1), pp. 88-108. https://doi.org/10.1002/poi3.197

Coe, K., Kenski, K. \& Rains, S. A. (2014). Online and uncivil?: Patterns and determinants of incivility in newspaper website comments. Journal of Communication, 64(4), pp. 658-679.

Committee on the Elimination of Racial Discrimination. (2013, 26th September). General recommendation no. 35. Available at https://bit.ly/3teKByE

Cooper, H. M. (1998). Synthesizing research: A guide for literature reviews. London: Sage Publication.

Delgado, R. \& Stefancic, J. (2004). Understanding words that wound. Boulder, $\mathrm{CO}$ and Oxford: Westview Press. 
Dryzek, J. S. (1990). Discursive democracy: Politics, policy, and political science. Cambridge: Cambridge University Press.

Facebook. (2020, August). Community standards. Recent updates. Available at https://cutt.ly/KkoeINj

Fink, C. (2018). Dangerous speech, anti-Muslim violence, and Facebook in Myanmar. Journal of International Affairs, 71(1.5), pp. 43-52. Available at https:// cutt.ly/NkoeKzy

Gagliardone, I., Pohjonen, M., Zerai, A., Beyene, Z., Aynekulu, G., Gebrewolde, T., Seifu, M., Stremlau, N., Bright, J., Bekalu, M. \& Moges, M. (2015). Mechachal: Online debates and elections in Ethiopia. Report One: A preliminary assessment of online debates in Ethiopia. Available at https://cutt.ly/HkoeCR2

Gelber, K. (2019). Differentiating hate speech: A systemic discrimination approach. Critical Review of International Social and Political Philosophy, pp. 1-22. https://doi.org/10.1080/13698230.2019.1576006

Gerstenfeld, P. B., Grant, D. R. \& Chiang, C.-P. (2003). Hate online: A content analysis of extremist internet sites. Analyses of Social Issues and Public Policy, 3(1), pp. 29-44. https://doi.org/10.1111/j.1530-2415.2003.00013.x

Habermas, J. (2007). The theory of communicative action: Reason and the rationalization of society. Vol. 1. Boston, MA: Beacon.

Hilmer, J. D. (2010). The state of participatory democratic theory. New Political Science, 32(1), pp. 43-63. https://doi.org/10.1080/07393140903492118

Hunt-Grubbe, C. (2007, 14th October). The elementary DNA of Dr Watson. The Times. Available at https://cutt.ly/VkorOan

Kleinberg, B., Van der Vegt, I. \& Gill, P. (2020). The temporal evolution of a farright forum. Journal of Computational Social Science. https://doi.org/10.1007/ S42001-020-00064-X

Kuehn, K. M. \& Salter, L. A. (2020). Assessing digital threats to democracy, and workable solutions: A review of the recent literature. International Journal of Communication, 14(22), pp. 2589-2610. Available at https://cutt.ly/ZkorJfM

Langlois, G. \& Elmer, G. (2013). The research politics of social media platforms. Culture Machine, 14, pp. 1-17.

Lawrence III, C. R. (1993). If he hollers let him go: Regulating racist speech on campus. In M. J. Matsuda, C. R. Lawrence III, R. Delgado \& K. W. Crenshaw (Eds.), Words that wound: Critical race theory, assaultive speech, and the First Amendment (pp. 53-88). Boulder, CO: Westview Press.

Marková, I. (2000). Amédée or how to get rid of it: Social representations from a dialogical perspective. Culture \& Psychology, 6(4), pp. 419-460.

Matamoros-Fernández, A. (2018). Inciting anger through Facebook reactions in Belgium: The use of emoji and related vernacular expressions in racist discourse. First Monday, 23(9). https://doi.org/10.5210/fm.v23i9.9405

Matamoros-Fernández, A. (2017). Platformed racism: The mediation and circulation of an Australian race-based controversy on Twitter, Facebook and YouTube. Information, Communication \& Society, 20(6), pp. 930-946. https://doi.org/10. 1080/1369118X.2017.1293130

Matsuda, M. J. (1989). Public response to racist speech: Considering the victim's story. Michigan Law Review, 87(8), pp. 2320-2381.

Meddaugh, P. M. \& Kay, J. (2009). Hate speech or "reasonable racism”? The Other in Stormfront. Journal of Mass Media Ethics, 24(4), pp. 251-268.

Miller, M. L. \& Vaccari, C. (2020). Digital threats to democracy: Comparative lessons and possible remedies. The International Journal of Press/Politics, 25(3), pp. 333-356. https://doi.org/10.1177/1940161220922323 


\section{Liriam Sponholz}

Neuberger, C. (2014). Konflikt, Konkurrenz und Kooperation: Interaktionsmodi in einer Theorie der dynamischen Netzwerköffentlichkeit [Conflict, concurrence, and cooperation: Modes of interaction in a theory of the dynamic networked public sphere]. Medien \& Kommunikationswissenschaft, 62(4), pp. 567-587. https://doi.org/10.5771/1615-634x-2014-4-567

Nockleby, J. (2000). Hate speech. In L. W. Levy, K. L. Karst \& A. Winkler (Eds.), Encyclopedia of the American Constitution (pp. 1277-1278). New York: Macmillan.

Papacharissi, Z. (2004). Democracy online: Civility, politeness, and the democratic potential of online political discussion groups. New Media \& Society, 6(2), pp. 259-283. https://doi.org/10.1177/1461444804041444

Poole, E. A., Giraud, E. \& De Quincey, E. (2019). Contesting \#StopIslam: The dynamics of a counter-narrative against right-wing populism. Open Library of Humanities, 5(1). https://bit.ly/3dkn215

Rowe, I. (2015). Civility 2.0: A comparative analysis of incivility in online political discussion. Information, Communication \& Society, 18(2), pp. 121-138.

Sarrazin, T. (2010). Deutschland schafft sich ab: Wie wir unser Land aufs Spiel setzen [Germany abolishes itself: How we're putting our country in jeopardy]. München: Dt. Verl.-Anst.

Searle, J. R. (1980). The intentionality of intention and action. Cognitive Science, 4(1), pp. 47-70.

Searle, J. R. (1969). Speech acts: An essay in the philosophy of language. Cambridge: Cambridge University Press.

Snyder, H. (2019). Literature review as a research methodology: An overview and guidelines. Journal of Business Research, 104, pp. 333-339. https://doi.org/ 10.1016/j.jbusres.2019.07.039

Sponholz, L. (2018). Hate Speech in den Massenmedien: Theoretische Grundlagen und empirische Umsetzung [Hate speech in the mainstream media: Theoretical approaches and empirical operationalization]. Wiesbaden: Springer Verlag. https://doi.org/10.1007/978-3-658-15077-8

Stone, G. R. (2000). First amendment. In L. W. Levy, K. L. Karst \& A. Winkler (Eds.), Encyclopedia of the American Constitution (pp. 1055-1057). New York: Macmillan.

Stryker, R., Conway, B. A. \& Danielson, J. T. (2016). What is political incivility? Communication Monographs, 83(4), pp. 535-556.

Tsesis, A. (2013). Inflammatory speech: Offense versus incitement. Minnesota Law Review, 97, pp. 1145-1196.

Twitter (n.d.). Hateful conduct policy. Available at https://cutt.ly/Akotx4H

Van Dijck, J. \& Poell, T. (2013). Understanding social media logic. Media and Communication, 1(1), pp. 2-14.

Waldron, J. (2010). Dignity and defamation: The visibility of hate. Harvard Law Review, 123(7), pp. 1596-1657.

Weber, A. (2009). Manual on hate speech. Strasbourg: Council of Europe Publ.

Weber, M. (1949). The methodology of the social sciences. Glencoe, IL: Free Press.

Weston-Scheuber, K. (2012). Gender and the prohibition of hate speech. QUT Law Review, 12(2), pp. 132-150. https://doi.org/10.5204/qutlr.v12i2.504

Wodak, R. (2015). The politics of fear: What right-wing populist discourses mean. Los Angeles, London, New Delhi, Singapore, Washington DC: Sage. 
Part II

Political and ideological polarisation 

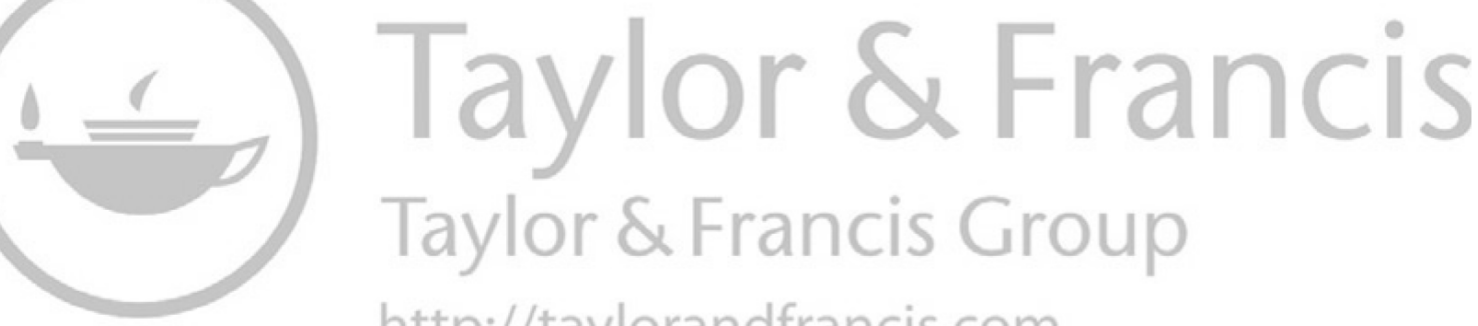
http://taylorandfrancis.com 


\title{
5 There ain't no rainbow in the 'rainbow nation'
}

\author{
A discourse analysis of racial \\ conflicts on twitter hashtags in \\ post-apartheid South Africa
}

\author{
Allen Munoriyarwa
}

\section{Introduction - South Africa's 'toxic' race relations}

Since the advent of Twitter in 2006, South Africa has witnessed a spectacular explosion of racist discourse on social media platforms. According to the South Africa Human Rights Commission (SAHRC, 2016), the centres of explosive racist discourses are Twitter and Facebook. SAHRC (2016) further notes that recent racist outbursts on Twitter and Facebook threaten the creation of a non-racial society and general social cohesion in South Africa. The surge of racist rants in South Africa reflects a society that is increasingly becoming racially polarised (South African Institute of Race Relations, 2018). The SAHRC trend analysis report (2016) reveals that discrimination on the grounds of race remains the highest of equality complaints, with an annual increase in high-profile derogatory incidences frequently aimed at black Africans. Similarly, Daniels (2009), Rauch and Schantz (2013) and Shepherd et al. (2015) note that social media have become a major conveyer of hate crimes against racial minorities and a major reason for the failure of multiculturalism as an institutional practice at a global level. Social media discussions on the subject of race in South Africa have served to highlight how racism remains pervasive and toxic (SAHRC, 2016). Some studies, such as those by Mafoko (2017) and Stephens (2018), have argued that the 'rainbow nation' that the first democratically elected president of the country, Nelson Mandela, envisaged is now history - not a lived reality.

Many reasons have been suggested to account for the increasing incidences of racism in post-apartheid South Africa. It has been suggested that racism in South Africa is still deeply rooted in the social structures of the post-apartheid state (McDonald, 2011) and entrenched in South Africa's collective psyche (Rich, 1990). It cannot, therefore, be wished away without a systematic dismantling of the institution and beliefs that sustained it for over a century. It has not been easy to transform South Africa's institutions, and to an extent, people's mindsets to accept 
multi-racialism (Stephens, 2018). The skewed distribution of the country's economic wealth and comforts, such as land, in favour of the minority whites (Head, 2018), has also been central to the resurgence of racism (Chaudhry, 2015). Poverty and unemployment are higher amongst the black population in post-apartheid South Africa (Statistics South Africa, 2019) compared to other minority races. Transition from apartheid enfranchised blacks politically (McDonald, 2011), without corresponding economic power and resources. This has given rise to violent and racist agitation for a redistribution of the wealth of the country - especially land (Chaudhry, 2015).

The agitation has bred racial animosity between whites and blacks, with the latter asserting that the economy has not been transformed adequately enough to serve the previously disadvantaged black majority (Bhorat, 2015). This has led to the emergence of confrontational and militant politics and the formation of radical political parties - the Economic Freedom Fighters (EFF) and the Black Land First (BLF). These political parties have gained popularity by raising issues of economic and social exclusion as an immediate threat to social cohesion amongst races (Gillwald, 2018). In some instances, these radical political parties have instigated racial tensions (SAHRC, 2016) by openly agitating for the extermination of other races. For example, leader of the EFF, Julius Malema, was found guilty of aggravating racial tensions by singing the anti-apartheid song, 'Kill the Boer'. The BLF party was de-registered by South Africa's Electoral Court in May 2019 because it bars whites from being members of the party on ground of their colour. On the other hand, attacks on white-owned farms have raised fears of white alienation from society and strengthened media narratives of white genocide and claustrophobic feelings amongst rightwing groups.

Many incidences of racism have fed into the already polarised debates on racism in South Africa. Vicky Momberg, a white former estate agent, was convicted of crimen injuria following a viral video in which she racially insults a black police officer, who had assisted her after an alleged smash and grab incident. She was found guilty of using the ' $k$ ' word, a derogatory term, 48 times, resulting in a three-year sentence. Penny Sparrow, another white former estate agent, was fined R150,000 (about US\$10,000), following a Facebook post in which she likened black people to monkeys. These incidences and many others point to the fact that racism still lingers in the country's post-apartheid society. What has changed is the extent to which racist sentiments are now being expressed openly on social media. This chapter, therefore, seeks to explore the discourses of engagement amongst Twitter users about race issues. Analysing Twitter discourses can be intellectually productive in ascertaining the nature of debates on crucial societal issues like race and racism, particularly in race-sensitive societies such as post-apartheid South Africa. 


\section{Racism in the age of social media}

Scholarship on the relationship between racism and social media is both wide and eclectic. Various geographical contexts have produced different scholarly research in this field. This type of research is still growing in different geographical and political contexts. Beyond the SAHRC (2016) report, South Africa is yet to produce scholarly research in this field. Jackson (2019) argues that Internet platforms in general, and Social Networking Sites (SNS) such as Twitter can be platforms on which racist discourses thrive because of the ability of discussants to hide their identities. Glaser and Kahn (2005) agree that these spaces can increase expressions of racial prejudice. Daniels (2009) notes that online space like SNS increase desensitisation to hate language and Online Disinhibition Effect (ODE). ODE is when participants feel emboldened to say what they would not say in everyday life because of their ability to hide their identities (Lowry et al., 2016).

Online Disinhibition may take two forms (Lowry et al., 2016). It may assume the form of benign disinhibition which is a positive reaction to online actions that foster understanding amongst groups. But it can be toxic disinhibition which is a negative reaction to online debates and actions. These reactions are enabled by dissonance anonymity - where real identities are hidden by participants. By hiding identities on SNS, participants are freed from the moral and psychological constraints which usually guide their behaviour (Farrington et al., 2017). Lowry et al. (2016) further argue that invisibility on online platforms can increase levels of disinhibition. Invisibility refers to anonymity - where online space users are sometimes not known (Farrington et al., 2017). Krotoski (2013) states that online spaces such as social media platforms lead to 'deindividuation' where “... people feel less personally responsible for their actions and do [say] things that are impulsive, irrational and normally restricted by their inhibitions" (p. 111). Suler (2004) further notes that online platforms have increased 'asynchronicity' - where people feel they do not have to deal with the consequences of their online actions and behaviours.

Furthermore, conversations about race on social media platforms minimise the visible signals of status and authority, in the process creating some sense of a level playing field (Farrington et al., 2017). Suler (2004) adds that "people are much more willing to speak and misbehave" (p. 324). Thus, social media platforms have promoted racist behaviour (Farrington et al., 2017). Internet and online-based spaces therefore provide a 'backstage' environment, 'where users feel free to express racist opinions and material' (Suler, 2004:65). Spiker (2012) argues that "through the seeming privacy of social media platforms, their individualistic communications processes and the relative anonymity of the interactions, cyberspace becomes a 'safe space' for normally borderline and more abhorrent views" (p. 56). However, it should be noted that in recent times, anonymity has been difficult 
to achieve (Farrington et al., 2017). This is because of increasing trends towards authenticity on social media sites, and "cultural shifts in what is considered personal or private information, and the actions of some online users to reveal the identities of others" (Farrington et al., 2017, p. 46). Yet, the perception of privacy on SNS may still encourage expressions of prejudice (Glaser \& Kahn, 2005).

In all these studies on social media and racism, there is an agreement that social media platforms have allowed for more 'active' participation in race debates (Ruddock, Hutchins \& Rowe, 2010). Other scholars assert that racism is never static (Cleland, 2014). What social media platforms have done is to allow old racial prejudices to be broadcast in new social settings anonymously via smartphones and computers (Cleland, 2014). Jakubowicz (2017) notes that cyber racism is an increasingly "prominent issue from Myanmar, to India, from the US to Africa and throughout Europe" (p. 41). Cyber racism undermines the "cohesion of modern multicultural societies" (Bliuc, Jakubowicz \& Dunn, 2019, n.p.). Matamoros-Fernández (2017) further asserts that due to their "design, technical affordances, business models and policies - and the specific cultures of use associated with them, social media platforms have led to the rise of 'platformed racism"' (p. 930). While research on social media and racism is steadily growing in other geographic contexts, little academic attention has been given to examining racist discourses on South Africa's Twittersphere, where racist sentiments have risen virulently (SAHRC, 2016).

\section{Theoretical framework: discourse theory}

There are many approaches to discourse analysis across disciplines (Zienkowski, 2016). Prominent approaches to discourse theory focus on smallscale utterances as linguistic phenomena, whereas other approaches focus on the narrative, the ideological and/or power-related dimensions of language use (Marchart, 2011). Other approaches see society as discourse, and hence do not make a distinction between discourse as language in use and discourse as a broader set of semiotic practice (Jørgensen \& Phillips, 2002). Discourse theory holds, amongst many of its tenets, that some aspects of society, for example, its political structure and issues of identity, can be understood through the study of that society's categories of discourse (Zienkowski, 2016).

Discourse should be understood as both a theoretical framework for understanding society and a methodological procedure of analysing language functions within societies (Zienkowski, 2016). This is because reality can only be understood through language (Jørgensen \& Phillips, 2002). Thus, theory cannot be separated from the analysis (Laclau, 1994; Marchart, 2011). Zienkowski (2016) states that the approaches adopted by other scholars that try to build a bridge between discourse theory and discourse analysis do not help. Reality is discursively constructed (Deligiaouri, 2019), 
and people's knowledge of issues is dependent on discourse (De Goede, 2009). Discourses ascribe specific meanings to events (De Goede, 2009) and at the same time, provide the tools for the interpretation of those events (Deligiaouri, 2019).

At the centre of discourses' construction of meaning is the dominant discourse (Deligiaouri, 2019). This dominant discourse is often channelled through media platforms (Chouliaraki \& Fairclough, 2010). Discourse theorists (Laclau \& Mouffe, 2001; Phelan \& Dahlberg, 2014) further argue that it is not possible to separate meaning from action. Discourse theory places (language) discourses at an ontological level (Deligiaouri, 2019) which means all objects and issues are discursively constructed. For example, an issue like racism can be (mis)understood through the discourses that accompany its discussion. Discourses reveal power dynamics and configurations in given societal contexts (Jørgensen \& Phillips, 2002). Subjects are able to construct their identities and institute their relations (Chouliaraki \& Fairclough, 2010).

This chapter utilises discourse theory as an analytical framework to explore race debates on Twitter in post-apartheid South Africa. What kind of (racial) identities were constructed through social media discourses particularly on Twitter? In what ways did users institute relations through discourse and what kind of power dynamics emerged out of Twitter discourses on race?

\section{Methodology}

This study utilises two specific incidences of racism that set Twitter alight (Daniels, 2017). These were the Penny Sparrow incident (which gave birth to a Twitter hashtag - \#Pennysparrow), and the Vicky Momberg incident (which gave rise to \#VickyMomberg). The incidents chosen happened in a period of 18 months - April 2017 to September 2018. The sample includes 120 purposively sampled tweets from the two hashtags and had to be about the two racial incidents mentioned above. It was noted that most of the tweets on these two hashtags had nothing to do with the incidents, which explains why they had to be sampled purposely. Retweets were not included as they simply reiterated what was already on the platform. Twitter was chosen because the use of this microblogging platform for debates on race and racism in South Africa is increasing (SAHRC, 2016). Also, digital platforms such as Twitter have the advantage of allowing digital texts like tweets to be collected and analysed easily (Dang-Xuan et al., 2013).

This chapter utilises an 'informalised' version of Critical Discourse Analysis -CDA- (Van Dijk, 2019). Informal CDA still utilises texts, but its advantages are twofold: it does not align itself to one specific 'strand' of CDA, and it is a 'user-friendly' approach for researchers who come from a media/communication/journalism background (Van Djik, 2019), with no 
grounding in fields like linguistics. More so, this kind of approach is utilisable in discourse research which is largely exploratory and seeks to clarify the nature of issues (as this chapter endeavours to do), and for research that is broadly descriptive. It has been utilised successfully in other mediacentric researches (for example, Chibuwe, 2017; Chiluwa, 2019). In this chapter, CDA explores the nature of racial conflicts, the value judgements each racial group attaches to the other, as well as "the ideological perspectives and evaluations of the other" (Chiluwa, 2019, p. 232). 'The other' in this context is taken to mean two racial groups - blacks and white. This helps to reveal the implicit and explicit meanings of tweets and how they have been manipulated by users to create in-groups and out-groups, exposing the agendas of each racial group and the potential of these discourses to aggravate the already existing racial tensions and cleavages.

CDA has three major dimensions (Hammersley, 2003). The first dimension is about words and their characteristics. When speakers, in this case Twitter users, choose certain words, they show a certain attitude to the subject (Fairclough, 2001). Thus, choice of words makes us feel whether we are part of the in-group or out-group in the opinion of others. The second dimension acknowledges language as a bearer of change (Janks, 1997). The words we use are not value-free (Potter et al., 1990). They contain values and attitudes in addition to being polysemic (Fairclough, 2001). The last dimension is the acknowledgement that language creates opinions, social relations and praxis. The themes that emerge from the sampled tweets are discussed in the following section. Examples of significant discourses single words, phrases and sentences - are presented in the analysis. The two hashtags selected are public spaces, and therefore, the selection of tweets did not pose any ethical considerations since the data was already in the public domain. The names of the users, however, will be omitted from the analysis.

\section{Findings: the discursive construction of race discourses on digital platforms}

The two hashtags selected for this research highlighted the prevalence of three main 'nodal points' around which race discourses were produced. These nodal points are fear, othering and toxic masculinity discourses. This section discusses these nodal points as part of the discursive construction of race debates on Twitter.

\section{Production of fear-mongering discourses through Twitter}

Discourse of fear may be defined as the pervasive communication, symbolic awareness and expectation that danger and risk are central features of the affective environment, or the physical and symbolic environment as people define and experience it in everyday life (Pfuhl \& Henry, 1993; 
Altheide, 2018). On the selected hashtags, discussants saw each other as 'super-predators' that would devour the other race. Pro-white tweets reframed the apartheid era discourse of the 'swart gevaar' - the dangerous, violent and barbaric black - referred to, in apartheid history, as the 'black peril' (Brown, 1987; Posel, 2001). On the other hand, problack Twitter users referred to whites as 'Lekgoa', an equally offensive colonial-era racist word meaning the 'pink pigs'. Pro-black tweets also referred to the fear of a 'boer menace'. Fear was often used to explain the worst effects of racism in South African society. Discourses of fear emphasised the future consequences of persistent racism. Characteristic phrases that defined fear were:

The only way to get rid of this boer menace is to get rid of them \#Pennysparrow

Where are our grenades and rifles... we need to get rid of the whites and sent them back to wherever their $\mathrm{f} * * *$ ancestors come from...Otherwise we are going to have a war again here.... \#VickyMomberg

How will our children grow in this racist country...they will know nothing but hate... and we are slowly drifting into chaos... the kaffirs should stop this....

These boers want a war and I see one soon....

Of importance to note in tweets above is the referential use of two terms kaffir and boer. Both terms are racist. Kaffir has been used as a racist insult to blacks during the apartheid regime. Boer has been used from as far back as the Anglo-Boer War in the 1700s to refer to whites of Afrikaner descent. In post-1994 South Africa, both words have been outlawed (SAHRC, 2016). The use of these terms in these moments was, possibly, meant to evoke the fear during that era of apartheid. Reference to past racist incidents and to colonialism itself was in an 'apocalyptic sense', exposing the personal and psychological dimensions of how each race perceives the other as a danger and risk, not only to society, but even at a personal level.

Fear operated at three levels of discourse on both hashtags. First, it operated at a level that the researcher calls 'christening level'. At this level, isolated incidents of racism, like the Penny Sparrow and the Vicky Momberg, were christened as trends. For example, the Penny Sparrow racist spat was quickly named a menace, and when a few months later Vicky Momberg was convicted of racist attacks, the hashtags quickly called this 'the behaviour of the white men', soliciting the following responses on the two hashtags:

I think we'd rather be weary of the aftermath of these kinda action... blacks should be united for a war against the whites...watch out!! We need to revoke European's South Africa citizenships mann.... In fact, we need to kill all white people in South Africa... 


\section{Allen Munoriyarwa}

Some users were more vicious on the space. For example, the following tweets appeared on the space \#VickyMomberg:

We should get rid of white thugs who cannot get rid of their racist past....

In relation to this, a user responded,

What about uneducated, lazy blacks who make a living out of rape and bank robbery...?

A user responded to this by stating on the platform,

It was your father who stopped my father from going to school...now you think you are clever....you are just a beneficiary of murder....

The use of discourses like thugs, rapist and bank robbers has a number of connotations. First, it incites a fear of the other by conjuring up images of violence. Second, it 'validates' stereotypes of other races.

It is imperative to note that all these reactions stemmed from a singular incident that was then appropriated to become a grand racist discourse and ideology of whites. Thus, these two incidents were christened 'the white men's menace' although they were two separate incidents unrelated to each other.

The second level of operation is what can be termed the 'level of misdirection'. This was when attention was shifted from real issues to focus on other issues not necessarily about racism. For example, the Vicky Momberg racism spat was related to scary orations of 'the white men's arrogance' and their disinterest in the 'rainbow nation'. The following tweets on the \#VickyMomberg confirm this:

Since 1894 the white farmers have been killing and raping our sisters and brothers. They do not seem to want to stop...\#VickyMomberg

The white men own everything from land to industries... they just can't share... there must be some boer cleansing...

This country needs fair distribution of resources especially land... we cannot live in squatter camps while the boer enjoys the wealth of this country...

These tweets have no relation to the subject matter under discussion - the racist utterances of Vicky Momberg. Thus, in a way, Twitter users tended to misdirect their wrath towards other issues and raise other discourses unrelated to the matter at hand. Perhaps this might be a sign of simmering disillusionment with the high levels of inequalities existing in South Africa (Gillwald, 2018). South Africa is one of the world's most unequal 
countries in terms of wealth distribution (Bhorat, 2015). Possibly this was an expression of offline anger and frustration on online spaces, triggered by non-related incidents.

Third, the discourse of fear operated on a level that can be termed 'the repetition level'. At this level there was overemphasis, through repetition, of the putative danger posed by other racial groups. Thus, when a racist incident was christened as a menace, it was then 'misdirected' to include, in its debates on these platforms, other issues unrelated to the incident. But, whenever debates about Penny Sparrow or Vicky Momberg's intentions were discussed, there was an overemphasis of the 'fact' that their racist utterances were part of a broader 'consensus' amongst whites to get rid of blacks. Three tweets illustrate this discourse of repetition thus:

We are going to get rid of the white men by launching a full-scale war and reclaim our land \#VickyMomberg

The whites are a menace since they came to this Africa... there was never a white man here before... \#Pennysparrow

Mandela made a mistake...let's forget about the rainbow nation...f***: it... to hell with...\#VickyMomberg

Association with past histories was used in this instance to inform the creation of the other. Accounts of past 'sins' provided a historical linkage, through discourse, of the past to the present to offer 'clear insights' of the 'danger' that the other race is. The problem with discourses of fear is that other competing discourses that may be more rational and critical would lose out once platforms of discussions are dominated by fear discourses. Burke (1791) aptly noted, "no passion so effectually robs the world of all its powers of acting and reasoning as fear" (p. 109). Waller-Carr (2018) agrees, "It is through the performativity of fear, weighted in past histories, in discourse and its circulation through online platforms that [it becomes] reality" (n.p.). A critical-rational debate on why South Africa has receded into its racist past did not materialise on these two hashtags. Users resorted to a language of emotions, became tied to specific groups of races and in turn became bogged down in fear-mongering discourses that culminated in 'othering'.

\section{Discourses of 'othering'}

The danger of fear-based race debates on these hashtags was that they progressively drove a wedge between blacks and whites. This led to the prominence of 'othering' as a nodal point of race discourses on these Twitter hashtags. By "othering", it is meant any action by which an individual or group becomes mentally classified in somebody's mind as "not one of us" (Dervin, 2012). Canales (2000) notes that sometimes it is easier to dismiss other people as being in some way less human and less worthy of respect 
and dignity. Discourses of 'othering' arguably goaded by fear were prevalent in the two hashtags. For example, the following tweets from the two hashtags show the prevalence of the 'othering' discourse:

Penny Sparrow is evil, and harboured hatred towards black people, but she deserves to die just like all the Afrikaans....

All whites are like Jews, they deserve an AK and 5 grenades

Whites are foreigners on this land why are they making noise? To hell with all whites they should go back to their motherland...

The basis of this 'othering' discourse should be traced to apartheid animosity (Smith, 2003). Central to the apartheid system were discourses of 'othering'. And these discourses seem to have endured into the postapartheid state. Discourses of 'othering' dehumanised other races and, in turn, hardened responses from other participants. For example, the following exchange on the \#VickyMomberg is noted:

All whites are like Jews, they deserve an AK and 5 grenades

Response: This dumb sh!t would probably miss (Even with his Ak \& 5 grenades)!! expect him to 'pull the grenade and throw the pin'!

Another response: Well, all baboons and monkeys would miss as well...

There were two net effects of these kinds of discourses. First, they spurred further racist discourses on the hashtags. Second, they wore away any residual civility and rationality on the hashtags, making the platforms spaces for 'shouting matches' amongst participants. This gave rise to a discourse culture of bullying on the platforms as participants fought and positions hardened over the issue of racism. Two characteristics of othering were common. First, the racially different other was linked to an impending apocalypse. Each side, black and white, began discussing each other in the discourses in terms of being an immediate danger to the stability of the country and its future. For example, the following tweets illustrate the point:

Black pple should focus on their corruption and within years they would have finished looting this country...\#Pennysparrow

They $\mathrm{R}$ racists because they hold blacks to a lower standard than they did Penny Sparrow.... \#Pennysparrow

We should never long for white rule... what an evil it will be...\#Pennysparrow

The second characteristic was the manifestation of discourses of captivity. Both blacks and whites on the hashtags saw themselves as captives of the other. Often, they had to go back into history to create a shared political 
community that was anti-other and that benefitted from a nostalgic and shared past. Pestilential metaphors of victimhood were used to describe the other. For instance, phrases like 'the white men plague', 'the black men tsunami in our beaches and streets' were often used in some tweets on the hashtags. Another example is the use of word phrases, like 'black killers', 'bloody exploiters', 'unforgiving whites', etcetera, often used to describe the others. In some tweets, racism was metaphorically referred to as 'the disease of the white men', 'a war' and 'a disaster'. One post on the \#VickyMomberg referred to racism as 'a military attack on the rainbow nation'. New signifiers were often associated with racism; for instance, one tweet referred to it as 'the Boer threat' against South Africa. Belligerent discourses that often accompanied these comments agitated for 'the elimination of the white men, especially the Boer' as a solution to racism. Thus, the idea of racism on hashtags was often inundated with negative comments to the extent that one could argue that hashtag users ceased to debate racism and started to construct it in different discourses of their own.

\section{(Toxic) masculinity discourses}

Another prominent discourse on the hashtags was toxic masculinity which manifested itself in many different linguistic expressions. Masculinity means the quality of being men (Harper \& Harris III, 2010). Masculinity becomes toxic when it exhibits exaggerated behavioural traits like violence, dominance and sexual aggression (Harper \& Harris III, 2010). The prevalence of masculinity discourses on these hashtags was arguably a manifestation of the incivility of the hashtag platforms. Masculinity posts on the hashtags set participants on a collision course, as each post goaded other participants into retaliation. For example, the following conversation on \# VickyMomberg illustrates the point:

We should rape all white women and their children until they flee... this is what they did to our own women...\#VickyMomberg

I forgive you for having no brains at all... you think like a monkey... are you human?

So, Vicky Momberg thinks blacks are not human beings... we should perhaps send her a delegation of Sifiso Makhubo and Lonwabo Solontsi? She might find that very nice?

(Sifiso Makhubo hanged himself in a South African prison, before the start of his trial. He was facing 34 counts of rape. Lonwabo Solontsi was given 706 year in prison for 41 counts of rape). Another crude tweet read:

Raping a white racist would be the best experience....

It is instructive to note that even Twitter hides these comments as 'sensitive comments'. They illustrate the extent to which the platform had been 
invaded by toxic masculinity that discussed issues not only unpalatable and uncivil, but equally unrelated to the issue at hand. It is also important to note that toxic masculinity was a way in which the hashtags mutated from being purveyors of information and a platform on which Twitter users engaged, to spaces on which a more virulent and aggressive form of racism was reproduced. Judging by the discourses above, hashtags became a space for the participatory reproduction of racism. This explains why the SAHRC (2016) notes that discourses of racism now find resonance and encouragement on social media platforms like Twitter.

\section{Discussion: from interpretation to reproduction of racism on twitter hashtags}

This chapter has explored the discourses of race and racism in South Africa as they unfolded on two selected Twitter hashtags. From the evidence, it was noted that the platform had become a space through which racism was reproduced. While some users admonished the offensive otherness that perpetuated tropes and stereotypes of other races, most users fell into dichotomised discourses of villains, martyrs and victims. Consequently, the hashtags, by extension, became spaces where individuals were brought together through feelings of injustice and anger in ways that further stoked fear and racism. The problem with discourses of fear is that they distract attention from serious issues to trivialities. Fear, as noted from the discourses, stretched the truth beyond recognition by manufacturing and exaggerating the threat that each racial group posed to the other.

The nastiness and vitriol of the hashtag comments triggered fear-evoking 'flame wars' (Dervin, 2013). In the process of generating fear about the racial other, racial groups were treated as morally inferior. Whites, for example, were constructed in discourses as a dangerous race, invaders and thugs from the North. In the process, the North was othered. The overall fixation of discussants on stocking collective racial anxieties by focusing on threats posed by the racially different other has deeper consequences going forward. One of those consequences is that as people become more fearful of the other, they become less tolerant of each other and more willing to accept bad policies specifically tailored to curtail the perceived threat posed by the other (Heacox, 2020).

For example, certain racial groups can be susceptible to support the need for legislation that controls the presumed menace another racial group is thought to cause. Already in South Africa, the SAHRC (2016) has warned of the danger that social media platforms like Twitter are causing to racial cohesion. In March 2017, the then Minister of State Security in South Africa, David Mahlobo, called for social media to be regulated as "it was threatening to undo the gains against racism made in the post-apartheid era...". South Africa's Film and Publication Board made the same call in 2018. Thus, racist discourses on Twitter may play into the hands of sections that 
have always advocated for the regulation of these platforms for fear that they may cause insurrection. These groups may lose sight of the fact that regulation of such platforms can lead to the erosion of free speech. This fear that social media platforms like Twitter may be corroding postapartheid race relations should be juxtaposed with the fear that overregulating such platforms would equally corrode free speech.

Debates were often underpinned by discussions on the distribution of the wealth and comforts of the country. There were frequent posts on 'whiteness of the economy', a discourse that has also become a political rallying point offline, for other leftist political parties such as the EFF (Habib, 2019). Thus, in a way, race debates on Twitter mirrored offline debates on economic justice in the country. This intermixture of race issues with economic justice issues produced 'new chains of signification' (Deligiaouri, 2019). Racist incidents became 'entry points' through which persistent economic inequalities in post-apartheid South Africa could be explained, interpreted, criticised and even in some instances, justified. Social media reactions to racist incidents, therefore, caused a deep scepticism concerning South Africa's post-apartheid race relations. As discourses have shown, this scepticism goes beyond race relations. Central to it is the distribution of economic wealth and comforts, which in turn make race discourse on Twitter unsettling and tension laden. Yet, at the same time, this tension seems to have provided a 'cathartic moment' where users deal with lingering racial tensions of the past era.

\section{Conclusions and steps for future research}

This chapter has explored racist discourses on two selected hashtags on South Africa's Twittersphere. The overall conclusion is that the selected hashtags juxtaposed both anti-black and anti-white discourses that were equally vitriolic. The vitriol involved disparate instigators with broadly shared (black or white) targets and employing the same discoursal tactics (fear-mongering, othering and toxic masculinity). The results, furthermore, demonstrate how out-groups and in-groups were created on Twitter every time a racist incident erupted in South Africa. This chapter further highlighted how existing economic inequalities, a legacy of apartheid, galvanised and fed racism as 'digital mobs' kept referring to these inequalities in discussions, in their incessant 'verbal combat'.

This research was limited to two hashtags and was broadly exploratory because of the absence of research on this subject in South Africa. There is a need for further research on racism on social media in South Africa. Further research can, for instance, focus on a systematic review of offline consequences of hate discourses in the country. One aspect noted in this chapter was that racist discourses on these two hashtags were not coordinated by particular groups, but by what I can refer to as 'lone wolf racists', who acted on their own accord on the platform, but 'coincidentally' found 
like-minded participants in (dis)agreement with their views. This leaves another gap for future research - focusing on exploring how organised racist groups interact within and across social media platforms.

\section{References}

Altheide, D. L. (2018). Creating fear: News and the construction of crisis. New York: Routledge.

Bhorat, H. (2015). Fact check: Is South Africa the most unequal society in the world? The Conversation. Available at https://cutt.ly/XkobZ2n

Bliuc, A. N., Jakubowicz, A. \& Dunn, K. (2019). Racism in a networked world: How groups and individuals spread racist hate online. The Conversation. Available at https://cutt.ly/5koitNC

Brown, B. B. (1987). Facing the 'Black Peril: The politics of population control in South Africa'. Journal of Southern African Studies, 13(2), pp. 256-273.

Canales, M. K. (2000). Othering: Toward an understanding of difference. Advances in Nursing Science, 22(4), pp. 16-31.

Chaudhry, I. (2015). \#Hashtagging hate: Using Twitter to track racism online. First Monday, 20(2). doi: https://doi.org/10.5210/fm.v20i2.5450

Chibuwe, A. (2017). Language and the (re) production of dominance: Zimbabwe African National Union-Patriotic Front (ZANU-PF) advertisements for the July 2013 elections. Critical Arts, 31(1), pp. 18-33.

Chiluwa, I. (2019). Discourse Analysis and Conflict Studies. SAGE Research Methods Cases. https://www.doi.org/10.4135/9781526468208

Chouliaraki, L. \& Fairclough, N. (2010). Critical discourse analysis in organizational studies: Towards an integrationist methodology. Journal of Management Studies, 47(6), pp. 1213-1218.

Cleland, J. (2014). Racism, football fans, and online message boards: How social media has added a new dimension to racist discourse in English football. Journal of Sport and Social Issues, 38(5), pp. 415-431.

Dang-Xuan, L., Stieglitz, S., Wladarsch, J. \& Neuberger, C. (2013). An investigation of influential and the role of sentiment in political communication on Twitter during election periods. Information, Communication \& Society, 16(5), pp. $795-825$.

Daniels, J. (2009). Cyber racism: White supremacy online and the new attack on civil rights. Lanham, MD: Rowman \& Littlefield.

Daniels, J. (2017, 19th October). Twitter and white supremacy: A love story. Dame Magazine. Available at https://cutt.ly $/ 5 \mathrm{kokNgq}$

De Goede, M. (2009). Finance and the excess. The politics of visibility in the credit crisis. Zeitschrift für Internationale Beziehungen, 16(2), pp. 299-310.

Deligiaouri, A. (2019). Economic crisis and Greek crisis discourse: A discourse analysis of articles from The Economist referring to Greece (2009-2011). Journal of Language and Politics, 18(2), pp. 231-251.

Dervin, F. (2013). Cultural identity, representation and othering. In J. Jackson (ed.), The Routledge handbook of language and intercultural communication (pp. 181-194). London: Routledge.

Fairclough, N. (2001). Critical discourse analysis as a method in social scientific research. In R. Wodak \& M. Meyer (eds.), Methods of critical discourse analysis (pp. 121-138). London: Sage Publications. Introducing Qualitative Methods. 
Farrington, N., Hall, L., Kilvington, D., Price, J. \& Saeed, A. (2017). Sport, racism and social media. London: Routledge.

Gillwald, A. (2018, 8th November). Data deficit means we're in the dark about the digital divide. Quartz Africa. Available at https://cutt.ly/RkobctH

Glaser, J. \& Kahn, K. (2005) Online prejudice and discrimination: From dating to hating. In Y. Amichai-Hamburger (Ed.), The social net: Understanding our online behavior (pp. 247-274). Oxford: Oxford University Press.

Habib, A. (2019). Rebels and rage: Reflecting on\# FeesMustFall. South Africa: Jonathan Ball.

Hammersley, M. (2003). Conversation analysis and discourse analysis: Methods or paradigms? Discourse \& Society, 14(6), pp. 751-781.

Harper, S. R. \& Harris III, F. (2010). College men and masculinities: Theory, research, and implications for practice. London: John Wiley \& Sons.

Heacox, K. (2020, 22nd October). Beware the bamboozle. Anchorage Daily Beast. Available at https://cutt.ly/Gko4gqJ

Head, T. (2018, 4th April). Inequality has increased in South Africa since apartheid. The South African. Available at https://cutt.ly/rko4DUF

Jackson, S. (2019). The double-edged sword of banning extremists from social media. doi: 10.31235/osf.io/2g7yd

Jakubowicz, A. (2017). Alt_Right White Lite: Trolling, hate speech and cyber racism on social media. Cosmopolitan Civil Societies: An Interdisciplinary Journal, 9(3), pp. 41-60.

Janks, H. (1997). Critical discourse analysis as a research tool. Discourse: Studies in the Cultural Politics of Education, 18(3), pp. 329-342.

Jørgensen, M. W. \& Phillips, L. J. (2002). Discourse analysis as theory and method. London: Sage.

Krotoski, A. (2013). Untangling the web. London: Faber \& Faber.

Laclau, E. (1994). Introduction. In E. Laclau (ed.), The making of identity politics (pp. 1-10). London: Verso Books.

Laclau, E. \& Mouffe, C. (2001). Hegemony and socialist strategy: Towards a radical democratic politics. Singapore: Verso Trade.

Lowry, P. B., Zhang, J., Wang, C. \& Siponen, M. (2016). Why do adults engage in cyberbullying on social media? An integration of online disinhibition and deindividuation effects with the social structure and social learning model. Information Systems Research, 27(4), pp. 962-986.

Mafoko, Z. (2017, 28th July). The dream of the Rainbow Nation is history, not our reality. Daily Maverick. Available at https://cutt.ly/2koC2RA

Marchart, O. (2011). From media to mediality: Mediatic (counter-) apparatuses and the concept of the political in communication studies. In L. Dahlberg \& S. Phelani (eds.), Discourse theory and critical media politics (pp. 64-81). London: Palgrave Macmillan.

Matamoros-Fernández, A. (2017). Platformed racism: The mediation and circulation of an Australian race-based controversy on Twitter, Facebook and YouTube. Information, Communication \& Society, 20(6), pp. 930-946.

McDonald, P. D. (2011). The present is another country: A comment on the 2010 media freedom debate. Ecquid Novi: African Journalism Studies, 32(2), pp. $122-134$.

Pfuhl, E. H. \& Henry, S. (1993). The deviance process. New York: Transaction.

Posel, D. (2001). What's in a name? Racial categorisations under apartheid and their afterlife. Transformation, 47 50-74. 


\section{Allen Munoriyarwa}

Potter, J., Wetherell, M., Gill, R. \& Edwards, D. (1990). Discourse: Noun, verb or social practice? Philosophical psychology, 3(2-3), pp. 205-217.

Rauch, S. \& Schantz, K. (2013). Advancing Racism with Facebook: Frequency and purpose of Facebook use and the acceptance of prejudiced and egalitarian messages. Computers in Human Behaviour, 29(3), pp. 610-615.

Rich, P. (1990). Race, science, and the legitimization of white supremacy in South Africa, 1902-1940. The International Journal of African Historical Studies, 23(4), pp. 665-686.

Ruddock, A., Hutchins, B. \& Rowe, D. (2010). Contradictions in media sport culture: The inscription of football supporter traditions through online media. European Journal of Cultural Studies, 13(3), pp. 323-339.

SAHRC. (2016, 6th July). Increased complaints on racism means more people know their rights. Available at https://cutt.ly/9koNUFv

Shepherd, A., Sanders, C., Doyle, M. \& Shaw, J. (2015). Using social media for support and feedback by mental health service users: Thematic analysis of a Twitter conversation. BMC Psychiatry, 15(1). doi: 10.1186/s12888-015-0408-y

Smith, D. M. (2003). Introduction. In D. M. Smith (ed.), The apartheid city and beyond: Urbanization and social change in South Africa (pp. 1-10). London: Routledge.

South African Institute of Race Relation. (2018). Race relations in South Africa: Reasons for hope 2018. Available at https://cutt.ly/ckoOiPv

Spiker, R. L. (2012). From my living room to yours: A grounded theory typology of racial discussions on YouTube. [Doctoral dissertation]. University of Cincinnati, OH. Available at https://etd.ohiolink.edu/

Statistics South Africa. (2019, 4th April). Five facts about poverty in South Africa. Available at http://www.statssa.gov.za/?p=12075

Stephens, C. (2018, 28th May). Whatever happened to the Rainbow Nation? IOL. Available at https://cutt.ly/Kko8Ucx

Suler, J. (2004). The online disinhibition effect. Cyberpsychology \& Behaviour, 7(3), pp. 321-326.

Waller-Carr, F. (2018, 2nd November). Affect, discourse and politics: Interrogating narratives of fear. Available at https://cutt.ly/6ko47Fo

Zienkowski, J. (2016). Discourse theory on the logics of articulation, politics and subjectivity. In J. Zienkowski (ed.), Articulations of self and politics in activist discourse (pp. 35-89). Cham: Palgrave Macmillan. 


\section{Blessed be the fight \\ Misogyny and anti-feminism in \\ The Handmaid's Tale}

Laura Cortés-Selva and

Susana Martínez-Guillem

\section{Introduction}

Television series have acquired importance as transmission vehicles of political, cultural and social contents to society. In this sense, The Handmaid's Tale implies an example of richness of content and the ability to talk about controversial issues such as gender equality, lesbianism, prostitution, nativity, abortion, surrogate motherhood, family models, race, social class, religion, surveillance, control and violence unified by a thematic concern related to resistant female voices, as explained in Howell's (2019) survey of the transmedia shape of the Gilead universe (Gileadverse). This feminine universe, present through symbols such as language itself, is analyzed by Moreno-Trujillo (2016) to show the importance of its control: "Language is a key weapon for the reigning dystopian power structure. Therefore, the process of taking control over the means of language, representation, memory, and interpellation is a crucial weapon and strategy in moving dystopian resistance" (Baccolini \& Moylan, 2003, p. 25). In this sense, it is symptomatic that in Gilead, handmaids lose their original names to take on a new one: Of-commander's name. For example: Offred (originally named June) comes from Of-Fred (name of Mr Fred Waterford and a prefix denoting "belonging to" or "offered to") (Atwood, 2017).

Matthews (2018) examines the subject of gender as it influences selfidentity, agency, power and subjectivity in terms of consciousness and embodiment. This kind of speculative fiction provides the ideal landscape for discussions about alterity, oppression and hegemony, especially along the axes of gender and race.

From a bioethics and biopolitics point of view, Cambra-Badii, Mastandrea and Paragis (2018) reflect on the consequences that birth control through surrogate motherhood could have for women. The authors continue with the idea of the oppressive character of a society in which women would have pre-established roles linked to procreation, caregiving work and pleasuring men.

Miceli (2018) discusses the different models of families shown in The Handmaid's Tale, from traditional ones to new models such as homosexual 
or mono-parental ones, and women's roles in them. Hanlon-Rubio (2003, p. 4) explains that many Americans believe that giving equal importance to all types of families (same-sex families, mononuclear families and so on) is destructive to the traditional concept of family and that "it is not beneficial to focus on the diversity of family life in the United States". In this respect, the patriarchal nuclear family is only "a historical and culturally specific" social institution and not something "natural", and that is why it is used in Gilead and in real societies, "in the organization of social and cultural life" and in "the acquisition of male and female gender identities and the moral order" (Wright \& Jagger, 1999, p. 4).

Crespo-Pereira, Fernández-Holgado and Márquez-Domínguez (2018) claim that the rise of authoritarian parties in several countries around the world has resulted in the loss of women's rights and the rights of minorities groups.

Original book author Margaret Atwood (1985) is a Canadian professor, a militant feminist and political activist who wrote the book in the 1980s during Reagan's presidential term. Although it had been adapted into an opera, a ballet, a graphic novel, as well as a film of the same title directed by Volker Schlöndorff in 1990, it was not until 2017 that its adaptation to The Handmaid's Tale TV series has had a powerful impact, becoming what Howell (2019) calls a Gileadverse, a transmedia universe. Winner of five Emmys, two Golden Globes and a Peabody Award, The Handmaid's Tale is not only a high-quality TV series but also a political one with a powerful impact on society (Hendershot, 2018).

First aired via video-on-demand in 2017, The Handmaid's Tale tells a fictional story about a state coup in the United States which then becomes the Republic of Gilead, a world in which fundamentalists take control and abolish the established laws concerning women rights, and create new ones that forbid them to work outside of the home, have properties, read or write. Women are forcefully confined to private life, and gender roles and social class govern their lives. There is a real and a symbolic violence (Bourdieu, 2000) explained in the TV series through visual symbols and language. Nevertheless, this violence is only possible - as Simone de Beauvoir says - with accomplices who are mainly women, such as Serena Joy, one of the main characters from the TV series and Mr Waterford's wife. The TV series condemns the betrayal of women by women even more strongly (Hendershot, 2018).

Although there is no worship of God, the Bible is present in the Republic of Gilead through Old Testament writings. According to Atwood (2017):

The Republic of Gilead is built on a foundation of the 17th century Puritan roots that have always lain beneath the modern-day America we thought we knew. The biblical precedent is the story of Jacob and his two wives, Rachel and Leah, and their two handmaids. (...) The handmaids could not claim the sons, they belonged to the respective wives. 
Bruce Miller is the creator of this television series that ended in 2019 after its third season, but was supervised and produced by Margaret Atwood, actress, and the main character Elisabeth Moss, MGM Television, and mainly distributed by Hulu. In a context where women have suffered discrimination in the cinema industry (Cortés-Selva, 2020), it stands out that most of the TV series production staff is composed by women with names such as Reed Morano, Floria Sigismondi, Kate Dennis, Kari Skogland or Daina Reid, who directed most of the TV series' chapters. Atwood's book had already been scripted and was in production when Donald Trump was elected as President of the United States in November 2016. In fact, the premiere of the TV series was on April 26, 2017, so it could only be a premonition of Trump's mandate. As a consequence, although the first season wasn't a direct reaction to current events, it could be seen as an allegorical response to Trump's political moment. The country had just elected a president who, among other things, had vaunted his own acts of sexual assault and was doing his best to eliminate reproductive rights for women (Hendershot, 2018). Interestingly, Atwood makes a reflection upon the concept of normality and how its definition is based on what people are used to. As in one scene of episode 9 from season 1 - aunt Lydia tells handmaids that ordinary is just what you're used to. So unusual things - after a while - could become ordinary.

With a gender perspective and through visual style analysis, the aim of this chapter is to offer a reflection on the message that Atwood sends through the misogynist and anti-feminist content present in The Handmaid's Tale pictures. We can consider those that send a political message as political images. As a result, visual communication could be considered a kind of communication that uses images as a means to communicate political messages. In an era of information excess and scarcity of time, images are the most powerful media type to capture the public's attention (Lilleker, Veneti \& Jackson, 2019), and to send simple but powerful messages. Images have become of primary importance in political communication in the last few years, and are designed according to visual language to provoke the most powerful emotional impact (Scammell, 2016). Due to the potential to influence human behavior and mobilization, images seem to be capable of supporting an active engagement in an apathetic and unengaged citizenship (Wahl-Jorgensen, 2019). As a consequence, visual communication plays a fundamental role in political content dissemination. Political parties and activists, knowledgeable of their rhetorical power (Way, 2016), use them in their messages with the intention of awakening consciousness, persuasion and manipulation. In fact, in this last sense, images have become the main actors in the populist phenomena (Giménez \& Schwarz, 2016).

It is well known that cinema is made from moving pictures and each frame is a still picture itself. Through film or digital devices, there is a mise en scene where actors play and develop a role in a fictional world built in space and time. These elements, which are part of production departments in the cinema industry, have the same purpose: to support the main story. 
Visual elements, together with sound and acting, send messages to audiences with different levels of interpretation. One is through sound (mainly dialogues but also music and sound effects) and the other is through the mise en scene (the elements and actors inside the frames cause different meanings and emotions).

The objective of this chapter is to analyze the main visual style elements present in The Handmaid's Tale, and to this end, we will conduct an analysis of the three seasons of the television series by mainly concentrating on the visual style, focusing on cinematography, set design and costumes (Cortés-Selva, 2018), and comparing them with pictures taken from activists in the United States and around the world. An ad-hoc table was designed in order to answer the following questions: Which of the visual elements analyzed in the TV series do activists around the world adopt? Where (countries and cities)? For what purpose?

\section{The rise of (far) right-hand politics as an international phenomenon}

Before we move on to the specific analysis, it is important to sketch the broader historical and socio-political context in which The Handmaid's Tale can be placed. The last decade has witnessed a resurgence of neoconservative and even neofascist political projects throughout the globe. It could be argued that the current "populist conjuncture" (Frøslee Ibsen, 2018) shaping political action across different nation states has provided a particularly fertile ground for these initiatives to legitimize and obtain widespread support for their proposed political projects. From the European Union and its border states, to the United States and Latin America, candidates and parties are successfully capitalizing on exclusionary rhetoric and accompanying legal measures that would have been unthinkable just a few years ago, and that can be linked to a widespread "legitimation crisis" shaped by political-administrative and socio-cultural dynamics (Habermas, 1988; Frøslee Ibsen, 2018).

Different "discursive shifts" (Krzyżanowski, 2018) have thus made it possible for explicitly xenophobic, racist or sexist discourses to become part of mainstream political practice, both in EU countries and the European continent as a whole, as well as in settler societies such as the United States and Brazil. In spite of geographical, historical, economic and cultural differences, the similarities are striking: The defense of liberal multiculturalism is routinely substituted by blatant attacks towards those deemed 'Others' and calls for ethno-national supremacy. The feminist movement is dismissed as part of a conspiratory "gender ideology", in some cases equated to the Nazi regime (Kitson, 2019). Privileged social actors easily reposition themselves as victims - of media manipulation in the shape of 'fake news', of legal provisions aimed at countering historic inequalities. The list goes on and on. 
Rather than being an anomaly, this current neo-conservative wave can be observed as a reaction, not only to the failure of neoliberalism and its accompanying loss of privileges for some (which is a more socio-economic explanation), but also to recent feminist, anti-racist and environmental struggles for equity and social justice, which are more related with the so-called 'cultural' aspects of social dynamics. Some examples include: \#niunadimeno, SOS racismo, Fridays for future or Movimento dos Trabalhadores Sem Terra. The discursive frames that provide information on the current 'legitimation struggle' are thus both transnational and transversal, i.e. circulating from institutional, to mediated, to everyday cultural practices. More importantly, they also exemplify a tension between morality and authority (Van Leeuwen, 2008; Abulof, 2015) as a defining characteristic of the current "crisis in the legitimacy of the political order" (Frøslee Ibsen, 2018, p. 2).

\section{Trump's 'unorthodox' politics and the normalization of sexism}

In this broader context, politics has become increasingly 'spectacularized', regardless of whether we consider 'right-wing' or 'left-wing' political parties (Martínez-Guillem, 2019). We are now witnessing a proliferation of 'performance politics' that make it increasingly harder to sustain a clear-cut division between so-called 'political' and 'non-political' spaces (FilardoLamas \& Boyd, 2017). As Wodak maintains, it is important to consider politics as a "ubiquitous [...] ordering of social relations in both public and private life" (Wodak \& Forchtner, 2018, p. 43) a theme that, as we later discuss, is prevalent in The Handmaid's Tale. Even though such 'scandalization' tendencies in politics tend to be discussed under the umbrella term of 'populist conjuncture', it is important to bear in mind that there is a distinction between an expansive - typically left-wing - and a reductive typically right-wing - populism (Wodak, KrosraviNik \& Mral, 2013), and thus, similar political practices may be put at the service of very different or even antagonistic political projects.

With regard to the US context, and especially after the election of Donald Trump, different authors point to "a shift in discourse and a normalization of racist, nationalistic and nativist narratives" within an overall "neofascist authoritarian turn" (Gounari, 2018, p. 209). Moreover, within the previously mentioned crisis in the political system, unorthodox, seen as 'direct' ways to communicate with and as an 'average' person, has become an effective aspect of Trump's (right-wing) populist persona. Trump's style is also a prime example of the broader scandalization and provocation strategies that Wodak (2015) documented in her examination of (far) right political discourses. As Wodak and Kryzanowski (2017) explain, "Donald Trump's US-Presidential victory is believed to stem - to a large extent from his unconventional, aggressive, and offensive use of social media, and 
specifically tweets, explicitly attacking his opponent Hillary Clinton and the traditional liberal media" (p. 4). The current algorithmic-driven (social) media landscape, where impactful headlines have a better chance of becoming viral and thus influential, definitively facilitates these processes (Blankenship, 2020).

Among the explicit targets of Trump's 'directness' we find women. In the current "politics of enmity" landscape (Mbembe, 2017), he has been able to normalize a sexist and misogynist imagery that resonates with those who feel unjustly attacked and disadvantaged by civil rights advancements, thus defining women as the enemy "obligatory to the process of subject formation" in this context (Borba, Hall \& Miramoto, 2020). In this sense, Trump's electoral victory in 2016 becomes less surprising if, instead of focusing on the unexpected amount of support that he was able to gather, we consider an equally important factor, namely the lack of support for his main opponent, Democratic Party's leader Hillary Clinton.

Apart from being successfully framed as a representative of the establishment by Trump's campaign (which was a way to capitalize on the legitimation crisis discussed above) Clinton was also importantly framed as a woman. Astonishingly, a key part of Trump's campaign was focused on how this fact alone (being a woman) made Clinton unsuitable for presidency, which speaks to the power that a misogynist discourse could have in the context of a perceived crisis of white masculinity and its subsequent loss of unearned privileges. Moreover, even within the more progressive electorate, the fact that Clinton was a white, liberal woman, supposedly embodying the current face of feminism, earned her the confidence of other white liberal women, but not of women of color, which speaks to the difficulties faced by feminism when having to also consistently advance anti-racist demands (Martínez-Guillem \& Barnes, 2018).

Lakoff (2017, p. 595), for example, unapologetically and significantly attributes Trump's victory to misogyny. In her reading, Clinton was caught in the classical double-bind of women leaders, one that sees us as incompetent due to our assumed incapacity to be assertive, but then disciplines us as 'emotional', 'aggressive' or 'bitches' when we are. On the other hand, "Trump's performances, with their continuous 'name-calling', 'hollowness' and 'infantile behaviour' were viewed as legitimate, because a man was performing them" (p. 597). It is important to highlight that such performances consistently included sexist remarks against women reporters, politicians or even the women in Trump's own family (Heimbrod, 2020). Misogyny had then a dual effect on the 2016 US presidential election: it prevented Hillary Clinton from becoming the first woman President, thus evidencing how large portions of the electorate misidentified the immense step towards gender equality that she represented, and it enabled many Americans' identification with Trump's claims for a 'Great America (again)', which resonated as legitimate, especially for white males. As Lakoff (2017) explains: 
America's most recent Golden Age was located somewhat fuzzily around the 1950s, after the war that made the U.S. the leader of the free world, and before all the disturbances of the " 60 s, when the laws changed to allow others than white males entrée into all the good things America had to offer: education, jobs, power, status. That was the snake in the Trump voters' Eden. For that brief shining moment between 1945 and 1973, America was Great for the Trump constituency. To Make America Great Again, the results of the Civil Rights and Women's Movements had to be undone.

Along similar lines, Gounari (2018) points out that "America has never been 'great' for Native Americans, African-Americans, Latinos, immigrants and other 'minorities', women, and the poor" (p. 211). The interpellated political subject of Trump's rhetoric of 'greatness' thus emerges as a white, masculine, heterosexual male. More specifically, the normalization of sexism is in line with a broader regressive tendency across the globe that tends to position gender as 'the enemy of many nations' through its association with the negative connotations of the term 'ideology' that try to connect feminism with an attack on males, traditional and/or religious values, instead of highlighting its intervention in the struggle for women's rights (Borba, Hall \& Miramoto, 2020, p. 2). It is within this broader context that we next examine the specifics of the different visual symbols put forward in The Handmaid's Tale.

\section{Analysis and results}

In this part of the study we offer the main results found after conducting visual style analysis. To this end, we have divided it according to the most relevant elements: costume design, art direction and cinematography.

\section{Costume design}

Ann Crabtree is the mastermind behind The Handmaid's Tale costume design (Butterworth, 2017). In Gilead, men and women are differentiated to prevent any confusion between them and to show their different gender roles. As Martínez-Moreno (2008) points out, it could be considered as a hyperbole of what has happened in societies over centuries:

Due to power and prestige, the ruling class will not consent to be confused with the subjugated class. Because of questions related to gender relations, men and women will try not to be confused between them (...). It's not only a question of class and gender differentiation but to clarify which are the specific roles in the social context. 
The first differentiation is based on gender: male and women. Black is the color of men, without class distinction. As the masculine renunciation coined by Martínez-Moreno (2008), men's costumes evolved at the beginning of XIX century towards a severe uniformity: black, grey and brown would be, from that moment on, men colors. It mainly resembled who was in charge: white heterosexual men. In Gilead, although every man is dressed in black, upper-class men such as commanders were distinguished from lower-class men such as guards, by the quality, shape and cut of their clothes. Commanders wear black suits, white shirts, vest and straps that together with a perfectly styled hair and - in some cases - a beard (a distinctive feature of men) is the uniform of the ruling class. On the contrary, lower-class men in Gilead such as Nick, who in the first season is a guard, also wear black clothes but of a lower quality and casual cut. Other men that serve as military guards in Gilead, also from a lower class, wear black military clothes and guns.

Although women in Gilead have been silenced, they wear clothes that speak by themselves about who they are and what they represent. In this sense, it is possible to create a taxonomy according to two criteria: social class and fertility. There is a distinction between high-class and lower-class women, and among these, they are classified according to their reproductive capacity.

\section{Colors in Gilead are mainly used as symbols such as in Nazi's concentration camps}

Blue and red, the more vibrant colors of the TV series, are chosen to differentiate the most important women in the Republic of Gilead: wives and handmaids. On the other hand, brown is the color for Aunts, special women in Gilead, neither high nor lower class but a kind of military class. She could be considered a cross between blue and red. The rest of the women in Gilead (Marthas, Econowives, Unwomen) use low saturation colors such as grey. Only girls wear pink clothes (the sum of red plus white as an allegory of their state of fertility), and widows from higher classes wear purple costumes (the sum of blue plus black as an allegory of their state of infertility). Lastly, white, as a classic symbol of purity, is the color of brides before marrying.

High-class women are commander's wives such as Serena Joy, a character inspired by Phyllis Schlafly, an anti-feminist and a public advocate for domestic women. Serena and the rest of the commanders' wives wear austere and plain dresses in teal (greenish blue). This color is a symbol borrowed from the Christian iconography of the late medieval, early Renaissance period, as Atwood explains: "Virgin Mary would inevitable wear blue or blue-green" (Vineyard, 2017). While teal is beautiful, it's also a color of subservience. Commanders' wives do not have a voice; they don't have much more power than the handmaids or the Marthas. They are at the mercy of their husbands and are punished when they disobey or step out 
of line. As the meaning of feeling blue, the teal color of Serena's clothing is associated with unhappiness, sadness and depression, as it is unveiled throughout the TV series. This outfit is crowned by the bun hairstyle. Serena Joy's mother wears purple costumes like the Purple Heart awarded to soldiers wounded in battle. As a widow and an old woman, her power of decision is reduced exclusively over her daughter.

In a society dominated by a largely sterile population as a consequence of environmental disasters, women are classified according to their fertility. Among the lower class, handmaids are at the top as the only fertile women in the Republic of Gilead. In a dichotomy, although they are considered precious two-legged wombs and receive special treatment, they are required (as in Ceausescu's regime) to give birth, including Ceremony acts of rape. Handmaids are dressed with a long and loose deep red color dress, long enough and shapeless to not be able to see any flesh or curve. Borrowed from Christian iconography of Mary Magdalene (Vineyard, 2017) and as an allusion to blood of parturition (Atwood, 2017), red indicates fertility but also represents passion, power and courage. As a hue that stands out, red is perfect for avoiding any tries to escape. Handmaids also wear red cloaks to go outside when the weather is cold, and white bonnets with wings that symbolize purity and innocence. As Atwood (2017) explains, the inspiration came from mid-Victorian costumes, from an 'Old Dutch' cleanser package from the 1940s and from nuns' habits. The shape of the bonnet prevents women to see and to be seen, transforming them from individuals to objects, without a name and without a face.

Aunts are middle-aged barren women and Gilead sympathizers who have a certain amount of authority compared to other women (they are permitted to read for example). With a masculine and military style, their main mission is to re-educate and train handmaids, to whom they don't doubt to punish if necessary. Aunts such as Lydia wear brown clothes, the color of military uniforms of World War I and some accessories such as a military hat and a Gilead Republic pin.

In the Republic of Gilead, we can also find Marthas, mature women who cannot bear children but who can raise other people's, and are domestic servants in charge of house maintenance, cleaning and meals. They wear dull green smocks similar to a surgeon's gown, a long and concealing dress with a bib apron over it. As a symbol of their insignificance, other women in Gilead called Econowives wear grey costumes. Married to men from a lower social class, they are expected to perform all the duties of a good wife: satisfying their husbands, giving them companionship and bearing their children. Grey is also the color of socially unaccepted women from the Republic of Gilead, who are punished to work in the polluted colonies to finally die. Called Unwomen, among them we find rebels against the system, sterile women, widows, lesbians, feminists, nuns, Jezebels past their prime but also handmaids who do not bear a child during their three two-year assignments. 


\section{Laura Cortés-Selva and Susana Martínez-Guillem}

Lastly, girls from the Republic of Gilead wear pink costumes as a symbol of the pre-menstruation stage and purity. Until they reach that stage, they are trained under strict surveillance to learn how to accomplish their main role as a mother-woman. This is another important issue of Atwood's ustopia inasmuch as Martínez-Moreno (2008, p. 25) states, during the World War II, fascist regimes made efforts to combine the idea of woman-mother with the support of the Catholic Church, which celebrated the symbolic meaning of the Virgin Mary.

Throughout the TV series, the costumes work as a uniform to classify people, and slightly vary on special occasions such as funerals. Nevertheless, one occasion in Gilead stands out when the costume transforms radically: in Jezebel, the brothel. Only for commanders' special needs, it is an example of the double standard that prevails in these totalitarian regimes: rules are imposed for everybody - especially women - but with exceptions - men from the ruling class, commanders. For that reason, sex, which is only permitted for procreation, is not forbidden for men such as Mr. Waterford who chooses a special costume for his handmaid called Offred, quite opposite to Gilead's rules: a short, tight and bright dress that, together with her loose hair, creates a perfect set for having pleasant sexual relations with a woman of his property. Women commodification in these scenes is even more notorious.

\section{Art direction and cinematography}

The Handmaid's Tale cinematography is characterized by the presence of shots of shapes ranging from close-ups, focused on main characters and placing the audience quite close to the characters' feelings and thoughts, and wide shots that describe the main locations (architecture) of the TV series and the characters' staging. Among them we can find outdoor areas, open spaces where rituals and ceremonies are unfolded and where buildings such as the new Rachel and Leah Center (also known as the Red Center) stands out due to its architectonic style and symbols that echo totalitarian regimes.

In the characters' staging, movements and figures in Gilead's ceremonies are framed by overhead shots with quadrangular and symmetrical compositions, but also with circular shapes in allusion to feminine symbolism. As in a military parade, uniformed women placed in rows of two rhythmically occupy their places in ceremonies such as Particicution, a specific type of execution conducted by handmaids who are obliged to participate. It involves the assassination of men accused of crimes such as rape.

Light, as a potential signifier in every movie, acquires extreme and violent characteristics according to the storytelling in this TV series. In indoor locations (mainly the commander's houses where handmaids are confined) light comes almost exclusively through the windows, creating a chiaroscuro where darkness shapes silhouettes and shadows. As a symbol of character isolation and loneliness, lighting grows even darker in season 2 and the 
number of high overhead shots seems to intensify. In addition, the use of shallow focus continues placing the audience close to the characters' minds and emotions. On the opposite side, light overfills outdoor locations where handmaids can move around the city under strict surveillance.

\section{Societal response: citizen-led forms of visual communication}

Since President Trump's election, there has been a massive women mobilization independently from the television series. It started with the Women's March (\#Womenmarch) in Washington on January 21, 2017, the first protest against Donald Trump politics and misogyny. Afterward, The Handmaid's Tale's first season premiered on April 2017 and mostly women but also some men started attending marches and protests, first in different states of the United States, and afterward, around the world. What started in Texas in 2017 as a marketing strategy from Hulu to promote The Handmaid's Tale's premiere, inspired activists around the world such as NARAL Pro-Choice (a movement supporting abortion-rights for women). Since then, and with the help of social media, many reproductive rights activists in the United States and around the world have used some of the visual symbols from the TV series to protest against abortion restrictions in Washington, DC; Alabama and Georgia; Northern Ireland, Buenos Aires and Queensland. Visual codes from The Handmaid's Tale are also used to protest against women sexual harassment at work (linked to the \#metoo movement and the cinema industry): against Brett Kavanaugh's confirmation as Supreme Court Judge and Vice-president Mike Pence's visit to Philadelphia. This phenomenon has also spread around the world to protest against Trump's visits and policies against feminism, climate change or immigration, as in Poland or the United Kingdom.

These women are not only wearing the Handmaid's uniform, but are also staging in a similar way as in the TV series: walking in rows of two and with heads down in a silent and submissive attitude. Some of them are also carrying banners with texts from the television series such as Nolite te bastardes carborundorum (Don't let the bastards wear you down), which was also adapted by Hillary Clinton in her speech at the 100th anniversary of Parenthood as follows: We can never let them grind us down.

\section{Conclusions}

Atwood's ustopian message is developed under a system of visual and textual codes present throughout the TV series' mise en scene. Color is used as a code to primarily classify women according to social class and fertility. Muted colors without saturation (grays) are used for 'useless' women (rebels, lesbians, econowives, Marthas and unwomen) and bright colors for the most important women in Gilead, mainly Handmaids (red) and commander's wives (blue), but also Aunts (brown) as a military class, 
intermediates between the first and the second women classes. Lighting in the TV series is used to intensify emotions in the characters' staging ranging from light to dark as a symbol of the darkness of Gilead's ideology.

Through shallow focus and close-up shots, The Handmaid's Tale places audiences close to the characters' emotions. On the opposite side, wide shots describe the character's staging in rows of two, quadrangular and circular shapes, as well as the totalitarian regime's architectural style.

Some women in the United States and around the world have adopted some of the visual and textual codes developed in this Gileadverse. Handmaids' red and white uniforms, mise en stage (head down and movement in rows of two), silence and texts such as Nolite te bastardes carborundorum are used as symbols of struggle to obtain, but also to maintain, women rights won over the past centuries. In real-life demonstrations, streets and public buildings representative of Justice change to Gilead buildings and streets, where activists stand outside or even inside to protest, as well as city streets.

This handmaid's movement that started on the streets of Texas the first year of Trump's term spread first in different states of North America and afterward, around the world via social media. Pictures from handmaid's activists published in newspapers and in social media have provoked an emotional impact and a call for action, inspiring an international feminist movement by turning cosplay into a political act. What started as a response to some of Trump's policies against abortion laws has become an anti-Trump movement that includes issues such as feminism, gender discrimination and sexual harassment, but also climate change and immigration policies that collectively shapes and asks for a cultural change.

Women's control through their bodies (sexuality and reproduction) and psychology (submission) has been an issue of every repressive regime in the world. Misogyny, fear and hate towards women are dangerous and underestimated components of extremism and far-right white men supremacy. With any cultural change there is a push and a pushback and, in this context, there seems to be a rise of extremists who are expressing scorn for democratic institutions. In this sense, Atwood's message of warning urges women to resist and fight against these extreme and hateful speeches through action and voice.

\section{Acknowledgments}

This research has been possible thanks to the European Regional Development Fund support.

\section{References}

Abulof, U. (2015). Normative concepts analysis. Unpacking the language of legitimation. International Journal of Social Research Methodology, 18(1), pp. 18-89. doi: 10.1080/13645579.2013.861656 
Atwood, M. (1985). The handmaid's tale. London: Vintage.

Atwood, M. (2017, 10th March). Margaret Atwood on what The Handmaid's Tale means in the age of Trump. The New York Times. Available at https://nyti. ms/2QZ7WCk

Baccolini, R. \& Moylan, T. (2003). Introduction dystopia and histories. In T. Moylan \& R. Baccolini (Eds.), Dark horizons (pp. 14-41). New York: Routledge.

Blankenship, C. M. (2020). President, wrestler, spectacle: An examination of Donald Trump's firing tweets and The Celebrity Appresident as response to Trump's media landscape. Journal of Communication Inquiry, 44(2), pp. 117-138.

Borba, R., Hall, K. \& Miramoto, M. (2020, 30th January). Discourse and the geopolitics of gender: Feminist refusal meets enmity. IGALA Blog: Language, Gender, and Sexuality. Available at https://cutt.ly/wkpa2Iq

Bourdieu, P. (2000). La dominación masculina. Barcelona: Anagrama.

Butterworth, L. (2017, 12th December). Costume designer Ane Crabtree on creating The Handmaid's Tale's ghastly, gorgeous dystopia. Jezebel. Available at https://cutt.ly/sfWACrL

Cambra-Badii, I., Mastandrea, P. B. \& Paragis M. P. (2018). El mandato del nacimiento. Cuestiones bioéticas y biopolíticas en la serie El cuento de la criada. Revista de medicina y cine, 14(3), pp. 181-191.

Cortés-Selva, L. (2018). Tres décadas de estilo visual: evolución de la fotografía cinematográfica entre 1980-2010. Barcelona: UOC Press.

Cortés-Selva, L. (2020). Women and cinematography. In K. Ross (Ed.). The international encyclopedia of gender, media and communication. New York: John Wiley and Sons, Inc.

Crespo-Pereira, V., Fernández-Holgado, J. A. \& Márquez- Domínguez, C. (2018). La distopía como tema emergente en la narrativa del siglo XXI. Estudio de caso: El cuento de la criada. Revista Ibérica de Sistemas e Tecnologías de Informaçäo, 16(11), pp. 108-121.

Filardo-Lamas, L. \& Boyd, M. S. (2017). Critical Discourse Analysis and Politics. In J. Flowerdew \& J. E. Richardson (Eds.), The Routledge handbook of critical discourse studies (pp. 312-327). London: Routledge.

Frøslee Ibsen, M. (2018). The populist conjuncture: Legitimation crisis in the age of globalized capitalism. Political Studies, 67(3), pp. 795-811. doi: $10.1177 / 0032321718810311$

Giménez, E. \& Schwarz, N. (2016). The visual construction of 'the people' and 'proximity to the people' on the online platforms of the National Front and Swiss People Party. Österreichische Zeitschrift für Soziologie, 41(2), pp. 213-242.

Gounari, P. (2018). Authoritarianism, discourse and social media: Trump as the 'AmericanAgitator'. In J. Morelock (Ed.), Critical theory and authoritarian populism (pp. 207-227). London: University of Westminster Press.

Habermas, J. (1988). Legitimation crisis. Cambridge: Polity Press.

Hanlon-Rubio, J. (2003). A Christian theology of the family. Mahwah: Paulist Press

Heimbrod, L. (2020, 13th January). All the times Donald Trump shockingly joked about 'dating' daughter Ivanka Trump. International Business Times. Available at https://rb.gy/78jlit

Hendershot, H. (2018). The Handmaid's Tale as Ustopian allegory: Stars and stripes forever, baby. Film Quarterly, 72(1), pp. 13-25. Available at https://cutt. ly/5kps $5 \mathrm{rI}$ 
Howell, A. (2019). Breaking silence, bearing witness, and voicing defiance: The resistant female voice in the transmedia storyworld of The Handmaid's Tale. Continuum, 33(2), pp. 216-229. doi: 10.1080/10304312.2019.1569392

Kitson, M. (2019, 1st March). Spanish ultraconservative group launches bus campaign against 'feminazis'. El País. Available at https://rb.gy/guouhd

Krzyżanowski, M. (2018). Discursive shifts in ethno-nationalist politics: On politicization and mediatization of the "refugee crisis" in Poland. Journal of Immigrant \& Refugee Studies, 16(1-2), pp. 76-96. doi: 10.1080/15562948.2017.1317897

Lakoff, R. (2017). The hollow man: Donald Trump, populism, and post-truth politics. Journal of Language \& Politics, 16(4), pp. 595-606.

Lilleker, D. G., Veneti, A. \& Jackson, D. (2019). Introduction: Visual political communication. In A. Veneti, D. Jackson \& D. G. Lilleker (Eds.), Visual political communication (pp. 1-13). Switzerland: Palgrave MacMillan.

Martínez-Guillem, S. (2019). Performing (in) places, moralizing (through) spaces. Podemos' parliamentary performances. Journal of Language \& Politics, 18(6), pp. $803-825$.

Martínez-Guillem, S. \& Barnes, C. C. (2018). Am I a good [white] mother? Mad Men, bad mothers, and post(racial)feminism. Critical Studies in Media Communication, 35(3), pp. 286-299.

Martínez-Moreno, R. M. (2008). Construcción cultural y constitución social: las técnicas modeladoras de la silueta femenina desde el corsé a la cirugía. In A. Téllez-Infantes \& J. E. Martínez-Guirao (Eds.), Investigaciones antropológicas sobre género: de miradas y enfoques (pp. 11-41). Elche: Universidad Miguel Hernández

Matthews, A. (2018). Gender, ontology, and the power of the patriarchy: A postmodern feminist analysis of octavia Butler's WildSeed and Margaret Atwood's The Handmaid's Tale. Women's Studies, 47(6), pp. 637-656. doi: 10.1080/ 00497878.2018.1492403

Mbembe, A. (2017). Politicas da inimizade. Lisboa: Antígona

Miceli, B. (2018). Religion, gender inequality, and surrogate motherhood in Margaret Atwood's The Handmaid's Tale. CoSMo Comparative Studies in Modernism, 12. doi: 10.13135/2281-6658/2580

Moreno-Trujillo, M. P. (2016). El cuento de la criada, los símbolos y las mujeres en la narración distópica. Escritos 24(52), pp. 185-211. Available at https://cutt.ly/ DkpdWUV

Scammell, M. (2016). Designer politics: How elections are won. London: Springer. Van Leeuwen, T. (2008). Discourse and practice: New tools for critical discourse analysis. Oxford: University Press. doi: 10.1093/acprof: oso/9780195323306.001.0001

Vineyard, J. (2017, 14th June). Margaret Atwood annotates season 1 of The Handmaid's Tale. The New York Times. Available at https://nyti.ms/2uqvyYH

Wahl-Jorgensen, K. (2019). Emotion, media and politics. New York: John Wiley.

Way, L. C. (2016). Protest music, populism, politics and authenticity. Journal of Language and Politics, 15(4), pp. 422-446.

Wodak, R. (2015). The politics of fear: What far-right discourses really mean. London: Sage.

Wodak, R. \& Forchtner, B. (2018). Introducing the language-politics nexus. In R. Wodak \& B. Forchtner. (Eds.), Routledge handbook of language and politics (pp. 1-14). London: Routledge. 
Wodak, R., KrosraviNik, M. \& Mral, B. (2013). Right wing populism in Europe. Politics and discourse. London: Bloomsbury.

Wodak, R. \& Kryzanowski, M. (2017). Right-wing populism in Europe \& USA: Contesting politics \& discourse beyond 'Orbanism' and 'Trumpism'. Journal of Language and Politics, 16(4), pp. 1-14. doi: 10.1075/jlp.17042.krz

Wright, C. \& Jagger, G. (1999). Changing family values. New York: Routledge. 


\title{
7 Discursive construction of affective polarization in Brexit Britain
}

\author{
Opinion-based identities and \\ out-group differentiation
}

\author{
Monika Brusenbauch Meislová
}

\section{Introduction}

This chapter builds on emerging research that suggests that attitudes towards Brexit cut across traditional party lines are very strong and underpinned by emotion and identity. In fact, Leave versus Remain affiliations now seem a more prominent source of identity than traditional party identification: "There is now strong evidence that Brexit-based identity polarisation is a key trend in the UK - and, by a number of measures, is as strong or stronger than political party consolidation" (Duffy et al., 2019, p. 16; similarly also Murray, Plagnola, \& Corra, 2017). For instance, a 2018 survey demonstrated that while only $9 \%$ of the British population had a very strong partisan identity, $44 \%$ identified as having a very strong Brexit identity, with this identification being strong on both sides of the Leave-Remain argument (Curtice, 2018). As such, Brexit has been creating a new source of political identification (apparently, intrinsically highly rewarding) which is capable of reshaping political divisions and reinvigorating political participation.

These Brexit identities are characterized by affective polarization which is, at a basic level, defined as "an emotional attachment to in-group partisans and hostility towards out-group partisans" (Hobolt, Leeper, \& Tilley, 2018, p. 4; also Duffy et al., 2019, p. 16). This is more than just mere ideological polarization over political matters: "Antipathy towards partisan opponents has escalated substantially among citizens. This has meant that increased in-party favoritism has been matched by greater negative stereotyping and out-group discrimination" (Hobolt, Leeper, \& Tilley, 2018, p. 4). As Hobolt, Leeper and Tilley (2018) argue, the emerging affective polarization around Brexit identities compromises "people's willingness to talk across the political divide" (p. 73).

Essentially, this affective polarization manifests itself in two different ways: (1) differentiation, whereby "one side views the other side's traits as negative and its own traits as positive, or one side reduces interaction with the other side" (Duffy et al., 2019, p. 8), and (2) perception bias, when "people experience the same realities in completely different ways, depending on

DOI: $10.4324 / 9781003109891-9$ 
the Brexit identities with which they associate" (Duffy et al., 2019, p. 8). It is the former aspect - differentiation - that is the primary focus of this chapter.

Substantially, this differentiation discursively reveals itself in different modes of de-legitimation of the out-group(s). With this chapter aligning itself with the definition of hate speech as "forms of expression that are motivated by, demonstrate or encourage hostility towards a group - or a person because of their membership of that group" (OSCE, 2009, p. 17), these various dissimilation strategies essentially qualify as examples of hate speech.

Against this background, this chapter deals with the pertinent question of how Leavers and Remainers, as opinion-based groups, communicate, share and exchange their perceptions, cognitions and emotions in regard to out-groups. More specifically, its aim is to investigate which topics, discursive strategies and linguistic devices have been employed by British politicians to construct Leave and Remain identities in a sense of out-group antagonism(s) in contra-distinction to the given in-group.

Drawing on the discourse-historical approach (DHA) to critical discourse studies, this chapter is located within the qualitative research tradition, belonging to the domain of constructivist and critical research and following the interpretive paradigm. By looking at how Leavers and Remainers discursively construct the "other", the inquiry provides an empirical example of (a part of) collective identity formation and meaning-making in the process of Brexit, and adds to the literature on growing affective polarization along Brexit lines in the UK. So far, surprisingly little work has been done in explaining how these Brexit identities are constructed in public discourse, so it is my hope that this study will encourage further research and discussion of this fascinating phenomenon.

This chapter is structured as follows. The first two sections put forward a theoretical and methodological framework for the analysis. The third section then provides a general overview of out-group discourse in the Brexit debate and sets the scene for the subsequent two-level empirical analysis: (1) thematic and (2) an in-depth. The conclusion concisely summarizes the key argument and contextualizes the empirical findings.

\section{Theoretical considerations}

The conceptual and theoretical framework of the chapter is that of Critical Discourse Analysis, and, in particular, of the DHA (Wodak, 2004; Reisigl \& Wodak, 2001; Titscher et al., 1998). Critical Discourse Analysis perceives both written and spoken discourses as "a form of social practice" (Fairclough \& Wodak, 1997, p. 258). The governing assumption underscoring this chapter is thus a dialectical relationship between certain discursive situations on the one hand and the institutions and social structures in which they are embedded on the other. Put differently, situational, institutional and social contexts affect and constitute discourses, while discourses simultaneously affect and constitute social and political reality (De Cilla, Reisigl, \& Wodak, 1999, p. 157). In other words, following Fairclough's (1992) 
assertion that "discourse is a practice not just of representing the world, but signifying the world, constituting and constructing the world in meaning" (p. 64), this chapter does not deal only with representations and discourses about Brexit identity, but Brexit identity is understood here as an "internalized structuring impetus which more or less strongly influences social practices" (De Cilla, Reisigl, \& Wodak, 1999, p. 156). As such, I base my research on the assumption that Brexit identities conceived as specific forms of social identities, are - just like national identities - "discursively, by means of language and other semiotic systems, produced, reproduced, transformed and destructed" (De Cilla, Reisigl, \& Wodak, 1999, p. 152).

In line with Wendy Brown's (1998) argument that collective identity is often developed as a result of external forces and the collective's response to them, Brexit identities were stirred and created by a huge political shift. In fact, the Brexit result itself is, after all, understood as an example of identity politics (Kuhn, 2019). Both Leavers and Remainers have been going through a process of producing shared meanings to construct collective identity (Polletta \& Jasper, 2001; Schwalbe \& Mason-Schrock, 1996). These meanings provide the basis on which groups can (and do) define boundaries and a sense of belonging, binding individuals together and providing means of orientation in post-referendum Britain (and the world).

Against this background, this chapter holds that the construction of Brexit identity, just like other opinion-based group identities, is inter alia facilitated by constructing and framing an out-group. Identities are "constructed through, not outside, difference", Hall and Du Gay (1996) write, and it is only "through the relation to the Other, the relation to what it is not that the positive meaning of any term - and thus its 'identity' - can be constructed" (pp. 4-5).

\section{Methodological considerations}

The corpus analyzed in this study consists of a collection of speeches by prominent Leave and Remain politicians. As a "coherent stream of spoken language that is prepared for delivery by a speaker to an audience for a purpose on a political occasion" (Charteris-Black, 2014, p. xiii), political speeches belong to a discursive genre strategically aimed at "influencing others, using rhetoric to persuade, excite, and claim leadership" (Klebanov et al., 2008, p. 448). Hence, they represent highly performative texts, drawing on genre conventions and making extensive use of metaphor (Fairclough, 2000).

Due to space constraints and the need to strike a balance between breadth and depth of analysis, this chapter focuses on analysis of ten speeches by prominent Leave and Remain politicians: Nigel Farage and Boris Johnson on the Leave side, and Tim Farron and Vince Cable on the Remain side. All the speeches deal with Brexit and have been selected on a number of criteria (including the title of the speech; its subject outlined in the introductory sentences; the occasion on which it was delivered; the nature of the intended audience) in order to provide a balanced sample. The following table sums up the key features of the corpus. 


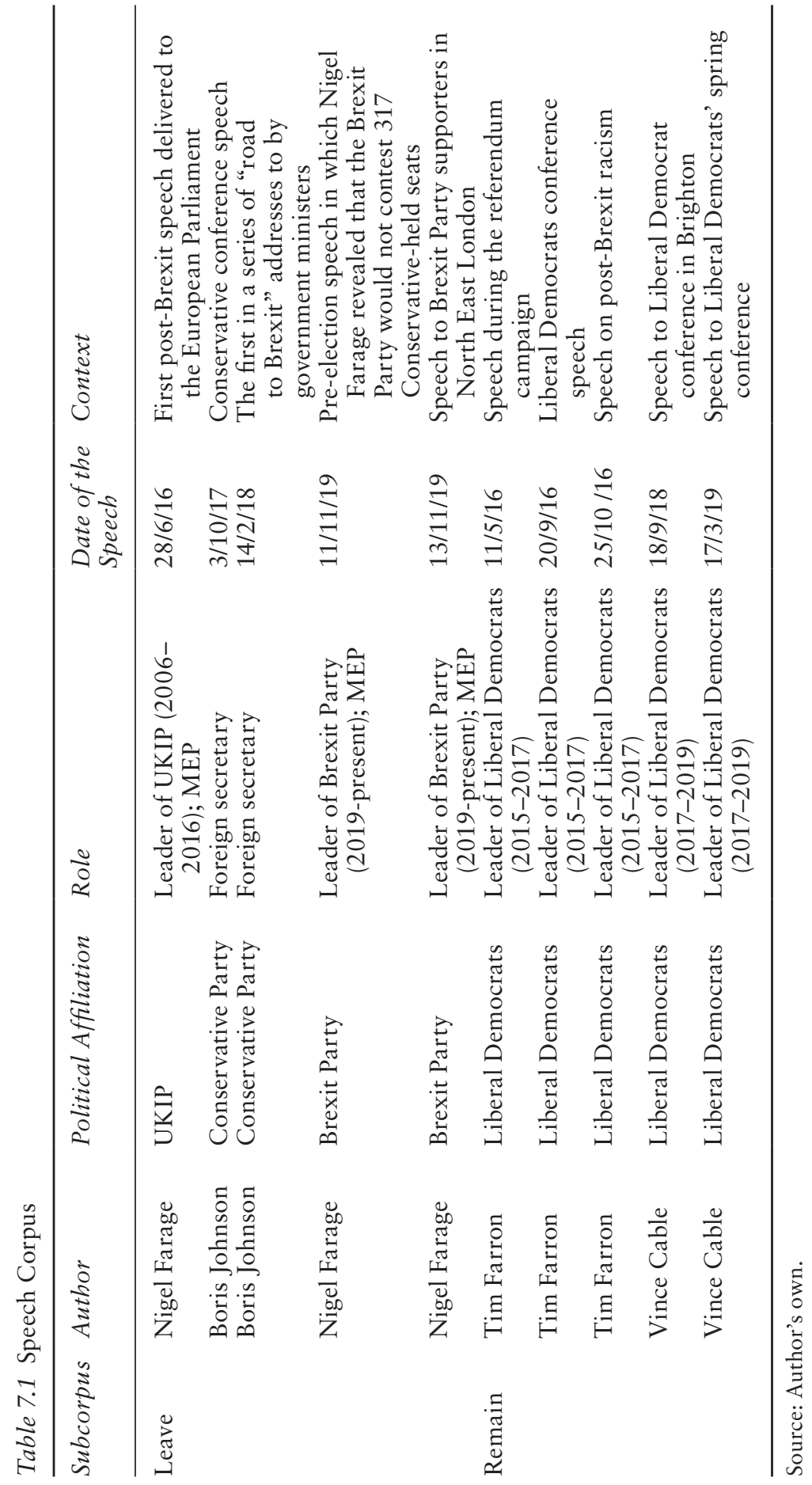


In accordance with DHA, guided by Krzyzanowski's $(2010,2018)$ approach, the analytical part of this chapter will follow the two-level pattern: (1) a thematic analysis and (2) an in-depth analysis (for application of this approach see, for instance, Zappettini [2019]). The thematic analysis will focus on easily identifiable dominant narratives that characterize the portrayal of out-groups and dissect the core themes which form the structure of the out-group discourse (Krzyzanowski, 2010, pp. 81-83; Krzyzanowski, 2018, p. 83). In the words of Van Dijk (2001), constituent topics "conceptually, summarize the text, and specify its most important information. In theoretical terms such topics can be described as semantic macro-propositions, that is, as propositions that are derived from sequences of propositions in the text" (p. 83). They will be identified by means of indicative analysis, i.e. via "decoding the meaning of text passages - usually taking place via several thorough readings - and then ordering them into lists of key themes and sub-themes" (Krzyzanowski, 2010, p. 81), with the emphasis being on discourse topics (Van Dijk, 2001), not text topics. The second level of the analysis will investigate the structure of the discourse underlying the said contents and focus on the linguistic forms involved in the construction of out-groups (Krzyzanowski, 2010, pp. 83-89; Krzyzanowski, 2018, p. 83). In other words, it will pay particular attention to the immediate linguistic devices (mostly in the sense of lexical units and syntactical means) that enable the hostile communicative acts and sentiments that underlie various assertions of out-group differentiation. This will allow us to look also at the micro-practices that Leavers and Remainers engage in to construct the other and give collective identity categories certain meaning(s).

\section{Out-groups and Brexit polarization}

Both Remainers and Leavers display a clear tendency towards dichotomization - a tendency in which they categorize the world into rigid and simplistic dichotomies of us versus them. As noted in the above discussion, the animosity across Brexit opinion-based groups in fact cross-cuts long-standing partisan divisions (Hobolt, Leeper, \& Tilley, 2018). Essentially, both Remainers and Leavers constructively and reproductively employ the strategy of presupposing inter-group differences and heavily engage in out-group denigration in the sense of hate-based offending of the other. In the words of Duffy et al. (2019): "In the period after the EU referendum, signs of this differentiation - where one group stereotypes the other and treats them with bias - surfaced in the UK, built around Leave and Remain identities" (p. 57) (similarly also Hobolt, Leeper, \& Tilley, 2018).

As further mapped out below, such generation of negative characteristics about the out-groups serves a number of difference purposes. Not only does it legitimize the in-group's antagonism against the out-group per se, 
but it also validates the in-group's own actions. At the same time, while producing opportunities for social validation of ideas and shared cognition, it also provides conceptual bases around which the Remain/Leave collectives can cohere. Last but not least, the dissimilation strategies also help create group-internal homogenization of the out-groups and, in so doing, strengthen distinct shared experiences and build internal consensus around the in-group's meaning and identity.

As the careful reading of the speeches reveals, most of the out-group differentiations in the Brexit debate are relational, rather than non-relational, meaning that very often, to achieve positive in-group evaluation, the speakers apply the repeated comparative to indicate the relationship of comparison. Indeed, the out-group is often presented, commonly in terms of dichotomized values, as a diametric opposite to the in-group.

Importantly, in the Brexit context, discursive constructions of out-groups as the other are closely accompanied by in-group favoritism. Put another way, out-group denigration necessarily goes hand in hand with in-group superlatives. Indeed, the dissimilation strategy can be also understood as a strategy of emphasizing in-group singularity. As De Cilla, Reisigl, and Wodak (1999) argue, "the relationship of uniqueness is nothing but a relationship of difference to all other elements involved in the comparison" (p. 162). Both sides of the Brexit arguments thus switch with equal facility between the discursive strategies of dissimilation (aiming at the construction of inter-group differences) and discursive strategies of assimilation (aiming at the construction of intra-group sameness) (De Cilla, Reisigl, \& Wodak, 1999). Yet, however interesting, an analysis of this in-group favoritism unfortunately falls beyond the remit of this study.

Before turning to the detailed two-level analysis, let us dwell briefly on how the referent out-group(s) are generally named and referred to linguistically in the Brexit context. As we will see, the dissimilation will vary in its degree of abstraction/attribution specificity, with both groups changing the level of vagueness-specificity very quickly.

Both Remainers and Leavers constantly categorize the other into various groups. For Remainers, the out-group is ordinarily referred to as the Conservatives (or the Tories, rather than the Conservative Party), the Labour Party (the Labour), UKIP (or UKippers), occasionally more specifically as the Conservative Brexit Government (a Conservative government); the Corbyn crowd; or Labour people. Leavers most often position the Conservative Party, the Labour Party (Labour), Liberal Democrats (the Lib Dems, or pejoratively fanatics in the Liberal Democrats) as the others. Both groups also accentuate certain people ad hominem: in the case of Remainers, it is mostly Jeremy Corbyn and David Cameron; in the case of Leavers, it is Theresa May (Mrs May) and Boris (rather than Boris Johnson). Sometimes, the level of vagueness increases, with the Remainers calling the out-group governments, politicians, English nationalists (anti-European nationalists). Leavers seem to use a larger variety of expressions, including, for instance, 


\section{Monika Brusenbauch Meislová}

the multinationals, the merchant banks, the big politics, the establishment or calculating forces of darkness. On several occasions, however, they opt for vaguer expressions, such as, for instance, some people. Notably, the Leavers often refer to Remainers (both Nigel Farage and Boris Johnson) or Remainiacs (especially Nigel Farage) as the other, while this tendency is much less obvious the other way around. Unlike the Leavers, the Remainers also more often add the "Brexit" signifier (as in Brexit economists).

As we can see, the speakers do not presuppose out-group heterogeneity, but rather out-group sameness. In other words, the political figures under scrutiny here do not distinguish, for instance, between Labour Remainers and Labour Leavers - for them, the Labour as a whole is an out-group. This said, the mentality traits attributed to the out-group include heterogeneous stereotypical qualities such as xenophobic, absurd, uncaring, reckless in the Remain subcorpus and fanatic, abject, in denial, angry and upset in the Leave subcorpus. It follows that both camps discursively create a homogeneous out-group with a shared mentality and convey the message that the above-mentioned traits of absurdity, carelessness, angriness and others characterize each single member of the imagined out-group equally. Yet, the previous research has suggested that a homogeneous out-group is perceived as more threatening than a heterogeneous one (Corneille et al., 2001).

\section{Thematic analysis: core topics}

\section{Narratives common to both subcorpora}

In both subcorpora, the analysis of narratives emphasizing the "othering" of the out-group reveals five semantic macro-areas related to the discursive construction of the out-group in the Brexit discourse: (1) narrative of a political failure; (2) narrative of a damage done; (3) narrative of incompetence; (4) narrative of a threat; (5) narrative of a betrayal. While reporting these narratives separately for reasons of analytical clarity, it is worth noting that, in reality, these macro-areas do not function completely independently rhetorically, and instead are often closely interrelated. In what follows, the chapter will explore each of them, while providing textual examples of each case.

\section{Narrative of political failure}

The narrative of a political failure caused exclusively by the out-group functions in a number of ways. As we can see in excerpts (1) and (2), ex negativo, it serves to portray the out-group as a group that has failed. At the same time, both groups pre-empt condemnation of their own Brexit-related failures by blaming others. Lastly, it also helps construct and negotiate a collective political experience. While the main topics include political failings (in a rather general sense, as opposed to the narrative of the damage done) in both cases, the Remain side accentuates the selfishness of the 
out-group, while Leavers focus on the disrespect for the referendum result. These aspects may be illustrated by the following examples (1) and (2):

(1) David Cameron's handling of our relationship with Europe is a master class in selfish, shallow short-termism. Party before country at every turn (Tim Farron).

(2) [...] by the Labour Party, who have completely broken their manifesto pledge in 2017 to respect the result of the referendum (Nigel Farage).

\section{Narrative of the damage done}

Closely related to the narrative of failure is the narrative of the damage done. As examples (3) and (4) illustrate, the out-group is constructed as having taken a position that has caused much specific damage and harm - not only to the in-group but also to the country as a whole. This narrative functions primarily to denote past inappropriate out-group action (mostly political but also economic). At the same time, by emphasizing emotional ties to the country and national pride, it also serves to activate national identity. Here, the Brexit-based identity thus becomes closely linked to the national identity. The following main topics that relate to the construction of the narrative of the damage done have been identified: on the side of Remainers it is especially fragmentation, discontinuity, new divisions, new fault lines and decline; on the side of the Leavers it is mostly crisis and protraction.

(3) David Cameron risked our future, and he lost. And while he waltzes off to riches and retirement, our country is plunged into economic uncertainty, insecurity and irrelevance on the world stage [...] The Tories took the gamble, but Britain will pay the price. What an absolute disgrace (Tim Farron).

(4) And I think, exhausted Brexiteers - Brexhaustion I think is the phrase - said "well, if we've got a good deal, isn't that just fantastic?" I have to say, I was very, very unhappy with this new EU Treaty with the attached Political Declaration [...] And I drew the conclusion that it simply wasn't Brexit. There were many, many concerns (Nigel Farage).

\section{Narrative of incompetence}

The arguments of incompetence, and thereby of inferiority, conceptualize the out-group as being utterly impotent vis-á-vis various aspects of Brexit and management of its consequences (which are, by definition, extremely broad, complex and varied). At the same time, it carries connotations of the lack of professionalism and malevolence (this especially in Nigel Farage's 
discourse) in the sense of what the out-group is and has been unable to do or fulfil (mostly govern and protect national interests). Hence, much emphasis is put on the contentious and harmful nature of the out-group's untoward policies, views and arguments as well as its necessarily limited capacity to govern capably. On both sides, the key topics include unrealistic aims and plans (or the lack of plans), contradictory policy goals and incoherent promises. The Remain camp also puts emphasis on self-indulgence, ineptitude and inhumanity. This narrative is particularly notable in sections of the speeches in which the communicating individuals develop ideas for shared injunctive norm in terms of the desired change(s) they want to see in their country. Examples of the narrative of incompetence are apparent in excerpts (5) and (6) (Remain subcorpus) and (7) (Leave subcorpus) below.

(5) And to make things worse, this government is so lacking in talent that it employs a Secretary of State for Northern Ireland who makes even Chris Grayling look like a serious figure. [...] Ireland, like Czechoslovakia in pre-war days, is seen as a faraway country of which they know nothing and care less. [...] She has revealed an ugly truth: that peace in Ireland matters less than peace in the Conservative Party (Vince Cable).

(6) There are millions of Conservative voters who are disgusted with the incompetence, the self-indulgence and the inhumanity of this Tory Government but so long as Labour appears to be a nightmare, they will cling to the Tory nurse, for fear of something worse (Vince Cable).

(7) Of all the areas where Corbyn is content to talk this country down, there is none more ludicrous and vacillating than his policy on Brexit. In the customs union one week, out the next, in the single market, out the next. In out, in out (Boris Johnson).

\section{Narrative of threat}

The fourth topical main focus is on threat. The narrative of threat differs from the narrative of incompetence insofar as it is more dangerous. As excerpts (8) through (11) exemplify, unlike the narrative of failure, the narrative of threat focuses on the failures to come. The out-group (and its policies) is portrayed as the source of a Brexit-related threat, as posing a threat not only to the in-group but also to the nation per se - to political, economic and social stability; prosperity; and the general British way of life. Very often we see exaggerated discourses of threat that (especially in Nigel Farage's discourse) do not function on the basis of logic or rationality but instead serve to create panic. The headings found most relevant for the analysis of the construction of the threat narrative were risk, reckless and divisive. While the Remainers work with the threats especially in a sense of reducing workers' rights, environmental protections and financial 
regulations on the banks (strong especially in Tim Farron's discourse), Leavers focus mostly on the threat of a second referendum which, according to them, would be "disastrous for trust in our entire democratic system, disastrous for business, for investment into our country" (Nigel Farage) and would "frustrate the will of the people" (Boris Johnson).

(8) We keep being told, not least by the Chancellor, that once Brexit is agreed and delivered, the fog of uncertainty will lift and there will be a surge of renewed confidence in the UK [...] But this is a triumph of political fantasy over economic reality. Any well-run business can see that chronic uncertainty would follow any endorsement of the Withdrawal Agreement (Vince Cable).

(9) Conservative Brexit Government that, without us to restrain them, are showing their true colours: reckless, divisive and uncaring; prepared to risk our future prosperity for their own short-term gain (Tim Farron).

(10) It would be disastrous. And in leaving Britain in this limbo locked in the orbit of the EU but unable to take back control. Unable to do proper free trade deals. Labour would inflict a national humiliation on a par with going cap in hand to the IMF (Boris Johnson).

(11) [...] stopping the fanatics in the Liberal Democrats who'd sign us up to everything, wouldn't they, the United States of Europe, European army, you name it, I mean they even want to revoke the result of the referendum (Nigel Farage).

\section{Narrative of betrayal}

Another semantic macro-area applied by the officeholders in their public statements on Brexit is the narrative of betrayal. As demonstrated by examples (12) and (13), central to this construction, heavily underpinned by emotions (more than the narrative of political failure), is the act of betrayal (or actions that will elicit feelings of betrayal). Here, the blame is laid at the feet of those who argued for Leave (Remain subcorpus), and those who argued for Leave and haven't been able to carry out the referendum result properly (Leave subcorpus). The main topics here are treachery (Brexit betrayal), sabotage and loyalty.

(12) The Corbyn crowd like to talk in terms of loyalty and betrayal. Well, there is no surer way to betray the people you represent than to let your opponents win (Tim Farron).

(13) Three and a half years of delay; three and a half years of a Remain Parliament; a total sellout of Brexit from Mrs May and from the 
Labour Party a complete betrayal of five million of their own voters who voted Leave in that referendum, and they promised they would respect that vote (Nigel Farage).

\section{Exclusive narratives}

Apart from the four semantic macro-areas common to both sides intimidated above, there are also two more macro-areas deployed by either only Remainers or Leavers: (6) narrative of defeat (employed by the Leavers) and (7) narrative of victimizer (employed by the Remainers).

\section{Narrative of defeat}

The narrative of defeat creates an impression of the out-group as defeated by the ordinary people. It functions mainly to accentuate the change in political opportunities, thereby making the context favorable towards future action and effecting further (re)mobilization efforts of the in-group (especially in a sense of various pro-Brexit marches and rallies). The main topics include the strength of the ordinary people, the oppression, rejection and giving back. Example (14) illustrates this narrative rather well.

(14) Because what the little people did, what the ordinary people didwhat the people who'd been oppressed over the last few years who'd seen their living standards go down did - was they rejected the multinationals, they rejected the merchant banks, they rejected big politics and they said actually, we want our country back, we want our fishing waters back, we want our borders back (Nigel Farage).

\section{Narrative of victimizer}

Constituting a form of repeated out-group discourse on the side of the Remainers (but not Leavers) is a narrative of victimizer. As in excerpt (15), Remainers background the idea that the out-group is a victimizer - someone who has inflicted deprivation on the in-group. The main topic here is that of refusal (to share, to work together).

(15) But I couldn't work with Jeremy Corbyn, because Jeremy Corbyn would never work with me. I wanted to work with him during the referendum campaign, but he wouldn't share a platform (Tim Farron).

\section{In-depth analysis: linguistic means and forms of realization}

The analysis that follows illustrates at least some of the most prominent linguistic means and forms of realization employed to construct the negative out-group presentation. 
Importantly, the functional means of othering are marked by an us-them person deixis. Indeed, a key expression of difference is through the use of the exclusive personal "they/them" pronoun (including all the corresponding possessive pronouns). Its use is convenient, as it replaces the various differences in political beliefs, class, education, age, etc., with a simple "them". This "them" has a number of different referents, depending on the context, but it usually and unsurprisingly refers to the group collective of the "Remainers" in the Leave subcorpus and Leavers in the Remain subcorpus.

An important means of out-group exclusion in the context of Brexit is through metonymies which enable the speakers to create the semblance of homogeneity, gloss over differences among individuals, keep them in the semantic background and treat them uniformly and undifferentiatedly as non-individuals (Reisigl \& Wodak, 2001, p. 56). In so doing, both camps realize the negative other-presentation through the referential strategy known as synecdochization, making use of both particularizing synecdoche (pars pro toto; a part standing for the whole) and generalizing synecdoche (totum pro parte, the whole standing for a part). It is especially the particularizing synecdoche (such as, for instance, the Remainer, less frequently the Leaver) that provides the speaker with a means of "stereotypical generalisation and essentialisation that refer in a levelling manner to a whole group of persons" (Reisigl \& Wodak, 2001, p. 57). More specifically, when referring to the out-group, both camps heavily apply the strategy of politicization via the linguistic means of politonyms. These include the sub-strategies of classification (classonyms such as "the establishment", "the class" and the "ordinary people"), party political alignment (party names [often synecdoches] such as the Tories), organizationalization (political organizationyms such as "the government party") and professionalization (political professionyms such as "the prime minister" (Reisigl \& Wodak, 2001, pp. 48-52).

Furthermore, to express negative affect and convey an image of the out-group as the despised other, both Leavers and Remainers name their opponents debasingly, derogatorily and vituperatively. It is especially the Leave politicians who use single appellative anthroponymic terms such as "Remainiac", which are sufficient enough to perform "the othering act" on their own insofar as these forms of address connotatively convey negative, reproachful, insulting meanings, with no need for any other attributive qualifications.

As already indicated above, among the most frequent prejudiced negative traits and attributive qualifications ascribed to the out-group identified in the Leave subcorpus are fanatic, abject, in denial, angry and upset. The Remainers associate the out-group with heterogeneous mentality traits and stereotypical qualities such as xenophobic, absurd, uncaring, reckless. The Leave campaign (and especially so, Nigel Farage) also refers to the Remainer out-group by using somatonyms (anthroponyms denoting mental deficiencies), as in "fanatics", for instance. 
Often enough, however, both camps refer also to the "silent other", pursuing negative other-presentation without an explicit referent (they). Such naming of the "other" ensures that the out-group remains nameless, with its specificity and any material particulars being completely erased. No less interestingly, it is the Leavers that more frequently address the out-group directly - as in "remember you told us we were leaving by the end of 2020; remember you told us we're not going to have political alignment" (Nigel Farage), or "if you're a Remainer, here's your fear" (Nigel Farage). Notably, both Tim Farron and Vince Cable refer to Cameron's governments (the first of which Liberal Democrats participated in) as governments, thus depicting the out-group as a collective actor that does not include themselves, even though they were part of David Cameron's first, coalition government (2005-2010).

Finally, what is also apparent in both campaigns' discourses is their confident approach and absence of doubt. In what can be termed as a "bald on-record strategy", both sides usually adopted neither hedging or mitigation techniques, nor modality or modifying particles (which generally emphasize the uncertainty and subjectivity of a speaker) in order to present the out-group in any timid way.

\section{Conclusion}

Over the past couple of years, Brexit identity has become a very strong affective differentiator, with the polarization that it generates being rather intense in terms of stereotyping, emotional commitment, prejudice and various evaluative biases. Having adopted the general orientation of the DHA in Critical Discourse Analysis, this chapter has provided an empirical illustration of the multi-faceted processes of collective identity formation and meaning-making in the context of Brexit. The analysis and the examples presented all underscore the importance of context-dependency in the construction of Brexit identities and highlight the central role played by the othering here. In a summary, the analysis shows that a key structuring device in constructing Brexit identity is in-group/out-group dichotomy, with the communicating individuals viewing their perceptions, cognitions and emotions as validated/shared (or not validated/shared) against the out-group.

As shown above, the political discourse of both Leavers and Remainers is continually and abundantly replete with references to the out-groups, which are constructed not in terms of similarities, but differences. With people on both sides of the Leave-Remain divide engaging vigorously in discursive tugs-of-war with each other, the analysis demonstrates their readiness to exclude the others from their in-group as the constructed collective and to debase (and even demonize) them. In both cases, the deployed "us versus them" narratives as well as the various assertions of out-group hate/outrage effectively draw attention to opinion-based group differences, pit one group against another and create inter-group tension. 
The first level of analysis looked at the main themes in the out-group discourse and identified those that are common to both camps as well as those that are unique for each (namely, the narrative of defeat in the Leave subcorpus and the narrative of victimizer in the Remain subcorpus). Taken together, these topics map out a broader story of identity realignments in the UK. An interesting feature that became apparent were the elements of active political participation as a constitutive component of the out-group's identity.

The second level of analysis focused briefly on the linguistic means and forms of realization, looking especially at the key tropes that the speakers frequently rely on to construe the imagined out-group Leaver/Remainer community. By illuminating the core discursive strategies, argumentative schemes and main representations of the other that sustained the de-legitimation of the out-group for both sides of the Brexit debate, the analysis helped to better understand the ways opinion-based groups are imagined and constructed.

Finally, there remains ample potential for further research. The next step in my research is to apply a wider notion of the "political" which focuses not merely on the public discourses of the elites in power but also analyzes other corpora such as media articles, interviews and group discussions. Factoring in other contexts as well, including private (or quasi-private) settings of different degrees of formality, will allow for a fuller and more detailed account of how Brexit identities are being formed in discourse. Moreover, with the Leave and Remain camps being extremely diverse and spanning a large spectrum of political and other expressions, addressing this diversity in out-group discourses is another issue worthy of further reflection. Lastly, it is important to bear in mind that Brexit-based identities, both on the group and individual levels, are dynamic and change over the course of time.

\section{Funding information}

Writing of this chapter was supported by Masaryk University (MUNI/A/1138/2020 Perspectives of European Integration in Context of Global Politics III).

\section{References}

Charteris-Black, J. (2014). Analysing Political Speeches: Rhetoric, Discourse and Metaphor. Basingstoke: Palgrave Macmillan.

Brown, W. (1998). Wounded Attachments: Late Modern Oppositional Political Formations. In J. B. Landes (ed.), Feminism, the Public and the Private (pp. 448-74). New York: Oxford University Press.

Corneille, O., Yzerbyt, V. Y., Rogier, A., \& Buidin, G. (2001). Threat and the Group Attribution Error: When Threat Elicits Judgments of Extremity and Homogeneity. Personality and Social Psychology Bulletin, 27(4), pp. 437-446. doi:10.1177/0146167201274005 


\section{Monika Brusenbauch Meislová}

Curtice, J. (2018). The Emotional Legacy of Brexit: How Britain Has Become a Country of 'Remainers' and 'Leavers'. Available at https://cutt.ly/1ksHfPp

De Cilla, R., Reisigl, M. \& Wodak, R. (1999). The Discursive Construction of National Identities. Discourse \& Society, 10(2), pp. 149-173.

Duffy, B., Hewlett, K., McCrae, J. \& Hall, J. (2019). Divided Britain? Polarisation and Fragmentation Trends in the UK. Available at https://cutt.ly/DksHnxP

Fairclough, N. (1992). Linguistic and Intertextual Analysis within Discourse Analysis. Discourse and Society, 3(2), pp. 193-217.

Fairclough, N. (2000). New Labour New Language? London: Routledge.

Fairclough, N. \& Wodak, R. (1997). Critical Discourse Analysis. In T. Van Dijk (ed.), Discourse as Social Interaction. Discourse Studies: A Multidisciplinary Introduction (pp. 258-84). London: Sage.

Hall, S. \& Du Gay, P. (1996). Questions of Cultural Identity. London: Sage.

Hobolt, S., Leeper, T. J. \& Tilley, J. (2018). Divided by the Vote: Affective Polarization in the Wake of Brexit. Available at https://cutt.ly/YksHGbS

Klebanov et al. (2008). Lexical Cohesion Analysis of Political Speech. Political Analysis, 16(4), pp. 447-463.

Krzyzanowski, M. (2010). The Discursive Construction of European Identities: A Multi-Level Approach to Discourse and Identity in the Transforming European Union. Berlin: Peter Lang GmbH.

Krzyzanowski, M. (2018). Discursive Shifts in Ethno-Nationalist Politics: On Politicization and Mediatization of the "Refugee Crisis" in Poland. Journal of Immigrant \& Refugee Studies, 16(1-2), pp. 76-96.

Kuhn, T. (2019). Grand Theories of European Integration Revisited: Does Identity Politics Shape the Course of European Integration? Journal of European Public Policy, 26(8), pp. 1213-1230.

Murray, I. R., Plagnola, A. C. \& Corra, P. J. (2017). When Things Go Wrong and People are Afraid": An Evaluation of Group Polarisation in the UK Post Brexit. SSRN. doi:10.2139/ssrn.3041846

OSCE. (2017). Preventing and Responding to Hate Crimes. A Resource Guide for NGOs in the OSCE Region. Warszaw: OSCE's Office for Democratic Institutions and Human Rights. Available at https://cutt.ly/7ksJpuw

Polletta, F. \& Jasper, J. (2001). Collective Identity and Social Movements. Annual Review of Sociology, 27(1), pp. 283-305.

Reisigl, M. \& Wodak, R. (2001). Discourse and Discrimination. London: Routledge.

Schwalbe, M. \& Mason-Schrock, D. (1996). Identity Work as Group Process. In B. Markovsky, M. Lovaglia \& R. Simon (eds.), Advances in Group Processes (pp. 115-149). Greenwich, CT: JAI Press.

Titscher, S., Wodak, R., Meyer, M. \&Vetter, E. (1998). Methoden der Textanalyse. Leitfaden und Überblick. Bonn, Germany: VS Verlag für Sozialwissenschaften.

Van Dijk, T. A. (2001). Critical Discourse Analysis. In D. Schiffrin, D. Tannen \& H. E. Hamilton (eds.), The Handbook of Discourse Analysis (pp. 349-371). Oxford: Blackwell.

Wodak, R. (2004). Critical Discourse Analysis. In C. Seale, G. Gobo, J. F. Gubrium \& D. Silverman (eds.), Qualitative Research Practice (pp. 185-202). London: Sage.

Zappettini, F. (2019). European Identities in Discourse. A Transnational Citizens' Perspective. London: Bloomsbury Academic. 


\title{
8 The public debate on Twitter in the Iberian sphere
}

\author{
Comparative analysis of the \\ characteristics in Portugal \\ and Spain
}

\author{
Juan Antonio Marín Albaladejo \\ and João Figueira
}

\section{Introduction}

The growth of social networks as a means of accessing political information has been accompanied by an increased concern about phenomena such as echo chambers (Sunstein, 2017), "filter bubbles" (Pariser, 2011), accelerated diffusion of fake news (Allcott \& Gentzkow, 2017), spread of hate speech (Ben-David \& Matamoros-Fernández, 2016; Eddington, 2018), and radicalization of public debate (Valera, 2012). In this scenario, several studies argue that the social media conversation seems to be characterized by the strengthening of hostile messages against ideological adversaries and the increase in polarized positions (Hernández-Santaolalla \& SolaMorales, 2019).

The dissemination of the debate towards extremes is often associated with the fact that digitalization has multiplied the possibilities of selective exposure to information consumers, who tend to interact mostly with users and messages that match their views (Gvirsman, 2014). In this sense, Pariser (2011) pointed out that the positions of citizens were also reinforced by the automatic and personalized selection of content which Internet algorithms offer based on the previous preferences of individuals.

On the contrary, the results of other works reject the hypothesis that links polarization with the predominance of ideological bubbles or resonance chambers in the digital ecosystem of contemporary societies (Cardenal et al., 2019; Fletcher \& Nielsen, 2018). After reviewing the literature on studies conducted in Europe, Fletcher and Jenkins (2019) concluded that there was not enough scientific support for these theories; furthermore, part of the research even suggested that users had more contact with views different to their own inclinations. In fact, although it has been shown that personal interactions between members of groups with dissimilar visions can have depolarizing effects - by moderating antagonistic positions (Grönlund, Herne \& Setälä, 2015) - it is still unknown whether virtual deliberation with opposing ideological minds through social networks 


\section{4}

Juan Antonio Marín Albaladejo and João Figueira

tends to increase or decrease polarization. In this sense, an experimental study by Bail et al. (2018) indicated that prolonged exposure to messages from Twitter accounts with a contrary ideology helped to radicalize the judgements.

In any case, political polarization can be considered as a "global pandemic", in the words of Moisés Naím (2019). It is a phenomenon spread across many democratic countries which hinders governance and public debate. For example, a survey published by the Pew Research Center (2019) showed that $85 \%$ of US citizens claimed that the tone of the political discussion had become more negative and less tolerant. The enlargement of polarization has been related not only to the phenomenon of anti-politics, but also with the predominance of "post-truth communication" (Waisbord, 2018), in which reality is often distorted and "emotion prevails over reason as a way of arguing” (Hernández-Santaolalla \& Sola-Morales, 2019, p. 116).

Above the rational debate of ideas and the search for consensus, emotional rhetoric usually stands out in the messages transmitted by political actors in social networks, which has been linked to the extension of the Manichaean style characteristic of populism (Arroyas \& FernándezIlundain, 2019; Waisbord, 2018). According to Engesser et al. (2017), social media facilitates the notion of "the people" and "gives the populists more freedom for the use of strong language when attacking the elites and ostracizing others" (p. 1123).

Nevertheless, when analysing the behaviour of different actors in social media, it is important to take into account national contexts (Hallin \& Mancini, 2004). For example, Barberá, Vaccari and Valeriani (2017) detected that the degree of political parallelism which characterizes traditional media systems tends to reflect the use of journalists' and news outlets' Twitter accounts. Therefore, professionals who work in countries with higher partisan alignment - as is the Spanish case - are more likely to use this social network "to provide commentary on the news" (pp. 27-28). Similarly, regarding the polarization levels of online news consumers, research has found that differences between countries have not changed significantly with digitalization. Thus, a study carried out in 22 countries by Newman et al. (2017) underlined that the degree of audience political parallelism in digital environments usually kept in line with Hallin and Mancini's (2004) models, where the partisanship of the citizens' news sources of reference was greater in southern Europe countries (polarized pluralism model) than those of the North (democratic corporatist). Along the lines indicated by more recent studies (Brüggemann et al., 2014; Büchel et al., 2016), Portugal continues to distance itself from the characteristics of the model in which it has traditionally been classified and, in fact, presents the lower levels of audience polarization among the countries analysed (2017).

On a global level, the hostility of certain social network users towards opposing positions appears as a factor that can influence polarization and contribute to increasing tension in public conversation. This behaviour on 
the Internet tends to hinder the exchange of ideas and intimidates journalists or other actors who participate in the public discussion (Wolfe, 2019). Specifically, as explained by Hernández-Santaolalla and Sola-Morales (2019), Twitter is one of the channels where these aggressive behaviours may turn the debate into "a forum of attacks, obloquies and insults based on emotionality" (p. 117). Neither should one ignore the still unknown effect that alternative digital-born news outlets which spread hyper-partisan nor can populist messages produce on polarization, since its contents can reinforce the extremist positions of certain citizens and influence the political discourse (Fletcher \& Jenkins, 2019). In summary, in this environment where false news travels faster (Vosoughi, Roy \& Aral, 2018), automated accounts with inflammatory contents proliferate (Stella, Ferrara \& De Domenico, 2018), the sentimental rhetoric of actors participating in the public conversation prevails, alternative news sources emerge, and digital media compete to monetize clicks, it is convenient to pay attention to polarizing frames and hate speech in social networks that may contribute to public sphere fragmentation and strengthen the visions of intolerant and extremist minorities.

In the context of a widespread increase in political radicalism, how is this phenomenon visible in the Portuguese and Spanish Twitter scenario? Being two neighbouring countries with cultural proximity, it was the aim of this research to compare the polarization in public speeches and to observe the degree of hostility of journalists, party leaders, and users' comments. Is the Portuguese reality, in this domain, similar to the Spanish? The results have shown that there are some relevant similarities and differences between the two countries' Twitter discourses.

\section{Portuguese and Spanish context}

There are important commonalities in the evolution of the political systems of Spain and Portugal (Lisa \& Molina, 2018). Both countries acceded to parliamentary democracy in the mid-1970s and integrated simultaneously into the European communities in 1986. Furthermore, the global recession of 2008 had a profound impact on these states; in return for different types of financial bailouts, they have had to submit some of their economic policies to the supervision of the European Troika (Commission, the European Central Bank [ECB] and the International Monetary Fund [IMF])). Likewise, during most of their democratic period, two centre-left and centre-right parties (PSOE and PP in Spain; PS and PSD in Portugal) have alternated in government and concentrated a large majority of votes. Nevertheless, the electoral results in recent years have produced a more fragmented party system.

Despite these similitudes, their political regimes are different in the form of government and territorial structure. In Spain, after the death of General Francisco Franco, the democratic transition process meant the acceptance 
of a constitutional monarchy. In Portugal, the revolution that dismantled the so-called Estado Novo brought with it the establishment of a semipresidential republic in which the head of state, who emerges from elections, has greater decision-making functions in the political life. Regarding the territorial model, the Spanish autonomic state and the continuous nationalist claims in the Basque Country and Catalonia contrast with the centralism of the Portuguese state and the absence of regional parties in its Parliament (Lisa \& Molina, 2018).

Before the elections held in 2015, Spanish democracy had presented a bipartisan dynamic only broken by the power of nationalist parties in some communities. Thus, the successive electoral growth of new political groups such as Ciudadanos (Citizens), Podemos, and Vox has increased the pluralism of options that can be decisive in governance.

The origin of the gap that has strengthened new parties has been linked to the increase in disaffection that emerged in the context of the economic crisis and the proliferation of scandals during the last decade; these have even affected the Crown. Since its birth in 2014, Podemos has identified with left-wing populist narratives and been characterized by criticism of the corrupt elite, to which they attribute the fault of all social problems (Arroyas \& Pérez, 2016).

Unlike most European countries, Spain and Portugal did not have farright parties in their parliaments until recently. The turning point in this aspect occurred in Spain with the Andalusian regional elections of 2018 and the successive electoral calls of the following year, which made Vox a relevant actor as the third largest party in Congress. This group offers a nationalist discourse focused on the defence of cultural traditionalism and challenging gender policies. Its rise has coincided with the worsening of the Catalan problem, which this party proposes to solve through measures such as the illegalization of pro-independence forces.

Similarly, Portugal saw a far-right party - Chega! (Enough!) - gain a seat in Parliament for the first time in 2019. Its leader, André Ventura, is the author of a populist discourse that asserts itself against the "current political system" and advocates for restrictive immigration measures. Two other small parties - Livre (Free) and Liberal Initiative - also elected one deputy each for the first time in the most diverse parliamentary composition of Portugal's recent history. These results have been produced in a context in which both renewed racist tendencies and new anti-racist movements are emerging.

Despite the growth of the extreme right and the radical tone of new parties, groups with a moderate discourse maintain dominance in the Portuguese political scene. Thus, in the last general elections, the Socialist Party $(P S)$ won with around $37 \%$ of the vote, followed by the centre-right Social Democrats $(P S D)$ with $28 \%$. In the previous four years, PS of Antonio Costa governed with the support of two hard-left parties: Left Bloc and the Portuguese Communist Party. 
In Spain, the greater parliamentary fragmentation has accentuated ideological blocs and complicated governance, holding up to four general elections between 2015 and 2019. After the last elections, the Socialist Party (PSOE) led by Pedro Sánchez and Podemos formed the first coalition government in the current democratic period.

The media ecosystem of the two Iberian countries also offers similarities and differences. In both there is a low circulation of newspapers; this contrasts television consumption, which reaches large audiences and, until the growth of the Internet, was the main form of media used by citizens for news. In addition, most of the TV and radio channels pay special attention to political issues, and many former politicians and current deputies make comments on talk shows. The state intervenes in the audio-visual sector through public broadcasters and with the granting of media licenses. Various communication groups dominate the market in Spain and Portugal, although the system has become more fragmented in recent years and native digital media linked to independent projects has proliferated.

Among the differences, we can highlight the popularity in Portugal of the tabloid Correio da Manhã, which is the audience leader in the country. In contrast, this type of printed daily newspaper does not currently have a significant presence in Spain.

Likewise, despite the loss of influence of the major headlines of the national press (Público, Jornal de Notícias, Diário de Notícias, Expresso, etc.) and the economic difficulties these newspapers face, they still maintain high levels of trust and attempt to preserve their independence from the parties. In this sense, research shows that Portuguese journalists have achieved greater autonomy and "professionalism than is found in other Southern European countries" (Hallin \& Mancini, 2017, p. 161; see also Brüggemann et al., 2014; Büchel et al., 2016).

However, the distancing of political positions towards extremes are reflected in the Spanish media environment. Unlike the Portuguese system, it continues to show the same elements of the polarized pluralism model that Hallin and Mancini (2004) identified in the countries of Mediterranean Europe. The continuity of this system is characterized by high political parallelism of media, ideological biases in audiences, constant attacks on the rival, and scarce criticism of related politicians. Thus, although there have been specific cases of disagreement with the leaderships of the parties ideologically close to their editorial positions (Teruel, 2016), the content of the main newspapers (El País, El Mundo, La Vanguardia, ABC, etc.) and native digital media (El Confidencial, ElDiario.es, El Español, Okdiario, etc.) are still characterized by large doses of partisanship.

Moreover, the low trust of the Spanish citizens in media adds to these elements. The Digital News Report 2020 indicated that only 36\% regularly relied on news, which placed Spain 23rd in the list of 40 countries included in the analysis. The same study showed that, between 2015 and 2020, Portuguese confidence in news fell by $9.1 \%(65.6 \%-56.5 \%)$. However, 
among the countries analysed, Portugal - along with Finland - produced news that was most trusted by its citizens (Newman et al., 2020).

Although the Internet has become the main source of information - and despite the fact that more than half the population in both countries use social networks for news consumption - there is an increasing concern about the danger of the online dissemination of hoaxes and fake news contributing to the reinforcement of hate speech and polarization.

\section{Hate speech and polarizing language}

So-called "cyber utopianism" (Morozov, 2012) is not leading the citizenship to a better level of democracy. Actually, social media provides the prime setting for hate speech and the messages that incite violence to take place nowadays. "A great proliferation of extremist messages is taking place all over Europe", as Cabo-Isasi and García-Juanatey $(2016$, p. 4) stated, underlining the reports of UNESCO and European Commission Against Racism and Intolerance, as well as denouncing and showing concern for the problem.

The Online Civil Courage Initiative (OCCI) research report about "Hate speech and radicalism online" edited by Baldauf, Ebner and Guhl (2019) analysed the problem in detail. Given the gravity and complexity of a phenomenon that exists on a global scale, that study proposed an uprising by decent people in order to fight the radicalism and hate speech in social media.

Despite the diversity of situations in which the term hate speech may be used, we understand it as an expression that incites any types of intolerance, violence, and prejudice (Gagliardone et al., 2015). This phenomenon is visible and notorious in Spain, where the broad study made by Ben-David and Matamoros-Fernandéz (2016) showed evidence of the prevalence of groups who used social media as a tool to spread ideas of hate, discrimination, and political extremism.

In Portugal, the presence of radical political forces - especially within the right wing - is a reality that the country has known since October 2019's legislative elections. This new political scenario has contributed to the growth of a more aggressive public discourse, although social media have long been used by citizens to attack other citizens or groups. The phenomenon is known, but still requires further research. This chapter is a contribution to this area.

Both political polarization and hate speech are mainly manifested through language that activates certain frames (Demszky et al., 2019). Therefore, extremism and the different forms of discrimination or hostility towards individuals and groups are detected by analysing the use of terms and symbolic devices that express stereotypes, offenses, and social divisions.

As Van Dijk (2003) showed, this type of discourse describes an antagonism between the own reference group that is identified only with positive 
aspects and others that are stigmatized with negative words and images. Moreover, among the discursive practices associated with radicalism on the Internet, the dissemination of hoaxes and rumours that seek to reinforce prejudices or discredit political rivals is of increasing importance. According to Fernández-Smith (2017, p. 117), the line that distinguishes hate speech of the rational debate from different points of view lies in the presence of features such as "the use of insult, hurtful irony, argumentative fallacy, more or less veiled threat, etc.". Consequently, the behaviours of media, citizens, and elites in the digital environment of each country play an important role in contributing to the extension of extremist and inflammatory discourses.

\section{Objectives, hypotheses, and methodology}

From a comparative perspective, the main objective of this chapter is to offer an analysis of the political, media, and citizen discourse within Twitter in Spain and Portugal. As noted in the theoretical framework, the two countries have differences in their most recent political and media culture. This would therefore be reproduced in the behaviour of the actors on a social network like Twitter. Taking this premise as a reference, we propose the following hypotheses:

H1. Personal twitter accounts of Spanish journalists tend to include more political opinions and partisan alignment than those of Portuguese professionals.

$\mathrm{H} 2$. The critical message towards political rivals and polarizing frames prevails most among leaders of the Spanish parties in this social network. Moreover, these kinds of tweets experience higher dissemination by users.

H3. User replies in media tweets that contain political information are usually less offensive, hostile, and discriminatory in Portugal than in Spain.

The methodology has combined the quantitative and qualitative analysis of the three sets of samples examined. The first was formed by the tweets of 12 Spanish and Portuguese journalists who were selected for their number of followers, their links with digital media, and their dedication to commenting on political news. As a unifying criterion, professionals who published almost all their messages in Catalan were discarded in Spain. The second collected the messages of leaders or spokespersons from six Spanish parties with the greatest parliamentary representation, while in Portugal - to cover a more similar ideological diversity, from radical left-wing to far-right and new tendencies - the accounts chosen were leaders of the three parties with the most seats, as well as of the three new forces that have a deputy in Parliament. ${ }^{1}$ The third sample included publications of the accounts in 
the social network of the main generalist printed newspapers (El Pais and Público) and of the most-read digital native media (El Confidencial and Observador) in each country (see Table 8.1).

The tool used to collect tweets was the Twlets extension connected to Google Chrome browser. Specifically, messages from journalists and politicians prior to 15 January 2020 were downloaded. As the frequency of publications of Portuguese politicians on this social network is usually much lower, the last 35 tweets that appeared on the account were analysed for each leader. In this way, a sample of 420 messages was obtained to be examined. Simple retweets without comments were discarded. At the same time criteria and number of messages (420) were used to configure the sample related to the accounts of journalists. However, in this case the selection

Table 8.1 Actors Analysed

\begin{tabular}{|c|c|c|}
\hline \multicolumn{2}{|c|}{ Name of the actor } & \multirow{2}{*}{$\frac{\text { Followers }}{1050.424}$} \\
\hline Journalists & Ignacio Escolar (@iescolar) & \\
\hline (Spain) & Pedro J. Ramírez (@pedroj_ramirez) & 540.322 \\
\hline & Antonio Maestre (@AntonioMaestre) & 414.319 \\
\hline & Jesús Maraña (@jesusmarana) & 389.117 \\
\hline & Carlos Cuesta (@carloscuestaEM) & 209.694 \\
\hline & Fernando Berlín (@radiocable) & 197.166 \\
\hline \multirow{6}{*}{$\begin{array}{l}\text { Journalists } \\
\text { (Portugal) }\end{array}$} & José Manuel Fernandes (@JMF1957) & 89.772 \\
\hline & Daniel Oliveira (@danielolivalx) & 83.554 \\
\hline & Henrique Monteiro (@HenriquMonteiro) & 43.912 \\
\hline & Fernanda Cancio (@fcancio) & 42.542 \\
\hline & Paulo Ferreira (@pauloferreira1) & 27.765 \\
\hline & Helena Garrido (@helenag) & 23.582 \\
\hline \multirow{6}{*}{$\begin{array}{l}\text { Political leaders } \\
\text { (Spain) }\end{array}$} & Pedro Sánchez (@sanchezcastejon) & 1468.432 \\
\hline & Pablo Casado (@pablocasado_) & 496.362 \\
\hline & Santiago Abascal (@Santi_ABASCAL) & 515.909 \\
\hline & Pablo Iglesias (@PabloIglesias) & 2605.444 \\
\hline & Inés Arrimadas (@InesArrimadas) & 681.527 \\
\hline & Gabriel Rufián (@gabrielrufian) & 790.495 \\
\hline \multirow{6}{*}{$\begin{array}{l}\text { Political leaders } \\
\text { (Portugal) }\end{array}$} & Antonio Costa (@antoniocostaps - PS account -) & 7.006 \\
\hline & Rui Rio (@RuiRioPSD) & 28.676 \\
\hline & Catarina Martins (@catarina_mart) & 87.630 \\
\hline & André Ventura (@AndreCVentura) & 36.375 \\
\hline & João Cotrim Figueiredo (@jcf_liberal) & 17.465 \\
\hline & Rui Tavares (@ruitavares) & 64.991 \\
\hline \multirow{2}{*}{$\begin{array}{l}\text { News outlet } \\
\text { (Spain) }\end{array}$} & El País (@el_pais) _ & 7747.420 \\
\hline & El Confidencial (@elconfidencial) & 888.859 \\
\hline \multirow{2}{*}{$\begin{array}{l}\text { News outlet } \\
\text { (Portugal) }\end{array}$} & Público (@Publico) & 737.908 \\
\hline & Observador (@observadorpt) & 153.686 \\
\hline
\end{tabular}

Source: Author's own. 
was made using only those most recent publications that referred to the national political issues of the respective country.

As for the analysis of news outlet accounts, a total of 7,191 tweets were downloaded. Due to the disparate frequency of publication, we decided to collect 2,300 from @el_pais (05-15 January 2020), 2000 from @Elconfidencial (27-12-2019 to 15-01-2020), 1,591 from @Publico (01-15 January 2020), and 1,300 from @observadorpt (01-15 January 2020). To explore users' interest in political issues, the 25 messages with the most retweets for each account were listed and the issues addressed within were identified. The messages related to political issues were used as a reference to obtain the sample for analysing users' responses, selecting a maximum of eight responses from each tweet, in the order of appearance. The small number of comments that are usually produced in many tweets of the Portuguese media meant that the list was extended to the 100 most retweeted of their accounts in this country. Despite this, the sample of comments was higher in Spain $(N=336)$ than in Portugal $(N=223)$.

In addition to recording general data, the codebook of the journalists' accounts classifies whether the type of tweet is informative or an opinion (it also includes a mixture of information and opinion) and whether or not the opinion is partisan. Qualitatively, criticisms and defences of members of certain political parties by journalists were also recorded.

To analyse the tweets of political leaders, the orientation of their messages was measured with four different categories: (1) Defence of proposals, measures, or actions (own, or third-party actors); (2) criticism, insults, or attacks on political rivals; (3) mixed (presents both mixed orientations); (4) not applicable (cannot be classified into the previous). As qualitative analysis, the most repeated keywords were extracted with the Wordle program, distinguishing the number of repetitions by political leader and country. Interpretatively, the most frequent words were subsequently associated with the presence of certain polarizing frames and discourses. Based on Calvo et al. (2017), the most retweeted messages and tweets with the highest number of favourites of each political leader were identified.

Regarding user replies, the tone of the messages was examined as well as the presence of offensive language or discriminatory speech. This category included all those tweets that contained attacks on the honour of other people, mockeries, insults, scurrilities, or promote some kind of prejudice, violence, or intolerance (Miró, 2016).

\section{Results}

\section{Journalistic polarization}

Contrary to one of the statements included in our first hypothesis, the analysis of tweets written by selected journalists and political commentators indicates that, in general, Spanish professionals do not tend to 


\section{Juan Antonio Marin Albaladejo and João Figueira}

editorialize or issue opinions on national political news in their personal Twitter accounts $(59.5 \%)$ to a greater extent than their Portuguese colleagues $(61.4 \%)$. Although opinionative tweets prevail in both countries, there is a contrast of uses between the accounts of the journalists analysed. In Spain, except in the messages of @iescolar (5.7\%) and @jesusmarana $(37.1 \%)$, the predominance of opinion is far superior to information (with percentages located mostly in a range between $62.9 \%$ and $97.1 \%$ for tweets examined). In Portugal, @danielolivalx (94.3\%), @HenriquMonteiro (91.4\%), and @fcancio (82.9\%) usually post opinionative comments, while others such as @pauloferreira1 (with 51.4\% of informative tweets), @JMF1957 (with 57.1\% of informative tweets), and, above all, @helenag (with $80 \%$ of informative tweets) often issue more information or link to news or political analysis.

However, the second part of the hypothesis is fulfilled. According to the high political parallelism that has traditionally characterized Spanish media systems and in the same line indicated by previous research mentioned in this chapter (Barberá, Vaccari \& Valeriani, 2017), the data show that partisan bias is also reproduced in the behaviour of journalists on Twitter. Thus, $52.4 \%$ of the messages scrutinized in Spain contain opinions that defend and/or criticize certain politicians or parties, representing $88 \%$ of total opinion tweets. Hence, almost all Spanish journalists frequently show partisan opinions in their comments (most of the percentages range from $90.9 \%$ to $100 \%$ ). As for the level of ideological polarization, in Spain two clearly differentiated blocks can be found. On the one hand, a group of the accounts of journalists analysed (@AntonioMaestre; @iescolar; @jesusmarana; @radiocable) is characterized, to a greater or lesser extent, by presenting tweets that project a defence of the leftist parties (PSOE-Podemos) and attack the actions and measures of the right opposition $(P P-C$ 's $-V o x)$ :

I do not know if Sanchez limits the power of Podemos but what it does seem, as Juliana says, is that the criticism of the right to the "kidnapped government" by the "social-communists" is limited. (@radiocable, 2020, January 10)

Meanwhile, others have been detected (@carloscuestaEM; @pedroj_ ramirez) in which most of the messages are aimed at transmitting a deeply negative image of the "progressive" coalition government and of Catalan and Basque independence formations:

PSOE and ERC close the "fringes" of the investiture. They intend to dress as normal a Government formed by criminals, coup plotters, seditious and embezzling. Negotiated with proetarras. And driven by those of the ERE case. And to top it off they give moral lessons. (@ carloscuestaEM, 2019, December 24) 
Portuguese professionals tend to express fewer partisan opinions $(30.9 \%$ of the messages scrutinized) on their Twitter accounts than their Spanish colleagues; the general use of a less aggressive tone and language is observed in this country.

When these individuals do editorialize on political issues, tweets focused on the defence of certain politicians or partisan criticism also prevails (50.4\% of their total opinion tweets). However, the predominant type of opinion and the ideological alignment of the comments vary significantly depending on the account analysed.

The visibility of partisan criticism is the highest in @fcancio $(72.4 \%)$, @ danielolivalx (63\%), and @JMF1957 (60\%), but it has less presence in the tweets with opinions of the other accounts, which tend to offer their analyses of the political and economic situation or focus more on the generalized behaviours of the parties and the institutional system. Despite the fact that certain ideological slants are detected in the tweets of all the Portuguese journalists examined, the polarization is especially manifested, on the one hand, in the numerous attacks by @danielolivalx and @fcancio on rightwing groups and Chega's leader. On the other hand, it appears clearly in the strong criticisms of @JMF1957 on the ruling Socialist Party.

\section{Politicians frames}

The message orientation transmitted in the tweets of Spanish leaders is considerably more critical than that of the Portuguese politicians. As Table 8.2 sets out, the percentage of tweets that essentially collect criticism, insults, or attacks on political rivals is almost double in Spain (39\%) than in Portugal $(20.5 \%)$. This can be related to the fact that Portuguese representatives often use this social network in order to defend proposals, measures, or actions of their own or other actors (48.1\%), compared to the low presence shown by this speech in the messages of the Spanish leaders $(21.3 \%)$. As for the number of tweets that mix the two types of guidelines - critical and propositional - this is slightly higher in Spain, although this mixed approach appears in a minority in both countries $(17.6 \%$ and $10 \%)$.

Table 8.2 Message Orientation of Political Leaders by Country

\begin{tabular}{llll}
\hline & Spain & Portugal & Total $(\mathrm{N}=420)$ \\
\hline Proposals, measures, or actions & $21.9(46)$ & $48.1(101)$ & $35(147)$ \\
Criticism, insults, or attacks on rivals & $39(82)$ & $20.5(43)$ & $29.8(125)$ \\
Mixed & $17.6(37)$ & $10(21)$ & $13.8(58)$ \\
Not applicable & $21.4(45)$ & $21.4(45)$ & $21.4(90)$ \\
\hline
\end{tabular}

Source: Author's own. 


\section{Juan Antonio Marín Albaladejo and João Figueira}

However, the hardness in the tone of the politicians' speech varies significantly within each country, so that those leaders of parties who are in the Government, and even their parliamentary allies, tend to show a more positive approach and focus less on offering hostile or attacking messages against their opponents. This is the case of Prime Minister Antonio Costa in Portugal, or the president Pedro Sánchez in Spain. In this regard, it should also be noted that the results of the tweets' analysis for his coalition government partner - the leader of Podemos, Pablo Iglesias contrast with the negative tone that had been detected in his speeches from earlier times (Arroyas \& Fernández-Ilundain, 2019; Arroyas \& Pérez, 2016). Specifically, most of his messages on the social network during the specific period under review are comments on cultural products or that announce his interventions in media; when talking about political issues, Iglesias often does so with a more propositional and mixed orientation than critical.

In both countries, the analysis highlights the negative and critical tone that prevails in tweets of politicians identified with the radical right, such as Santiago Abascal (Vox) and André Ventura (Chega). In the case of Spain, it is also linked to the discourse of the independentist Gabriel Rufián (ERC). Thus, the most polarizing messages that delve into ideological divisions and stigmatization of the antagonists have been found in these leaders' tweets.

The count of repeated keywords, which was carried out with the tool Wordle, also reflects the presence of different frames and discourses' tones within each country. Thus, in Spain the name of the state is widely used by all leaders except the ERC spokesperson. Moreover, words such as "government", "Sánchez", "PP", "PSOE", "Torra", "Vox", "against”, or "in opposition to" dominate and are mainly related to the prevailing antagonism between political forces. In addition, the frequent appearance of terms such as "state", "separatists", "allies", "ETA" (Basque terrorist group that ceased its activity in 2011), "betrayal", or "sovereignty" are connected with criticism or hostility on the part of $P P, V o x$, and C's representatives against the president of Government and nationalist and leftist parties that allowed his investiture. In contrast, in the socialist leader's sample of tweets there is the recurrent use of hashtags like "\#YesToMoveForward", "\#InvestitureSession", and "\#GovernmentOfSpain" to defend his appointment and legislature plan, as well as words such as "rights", "society", and "people" related to a social discourse that also dominates in the messages of Iglesias.

Regarding the Catalan problem, two opposing frames are distinguished in the analysis of frequent terms: On the one hand, one may observe a high use of words linked to a perspective focused on legality and courts' actions as a way to resolve the issue ("convicted", "justice", "court", etc.), especially in tweets of the centre and right opposition. On the other hand, with a lower frequency, a framework of "negotiation" or "dialogue" on this matter can be seen in some messages from the leaders of PSOE and ERC. 
If we look at the number of retweets and favourites in the publications of Spanish politicians examined, it is also verified that the messages containing polarizing speeches (in which the adversary is strongly attacked) are those that generate a greater diffusion by users. As an exception, a tweet of Iglesias was detected as humorous in code and the message of Sánchez, in which he affirms the attributes with which he seeks to identify his "Government of the Progressive Coalition", which was also detected with a positive tone.

In Portugal, the word "stability" appears among the repeated expressions and the general tone is less hostile. In addition, if we pay attention to the messages with the highest number of retweets and likes, we have not verified a visible amount of polarized speech in which the opponent is severely attacked. The toughest positions are found in a tweet by André Ventura, in which he accuses the president of the Assembly of trying to "silence" him, as well as a post by João Cotrim de Figueiredo (Liberal Initiative) in which he criticizes "the socialist incompetence".

We do not find many expressions of strong hostility among the most mentioned keywords in this period. The words "Portuguese" and "to do" are nearly at the top of the most referenced words in tweets. "State", "parliament", "work", and "support" are other words that we can frequently find. The prime minister usually maintains a soft tone; the same goes for the leader of the main opposition party, who toughens his speech less often than his Spanish counterpart, Pablo Casado. The most critical and attacking tone is reflected in the accounts of the leaders of Liberal Initiative and, above all, of Chega.

\section{Political interest and hostile speech}

In the accounts of the Spanish newspapers, the news on political issues reached the highest number of user retweets. In the Portuguese media which were analysed, political information also gained considerable attention on Twitter, although it was lower in favour of sports, crimes, scientific, cultural issues, etc., in this country.

If we extract the 25 most retweeted publications in each of the selected accounts, it can be observed that 19 are tweets about politics for @el_pais. For the account @Elconfidencial, this trend increases even further and there are only two publications not related to political issues (the 4th and 25 th). However, it must be taken into account that the investiture session of the president of the Government took place in Spain during the period analysed. Thus, this could increase the spread of political matters.

For@observadorpt, seven of the most retweeted publications are about Portuguese parties or prominent political figures in the country. However, nearly half of the tweets (12) were related to other topics; the most retweeted post was about an alleged medical malpractice. In @Publico, international affairs were most retweeted by users. Middle East and topics 


\section{Juan Antonio Marín Albaladejo and João Figueira}

related with the United States and Spain stand out among the topics discussed. Additionally, one can see international issues at the top of the ranking (13 tweets). Surprisingly, Portuguese political topics are almost absent.

The analysis of tweet replies on political issues published by the news outlets' accounts shows that the tone of the comments is predominantly negative for both countries (65.8\% in Spain and $62.3 \%$ in Portugal). Thus, the criticism of other people, actions, or measures prevails against the positive or neutral tone.

Regarding the presence of offensive language or discriminatory speech, $30.2 \%(169)$ of the responses that made up the total sample $(N=559)$ were characterized by attacks on the honour of other people, mockeries, insults, or encouraging some kind of prejudice. In addition, it should be noted that the frequency of occurrence for this type of discourse does not differ greatly between Spain (31.5\%) and Portugal (28.3\%). Thus, unlike the divergences that occur in the different levels of polarization shown by politicians, a greater similarity between both countries is detected in the case of the behaviour of Twitter users.

\section{Conclusion}

The main objective of this chapter was to compare the public debate on Twitter in Spain and Portugal. This research adopted the premise that the different characteristics of the political and media ecosystems between the two countries are also reflected in the social media conversation. This study has confirmed that, in general, the discourse is still more polarized in Spain than in the other Iberian country in this scenario. However, it has also revealed that the behaviour of some types of actors presents important similarities.

The results demonstrate that criticisms or attacks on political rivals predominate the discourse of Spanish leaders; this is also shown in the repetition of words related to the polarization of parties and in the messages with most retweets. In Portugal, in spite of the recent growth of radical forces, a more proactive general tone still prevails than in its neighbouring state.

Despite the high professional autonomy and low politicization with which journalism is traditionally identified in Portugal, we found a relevant presence of partisan opinions in the comments on Twitter in this country. Although the results show that the polarization and the hostile tone of journalistic discourse are lower than in Spain, the ideological alignment and high doses of criticism focused on certain parties are also observed in the accounts of Portuguese journalists.

Notwithstanding the differences in journalistic and political speeches, a negative tone and offensive language or messages that contain accusations and promote prejudice and intolerance appear with a similar frequency in the interventions of citizens in both countries. Although this behaviour is 
not representative of the majority among users, it offers a sample of the significative hostility against dissenting positions in this environment. This convergent trend between the citizen speeches reveals that the radicalism of public debate on Twitter seems to be homogeneous and independent of the political and media cultures of each country.

\section{Funding information}

This chapter has been made possible through the funding of the UCAM 2019 Research Support Plan (reference: PMAFI-10/19).

\section{Note}

1 It is also relevant to specify that the leader of the Communist Party (the fourth most voted political force in the 2019 elections) does not have Twitter account, while the spokesperson of PAN (the sixth most voted), André Silva (@ lourencoesilva1), has not been used it since 2016, where only four messages appear.

\section{References}

Allcott, H. \& Gentzkow, M. (2017). Social media and fake news in the 2016 election. Journal of Economic Perspectives, 31(2), pp. 211-236.

Arroyas, E. \& Fernández-Ilundain, V. (2019). The politics of authenticity in populist discourse. In E. Hidalgo-Tenorio, M. A. Benítez-Castro \& F. De Cesare (eds.), Populist discourse (pp. 17-32). London: Routledge.

Arroyas, E. \& Pérez, P. L. (2016). La nueva narrativa identitaria del populismo: un análisis del discurso de Pablo Iglesias (Podemos) en Twitter. Cultura, lenguaje y representación, 15 , pp. 51-63.

Bail, C., Argyle, L., Brown, T., Bumpus, J., Chen, H., Hunzaker, M. B. F., Lee, J., Mann, M., Merhout, F. \& Volfovsky, A. (2018). Exposure to opposing views on social media can increase political polarization. Proceedings of the National Academy of Sciences, 115(37), pp. 9216-9221.

Baldauf, J., Ebner, J. \& Guhl, J. (2019). Hate speech and radicalisation online: The OCCI research report. ISD. Available at https://cutt.ly/4ksZShg

Barberá, P., Vaccari, C. \& Valeriani, A. (2017). Social media, personalisation of news reporting, and media systems' polarisation in Europe. In M. Barisione \& A. Michailidou (eds.), Social media and European politics (pp. 25-52). London: Palgrave.

Ben-David, A. \& Matamoros-Fernández, A. (2016). Hate speech and covert discrimination on social media. International Journal of Communication, 10, pp. 1167-1193.

Brüggemann, M., Engesser, S., Büchel, F., Humprecht, E. \& Castro, L. (2014). Hallin and Mancini revisited. Journal of Communication, 64(6), 1037-1065.

Büchel, F., Humprecht, E., Castro-Herrero, L., Engesser, S. \& Brüggemann, M. (2016). Building empirical typologies with QCA: Toward a classification of media systems. The International Journal of Press/Politics, 21(2), pp. 209-232.

Cabo-Isasi, A. \& García-Juanatey, A. (2016). Hate speech in social media: A stateof-the-art review. Available at https://cutt.ly/nksZC7k 


\section{Juan Antonio Marín Albaladejo and João Figueira}

Calvo, D., Zamora, R., Sánchez, P., Moreno, R. \& Vizcaíno, R. (2017). La campaña de candidatos y partidos en Twitter durante el proceso de elecciones generales de 2015. In J. L. Dader \& E. Campos (eds.), La búsqueda digital del voto (pp. 195-228). Valencia: Tirant Lo Blanch.

Cardenal, A., Aguilar-Paredes, C., Cristancho, C. \& Majó-Vázquez, S. (2019). Echo-chambers in online news consumption. European Journal of Communication, 34(4), pp. 360-376.

Demszky, D., Garg, N., Voigt, R., Zou, J., Gentzkow, M., Shapiro, J. \& Jurafsky, D. (2019). Analyzing polarization in social media: Method and application to tweets on 21 mass shootings. Proceedings of the 17th Annual Conference of the NAACL.

Eddington, S. M. (2018). The communicative constitution of hate organizations online: A semantic network analysis of “make America great again”. Social Media+ Society, 4(3), pp. 1-12.

Engesser, S., Ernst, N., Esser, F. \& Büchel, F. (2017). Populism and social media: How politicians spread a fragmented ideology. Information, Communication \& Society, 20(8), pp. 1109-1126.

Fernández-Smith, G. (2017). Instrumentos lingüísticos de los discursos de odio en la prensa digital. Fragmentum, 50, pp. 99-122.

Fletcher, R. \& Jenkins, J. (2019). Polarisation and the news media in Europe. Scientific Foresight Unit, European Parliamentary Research Service. doi: 10.2861/059702.

Fletcher, R. \& Nielsen, R. (2018). Are people incidentally exposed to news on social media? A comparative analysis. New Media \& Society, 20(7), pp. 2450-2468.

Gagliardone, I., Gal, D., Alves, T. \& Martinez, G. (2015). Countering online hate speech. Paris: Unesco Publishing.

Grönlund, K., Herne, K. \& Setälä, M. (2015). Does enclave deliberation polarize opinions? Political Behavior, 37(4), pp. 995-1020.

Gvirsman, S. (2014). It's not that we don't know, it's that we don't care: Explaining why selective exposure polarizes attitudes. Mass Communication and Society, 17(1), pp. 74-97.

Hallin, D. \& Mancini, P. (2004). Comparing media systems. Cambridge: Cambridge University Press.

Hallin, D. \& Mancini, P. (2017). Ten years after comparing media systems: What have we learned? Political Communication, 34(2), pp. 155-171.

Hernández-Santaolalla, V. \& Sola-Morales, S. (2019). Postverdad y discurso intimidatorio en Twitter durante el referéndum catalán del 1-O. Observatorio (OBS*), 13(1), pp. 102-121.

Lisa, P. \& Molina, I. (2018). La evolución de los sistemas políticos de España y Portugal: convergencias en la diferencia. Real Instituto Elcano, ARI 49/2018.

Miró, F. (2016). Taxonomía de la comunicación violenta y el discurso del odio en Internet. IDP. Revista de Internet, Derecho y Política, 22, pp. 82-107.

Morozov, E. (2012). The net delusion. New York: PublicAffairs.

Naím, M. (2019, 23th January). The globalization of polarization. El País. Available at https://cutt.ly/HksXpFN

Newman, N., Fletcher, R., Kalogeropoulos, A., Levy, D. \& Nielsen, R. (2017). Digital News Report 2017. Oxford: Reuters Institute for the Study of Journalism.

Newman, N., Fletcher, R., Schulz, A., Andi, S. \& Nielsen, R. (2020). Digital news report 2020. Oxford: Reuters Institute for the Study of Journalism. 
Pariser, E. (2011). Filter bubbles: What the Internet is hiding from you. London: Penguin.

Pew Research Center. (2019, 18th July). Most Americans say political debate in the U.S. has become less respectful, fact-based, substantive. Available at https://cutt. $1 \mathrm{y} / 4 \mathrm{ksXk} 3 \mathrm{r}$

Stella, M., Ferrara, E. \& De Domenico, M. (2018). Bots increase exposure to negative and inflammatory content in online social systems. Proceedings of the National Academy of Sciences, 115(49), pp. 12435-12440.

Sunstein, C. (2017). \#republic: Divided democracy in the age of social media. Princeton, NJ: Princeton University Press.

Teruel, L. (2016). El impacto de la crisis política y económica sobre la polarización de los medios españoles. Historia y Comunicación Social, 21(1), pp. 202-220.

Valera, L. (2012). ¿Deliberación 2.0 o radicalización de la retórica partidista? Un análisis de las discusiones políticas en los muros de Facebook de candidatos políticos españoles. Textual \& Visual Media, 5, pp. 311-340.

Van Dijk, T. (2003). Ideología y discurso. Barcelona: Ariel.

Vosoughi, S., Roy, D. \& Aral, S. (2018). The spread of true and false news online. Science, 359(6380), pp. 1146-1151.

Waisbord, S. (2018). The elective affinity between post-truth communication and populist politics. Communication Research and Practice, 4(1), pp. 17-34.

Wolfe, C. (2019). Online trolls, journalism and the freedom of speech: Are the bullies taking over? Ethical Space: The International Journal of Communication Ethics, 16(1), pp. 11-21. 


\title{
9 Towards a new left-populist rhetoric in Turkey
}

\author{
Discourse analysis of \\ İmamoğlu's campaign
}

\author{
Gülüm Şener, Hakan Yücel and \\ Umur Yedikardeş
}

\section{Introduction}

In recent years, the political developments in the West and the resurgence of right-wing populist parties have popularised the debate on populism. Populism has different definitions, and the term is conceptualised in various ways such as an ideology, political style, or policies of political adversaries (Sözen, 2019, p. 268), and it transcends geography, time, and ideology. The common point made by the scholars studying populism is that it constitutes a threat to democracy. There are those who claim that populism could be a corrective factor for the errors and deficiencies of liberal democracies (Gidron \& Bonikowski, 2013, p. 20). Today's populist movements are generally seen as a consequence or crisis of globalisation and neoliberalism. The forms of populism may vary depending on geography, culture, and the political system involved. Contemporary populism is labelled "national populism," "right-wing populism," "left-wing populism," "neo-fascism," "hyper-nationalism," "authoritarian populism," and so on. This chapter focuses on left-wing populism in Turkey, specifically on the election campaign of Ekrem İmamoğlu, the candidate of the main opposition party CHP, who won the local elections and became the new Mayor of Istanbul in 2019.

One of the distinguishing features of authoritarian populist politicians is that they build their politics on the distinction between "us" and "them." The national community, based on the friend/enemy scheme, has a necessary "outside" from which it distinguishes itself. The anti-elite and illiberal populist politicians claim that they represent the "real people" and so encourage polarisation in society (Müller, 2017, p. 60). In Turkey, President Erdoğan, the leader of the Islamist-conservative party AKP who has been in power since 2002, regularly contributes to the political and social polarisation with his discourses and speeches in the mass media controlled by his government and on social media platforms. In this extremely polarised political climate, Ekrem İmamoğlu won the local elections on 23 June 2019. He became the new Mayor of Istanbul by defeating the ruling party AKP 
who lost control of Istanbul for the first time since 1994. Several factors may explain this success. However in this study, we focus on İmamoğlu's discourse during his electoral campaign. We argue that his campaign is a good example when it comes to overcoming political and social polarisation as it provides important clues on how to fight authoritarian populist politics. Going beyond left-populism, his campaign put forward the embracement of a pluralistic society, the unification of polarised groups, non-violent language, and modesty against the arrogance of a one-man regime, in addition to confidence in institutions that are against favouritism. Our research methodology involved collecting campaign data from İmamoğlu's social media accounts and conducting discourse analysis based on the data collected.

\section{Left-wing populism}

Meade (2019) argues that previous academics' focus on leader-centric and right-wing populist discourse obscures the display of populist discourse by left-wing movements and the role of democratic practices in constructing populist movements (Meade, 2019, p. 2). A relatively recent body of literature has been dedicated to left-populism, and it has been limited to the experiences in Latin America and Europe (Hawkins, 2009; Stavrakakis \& Katsambekis, 2014; Gerodimos, 2015; Katsambekis, 2016; Ramiro \& Gómez, 2017; Gratius \& Rivero, 2018; Hetland, 2018; Hart, 2019; Meade, 2019; Kioupkiolis \& Perez, 2019; De la Torre, 2019; Neyra, 2019). Mouffe (2018) states that right-wing populism and left-populism differ from each other in the construction of the "we" and the adversary that they define. While right-wing populism claims that it will bring back democracy and national sovereignty excluding numerous groups that are seen as a threat to society, left-wing populism aims to federate the democratic demands into a collective will to construct "the People" against the "oligarchy." It requires the establishment of a chain of equivalence among the demands of the workers, the immigrants, and the precarious middle class as well as other democratic demands, such as those of the LGBT community (Mouffe, 2018, pp. 43-45). Left-populists, whose central ideology is based on the dichotomy of "moral people versus corrupted elite" and on a charismatic leader, construct their agenda around egalitarianism, collective economic and social rights (March, 2007, p. 66). Right-wing populists use ethnicity to exclude minorities and left-wing populists construct the category of "the People" as the majorities of their nations that are excluded by neoliberal policies. They conceive them as a plurality of actors with different views and proposals (De la Torre, 2019, p. 67). The left-populist discourse opens up to a much wider audience without completely excluding the working class, claiming that capitalism harms not only the working class but the entire population except for a handful of elites (Uslu, 2019, p. 261). As Mouffe (2018, pp. 70-81) puts it, the strategy of left-populism aims to 
challenge post-democracy and re-establish the articulation between democracy and liberalism, putting democratic values in the leading role.

Certainly, the populist rhetoric needs to be analysed dimensionally as countries and their populist political movements are not identical (Elçi, 2019 , p. 4). According to Gerodimos $(2015$, p. 610$)$, the state of the political system and the levels of democratisation also play a crucial role in the development of different types of populism. One of the most interesting examples in the formation of the left-populist movement is the case of France. In the example of Jean-Luc Mélanchon's presidential election campaigns in 2012 and 2017, he stood for the newness of left-wing populism and its democratic implications (Chiocchetti, 2020, pp. 106-128). In an interview with L'Express Magazine, he says: "I have no desire to defend myself against the accusation of populism. This is the disgust of the elite. Go to hell all of them! Am I a populist? I agree." In another interview, "Our discourse confronts two categories, he says, the people and the oligarchy" (Birnbaum, 2012, pp. 110-111). In Spain, Podemos, who has adopted the anti-elitist discourse and represents a response against to the "crisis of representation," also points out the distinctive features such as its initial roots in "horizontalist" social movements, its "technopolitics," and a reflexive application of populist theory (Kioupkiolis \& Perez, 2019, p. 25). Katsambekis (2016, pp. 393-399) attributes Syriza's short march to power in Greece to a kind of left-populism that is both inclusionary and egalitarian, reflecting the plurality, heterogeneity, and subversive political orientation of the squares. By focusing on the Occupy Movement and the Tea Party Movement in the U.S to trace the similarities and differences between left-wing and right-wing populist discourses, Meade (2019, p. 8) indicates that both share a narrative of national decline that is caused by cultural losses and economic and structural changes due to economic globalisation. Both left- and right-populists blame politicians, particularly those from their own party, for these losses. However, the Occupy Movement members' conception of "people" is more pluralistic than that of right-wing populists who exclude portions of the working class on the basis of perceived work ethic, race, or religion (Meade, 2019, p. 10). However, Hetland (2018) shows the ambiguity of left-populism based on his analysis of Chavez's Venezuela. Although the radical left-populism in Venezuela created hope by reducing poverty and inequality, and deepening democracy following the 2014 crisis, Chavista's model confronted two challenges: The unsustainable material foundation and statist trap (Hetland, 2018, p. 277). Furthermore, the discourse of the Greek anarchists constitutes a coherent populist ideology (division between the people and the elites, appealing to the people as a homogeneous body, proto-totalitarian utopia, and calling for violence as a response to complex problems) (Gerodimos, 2015, p. 622) and also a distinct populist identity based on victimhood, anger, and revenge, collectively challenging democracy (Gerodimos, 2015, p. 608). The main problem in today's left-populism debates is how to balance the idea of 
"being a populist as a style and strategy, but not as the content of the political program," using a populist strategy based on the distinction between the people and the elites on the way to power and how to follow an egalitarian, inclusive, and liberating strategy and to ensure the ability to keep the initiatives together. Regardless of how it is constructed, populist discourse blurs the boundaries between the right and the left (Uslu, 2019, p. 268).

\section{Populism in Turkey}

Populism is not new in Turkey. Mudde and Kaltwasser (2017, pp. 39-40) argue that populism has become a more integral part of politics in the Middle East only in the 21st century. Populism is a characteristic of the ruling and opposition parties in more established democracies such as Israel and Turkey. Until recently, the Turkish version of political populism suggested that the Turkish nation, the country, and its religious values are in "great danger" and that the danger "coming from abroad" could be prevented if the country is unified under the leadership of a great leader (Kula, 2019, p. 811).

In Turkish politics literature, three types of populism can be distinguished: Social engineering in the early republican period, the import substitution regime in the multi-party system period, and finally, patronage and the centre-right analysis (Baykan, 2017, p. 164). According to Toprak (1992), a fertile ground for populism in Turkey has emerged from the beginning of the 20th century and continued as "intellectual populism" until the 1950s (Toprak, 1992, pp. 42-65). The populism of the early Republic era is characterised by "social engineering" of the single-party system, and based on the understanding of "for the people despite the people" by the elite. During this era, Turkish populism was formulated through the "Six Arrows" and functioned as a strategy to reject class politics and to defend national identity (Boyraz, 2020, p. 34). During the subsequent multi-party system period, populism can be considered as a rejection of the early Republican populism. According to Artunkal (1990, pp. 15-26), "populism authentique" developed against the intellectual populism of the modernising elites after the 1950s in Turkey. Tekeli and Şaylan (1978, p. 89, cit. Baykan, 2017, p. 165) claim that the populism principle, which was included in the program of the Democratic Party in the 1950s, was "by the people, with the people and for the people.". Baykan (2017) adds "populist patronage," a third period of populism, used by centre-right politicians to gain electoral support. According to Heper and Keyman (1998, p. 262), "populist patronage" is used by the politicians from the centre-right tradition to "present themselves as the will of the nation against the will of the state and the protector of the masses against the state elite." Populism has gained a new dimension with the AKP's accession to power in 2002. Yalvaç and Joseph $(2019$, p. 1) indicate that the AKP has followed different hegemonic projects, changing from an initial majoritarian populist politics to one of neoliberal authoritarian populisms to consolidate its hegemonic depth. 


\section{Gülüm Şener et al.}

Although the populist language of the centre-right political parties was effective between 1950 and 1970, a form of "left-populism" emerged in the 1970s. Despite the common belief that leftist parties and movements were always elitists in Turkey, the mass mobilisation beginning from the second half of the 1970s referred to the "left-populist discourse" (Baykan, 2017, p. 171). Left-populism remained weak until the 1960 s due to the fact that left-politics was not legal and was generally centred on a limited intellectual group which excluded the general public. Left-populism was only possible with the establishment and election of the TIP, the Workers' Party of Turkey, and the CHP's positioning itself on the left after the second half of the 1960s, that is, with a historical delay. In the 1970s, the CHP, led by Bülent Ecevit, adopted "left of the center" politics and turned from state elitism to a more nationalist leftist colour (Aslan, 2019, pp. 113-114). In the 1980s, the Social Democratic Populist Party represented another remarkable example of left-populism, mobilising the urban poor and lower middle classes against the neoliberal and conservative populism of the Motherland Party, ruled by Özal (Boyraz, 2020, pp. 36-37). However, after the 1980 Coup d'Etat, the party has returned to its constitutive ideology of Kemalism, and has become the protector of the establishment against the rise of political Islam (Elçi, 2019, pp. 5-6). According to Grigoriadis (2020, pp. 8-9), the right-wing populism has prevailed in Turkish politics due to demographic, political, and social reasons as well as due to the rupture of democracy by a series of coups, and the suppression of left-wing populist movements. Between 1980 and 2000, Turkish politics witnessed the struggle of elitist, pluralist, and Islamist populist political actors. Over the last 20 years, two concurrent populisms, "conservative" and "secular," have been dominating the political scene (Aslan, 2019, pp. 116-118).

There has been a transformation in secular politics in the last 20 years. Secular politics have manifested themselves in an elitist form for a long time. The Kemalist bureaucratic-intellectual elite, which holds state power, has brought secular politics to life in an authoritarian way. However, as an inevitable consequence of the melting power since the 1990s, the politics of secularism have moved away from an elitist form of politics and have started to adopt a populist form of politics. Examples include the Republic Meetings in 2007 and the Gezi events in 2013 that constitute the development of secular populism (Aslan, 2019, p. 118). Another step in radical leftwing populism can be illustrated by the performance of the HDP (People's Democracy Party) in the 2014 presidential elections and the 2015 general elections campaigns. The inclusive populism of the HDP challenged the AKP's right-wing populism based on authoritarianism, majoritarianism, and illiberalism by constructing a new and alternative "people" concept and by mobilising social movements within horizontal politics (Tekdemir, 2019, p. 346). Its discursively articulated pluralism included feminists, democratic Islamists, human rights activists, Alevi leaders, socialists, environmentalists, representatives of LGBTQ organisations, liberal-leftist intellectuals, and artists (Kaya, 2019, p. 809). The presidential campaign 
of Muharrem İnce, the CHP candidate in 2018, also had a strong populist discourse based on the antagonism of "poor" people versus "rich" elite (Sirma, 2019). The populist rhetoric that dominated the latest campaigns of HDP and CHP has enabled the alliance of the opponents and the increase of their vote. It moved even further forward with the İmamoğlu campaign and ended the 25-year AKP ruling in Istanbul.

\section{Methodology}

İmamoğlu's campaign consisted of two stages: The first stage started on 18 December 2018, the day that the CHP declared Ekrem İmamoğlu as their mayor candidate for Istanbul. This stage ended on 31 March 2019, the date of the local elections. Although İmamoğlu won the local elections with a difference of 23,000 votes, the Supreme Election Board (YSK) controversially cancelled the elections on 6 May 2019 after a complaint from the AKP. The local elections, only for Istanbul, were re-ran on the 23 June 2019 , and İmamoğlu regained with more than 800,000 votes (BBC, 2019).

The discourse analysis technique was used to reveal the left-populist discourse in İmamoğlu's campaign. The data, consisting of texts, images, and videos collected from his official social media accounts on Twitter, Facebook, Instagram, and YouTube between 18 December 2018 and 23 June 2019 , was analysed in the context of left-populist discourse. All posts on Instagram, Twitter, Facebook, and YouTube were obtained through a backtrack search. However, access to historical datasets and tweets on Twitter remains restricted which is the main reason why our data analysis was limited. No considerable difference was observed between the platforms in terms of discourse. However, the messages may vary due to the technical features of the respective digital platforms. For example, longer videos were shared on Facebook and YouTube compared to Instagram, and live broadcasts could be held on Facebook and Twitter.

Social media played a central role in İmamoğlu's campaign. While pro-government media outlets prefer to ignore or discredit the candidates of opponent parties, and TV debates gathering rival candidates are no longer broadcasted in Turkey, social media remains a primary medium to run a political campaign and to reach a larger audience. Although social media is closely monitored by the government and censorship is widespread in the country, politicians from opposition parties can still find an opportunity for representation on social media.

\section{Populist discourses of İmamoğlu's campaign}

\section{6 million Istanbul residents: unity against polarisation}

İmamoğlu's campaign offers a new construction of "the People," "16 million Istanbul residents" as an alternative to the Islamic conservative/ modern secular polarisation that AKP politicians have been feeding for 
years. Against the authoritarian and discriminatory discourses of the rightpopulism that divide the people into two poles as "us" and "others" as a support of partisanship, the left-populism is building an imaginary of a unified and equal society. İmamoğlu frequently emphasises equality and fraternity in his speeches, and he calls Istanbulites as "my fellow citizens" regardless of their origin, identity, lifestyle, and political view. Against the "othering" strategies and stigmatisation practised by the AKP, the "16 million Istanbul residents" discourse is used as a unifying factor and as a supra-identity in order to overcome social polarisation.

This narrative is also supported by a description of big city life with metaphors such as a "bus" or "apartment block." This emphasises the imagination of a diverse society where citizens live in the same apartment or travel on the same bus. This is where reconciliation and coexistence are dominant instead of conflict. In a TV program broadcast by the Habertürk TV channel on 24 December 2018, İmamoğlu says that Turkish society wants peace, friendly politicians, and sympathetic people:

At the end of the day, everyone goes home, they don't care who lives on the upper floor, who lives on the lower floor, or which party the next door neighbor vote for. We get warm in the same apartment block, we get cold in the same street.

In the campaign video posted on his social media accounts on 4 March 2019, citizens from various age groups, gender, and socio-economic levels travel together on a city bus. The external voice says:

Excuse me, which party did you vote for in the last election? Mrs. Aysel gave her vote to the party A, Mr. Ümit gave it to the party B, Mrs. Nimet gave to the party C and Mrs. Semra to the party D. Well, local elections are approaching. We all want to live together with love. We want transparent and fair municipalities. In short, no matter what political view we have, we are all on the same city bus. We are waiting for you for a five-year journey. Republican People's Party.

On the one hand, the fact that those citizens have different political views and support different parties is normalised. The AKP, on the contrary, is stamping out and criminalising those who have not supported themselves for years. On the other hand, by emphasising that they live in the same city, it is stated that the problems related to the city are common and that the local elections intend to solve the common problems of everyone beyond partisanship.

The emphasis on "We are one" is not only a discourse that is featured in advertising videos and TV speeches. It is also brought to life through the performance of İmamoğlu in his marketplace visits. In other words, it is not only said "We will overcome polarization if we are elected." At the same 
time, he visited the marketplaces and embraced conservative citizens who have voted for the AKP for several years, chatting, listening to their problems, and coming face-to-face with the rival party supporters. The main message of this performance is that polarisation can be overcome through dialogue. The embodiment of dialogue and tolerance occurs without underestimating or overlooking the AKP's supporters, and by respecting their preferences, for example, saying "Thank you" to those who would not vote for him, and by adopting a "calm" attitude in contradiction to "angry" and "vociferous" political figures.

\section{Liberating religion from the monopoly of right-populism}

Another tactic to overcome the Islamist conservative/modern secular polarisation is using a plethora of religious elements, which has mainly been appropriated by the Islamist parties. However, İmamoğlu's campaign does not establish a narrative like "religious people are always the victim" as the AKP systematically does. Rather, he draws a portrait of a politician who is devoted to his religion, who performs the Friday prayer with his people, and who does not misuse the name of Allah while also leading a modern lifestyle. The videos were prepared to introduce İmamoğlu, as he was unknown to most of the population at the beginning of the campaign. They were also circulated on his social media accounts, offering a narrative that blends the traditional and modern lifestyle of the İmamoğlu family. These videos include his journey from his hometown Trabzon to Cyprus where he studied for a short period of time, then on to Beylikdüzü where he settled with his family. In these videos, the values such as "homeland and nation," "reason and science," and "traditions and values" are put forward. The story of how he met "social democracy" is told to the public.

During the campaign, he frequently visited conservative districts that are seen as the "AKP's fortresses," such as Eyüp, Fatih, Bağcılar, Arnavutköy, and Başakşehir as well as the religious sites of symbolic significance for the AKP. Unlike the AKP politicians who favour a Sunnite interpretation of Islam, İmamoğlu approaches other religions and sects with respect. He celebrated the new year for the Armenian community in their church, he visited the leaders of the non-Muslim communities in Istanbul, and he met Alevi community several times. The instrumentalisation of religion can be seen as an effort to break down the prejudices against the CHP which was presented over the years as a "non-religious party" and as "a political party that disregards our religion" by the AKP and its voters. He displays a different image from the classical CHP candidates by referring to Islam often, praying with the Muslim community, or breaking fast in conservative families' houses during the month of Ramadan. These religious references are only used as the basis for his cultural values rather than as religious politics. This strategy helps to combine a secular understanding that is at peace with faith. 


\section{A populist leader connected to bis people}

The campaign draws a portrait of a politician embraced by his people, in contrast with the ruling elites who have lost their connection with the public, especially with the President who currently lives in his "palace" and cannot be easily reached by ordinary people. The campaign is mainly built on face-to-face communication, which is one of the oldest strategies of political communication; and local markets at the heart of everyday life and of the economic crisis are chosen as the principal stage for İmamoğlu's performance. There, he portrays a leader who can establish close contact and good relations with his citizens by listening to their problems and trying to solve them. The images shot in the marketplaces when he had travelled with the Beylikdüzü TV team were broadcasted without editing. The critics towards them by the AKP supporters are also shown uncensored. The images of İmamoğlu, who was surrounded by the public, highlight the fact that AKP politicians have been disconnected from the citizens. It also proves that CHP politicians are not "disconnected from the public" as the AKP members suggest.

During those visits, İmamoğlu frequently uses body contact by hugging people, shaking their hands, looking into their eyes, and listening to them carefully. The words most frequently used in his speeches are "beauty," "hope," "peace," "trust," "happiness," "young," "dynamic," and "entering into the heart of people." Later on, the candidate for the AKP, Binali Yllırım, copied this strategy. The "warm" contact with the citizens gained a new dimension as İmamoğlu broke fast with a conservative family every evening in their house during the month of Ramadan. Thus, the campaign was not limited anymore to city squares and public spaces. It also expanded into private sphere. Close contact with conservative people may have had mutual functions. First of all, it may have served to break the prejudices of the AKP voters against the CHP and to convince them to vote for the CHP by underlining the conservative background of İmamoğlu. Second, it may have released the prejudices of the CHP voters about conservatives by making conservative citizens visible. In this sense, the "warm contact" strategy with the public may also have played a significant role in overcoming the polarisation between two groups.

\section{"Everything will be fine": hope and non-violence against the politics of fear}

İmamoğlu's campaign mobilises non-violent communication as a primary tactic to overcome polarisation and partisanship. The language of "hope," "love," and "tolerance" predominates the campaign against the toxic language of pro-government media and social media trolls. Without "othering" or targeting his rivals and their voters, a positive language is used in his campaign, and all of the verbal attacks from the AKP supporters are 
ignored. A teenager running behind the campaign bus on 16 April 2019 shouted, "Brother Ekrem, everything will be fine my brother!" This sentence became the slogan of the campaign, and it went viral on social media. "Hope" is crystallised in this slogan of "Everything will be fine." Hopeful messages rapidly spread on social media.

Similar to the campaign in HDP's 2015 elections, this campaign also mobilises "hope." Unlike HDP's campaign, İmamoğlu ignores his opponent, AKP. He does not mention or target it, and he responds very cautiously to verbal attacks from the front of the government. Most importantly, he does not feed the "trolls." This tactic neutralises the attacks of the ruling party and their trolls, and it also strengthens İmamoğlu in terms of setting his own agenda. CHP's campaign strategist Özkan (2019) explains this tactic: "Without struggling with the feeling of 'Faith in Erdoğan' among the Ak Parti voters, we should have walked around and reached the result. In other words, we have seen that we can only win the Istanbul election with a campaign that deliberately keeps Erdoğan out of our agenda. We should have completely ignored Erdoğan. We should act as if there were no such politicians in our lives, and we should focus only on creating our own agenda" (p. 65). Unlike the right-populism, which is fed by throwing mud at the opponents and criminalising them, he takes advantage of ignoring the harassment and refusing to feed them by not reacting. He does not target politicians, but instead the on-going system. A unified and diversified people narrative is built against the "corrupted elites," described as "the mentality that has ruled Istanbul for a quarter century," "waste order," "grinch," and "unfair." Even on 7 May 2019, the day that the elections were cancelled, he went to Beylikdüzü and gave a message of hope: "We have a long road, high excitement and youth. We are Turkish youth who are thirsty for justice and have full faith in democracy. And we will never give up!"

\section{People ignored by neoliberalism: the urban poor, women, youth, children, etc.}

In contrast to the AKP's development discourses and mega-projects, the İmamoğlu's campaign focuses on social democrat projects that will improve the lives of ordinary and neglected people. His campaign makes visible the people forgotten by the AKP's neoliberal developmental policies; the emphasis is more on human-centred urban policies. The local election campaign, coinciding with one of the biggest economic crises in Turkey's history, favours social democrat projects against the AKP's developmental mega-projects to solve the daily problems of citizens. CHP candidate's projects include free transportation for mothers with babies, special care centres for elderly and disabled people and for children, the establishment of city and neighbourhood councils, green areas and reforestation projects, milk distribution for children, discounted transportation for university students, culture-art centres and libraries, etc. 
"Urban poverty" constitutes one of the campaign's most prominent themes. The videos from the local markets also served as a kind of alternative media, and they became the voice of subaltern subjects of neoliberalism. In a repressive regime where the mainstream media is controlled by the government and where censorship is widely practised and where even the reporting on the economic crisis is considered a crime, these videos have become the voice of the silenced masses, displaying the dimensions of the economic crisis and breaking the culture of fear. On 16 January 2019, a marketer in the Sultanbeyli marketplace said: "Now our people are hungry, they are in trouble. Ten years ago, we were making money; we could buy a house, a land. Now, we cannot feed ourselves." A conservative woman from Başakşehir said: "Everyone is afraid, for how long will they be afraid? Your child's bread was stolen. Everyone is hungry, everyone is unemployed. For how long will you be afraid? What is your solution?" In an environment where journalists, economics writers, and opponents are silenced, the video footage reveals the AKP's fall: "I have been voting for AKP for the last 16 years, this time I will not," say many citizens. In this respect, İmamoğlu's campaign reveals the AKP's weakness indirectly by making the public talk.

Women, youth, and children are the main target of the campaign. As a response to the AKP era, characterised by a decline of women's rights, the approach that alienates women is dominant and femicide is on the rise. There is a narrative of women who are active in business life and taking part in decision-making mechanisms in equal positions with men. Nurseries for working mothers, various measures related to the safety of women and reducing the violence against women, a $40 \%$ women quota in management, and an equality action plan were among the promises.

On 15 March 2019, Dilek İmamoğlu talks about her husband's women's policy and projects in a video. The modern women's myth, which is one of the important elements of Kemalist modernisation, is being reproduced in this video. Women are seen of as a symbol of modernity, dignity, and freedom. Dilek İmamoğlu embodies the Kemalist women's myth with her beauty, modern clothing, secular lifestyle, and the role of a mother of three, career and education. In addition to the emphasis on the modern Republic woman, conservative women receive also significant coverage in the campaign videos. We witness the conversations and hugs of İmamoğlu with women wearing headscarves in both commercial films and local market videos.

The youth, one of the groups most affected by the economic crisis, also has an important place in the İmamoğlu campaign. Against the "old" Binali, the youth and dynamism of İmamoğlu is often stressed. Imamoglu visits the CHP Youth Branches, universities, homes, and dormitories of university students and produces projects that are specific to young people. Children are also one of the target groups that stand out in the campaign. Various projects are offered specifically for children: Their right to education, nurseries, the elimination of economic inequality, free milk distribution, the 
construction of new playgrounds, etc. Unlike the AKP's Islamist generation creation projects, emphasis is placed on economic inequality and children's rights.

\section{Democratic values against the authoritarian regime}

During the campaign, "democracy," "democratic values," and "modesty" are the key concepts foregrounded against "authoritarianism." A vision of democracy based on pluralism, transparency, and equality, organised from bottom to top, where citizens will play an active role in decision-making is presented in the campaign. The emphasis is on "the People," not on the "leader": "We will succeed together, 16 million Istanbul residents will win." "Do not count on the leader, but on the system."

Another theme frequently mentioned during the campaign is the "principle of merit" against "partisanship" and "favouritism," which became common during the AKP period. His speech on 4 April 2019 went viral on social media: "The service to the Man, person, people, religious communities, foundations and associations is over. The service will restart for the İstanbul Metropolitan Municipality (İBB) and Istanbul residents. Keep your mind at peace." Through foundations and associations, he refers to the foundations and associations founded by the relatives of the President, gaining a profit from the Metropolitan Municipality. "Favouritism" will be replaced by "merit," and the trust placed in democratic institutions will be restored. This democratic vision also includes transparency and accountability. After İmamoğlu was elected, the İBB Assembly started broadcasting their meetings live on social media platforms.

The campaign also puts forward the "normalisation of the country." Unlike AKP politicians who only go to their own neighbourhoods and escape from meeting with their rivals on TV, İmamoğlu visited the election booths, wished them luck, and underlined the need for "normalising" the country. In the very first days of the campaign, the CHP candidate visited the former mayors. He shared the following message on his Instagram profile regarding these visits: "We set out to listen to everyone who has a say for Istanbul." After having held a meeting with the President Erdoğan on 10 January 2019, he made a live statement saying that he gained "very valuable anecdotes." He also participated in a TV program with Binali Yıldırım on 16 June 2019 which must have been the first in a long time. Unlike the revanchist tendency of the government, he accepted the legacy of past administrations and promised a "new beginning."

The emphasis on democracy became more prominent after the votes were recounted and the election was cancelled. Since then, the campaign turned into a struggle for justice and democracy. He called for moderation on social media on 8 May 2019:

The YSK made a decision and was unfair to us. He took away the election we won, which is 'halal' like our mother's milk. We know them. 
But it is not time for reckoning, it is time to look ahead, prepare for June 23rd, 2019. It is time to tell everyone about the votes of Istanbul, together with our citizens, that we aspire to 16 million people. None of citizens who says 'Everything will be fine' will not use language that distinguishes anyone on social media. Please, I ask everyone, go tonight, greet your neighbor at the Ifftar (the breaking of the Ramadan fast) and invite your neighbor to Ifftar. Do not run wild, do not discriminate against anyone. You're welcome, I'm inviting, and your heart is full of love. Everything will be very fine.

\section{Conclusion}

As explained above, the introduction of left-populism in politics in Turkey has remained both limited and delayed. Moreover, it was significantly interrupted in the decades following the 1970s. What we have seen in recent years is both a return to this populist language through local elections, and a populist reckoning with right-wing populism. Hence, left-populism, which we saw with the İmamoğlu campaign, is (re-)emerging.

İmamoğlu's campaign matches the left-wing populism embracing inclusive, pluralist, and egalitarian discourses; democratic values; and social democrat projects. The unification of "the People" against polarisation, the politics of hope against politics of fear of the AKP, places an emphasis on democratic values and institutions; the recognition of subaltern identities created by neoliberal politics and the inclusion of various identities are the prominent populist discourses of his campaign. The inclusion of all segments of society and the portrayal of "the People" as a plural and heterogeneous collective subject are in contrast with the exclusionary and polarising populism of the AKP. De la Torre (2019, p. 68) claims that populists state there to be two perils to plural and democratic politics: The transformation of rivals into enemies and their subordination to a charismatic leader. Unlike populist movements, the antagonism between "the People" and the corrupted elitists or "the Enemy" is implicitly given during the campaign. İmamoğlu could win the elections without "demonizing his enemies" (Mouffe, 2018, p. 41). According to Taşkın (2019), behind the success of the opposition parties in the political sphere over the last years, there are dynamic segments of society that are discontent with the authoritarianism in Turkey and the Istanbul local elections showed that a left-populist stance in the field of economy and a post-populist stance in the field of administration and democracy can regress right-populism.

\section{References}

Artunkal, T. (1990). Quelques remarques sur le populisme en Turquie. CEMOTI, 9, pp. $15-26$.

Aslan, A. (2019). Türk siyasi hayatında yeni dönem: Seküler versus muhafazakar popülizm, Muhafazakar Düşünce Dergisi, 57, pp. 103-122. 
Baykan, T. S. (2017). Halkçılık ve popülizm: Türkiye vakası ve bir kavramın kullanımları. Mülkiye Dergisi, 41(1), pp. 157-194.

BBC. (2019, 24th June). Seçim sonuçları: Ekrem İmamoğlu 800 binden fazla oy farkla İstanbul Büyükşehir Belediye Başkanı seçildi. BBC News. Available at https://cutt.ly/vks291Q

Birnbaum, P. (2012). La parabole de M. Mélenchon, Critique, 776-777, pp. 110-118.

Boyraz, C. (2020). Populism and democracy in Turkey: The case of the Republican People's party. Reflektif, 1(1), pp. 31-47.

Chiocchetti, P. (2020). 'Make way for the people!' Left-wing populism in the rhetoric of Jean-Luc Mélenchon's 2012 and 2017 presidential campaigns. In G. Charalambous \& G. Ioannou (Eds.), Left radicalism and populism in (pp. 106128). London: Routledge.

De la Torre, C. (2019). Is left populism the radical democratic answer? Irish Journal of Sociology, 27(1), pp. 64-71. doi: 10.1177/0791603519827225.

Elçi,E.(2019). The rise of populism in Turkey: A content analysis, Southeast European and Black Sea Studies, 19(3), pp. 378-408. doi: 10.1080/14683857.2019.1656875

Gerodimos, R. (2015). The ideology of far left populism in Greece: Blame, victimhood and revenge in the discourse of Greek anarchists. Political Studies, 63, pp. 608-625. doi: 10.1111/1467-9248.12079

Gidron, N. \& Bonikowski, B. (2013). Varieties of populism: Literature review and research agenda. Harvard University, Weatherhead Working Paper Series, 13-0004. Available at https://cutt.ly/pks9Vgy

Gratius, S. \& Rivero, A. (2018). Más allá de la izquierda y la derecha: populismo en Europa y América Latina. Revista CIDOB d'Afers Internationals, 119, pp. 35-61. doi: 10.24241/rcai.2018.119.2.35

Grigoriadis, N. I. (2020). For the people, against the elites: Left versus right-wing populism in Greece and Turkey. The Journal of the Middle East and Africa, 11(1), pp. 51-64. doi: 10.1080/21520844.2020.1723157

Hart, G. (2019). From authoritarian to left populism? Reframing debates. South Atlantic Quarterly, 118(2), pp. 307-323.doi: 10.1215/00382876-7381158

Hawkins, K. A. (2009). Is Chávez populist? Measuring populist discourse in comparative perspective. Comparative Political Studies, 42(8), pp. 1040-1067.

Heper, M. \& Keyman, F. (1998). Double-faced state: Political patronage and the consolidation of democracy in Turkey. Middle Eastern Studies, 34(4), pp. 259-277.

Hetland, G. (2018). The promise and perils of radical left populism: The case of Venezuela. Journal of World-System Research, 24(2), pp. 277-292. doi: 10.5195/ JWSR.2018.868.

Katsambekis, G. (2016). Radical left populism in contemporary Greece: Syriza's trajectory from minoritarian opposition to power. Constellations, 23(3), pp. 391-403. doi: 10.1111/1467-8675.12234

Kaya, M. (2019). The potentials and challenges of left populism in Turkey: The case of the peoples' Democratic Party (HDP). British Journal of Middle Eastern Studies, 46(5), pp. 797-812. doi: 10.1080/13530194.2019.1634398.

Kioupkiolis, A. \& Pérez, F. S. (2019). Reflexive technopopulism: Podemos and the search for a new left-wing hegemony. European Political Science, 18, pp. 24-36. doi: 10.1057/s41304-017-0140-9

Kula, O. B. (2019). Politik popülizm dili neden ve nasıl araçsallaştırır? Folklor/ edebiyat, 25(100), pp. 809-813. 


\section{Gülüm Şener et al.}

March, L. (2007). From vanguard of the proletariat to Vox Populi: Left-populism as a 'Shadow' of contemporary socialism. SAIS Review of International Affairs, 27(1), pp. 63-77. doi: 10.1353/sais.2007.0013.

Meade, R. (2019). Populist narratives from below: Occupy Wall Street and the Tea Party. IdeAs, 14. Available at https://cutt.ly/HkdhYI9

Mouffe, C. (2018). For a left populism. London: Verso.

Mudde, C. \& Kaltwasser, C. R. (2017). Populism: A very short introduction. Oxford: Oxford University Press.

Müller, J. (2016). Popülizm Nedir?. İstanbul: İletişim.

Neyra, R. (2019). Constructing the people: Left populism and degrowth movements. The EuropeanLegacy, 24(5),pp.563-569. doi:10.1080/10848770.2018.1550896.

Özkan, N. (2019). Kahramanın Yolculuğu. İstanbul: MediaCat.

Ramiro, L. \& Gómez, R. (2017). Radical left-populism during the Great Recession: Podemos and its competition with the established radical left. Political Studies, 65(1S), pp. 108-126. doi: 10.1177/0032321716647400

Sırma, E. (2019). 24 Haziran Seçimleri özelinde popülizm ve demokrasi ilişkisi. [Doctoral dissertation]. Pamukkale Üniversitesi, Denizli, Turkey. Available at https://cutt.ly/pkdjFZ8

Sözen, Y. (2019). Populist peril to democracy: The sacralisation and singularisation of competitive elections. Political Studies Review, 17(3), pp. 267-283.

Stavrakakis, Y. \& Katsambekis, G. (2014). Left-wing populism in the European periphery: The case of SYRIZA. Journal of Political Ideologies, 19(2), pp. 119-142.

Taşkın, Y. (2019, 12th December). Popülizm tartışmaları üzerinden son yerel seçimleri anımsamak. Birikim. Available at https://cutt.ly/skdj05O

Tekdemir, O. (2019). Left-wing populism within horizontal and vertical politics: The case of Kurdish-led radical democracy in agonistic pluralism. Journal of Balkan and Near Eastern Studies, 21(3), pp. 335-349. doi: 10.1080/ 19448953.2018.1497756.

Toprak, Z. (1992). Popülizm ve Türkiye'deki boyutları. In T. Z. Tunaya (Ed.), Tarih ve Demokrasi - Tarık Zafer Tunaya'ya Armağan (pp. 41-65), İstanbul: Cem Yayınları; Üniversite Öğretim Üyeleri Derneği.

Uslu, H. F. (2019). Riskleri ve vaatleriyle sol popülizm. Imgelem, 3(5), pp. 255-271.

Yalvaç, F. \& Joseph, J. (2019). Understanding populist politics in Turkey: A hegemonic depth approach. Review of International Studies, 45(5), pp. 786-804. doi: 10.1017/S0260210519000238. 


\title{
10 Anti-immigrant hate speech as propaganda
}

\author{
A comparison between Donald \\ Trump and Santiago Abascal on \\ Twitter
}

\author{
Ana I. Barragán-Romero and \\ María Elena Villar
}

\section{Introduction}

Propaganda is a manipulative form of communication used to obtain or maintain a position of power by an ideological group. Its use increases in times of authoritarian or populist governments to unite people around ideological movements and against a unifying enemy. The rise of right-wing, nationalistic, and anti-immigrant movements in Europe and the United States (U.S.) has heightened the use of propaganda. The current media environment allows users to assume content with which they agree, creating a media echo-chamber, and limits the social regulation that often tempers extreme speech on popular media. Social media facilitates hate speech by doing away with editors and gatekeepers and allowing people with extreme views to rally each other and validate their beliefs. In this chapter we examine the immigration-related tweets by Donald J. Trump, President of the U.S., and Santiago Abascal, President of Spain's Vox political party, both of whom are active on Twitter and stoke the anti-immigrant and nationalistic feelings in both countries.

Through a structured content analysis, we coded for characteristics of propaganda and hate speech in their immigration-related tweets, and identified similarities and differences between the two politicians both of whom have high activities and large following on Twitter. Specifically, we examine the extent to which Abascal and Trump use propaganda styles (affirmative, negative, or reactive), the identified enemies, a cornerstone of propaganda, referenced in the tweets, and the immigration-associated thematic frames most frequently used by each. This analysis contrasts and compares the style and content of antiimmigrant rhetoric on social media, as applied by two expert social opinion leaders, in two different political realities - one as incumbent and the other as opposition. 


\section{Political propaganda}

The concept of political propaganda is often used in relation to dictatorial governments, both left and right wing. However, as Domenach (1986) states, propaganda has many forms and unlimited resources. Thereby, propaganda is a communicative message that will adapt to the dominant technologies and resources at any given time. As long as there are political rivalries, there will be propaganda (Domenach, 1986). Thus, propaganda is a transhistorical phenomenon, which is not determined by a specific situation, but rather something that will happen whenever ideology and power are in tandem (Pineda Cachero, 2006).

Many authors have tried to define what constitutes propaganda (Herreros Arconada, 1989; Cunningham, 2002; O'Shaughnessy, 2004; Pineda Cachero, 2006; Huici Módenes, 2010). After World War II (WWII), and because of Nazi Propaganda and other dictatorships, this phenomenon has been linked to a negative use of communication and persuasion, where the receivers are conceived as a big group that behaves in the same way. This was the main idea during the years between the two world wars and the origin of the first research studies about political propaganda as a communicative discipline (Lasswell, 1927; Tchakhotine, 1985; Bernays, 2005; Ponsonby, 2005). In 2006, as a result of a review of the most representative global studies on propaganda, Pineda Cachero (2006) defines it as:

...a communication phenomenon dealing with content and ideological intent, by means of which an issuer (individual or collective) transmits a message interestedly and deliberately to obtain, maintain or reinforce a position of power over the thought or conduct of a recipient (individual or collective) whose interests do not necessarily coincide with those of the issuer.

(Pineda Cachero, 2006, p. 228)

As a rule, propagandistic messages include an enemy. Domenach (1986) identified simplification and homogenization of the enemy so that there is a notion of a single enemy. This resource was used in an extensive way in Nazi Germany, where messages were launched against Jews. This author wrote his research after WWII, making him a witness of the extensive use of propaganda during this period. Domenach (1986) also highlights that to focus on one person, hope and hate are the most elemental and beneficious way to develop the propagandistic message.

According to the content of the propaganda message and the enemy, Pineda (2008) defines three types of messages based on whether the message focuses on the source's agenda or its opponents: Affirmative propaganda, negative propaganda, and reactive propaganda. 
-Affirmative propaganda: There is no explicit enemy in the message. This type of communication just shows positive data about the propagandist, the sender.

-Negative propaganda: There is an explicit enemy in the message, and the information about it is bad. There is no sign of the propagandist in this kind of communication.

-Reactive propaganda: The propagandist appears as a solution against the enemy. Thus, there are two parts in this communication: The propagandist and the enemy. The good against the evil.

\section{Twitter and political communication}

In the current media environment, propagandistic messages circulate on the Internet and social networking sites (SNS), just where the target audience is. Political and electoral campaigns are in a phase of post-maturation on the Internet (Davis et al., 2009), where it is common to develop sophisticated websites, and attention is directed to SNS, which became a critical tool after the Barack Obama campaign in 2008 (Towner \& Dulio, 2012, p. 96). The Obama campaign was a preamble to the importance that SNS would take on in later election years. An example of this is the role they took in the election campaign of Donald Trump in 2016. The use of the SNS has been linked to the personalization of politics, with Twitter being the most studied SNS (Filimonov, Russmann \& Svensson, 2016, p. 3).

Twitter launched in 2006, reaching approximately 200 million accounts in just five years. Users post messages with up to 140 characters ("tweets") that appear both in their profiles and in their followers' feeds. Users can share other users' tweets, giving any individual public tweet the potential to reach far more users than those following the original sender. Users can also share photos and links in tweets. In addition to following other twitter accounts, users interested in specific issues or topics can search for keywords or "hashtags", or terms prefixed with a \# symbol.

Social media can be seen as providing access to information, but also as one of the biggest risks to democracy (Persily, 2017), due to the rise of political extremism. The 2016 U.S. political campaign arguably represents the latest chapter in the disintegration of the legacy institutions that had set bounds for U.S. politics in the postwar era. The Trump campaign was unprecedented in its breaking of established norms of politics. Yet this type of campaign could only be successful because established institutions especially the mainstream media and political party organizations - had lost much of their power, both in the U.S. and around the world (Persily, 2017).

The Trump campaign took advantage of a great social dissatisfaction and the fall of these institutions. Politicians and political parties of different countries, such as the Five Star Movement in Italy, Rodrigo Duterte in the Philippines, the Pirate Party in Iceland, and Marine Le Pen in France, have used SNS to send their messages to the audience. Furthermore, the 
achievement of SNS can be seen in the Brexit referendum (Persily, 2017). Between August 2015 and the 2016 election day, over 1 billion tweets were associated with the U.S. presidential race. By election day Trump had accumulated 13 million Twitter followers, with Hillary Clinton trailing behind at 10 million followers. Amplified by retweets, by mid-2016 Trump's social media posts were shared three times more than Clinton's on Twitter. Across media outlets both on and offline, Trump set the news agenda, with his supporters' avid retweeting amplifying discussion of his ideas. Trump soon realized that "incendiary language could command media attention or shift the narrative" (Persily, 2017, p. 67).

\section{Hate speech and immigration}

Hate speech is nothing new in propaganda. One example is the demonization of the German enemy in World War I, with the lies and exaggerations about the Germans marking the beginning of the concept known as atrocity propaganda (Barragán-Romero \& Bellido-Pérez, 2019). Although there was a reaction against propaganda after this conflict, totalitarian movements had found the perfect tool to spread hate. In fact, it is in part thanks to these propaganda messages that Mussolini and Hitler achieved their powerful positions in the 20s and 30s (Pizarroso, 1990; Taylor, 1990).

According to Kirk and Martin (2017), hate speech may be technically defined in legal terms as "written or verbal attacks on an individual or group's race, ethnicity, or gender" (p. 206), and are typically abusive, insulting, intimidating, or harassing, and can contribute to violence, hatred, or discrimination. However, in the U.S. largely due to the First Amendment, there are very few restrictions on political speech, even when it comes to hate speech. Therefore, it is not unusual to find hate speech in U.S. political discourse (Kirk \& Martin, 2017).

Beyond the inherent dangers of hate speech in any format, there are the particular amplified dangers that this phenomenon poses on SNS. Given the relevance of SNS in almost all facets of modern society, it is not surprising that modern hate speech leverages them as a perfect way to reach their audiences. "Among the many peculiarities of the 2016 presidential campaign, the most noxious may have been the way it normalized deeply divisive speech in public discourse, including hate speech" (Kirk \& Martin, 2017, p. 205). In fact, hate speech can be the perfect way to use the propaganda's simplification rule defined by Domenach (1986). It can also be shown in Donald Trump's policies against immigrants: He has characterized and reduced Mexican migrants as criminals, drug smugglers, rapists, and "bad hombres", among other highly negative attributions (Verea, 2018). This type of language has amplified anti-immigrant sentiment across the U.S.

Across Europe, immigration is also increasingly contested among citizens. With multiculturalism in decline since the 1990s, pressure has been 
placed on immigrants to integrate and conform. Following the economic recession and the resulting deterioration of living standards and increased competition for public resources between social groups, anti-immigrant attitudes have escalated. Immigrants have faced the very real consequences of the labels that have been attributed to them in public discourse (Milioni, Spyridou \& Vadratsikas, 2015). A recent study of hate speech in Finland found three distinct hate-related themes when discussing asylum seekers. These were related to imported violence, economics, and cultural identity. Hate speech was targeted towards specific ethnic groups and religions, which reflected the immigration and asylum seeking context in Finland. Interestingly, hate speech around immigration extended beyond asylum seekers into Finnish society (Insiders), to include negative speech towards government and groups that support immigration (Kaján, 2017).

In the U.S., Kirk and Martin (2017, p. 210) have established four specific kinds of appeals that carried overtones of hate in Donald Trump and Hillary Clinton's languages during 2016 presidential campaign: (1) Those that try to inflame the emotions of the followers; (2) those that fight for denigrate the outclass; (3) those appeals that try to harm the opponent; and (4) those whose main goal is to conquer.

\section{Hate speech and immigration in the U.S.: Donald Trump}

Following Trump's election victory in the U.S., public discourse has become increasingly intolerant, bigoted, and sympathetic to social abandonment. It is expected that this discourse will not remain isolated, but will instead seep into several other realms of society. This moment in politics and culture has leveraged ignorance to create an alarming anti-intellectualism that gave way to the rejection of critical thought and reflection. Throughout his election campaign, Trump's weaponization of lies left language devoid of meaning and credibility, and set the stage for a post-truth culture where deciphering opinions from facts is at times incredibly challenging. His seemingly endless stream of tweets has made it difficult for the public to piece coherent narratives together, while also seeking to dismantle trust in the very institutions attempting to hold him responsible for his words and actions - the media and free press (Giroux, 2017, p. 890).

Sensationalism, manipulation of emotion, and rambling have become staples of Trump's language, with his unflinching and unwavering disregard for the truth and reality leaving no space for, and actively discouraging or ignoring, valid criticisms or discussion. This landscape where falsehoods are the only constant has made it challenging to disentangle what Trump actually knows and means when he speaks about any issue, as he refuses to take responsibility for his words or actions politically, ethically, or socially. What, at surface level, may register as ignorance and incoherence, goes beyond that. Trump's disconnect with reality and even rationality have tapped into the everyday fears and moral panics associated with earlier periods of 
fascism (Giroux, 2017, p. 890). "Make America Great Again” was a sentence of division: The winning and the losing side (Kirk \& Martin, 2017, p. 211). Again, showing that propaganda works with simple messages. There are two sides, and the propagandist always chooses the good one. The big groups of identified enemies are, inevitably, the contrary of us and the big problem of our nation.

\section{Hate speech and immigration in Spain: Santiago Abascal}

In Spain, Vox and its leader, Santiago Abascal, work in a similar way. This is a right-wing extremist political party that grew dramatically in the 2019 elections, going from 24 representatives to 52 in just a few months. His speech has been described with ideas of authoritarianism, nationalism, reaction to cultural change, and unit against Catalonia (Anduiza, 2018).

Vox was born as a political party in 2013. "Vox" comes from a Latin word that means "voice". The majority of its political leaders came from Partido Popular, a conservative party that ruled Spain, with Mariano Rajoy as President, from 2011 to 2018. Abascal, Vox's leader, has belonged to Partido Popular from the 1990s to 2013, when he established Vox along with José Antonio Ortega Lara, Cristina Seguí, José Luís González Quirós e Ignacio Camuñas. This new party was created to defeat Mariano Rajoy's right-wing policies. Two years earlier, Abascal wrote a book called En defensa de España. Razones para el patriotismo español, ${ }^{1}$ a text signed by DENAES Foundation for the Defense of the Spanish Nation. The main idea of Vox is around Spanish unity and nationalism. Thus, they affirm that the otherness is responsible for the crisis and the collapse of patriotism. Vox and Abascal send messages everyday through their SNS where they demonize immigrants and refugees, arguing that they are rapists, criminals, and so on. Vox has pointed them as the responsible for crimes and violent acts, even citing false data (El País, 2019). Alfonso Aya, delegated prosecutor in hate crimes, has determined that some messages sent by Vox are attacks against minorities (EFE, 2019).

Samprieto and Sánchez-Castillo (2020) have studied the success of Santiago Abascal (the Vox candidate) on Instagram, where he has 566,000 followers (the biggest number of followers among Spanish politicians). They found Abascal shows the Spanish flag and the Vox logo in almost half of his Instagram pictures and uses the word "Spain" in the text frequently, highlighting his nationalistic agenda on SMS. Abascal uses pejorative words such as "golpistas" (coup leaders), "derechita cobarde" (coward little right), and "progres" (progressives) trying to catch media attention (2020).

\section{Othering through framing}

Public opinion of migration and migrants is greatly influenced by media frames (Lakoff \& Ferguson, 2006). Framing is a way to write or speak 
about an object or issue calling attention to specific aspects or characteristics. Specifically,

to frame is to select some aspects of a perceived reality and make them more salient in a communicating text, in such a way as to promote a particular problem definition, causal interpretation, moral evaluation, and/or treatment recommendation for the item described.

(Entman, 1993, p. 52)

Through framing, the author or editor of a text transfers the salience of specific attributes about an object via the selection and emphasis of particular interpretations of reality. Framing draws attention to the process of deciding who and what is important in a situation or story. Framing the concepts of politics and policy serves the purpose of creating societal meaning.

The words used to describe immigrants and immigration, as well as the issues and concerns made salient when speaking or writing about them, frame and highlight aspects and suggest angles from which to consider the issues. SNS have become a powerful tool for ideological framing because they allow direct communication between a source and an audience, without the filter of an editor or gatekeeper, and without the rigor of fact checking and citing sources. Also, since social media allows users to follow those accounts they are interested in, it gives ideologues a platform to reach large groups of people who already agree with them and reinforce their beliefs.

Discourse about immigrants often draws attention to ethnic and cultural characteristics, presenting them as "alien" to native populations and having the potential to disrupt the political and cultural order of a country or society by threatening its "purity" and "authenticity" (Triandafyllidou, 2000). Ter Wal (1996) referred to the "threat" frame specifically as a risk to public health. The "enemy" frame is also frequently seen in the media, presenting migrants as competitors taking the jobs of natives (Grobet, 2014).

Lakoff and Ferguson (2006) identified an "otherness" frame, which sees immigrants as threats to the culture, language, and values of the society, and found it to be a frame employed frequently by the media. Millioni et al. refer more specifically to the "victim frame" (e.g. exploited/helpless), a "threat" frame (e.g. criminal, alien, burden, etc.), and an "active agent" frame (e.g. worker, investor, member of society).

A recent study analyzed more than 7 million tweets using hashtags such as \#refugee, \#refugeecrisis, and others, and found the dominant frames revolve around security and safety on the one hand and humanitarianism on the other (Siapero et al., 2018). The study also found that some explicitly racist hashtags were associated with the security and safety frames. In general, the refugee issue on Twitter was found to be politicized and often used to further political interests. Siapera et al. (2018) also found that the 


\section{2}

Ana I. Barragán-Romero and María Elena Villar

more politicized frames around immigration revolved around the rhetoric of Donald Trump and the growing anti-immigration voices in Europe (Siapera et al., 2018).

\section{Research questions}

The main objective of this chapter is to analyze the similarities between Abascal and Trump on Twitter, as they are both politicians that have used SNS as the perfect tool to spread their rhetoric of hate. Based on the literature reviewed above, we posed the following research questions:

RQ 1: Is there a difference in the type of propaganda used by Trump and Abascal in immigration- and nationalism-related tweets?

RQ 2: Is there a difference in the perceived enemy named by Trump and Abascal in immigration- and nationalism-related tweets?

RQ 3: Is there a difference in the frame-related themes used by Trump and Abascal in immigration- and nationalism-related tweets?

\section{Method and sample}

The sample consisted of a random sample of 204 tweets from Donald Trump (@TheRealDonaldTrump) and Santiago Abascal (@Santi_Abascal) that included keywords related to immigration and nationalism between January 1 and October 31, 2019. The API (Application Programming Interface, which allows access to resources only available on the server) provided by Twitter has led to the proliferation of data services and software tools for searching based on keywords, scraping vast amounts of text data, and conducting automated sentiment analysis and sophisticated social media analytics. Social media data can be used in a variety of academic disciplines, including innovation management, stakeholder management, and content monitoring. Data can be tracked using APIs based on keywords, specific actors/authors, and specific URLs. Data can then be coded based on structural attributes (generally machine coded); sentiment, which can be machine coded or human coded; and topic- or trend-related coding. This study uses theme and topic coding for content analysis and identifying trends (Steiglitz et al., 2014).

Meltwater Explore is a social media listening tool that enables keyword searches to help monitor and analyze social media activity on several social media platforms. In a 2014 case study comparing Meltwater with two other social media monitoring tools, Meltwater was found to be the most extensive when searching for posts based on the selected keywords, particularly due to its ability to search retroactively given date parameters. This allowed for a greater reach and retention when finding posts by keywords (rather than hashtags, for example) in a past time period (Adi \& Hobby, 2013). 
Using the Meltwater social media monitoring tool, we used the following Boolean phrases to identify tweets that directly addressed immigration, refugees, or nationalism. The terms contraband and trafficking were included because both study subjects used this term in the context of illegal immigration. For the Trump sample the Boolean search phrase was: Author: "Donald J. Trump" AND (immig* OR alien OR wall OR undocumented OR Mexic* OR traffick* OR violen* OR refuge*). This resulted in 346 tweets (264 Unique hits). For the Abascal sample, the search criteria were: Author: "Santiago Abascal" AND (inmig* OR espan* OR violen* OR refugiad" OR contrabando"). This resulted in 381 unique tweets (241 unique hits). These specific search terms were selected after testing other combinations that resulted in different combinations of immigration- and non-immigration-related tweets. These search terms were selected for highlighting common topics around the current discourse of immigration and nationalism in the U.S. and Spain.

After eliminating retweets and tweets that were unrelated to immigration or nationalism, about half of Abascal's tweets were eliminated creating markedly different sample sizes for analysis (225 for Trump and 124 for Abascal). We then selected a random sample of 120 tweets from each candidate using Excel RAND function. Kim et al. (2018) found that a simple random sampling is more efficient than a constructed week sampling in terms of obtaining a more efficient and representative sample of Twitter data. Researchers eliminated duplicates (Abascal tends to share his own tweets), as well as any tweets that were determined not to be related to the issue under study (for example, some tweets about the Mexico trade deal referred to immigration and others only had to do with commercial trade). This yielded a final sample for analysis with 116 tweets by Trump and 88 tweets by Abascal.

\section{Coding}

The three main variables of interest for the research questions were propaganda type, perceived enemy, and frame-related theme. The coded variables are detailed below. We used an iterative process of pilot-testing and refining the codebook. The two investigators agreed on the criteria for the variable codes and conducted an inter-coder reliability test on the equivalent of $10 \%$ of the content in the study. For all variables where there was not perfect agreement between coders in the pre-test, we resolved all points of disagreement through consensus and clarified definitions for the codebook.

Inter-coder reliability was assessed by double-coding 20 tweets (an equivalent of $10 \%$ of the sample) and calculated Cohen's Kappa. The resulting coefficient of 84.5 exceeded the threshold for almost perfect agreement using the guideline outlined by Landis and Koch (1977), where the strength of the kappa coefficients $=0.01-0.20$ slight, $0.21-0.40$ fair, $0.41-0.60$ moderate, $0.61-0.80$ substantial, $0.81-1.00$ almost perfect, according to Landis and Koch (1977). Of the 16 -variable coded themes, 1 had moderate agreement, 5 had substantial agreement, and 11 had almost perfect agreement. 


\section{Ana I. Barragán-Romero and María Elena Villar}

\section{Type of propaganda}

Propaganda referred to the three types proposed by Pineda (2008): Affirmative, negative, and reaction. A tweet was coded as Affirmation Propaganda when the entirety of the tweet was pushed the agenda of the author's party or ideology, without referring to any opposing viewpoint. A tweet was coded as Reaction Propaganda when the message presents the author's agenda after explicitly presenting the opponent's agenda or when their own agenda was juxtaposed to an opponent's agenda that was explicitly mentioned in the tweet. A tweet was considered Negation Propaganda only the opponent's views are presented and/or critiqued explicitly and the propagate's view is implicit. The Cohen's Kappa coefficient for inter-coder reliability for the variables was 0.87 .

\section{Identified enemy}

One of the tools of propaganda is the demonization and oversimplification of a common enemy (Pineda, Macarro Tomillo \& Barragán Romero, 2012). We coded tweets that explicitly or implicitly identified an enemy using criteria based on the concept of portraying enemies: Negatively framing the so-called enemy in moral terms, and depicting the relationship to the opponent as a struggle of good against evil. Specifically we set out to determine if the immigrant enemy was identified by country or region of origin, or some other characteristic, or whether immigrants and refugees were enemies as a group. As such, we coded tweets that referred directly or indirectly to an enemy using the following codes: (1) Arab/Middle Eastern; (2) African; (3) Latin American; (4) Catalan; (5) Unspecified immigrants; (6) Unspecified refugees; and (7) Non-immigrant enemy. Political rivals (i.e. competing politicians or the opposing party in general) were not coded as enemies. However, some internal (non-immigrant) groups were framed as the evil side in a fight between good and evil, and portrayed as morally at fault. The Cohen's Kappa coefficient for inter-coder reliability for the variables was 0.86 .

\section{Frame-related themes}

Themes were coded according to the presence or absence of specific frame-related topics in the main text of the tweet. Frame-related themes were based on the themes identified in the literature and inductively after open coding of test tweets (prior to 2019 time period). The final frames and themes were chosen after open theme coding in a preliminary pilottest, and pre-testing the codebook with tweets from other time periods. We kept the most frequently occurring themes for the final analysis. We set out to code for frames that could contribute to anti-immigrant politics and support the rhetoric of hate and exclusion, but also frames that lauded the 
moral superiority of the author's agenda or ideology. A single tweet could be coded for more than one of the themes and thus fall under more than one frame. This resulted in the following themes grouped into three main frames:

-Immigrants as a Threat Frame: This frame included instances where the issue of immigration was presented around themes of crime, violence, danger, terrorism, invasion, or loss of culture. It also included references to "golpe de estado" (coup d'etat), or "golpistas" (rebels) in Spain, typically referring to Catalan separatist protesters.

-Law and Defense Frame: This frame was used when the tweet focused on issues of laws and deterrence as the response to immigration. Tweets were coded under this frame if they referred to borders, walls, illegal immigration, or immigration laws.

-Preserving Values Frame: Themes under this frame brought attention to what could be lost if immigration increases. Tweets were grouped into this frame if they were coded as including the themes of homeland, national security, and fairness. The Cohen's Kappa coefficient for inter-coder reliability for the variables was 0.83 for primary and secondary frame, and 0.86 for tertiary frame.

\section{Data analysis}

Data were entered directly into IBM SPSS® Version 20 for statistical analysis. Frequencies and descriptive statistics were obtained for all coded variables. The differences in propaganda type, enemy, and frame-related themes were assessed using chi-square.

\section{Results}

\section{Types of propaganda}

Almost half of Trump's coded tweets $(49.1 \%)$ were designated as affirmation propaganda, meaning that they only pushed his perspective or agenda without referring to an opponent's views. Only $27.3 \%$ of Abascal's tweets were of this type. An example of affirmation propaganda by Trump on October 2, 2019, stated:

Massive sections of The Wall are being built at our Southern Border. It is going up rapidly, and built to the highest standards and specifications of the Border Patrol experts. It is actually an amazing structure! Our U.S. Military is doing a GREAT job.

Abascal's most common type of propaganda approach was reactionary $(45.5 \%)$, where he specifically mentioned an opponent's position and presented his agenda or perspective as superior. Trump used this kind of 
message in his tweets (35.4\%). An example of reactive propaganda was posted by Abascal; in response to a news item about violent protests on October 28, 2019: "This is the multicultural Spain that the progressives of all parties want, from PP to separatists. Only VOX defends the immediate expulsion of illegal immigrants and legal ones that commit serious crimes".

Negation propaganda or messages that were limited to criticizing an opponent's position without presenting the author's agenda were used least by Trump, with only $15.5 \%$ of his tweets falling in this category. An example of negation propaganda include this one by Trump in reaction to tweet calling for Congress to ratify the U.S.-Mexico-Canada trade agreement on October 3, 2019: “The Do Nothing Democrats don't have time to get it done!" Abascal used negation propaganda in $27.3 \%$ of his tweets. An example of negative propaganda by Abascal is a tweet dates August 19, 2019, attacking a pro-immigrant non-governmental organization:

Open Arms is not an NGO, is the operating base of the extreme left working with the great multinationals and banks. When they attach Italy, they attach the sovereignty, identity and coexistence in Europe. Immigrants are their political commodity. Nothing more.

Abascal's reactive and negation propaganda is associated with the framing violence. His messages cite violent actions of the enemy to present himself and his party as the solutions. As seen in Table 10.1, violence is used in almost $50 \%$ of Abascal's tweets.

Table 10.1 Frames and Related Themes

\begin{tabular}{llll}
\hline Immigrant as Threat & Trump & Abascal & Chi-sq value; sig \\
\hline Crime & $22.4 \%$ & $5.8 \%$ & $10.871 ; p=0.001$ \\
Violence & $2.6 \%$ & $50.0 \%$ & $61.361 ; p<0.001$ \\
Golpe/Golpistas (Coup/ & $0.0 \%$ & $22.1 \%$ & $27.618 ; p<0.001$ \\
$\quad$ Rebels) & & & \\
Terrorism & $0.9 \%$ & $9.3 \%$ & $8.035 ; p=0.005$ \\
Invasion & $3.4 \%$ & $12.8 \%$ & $6.018 ; p=0.014$ \\
Law and Defense & Trump & Abascal & Chi-sq value; sig \\
Border(s) & $52.6 \%$ & $7.0 \%$ & $47.523 ; p<0.001$ \\
Wall(s) & $53.4 \%$ & $1.2 \%$ & $64.152 ; p<0.001$ \\
Illegal immigrants & $25.9 \%$ & $23.3 \%$ & $0.266 ; \mathrm{NS}$ \\
Immigration laws & $13.8 \%$ & $4.7 \%$ & $4.839 ; \mathrm{NS}$ \\
Preserving Values & Trump & Abascal & Chi-sq value; sig \\
Homeland & $9.5 \%$ & $24.4 \%$ & $7.825 ; p=0.005$ \\
Fairness & $0.9 \%$ & $7.0 \%$ & $5.357 ; p=0.021$ \\
\hline
\end{tabular}

Source: Author's own. 


\section{Enemy}

Trump's and Abascal's tweets were coded for the enemy that they put forth in their tweets. Enemies were presented as morally defective in that they caused or contributed to the problem of immigration as an existential threat. The most frequently identified enemy in Trump's tweets were "unspecified immigrants/refugees" (62\%, compared to $28 \%$ for Abascal), while for Abascal, the most frequently identified enemy were non-immigrant enemies $(42 \%)$ usually referring to leftist groups and politicians. Almost 1 out of $5(18 \%)$ of Abascal's tweets in the study period referred to the Catalan separatists as the enemy, rather than immigrants or refugees, cited a group that went against Spain's interests.

\section{Frame-related themes}

Frames were defined based on specific related themes (See Table 10.1). Abascal used the Immigrant as Threat frame more frequently than Trump. Half of the tweets by Abascal referred to danger, and just over one-fifth related (synonym) directly or indirectly to "golpistas", or people involved in a movement against the government [MOU1]. He often called them terrorists $(12.8 \%$ of tweets) and conflated these three themes to represent immigrants as threat. Abascal wrote:

This is the Smiles Revolution. A new episode of the golpistas' violence. Here in Spain, we do not abandon the people who suffer through violence for defending their flag. My support to this poor woman and my contempt for the coward who hit and threw her to the floor. Along with this text, there is a video of a woman holding a Spanish flag and being attacked by another person.

Another example reads:

Could you imagine that there is a plan to introduce terrorists as "refugees" in Europe through the connection between irresponsible governments-mafias-NGOs? They did that already in 2015. Bataclan's terrorists entered as refugees, as have many others. This is very well proved. And very well hidden.

Abascal tweeted "Against the irresponsibles that talk about the benefits of multiculturalism and the massive immigration, Vox claims surveillance and forcefulness against the Islamism that threatens our culture, our freedom and our own lives" and

Four German tourists are beaten and one left with a broken leg in a mugging in Barcelona. They were assaulted by a group of maghrebis (Northern Africans). Again. But the progressives continue with their open door policy to illegal and massive immigration. 
Under this frame, Trump was more likely to bring up crime $(22.4 \%$ of his tweets) than any other threat. He often mentioned drugs and human trafficking, but also an increase in crime in general as an expected outcome of immigration. For example, Trump tweeted "Great unity in Republican Party. Want to, once and for all, put an end to stoppable crime and drugs! Border security and Wall. No doubt!",

$23 \%$ of Fedarl inmates are illegal immigrants. Border arrests are up 240\%. In the Great of Texas, between 2011 and 2018, there were a total of 292,000 crimes by illegal aliens, 539 murders, 3,200 assaults, 3,426 sexual assaults and 3,000 weapons charges. Democrats come back!

and “...This will supersede USMCA. Likewise I am looking at an economic penalty for the 500 Billion Dollars in illegal DRUGS that are shipped and smuggled through Mexico and across our Southern Border. Over 100,000 Americans die each year, sooo many families destroyed!"

Another recurring theme was the notion of invasion by foreigners. Almost a tenth of Abascal's tweets used this theme to frame immigration as a threat. Trump used this frame, but much less frequently (4\%). An example of tweets using this frame is the Abascal's tweet: "In Rome, a very positive working meeting with@matteosalvinimi in the Italian Senate. We agree fully on the need to protect Europe's borders from massive immigration, and the respect for national sovereignty - and unity - of the EU member states", or when Trump tweeted:

...travesty that is taking place in allowing millions of people to easily meander through their country and INVADE the U.S., not to mention the Drugs \& Human Trafficking pouring in through Mexico. Are the Drug Lords, Cartels \& Coyotes really running Mexico? We will soon find out!

Trump was significantly more likely to use themes related to the "Law and Defense" frame referring to illegal immigration (as a violation of law), and defensive measures or structures including immigration laws, borders, or walls. More than half of Trump's tweets referred to the wall and the border, where Abascal used these themes in fewer than $7 \%$ of his tweets $1.2 \%$ for wall). Trump was significantly more likely to mention immigration laws (13.8\% compared to $4.7 \%$ by Abascal). These mentions could be about specific laws being discussed by the legislations or referring to the need for reforming immigration laws.

Abascal was more likely to appeal to themes that called for the preservation of lifestyles of values that could be lost with increased immigration. Almost a quarter of Abascal's tweets referred directly or indirectly to Spain as the homeland that needs to be guarded and celebrated. Trump used this 
theme in fewer than $10 \%$ of his tweets. Abascal also appealed to fairness and the perceived injustice against law-abiding Spaniards and people trying to protect the homeland. This is illustrated by Abascal's tweet:

This is the multicultural and progressive society that the left imposes and followed by the easily influenced. This is a precursor to the Chavismo (referring to Venezuela's leftist authoritarian regime) where honest Spaniards are left defenseless before mafias and the violent. Only Vox proposes the robust reforms that the situation requires.

\section{Conclusions}

The tweets by Trump and Abascal analyzed for this study meet the definition of propaganda established by Pineda Cachero (2006) because they, as politicians, use them to achieve or maintain a powerful position. As Domenach (1986) stated, propaganda is polymorphous and uses many resources, social media being one of them. Trump and Abascal use social media because it is the most effective way to reach their target audience. While SNS are the mediums of choice today, radio and television were the protagonists' mediums years before.

With respect to the first research question posed above, there were clear differences in the type of propaganda used by both men. About half of Trump's immigration-related tweets qualified as affirmative propaganda, meaning that they exalted Trump or his allies. Over a third $(35 \%)$ of Trump's tweets were reactive, where he mentioned an opponent's views or actions and then refuted them. He was less likely $(15 \%)$ to only attack without referring to his side of an argument in the same message. Abascal's most common form of propaganda was reactive, where he mentioned an opponent's ideas or actions and refuted them. This accounted for $45 \%$ of Abascal's tweets, followed by $27 \%$ of his tweets being negation propaganda, where he specifically attacks another person or group without presenting a counter argument in the same message. These results are in line with Donald Trump's personality and brand of bravado and self-promotion, and support the notion that Abascal's rhetorical strategy is primarily about attacking opponents, rather than only promoting his view.

As far as the second research question, there was one main difference between the subjects. The majority of Trump's tweets (62\%) identified immigrants as the enemy, while Abascal was more likely to identify leftists and separatists as the enemy. In other words, Trump identifies the enemy as external, and someone that has to be "kept out". Abascal more frequently identifies internal enemies that are "among us" and trying to cause trouble. As discussed previously, identifying an enemy to rally your followers and channel their anger is a key tool used in propaganda. These two opinion leaders provide clear enemies to blame and foster fear and protectionism. 
Finally, the third research question dealt with thematic frames around the issue of immigration. As presented in Table 10.1, Abascal was most likely to frame his statements around the immigrant (or separatists) as a threat, particularly a threat of violence. He was also more likely than Trump to focus on values, in particular the protection of the homeland and patriotic values. On the other hand, Trump was most likely to lean on frames around law and defense, with a particular focus on protecting the border and building a border wall. This difference is most likely due to their impression of their audiences and what they expect will be more likely to resonate. Trump frames his anti-immigrant propaganda around enforcing laws and borders, and Abascal highlights the threat to the homeland from violent outsiders.

Abascal and Trump both use social media as a way to promote negative feelings against immigrants framing them as threats, implying that they are responsible for crisis, crimes, and violent acts. This fits with the goal of propaganda to oversimplify a common enemy. As far as propaganda types, Trump was more preoccupied with advancing his agenda than putting down opposition agenda, although still used negating or reaction propaganda, where the majority of Abascal's tweets focused on the opposition's ideas by criticizing them or contrasting with his. The analysis of themes led to the conceptualization of frames that extend beyond previously identified frames around immigration: Law and Defense and Preserving Values.

The primary limitation of this study is the time period and the impact of different events affecting the two subjects (Trump in the U.S. and Abascal in Spain) at that particular time. The specific context would naturally affect the focus of immigration-related tweets. There are always challenges with content analysis of social media content based on keywords, since there could be relevant content that did not include any of the selected search terms. Finally, we conducted human coding of the content as opposed to machine coding of text. This limits the sample size but allows for more researcher interpretation of results based on context and images.

Future research on social media as a vehicle for anti-immigrant hate speech and propaganda, it would be important to examine how the content shared by leaders such as Abascal and Trump impacts others' communication about immigrants, and conduct broader cross-national comparisons to identify global trends in anti-immigrant propaganda.

\section{Note}

1 It can be translated as In defense of Spain. Reasons for the Spanish Patriotism.

\section{References}

Adi, A. \& Hobby, N. (2013). Social media monitoring in higher education: A case study of corporate marketing communications of Bournemouth University and its outreach to Asia. 2013st corporate and marketing communications in Asia conference proceedings. Available at https://cutt.ly/7kjGhjc 
Anduiza, E. (2018). El discurso de Vox. Agenda pública. Available at https://cutt. ly/BkjGQxq

Barragán-Romero, A. I. \& Bellido-Pérez, E. (2019). Fake News durante la Primera Guerra Mundial: Estudio de su representatividad en las portadas de la prensa española (ABC Madrid). Historia y Comunicación Social, 24(2), pp. 433-447.

Bernays, E. (2005). Propaganda. Brooklyn: Ig Publishing.

Cunningham, S. (2002). The idea of propaganda. A reconstruction. Connecticut: Praeger.

Davis, R., Baumgartner, J. C., Francia, P. L. \& Morris, J. S. (2009). The internet in U.S. election campaigns. A. Chadwick \& Ph. N. Howard (Eds.), Routledge handbook of internet politics (pp. 13-24). Abingdon (Oxon): Routledge.

Domenach, J. M. (1986). La propaganda politica. Buenos Aires: Eudeba.

EFE. (2019, 19th January). La Fiscalía alerta de que algunos mensajes de Vox podrían alentar el discurso de odio. El Mundo. Available at https://cutt.ly/xkjHd3Z

El País. (2019, 7th December). El discurso del odio. El País. Available at https:// cutt.ly/XkjHQAm

Entman, R. M. (1993). Framing: Toward clarification of a fractured paradigm. Journal of Communication, 43(4), pp. 51-58.

Filimonov, K., Russmann, U. \& Svensson, J. (2016). Picturing the party: Instagram and party campaigning in the 2014 Swedish elections. Social Media + Society, 2(3). doi: 10.1177/2056305116662179

Giroux, H. A. (2017). White nationalism, armed culture and state violence in the age of Donald Trump. Philosophy and Social Criticism, 43(9), pp. 887-910.

Grobet, A. (2014). Responsible reporting and perceptions of migrants in an era of unprecedented mobility. In G. Dell'Orto \& V. L. Birchfield (Eds.), Reporting at the southern borders (pp. 47-61). New York: Routledge.

Herreros Arconada, M. (1989). Teoría y técnica de la propaganda electoral (formas publicitarias). Barcelona: PPU.

Huici Módenes, A. (2010). Guerra y propaganda en el siglo XXI. Nuevos mensajes, viejas guerras. Sevilla: Alfar.

Kaján, E. (2017). Hate online: Anti-immigration rhetoric in Darknet. Nordia Geographical Publications, 46(3), pp. 3-22.

Kim, H., Jang, S. M., Kim, S. H. \& Wan, A. (2018). Evaluating sampling methods for content analysis of Twitter data. Social Media+ Society, 4(2). doi: $10.1177 / 2056305118772836$

Kirk, R. \& Martin, S.A. (2017). The dark power of words: Stratagems of hate in the 2016 presidential campaign. In J. R. Denton (Ed.), The 2016 US presidential campaign. political campaigning and communication (pp. 205-229). Cham: Palgrave Macmillan.

Lakoff, G. \& Ferguson, S. (2006). The framing of immigration. Berkeley, CA: The Rockridge Institute.

Landis, J. R. \& Koch, G. G. (1977). The measurement of observer agreement for categorical data. Biometrics, 33(1), pp. 159-174.

Lasswell, H. D. (1927). The theory of political propaganda. The American Political Science Review, 21(3), pp. 627-631.

Milioni, D. L., Spyridou, L. P. \& Vadratsikas, K. (2015). Framing immigration in online media and television news in crisis-stricken Cyprus. The Cyprus Review, 27(1), pp. 155-185. 
O'Shaughnessy, N. J. (2004). Politics and propaganda. Weapons of mass seduction. Manchester: Manchester University Press.

Persily, N. (2017). The 2016 U. S. election. Can democracy survive the Internet? Journal of Democracy, 28(2), pp. 63-76.

Ponsonby, A. (2005). Falsehood in war time: Containing an assortment of lies circulated throughout the nations during the great war. United States, New York: Kessinger Publishing.

Pineda, A. (2008). Un modelo de análisis semiótico del mensaje propagandístico. Revista Internacional de Comunicación Audiovisual, Publicidad y Literatura, 1(6), pp. 32-45.

Pineda, A., Macarro Tomillo, A. \& Barragán Romero, A. I. (2012). Semiótica de la propaganda: aplicación empírica de un modelo de análisis formal a portadas de prensa de la Guerra Civil Española. Anàlisi: quaderns de comunicació i cultura, 46, pp. 49-68.

Pineda Cachero, A. (2006). Elementos para una teoría comunicacional de la propaganda. Sevilla: Alfar.

Pizarroso, A. (1990). Historia de la propaganda. Notas para un estudio de la propaganda política y de guerra. Madrid: Eudema.

Samprieto, A. \& Sánchez-Castillo S. (2020). Building a political image on Instagram: A study of the personal profile of Santiago Abascal (Vox) in 2018. Communication \& Society, 33(1), pp. 169-184.

Siapera, E., Boudourides, M., Lenis, S. \& Suiter, J. (2018). Refugees and network publics on Twitter: Networked framing, affect, and capture. Social Media + Society, 4(1). doi: 10.1177/2056305118764437

Taylor, P. M. (1990). Munitions of the mind. War propaganda from the ancient world to the nuclear age. Glasgow: PSL.

Tchakhotine, S. (1985). El secreto del éxito de Hitler: la violencia psíquica. In M. De Moragas (Ed.), Sociología de la comunicación de masas. III. Propaganda política y opinión pública (pp. 154-191). Barcelona: Gustavo Gili.

Towner, T. L. \& Dulio, D. A. (2012). New media and political marketing in the United States: 2012 and beyond. Journal of Political Marketing, 11, pp. 95-119.

Triandafyllidou, A. (2000). The political discourse on immigration in southern Europe: A critical analysis. Journal of Community \& Applied Social Psychology, 10(5), pp. 373-389.

Verea, M. (2018). Anti-immigrant and anti-Mexican attitudes and policies during the first 18 months of the Trump administration. Norteamérica: Revista Académica Del CISAN-UNAM, 13(2), pp. 197-226. 


\title{
11 Hate speech and social polarization in Brazil
}

\author{
From impeachment to \\ Bolsonaro
}

Gisella Meneguelli and Carme Ferré-Pavia

\section{Introduction}

Brazil has become a pioneer country in Latin America for the growth in its far-right political forces. After the rise of President Jair Bolsonaro in 2018, conflicts in Chile, Bolivia and election results in Uruguay in 2019 have indicated that an increasingly radical ideology is taking shape in the region's politics. The full breadth of political conservatism still embraces South America. In the Brazilian case, it is not possible to make a political reading dissociated from the colonial heritage that directly affects the patriarchal and racial structure of the country. This question is clearly illustrated in Santos's (2020) analysis, which states that "since the 17th century, the three unicorns have been capitalism, colonialism and patriarchy" (p. 12), and they continue to act shamelessly in Brazil today.

The hate speech in Brazil began in 2013 with the June protests (June Journeys) and then continued in 2014 with the Football World Cup. These were capitalized by the right-wing parties and supported by the media with the intention of creating, through what Charaudeau (2007) calls the social-discursive imaginary, an ideological polarization in the country.

This type of discourse, based on "total idealism that invalidates science", seems to have made Brazil a case study, how it shows Jair Bolsonaro's handling of the coronavirus, which gave him the title of the worst ruler to deal with the disease in the world.

This chapter aims to analyse the socio-political course, including mass media, that enabled the rise of Bolsonaro since Rousseff's impeachment in the context of hate speech. The methodological focus is on the semiolinguistics theory of discourse analysis. First, there will be an observation of the protest posters that took over the streets in 2015 against the Workers' Party; later, there will be an exhaustive analysis of opinion articles from $V e j a$, the most widely read magazine at the time. This chapter seeks to demonstrate how the controversy portrayed by the magazine, according to the social-discursive debate, contributed to establishing a polarization of ideology in the country. 


\section{The June protests background}

The so-called June Journeys (protests against public transportation fare increases in 2013) became powerful political capital for Brazilian right-wingers, based on transmedia narratives (Scolari, 2013) of activist and journalistic stories then used during the 2014 World Cup in Brazil - the same year that President Dilma Rousseff was re-elected (Meneguelli, 20I5). The June 2013 demonstrations showed that occupation of the streets is an instrument of struggle for citizens and new forms of citizen participation. According to journalist Piero Locatelli (Mattos, 2014), the protests revealed that people can achieve their goals by taking over the streets, without the intermediation of institutions, and put an end to a deep-seated inertia in the country.

This sense of "empowerment" of the population extended to the 2014 Football World Cup, even though the protests were not as big. In Locatelli's analysis (Mattos, 2014), this decreased participation was due to the lack of a specific proposal to unite the protesters. Cava (Mattos, 2014) agrees that the World Cup did not trigger larger demonstrations due to difficulties in organizing protests during the event, especially because Brazilians have a strong identification with soccer. In addition, the police were prepared to contain any wave of demonstrations during the World Cup, even if this required support from the army.

In 2014, demonstrators proposed a "renewed political discourse, outside the traditional institutions" (Bentes, 2014, p. 253), bringing the event to life and documenting it. They created a technological network of outrage that used a language of action with an "autonomous capacity to communicate and organize" (Castells, 2013, p. 24). The movement that began in 2013 transformed into a giant wave in 2015 as a result of Dilma Rousseff's re-election as President. At that point, defence of polemic became a type of argumentation in the establishment of public conflict in Brazil.

To understand this wave, in terms of production of meaning within the method of discourse analysis, Meneguelli and Ferré-Pavia (2016) distinguish the concept of communication situation, which is commonly confused with that of context. The former refers to the physical-social environment of the language act, while the latter refers to the textual environment of the word. The context is therefore an internal part of the language act, while the communication situation is external to it, since it concerns all the conditions surrounding its production (Charaudeau \& Maingueneau, 2014), which allow us to interpret a statement as a kind of situational instruction.

From a discursive point of view, this means that every language act is performed in a situation of standardized communication, organized in accordance with the restrictions imposed by the mise-en-scène of the discourse. This defines the position of legitimacy of the language subjects, that is, who is authorized to take the floor. Each situation is unique because it is included in a particular domain of communication (political, media, 
academic, etc.) and embodies a certain purpose, which Charaudeau (2004) conceptualizes as visées discursives (discursive glances).

\section{Hate posters}

Analysing the posters used in the March 2015 protests in Brazil and considering the discursive construction of political polemic in the generation of public confrontation, Meneguelli and Ferré-Pavia (2016) took as a basis the concepts of dissent and polemic proposed by Amossy (2014). According to Amossy (2014), controversy is organized in the democratic sphere because it is part of public debate and political deliberation. In this sphere, dissent is a structuring category of conflict management, since it is a radical division of the feelings, interests, convictions that are in the thought and belief systems of those who disagree.

When analysing the posters, the researchers identified a paradox between a demand for the right to protest in public and a return of the military dictatorship, which reveals the argumentative limits of controversy and verbal violence as means to value the democratic environment. Despite their heterogeneous themes, the posters' background was the right to exercise public demonstration and disagreement. Methodologically, the posters were organized into the following four groups:

1 Attacks: Posters containing verbal and visual insults, threats, and death wishes against former President Luiz Inácio Lula da Silva and then President Dilma Rousseff.

2 Dichotomization: Posters containing ideological polarization by constructing a dichotomy of "us" versus "them", Marxism/communism versus liberalism, elite versus Workers' Party (PT).

3 Impeachment: Signs connecting political corruption to a single party, the PT; systematic use of the colour red (PT) versus the green and yellow colours of the Brazilian flag, symbolizing nationalism and militarism.

4 Military intervention: Posters calling for military intervention as a to save the country from Petista (PT) corruption, using verbs expressing a desire and demand for military intervention or a coup and/or external support from the United States.

In this wave of disruption, it is important to understand the discursive organization of the 2015 protests as a breeding ground that enabled the rise of the candidate Jair Bolsonaro in the 2018 presidential election, as well as his victory without having participated in the public debates with the other candidates.

Bolsonaro is a professional politician who remained a member of the Chamber of Deputies for almost three decades. He also established the political life of his three sons, who are now accused in the investigation of fake news produced by the so-called Hate Office. His son Flavio, who is a 
senator, is still suspected of being involved with the militias that are supposedly behind the assassination of Rio de Janeiro city councillor Marielle Franco and involved in a corruption scheme known as Rachadinha. However, the "myth" was constructed by disassociating him from political life, as if he were a regular citizen angry with the corruption of the government. He gave the impression that corruption could only be contained by a strong, austere man, without fear of opposing powerful figures in politics and the media. According to Martins (2017), "politically, we are of a liberal vocation, a liberalism founded on the traditions of personal power and political patronage, its opponents" (p. 26). This tradition is not so much anchored in a social conscience as it is in a national conscience, a terrain which was ready for the 2015 right-wing demonstrations and, later, Jair Bolsonaro.

Amossy (2014) analyses the radical discourse from the perspective of demonization of the other, which presents the adversary as an absolute evil to be fought against. Demonization was used as a strategy of polarization, built using hyperbolic attacks, the object of a moral reproach convened to expel the evil, PT.

We need to expand the demonized figure beyond the PT, the Workers Party, itself. The PT, in its 13 years of government, produced a more inclusive social project, which meant giving representation to segments considered subordinate, especially people of African descent and women. This meant a change in social relations in Brazil because the elites and the white middle class began to feel that their privileges were threatened. Public policies invaded private spaces, as the so-called subalterns began to have new spheres of representation. The strategy to contain these social advances was to prevent the re-election of Dilma Rousseff. Since the ballot boxes did not endorse the financial and political elites' plan, a legal-media script needed to be produced that would bring about impeachment with social support. Both for the impeachment of Rousseff and military intervention, the discourse was based on a far-right ideological matrix that was growing fast in Brazil and eager to change the country's political course, either by force or by way of a white-collar coup d'état. The far-right entered the political game, as the posters show, with the aim of taking power by way of accusation, insult, and intervention, taking advantage of a context of economic recession that caused social discontent.

Moreover, polarization reveals the different world views that shape the identities of social groups. The fallacy of defamation was used as a strategy to undermine Rousseff in the 2015 protest (2013) and clarified that morality is one of the conditions on which legitimacy is based in the political domain.

The attacks on Rousseff in the 2015 protests were organized with the aim of destroying her image to the point of causing a crisis of political trust in Brazil, which has even paved the way for mistrust of public institutions and weakened Brazilian democracy. The type of argument used to deconstruct both Rousseff's and Lula da Silva's images was, in fact, an 
ad hominem fallacy, aimed at disqualifying them personally. It sought to silence the PT and its public figures by excluding them from the political game, something that has become evident, a posteriori, with the impeachment of Dilma Rousseff and the imprisonment of Da Silva, preventing him from participating as a candidate in the 2018 election.

A key aspect is that the visée that guides the discourse of the posters is one of incitements, given that the demonstrating " $I$ " wants to "order" Rousseff to leave the function of head of state, but it does not have the authority to do so without providing evidence of what is illicit. While the incitement approach is dominant, the demonstration approach also comes into play when trying to establish that the PT is corrupt. In both types of discursive focus, the "you-citizen" is in the position of "having to believe" that Dilma Rousseff and her party should be excluded from politics. To do this, it is necessary to evaluate the image that is presented to them as true.

Validation of this truth was co-opted by the so-called traditional media, allied with the financial elite represented by the right-wing parties. Meneguelli (2017) analysed images of Dilma Rousseff in the online version of the most widely circulated national magazine, Veja, as well as part of the ethos that this medium built for itself in 2014 and 2015 (the period preceding the 2014 election until the beginning of Rousseff's second term).

The main criteria for choosing the publication Veja is because it is one of the preeminent voices of public opinion in Brazil, as Maffesoli points out (Vasconcellos, 2014).

\section{The 2016 Coup and the Brazilian media}

To analyse and explain the construction of images of Dilma Rousseff, we propose an analysis of the role of the media in the 2016 Coup from a linguistic-discursive point of view, based on the abundant use of a connotative linguistic category: the adjective. Adjectives are understood as discursive mechanisms for intentionality. In this case, from the media outlet analysed: Veja magazine.

The main function of traditional media, since the beginning of the history of the press in Brazil, has been identified as "articulation between dominant groups, which centralize, discipline and ideologically organize ideas, and the public to which they must be disseminated", according to Barbosa's study (2010, p. 183). In this sense, as Miralles (2011) attests, the role of the media in building public opinion in democratic societies must be conceived from a pluralistic conception that is suitable for public debate. This can only happen by offering citizens different perspectives on issues of collective interest. In the case of Veja, the journalists explicitly took sides and did not reflect between pro- and anti-judgement (impeachment), but used simplification procedures, applied to something complex, and moved away from the role that the media should play in informing readers about what is happening in the public space. 
Controversy is therefore extremely important because it allows for public confrontation and generates communities of protest, oversight, and regulation, as well as political action that drives social change. Both Amossy (2014), from studies on argumentation in discourse, and Miralles (2011), from studies on journalistic communication, agree that a culture of consensus can be threatening to democracy, as it creates the illusion that there is a homogenization of a plurality of identities. Thus, it can be dangerous for democracy to have a false idea of a society without conflict.

If an enemy - not an adversary - is introduced to the tense situation anchored in the slogan "the enemy must be destroyed or eliminated", a path is opened for verbal (and sometimes even physical ${ }^{1}$ ) violence to nullify the conflict. As stated by Amossy (2014), the nerve centre of democracy is not consensus, but the management of dissent. To assume that there is a consensus or to try to institute it as an ideal good is to establish a rhetoric that appeals to impartiality and neutrality with the aim of hiding conflict.

The danger of action-oriented discourse to eliminate the other is in creating an undemocratic principle that obstructs dialogue and the acceptance of differences. This threat has been evident since the re-election of former President Dilma Rousseff, when political, legal and media discourses explored corruption as being exclusive to a single political party, demonizing the images of Lula da Silva and Dilma Rousseff, personifying them as the evil faces of political corruption in Brazil.

From a linguistic point of view, polarization is established in lexical choices. The way in which the lexicon, and more particularly the names of the opponent, cast doubt on an opponent makes the speaker express his or her values in order to share them with his or her audience

\section{Opinion in Veja}

Twenty-eight opinion articles from the "Columnists" section in Veja were selected as a sample for research. Two of them are presented as examples in this article. The first was published before the 2014 presidential election. In it, Rousseff's social-discursive image is that of someone who is undemocratic and unreliable. Veja, for many years, has been one of the most widely read magazines in Brazil. Until the end of 2016, it was the magazine that had the largest distribution in Brazil, with an average of 1,112,000 copies, ahead of Época magazine, in second place, with an average of 340,200 copies.

Veja published a video about Dilma Rousseff's March 31st anniversary speech in 2014. On March 31, 1964, a coup d'état overthrew the democratic government of President João Goulart and established a military dictatorship headed by Humberto de Alencar Castelo Branco, which lasted until 1984.

In the first case (pre-election), the introduction, in which the voice of journalist Reinaldo Azevedo is framed as the revealer of truths giving 
evidence (the video) that Dilma Rousseff is a poor speaker because she does not know how to use Portuguese properly. To maintain its credibility, it presents data that prove what is said by building an ethos of reporter credibility in line with the journalistic communication contract.

The columnist builds his ethos by asserting an identity as a critical subject committed to the truth, when he affirms that he is obliged to describe what he sees: "But then I wouldn't be being me, okay", "Because I am who I am, and because it is a speech on truth, so let's go". But then, in contrast to his image as the "subject of truth", the discourse is related to expressions with negative values towards Dilma Rousseff. The explanation is as follows:

In (1) rede suja (dirty network), the columnist denounces the PT for going against freedom of the press; in (2) Venezuelan regime, Brazil is negatively associated with the governments of Hugo Chavez and Nicolas Maduro, both described as authoritarian; in (3) authoritarian governments, Rousseff is associated with terrorist actions for evoking her past during the time of the dictatorship. Strategically, lexical elements are selected to shape an image of the President as a representative who is not committed to truth and democracy and therefore not credible to speak about such issues in a speech regarding March 31,1964. We must also consider that the text "speaks" visually, both in the colours and the arrangement of the video at the beginning of the article, intentionally placed there to encourage people to read.

The text is written in two colours: red and blue. In social political imagery, red is associated with the left, socialism, communism and, in Brazil, the PT; blue represents freedom, the right and the social democratic party, the PSDB (Partido da Social Democracia Brasileira), the main opposition to the PT. The columnist's comments are marked in blue, which means he is aligned with the values of the right and freedom, as opposed to Rousseff's speech, which is highlighted in red. In Veja, there is a tradition of using the colour red (even in its printed version), according to research by Jodelet (2001), which shows that, when used predominantly, the colour is connected to the breakdown of social order.

We have seen, therefore, that the ethos constructed by Veja is one of a revealing subject of truth - faithful to the title that defines it: a magazine with a "revealing and regulating vocation" - which has its sights set on the speech of Dilma Rousseff. Her image is constructed as that of someone who is unreliable due to her association with authoritarian governments and her past as a guerrilla and, also, incompetent to govern, because her linguistic shortcomings "indicate" a disorder of thought. In an interview with journalist Mário Prata in 2010, he comments on the "sick feeling" that some Brazilian media have against the PT.

As we know, an essential feature of social representations is their power of influence. They circulate through the language in an interactive process between Veja's columnists and the magazine's readers, thus creating 
for Rousseff, in other articles, an image that "she speaks badly because she thinks badly". Since the President would not have any communication skills, Veja builds her image as a politician unable to express herself and, as a direct consequence, unable to be an efficient ruler for Brazil.

A cultured subject ethos is created using a language of power in which a single valid norm is cultivated. Rousseff is responsible for distorting her language, to the extent that she has created a new one for herself, "dilmês", because her thinking is inconsistent and chaotic.

There is no doubt that there is an ideological dispute that is materialized linguistically in the opposition between the Veja norm and the Rousseff disorder. The President's disorder represents the disorder of her government and the country. Dilma Rousseff (and the PT) socially represents another (popular) culture, which is gaining space in the social imagination with its rise in concrete and symbolic terms, while Veja opposes this cultural renewal by maintaining a conservative, authoritarian and ironic discourse, appealing to the literary knowledge of a literate elite.

In the second example (post-election), observing discourse after the 2014 elections, we will take as a case study an article published in Veja in which we can see the construction of an image that Dilma Rousseff and the PT are not reliable. The article is called Did Cunha create the economic crisis? The political crisis? The crisis of confidence? Poor Dilma! Cunha is a solution for her! ${ }^{2}$ Its author is Reinaldo Azevedo, and it was published on July 21, $2015 .^{3}$

In this article, 19 adjective expressions are used against Dilma Rousseff and the PT, including:

4 Poor Dilma.

5 Apocalyptic language of war.

6 Pure political terrorism.

7 Economic crisis.

8 Political crisis.

9 Crisis of confidence.

10 War image.

11 Flag of peace.

12 Withdrawal of the mandate.

13 Government executioner.

14 Hope factor.

15 Government without an agenda.

16 Type of solution.

17 Scapegoat.

18 Incompetence of the person.

The title of the article posits several crises in the Brazilian setting: economic, political and of confidence. The repetition strategy, as we have seen, 
is used to create a simplified reality effect, to be crystallized in the readers' cognitive structure. It should be noted that, as in other articles published around the same time, Veja creates a gradation of the seriousness of the crisis: economic, political and of confidence, as if the latter were the biggest problem afflicting Brazil.

It is necessary to take into account that by denying the relationship between the then President of the Chamber of Deputies, Eduardo Cunha, and the political crisis that had taken hold in Brazil, by silencing the political plots in which he had been shown to have participated, Veja not only simplifies reality, but also manipulates it.

By supporting Cunha, holding him up as (14) a factor of hope, Veja takes on the risk of losing face, that is, its positive image, becoming the image of an unethical and irresponsible media for its audience. Although Veja's text agrees with the norms, values and attitudes socially shared among its readers, who are outraged by the PT government, most of them do not agree with Eduardo Cunha's actions because they are against acts of corruption.

It is indisputable that Eduardo Cunha started a political war against the government of Dilma Rousseff, and this conclusion did not come only from an (15) agenda-free government that wants to use him as (17) a scapegoat to be (18) a solution for its own incompetence, which, yes, can and should be criticized by the opposition, since dissent should be a discursive practice in democracy.

The expression crisis of confidence must also be noted, and it appears repeatedly in many other Veja texts. It contains Veja's judgement of the Dilma Rousseff government and of Rousseff herself as a political figure. It is not surprising that the expression is repeated in several texts and even within the same text, and it has the discursive function of crystallization, transforming the problem of the crisis of confidence in Dilma Rousseff into a truth that can only be countered by her dismissal from the presidency. Perhaps such a reader would not read it because he was persuaded by propaganda spread by his or her community that the magazine is fake. But the explicit repetition of adjectives is reinforced by digital journalism. If we think about the circulation of a text on the web and the various ways it can be accessed by a reader, the repetition of a word/expression is a powerful resource in establishing a truth.

Nogueira (2013) states that when politics is deformed by the absence of a confrontation of ideas, the stigmatization of others occurs through discourse, which is structured in a hyperbolic, angry and resentful narrative. Veja's discourse adopts this kind of strategy by portraying Dilma Rousseff as intellectually unprepared and linguistically disjointed, with no real evidence of the relationship between such shortcomings and her government. Before the 2014 elections, Veja's discourse contained a tone of humour that ridiculed Dilma Rousseff's public persona through selected clippings from her parliamentary speeches, taken out of context. The images constructed with 
the analysed adjectives assign Rousseff the image of a non-democratic, unreliable and illiterate person, a characteristic that does not allow her to think.

The attributes amalgamated in an image of Dilma Rousseff were designed to undermine her legitimacy as President of Brazil. Through a legitimization process, the social body acknowledges someone as acting on its behalf. In the profile constructed by Veja, the candidate would not be competent to act legitimately on behalf of Brazilians, since she does not know how to do so. On Veja's side, its ethos has been formed by intellectual capacities, representative of high literacy and the "good" and "pure" Brazilian culture, and, therefore, capable of making a critical analysis that reveals Rousseff's inability to preside over the country.

An intentional media project created an illegitimate image of Dilma Rousseff so she would not win the 2014 presidential election, yet the reelection candidate won a majority of the votes to govern Brazil for another four years. It is not the intention here to spread the idea that Veja (or other media) constructed Dilma Rousseff's image based solely on the fabrication of lies. Many narrative facts selected by Veja refer to events that actually existed. Bad decisions on economic policy and corruption crimes did occur during the Petista administration, but the selection of those chosen to be narrated and discussed, the highlights, the implications of the subjects involved and those who were forgotten, contributed to linking negative aspects to the public image of Dilma Rousseff and the PT.

Following Dilma Rousseff's victory at the polls came a rhetoric of resignation that led to the discrediting of the President's image. Veja is no longer interested in attacking the legitimacy of Dilma Rousseff; her image of credibility must be destroyed, completely removing any trust in her, led by an idea of evil. While Veja's spirit was previously built up as a denouncer, a critic attentive to the evils practised by Rousseff and her party, it then became more combative, giving Dilma Rousseff the opportunity to surrender for her "crimes": resignation. However, the accused subject did not surrender because there was no crime, so Veja, from February 2015 onwards, began accusing her repeatedly.

As the crisis of confidence wore down the Rousseff government and the PT, the judge who coordinated the Lava-Jato operation, Sérgio Moro, gained legitimacy. With the help of the traditional media, Moro's image as a hero was built up. His mission was to overthrow Lula da Silva, which meant in practice preventing him from participating in the 2018 election, since the Petista represented a real risk to Bolsonaro's candidacy.

The political-legal-economic-media orchestration used Bolsonaro, a military man expelled from the Armed Forces who for almost three decades made a career in politics as a member of the Chamber of Deputies to the extent of forming a political clan with his three sons. As Levitsky and Ziblatt (2018) state, "while family businesses and army squadrons can be governed by orders, democracies demand negotiations, compromises and concessions" (p. 80). 


\section{Popularization of hate}

Social representations, as a great discourse of quotations presented to society, disconnect the text and separate it from its context. The dynamic process of social representations entails changes that can influence the behaviour of a community, as shown by several sociological studies (Jodelet, 2001; Moscovici, 1989, 2001; Schutz, 1999). The media helped to promote the change in social behaviour that occurred in Brazil with the reports on Operation Lava Jato ${ }^{4}$ by stoking dissent, which highlighted the problem of the false consensus that seemed to unite the country.

This would be explained, in part, by Solano Gallego's diagnosis (2016) that a set of reasons influenced the fall of the PT and the collapse of the Brazilian left. The first of these is related to the disastrous economic results implemented in Rousseff's second term and her lack of political leadership to get out of the crisis, as well as her party's corruption scandals, which were also decisive in polluting trust in the Petista government.

The second set of elements is linked to the political decisions made by the PT, according to the researcher, since lulism (from Lula) has opted for conciliation rather than for confrontation of the economic, political and media oligarchies. The cost of approaching this group led to the social-discursive idea that the PT is just "another party", provoking discredit in the political representation itself.

Finally, the third set of elements concerns respect for the concept of class. While the PT's policy enabled the integration of millions of historically marginalized citizens, using policies to promote consumption and redistribute income, a fraction of the privileged classes did not feel contemplated by the government and therefore sought to maintain their class privileges which in Brazil also include ethnic and gender privileges.

Solano Gallego (2016, 2018a, 2018b) has been studying the growth of the extreme right in Brazil. In her research, which includes surveys, she concludes that votes for Bolsonaro in 2018 were anti-system, which is a consequence of the second set of elements above. The denial of policy is a result of a collective anger that formed a dispersed, pro-authoritarian network. According to the researcher (Solano Gallego, 2016, 2018a, 2018b), the problem with the election of Bolsonaro is how it is reflected in what she calls the "Bolsonization of public life", that is, the popularization of hatred and intolerance was forged over the years by hate speech and political polarization.

However, it is necessary to contextualize Bolsonaro's political rise within a broader international spectrum. Since the Euro crisis in 2010, Europe has followed an austerity plan coordinated by neoliberal-oriented political and financial institutions. This model finds a paradigmatic political figure in Brazil to act in a polarized scenario. This tense situation began to be forged in 2013, creating a new neoliberal chapter that some consider to be neofascist. ${ }^{5}$ Despite all this, Donald Trump came to power in the United 
States in 2017, bringing with him a real imperialist threat in Brazil. According to Bandeira (2016), since Wall Street has lost its power in the face of China and Russia, the destruction of large Brazilian companies that have expanded throughout the world makes it easier for US multinationals to enter the Brazilian and Latin American markets.

\section{Conclusions}

The results of the research show the leading role of the traditional Brazilian media in building a social-discursive imaginary that circulated hate speech to further weaken agitations that had already been underway in Brazil since 2013. Hate speech gave a sense of legitimacy to Rousseff's impeachment and to all the following chapters of Brazil's recent socio-political history. The discourses that led to polarization were circulated largely through the media as part of a political game that had been defined in the 2014 election. Some of the right-wing parties were unsatisfied with the election results thus the media and judicial support gave legitimacy not only to the organization of Rousseff's impeachment, but to the creation of a character who would fit the role whose script was ready: Jair Bolsonaro.

In 2013, when the first displays of contempt for Dilma Rousseff's government began, it failed to deal with one aspect of democracy: dissent. However, in 2015 , the controversy was expertly managed by the right wing and the Brazilian elite, who knew how to use it to promote hate speech. Once hate speech is established as a social pattern, the ability to overcome dissent through language is lost. Discourse requires a minimum of agreement so that the subjects of the language build an arena in which each of them puts forward and defends their points of view, and attacks those of their adversaries. Controversy, as Amossy (2014) has taught us, allows democratic life to be organized through public debate and political deliberation. It is dissent, then, that structures the management of conflicts of opinion rooted in the thought and belief systems of the members of a society.

The protests against Rousseff were among the most interesting examples of hate speech, at least in Brazil, as shown by the posters from demonstrations. When hate speech becomes popular and constitutes the day-to-day mismanagement of political dissent, life in a democracy becomes poorer. The findings explained in this chapter also show how the dominant media, with the example of Veja, participated in a drift that led to the victory of the extreme right. It is essential to highlight the use of social networks, especially WhatsApp, in the propagation of fake news against the PT candidate, Fernando Haddad, which was decisive in the election result. Fake news manipulated socio-discursive imaginaries, for example, among young people, to whom Bolsonaro presented himself as an anti-system candidate; among evangelicals, for whom the discourse was oriented towards a risk of degenerating customs; or among the middle class, for whom the discourse was oriented towards class resentment, as social policies became clientelism for them (Arruda, 2020; Solano Gallego, 2018a). 
With the fall of Sergio Moro from the Ministry of Justice, ${ }^{6}$ Bolsonaro did not lose popularity. It has oscillated during the pandemic, but has recovered, and he already has his eyes on the 2022 electoral dispute.

\section{Notes}

1 It is important to remember the assassination of Rio de Janeiro councillor Marielle Franco in 2018 and the self-imposed exile of former federal deputy Jean Wyllys for suffering threats and not receiving protection from the Brazilian state, and so many other cases similar to his.

2 Eduardo Cunha was President of the Chamber of Deputies at the time. In March 2018, a judge sentenced Cunha to 15 years in prison for corruption, money laundering and tax evasion.

3 Retrieved from: https://veja.abril.com.br/blog/reinaldo/cunha-fez-a-criseeconomica-a-crise-politica-a-crise-de-confianca-pobre-dilma-cunha-e-pra-elauma-solucao/

4 Operation Lava Jato is a set of judicial investigations involving thousands of search and seizure and arrest warrants, with the aim of investigating a money laundering scheme that moved billions of reais in bribes. Lava Jato's legitimacy fell under suspicion, since the main judge for the operation, Sérgio Moro, accepted to be a Minister of Justice in Bolsonaro's government, acted illegally in the process according to a series of reports by The Intercept Brasil (https://theintercept. com/2019/07/05/scandal-for-bolsonaros-justice-minister-sergio-moro-grows-asthe-intercept-partners-with-brazils-largest-magazine-for-new-expose/).

5 There is a controversy among analysts and theorists about the suitability of the term fascist for Jair Bolsonaro's government. On that discussion see Fernando Haddad's interview with Spanish sociologist Esther Solano Gallego (available at https://www.youtube.com/watch? $v=$ fjwwxxsHs2Y) and an interview with Portuguese historian Manuel Loff (available at https://apublica.org/2019/07/obolsonarismo-e-o-neofacismo-adaptado-ao-brasil-do-seculo-21/).

6 Caused by Bolsonaro's intervention in the election of the chief of the Federal Police, an action that would have repercussions on the investigation of his son Flavio Bolsonaro in a corruption case.

\section{References}

Amossy, R. (2014). Apology for the polemic. Paris: Presses Universitaires de France. Arruda, J. A. (2020). Influência dos discursos religiosos evangélicos na campanha presidencial de 2018 no Brasil. Último Andar, 23(35). Available at https://cutt. ly/rkjNQRZ

Bandeira, L. A. M. (2016). O Brasil está na mira de Wall Street. In C. Proner, G. Cittadino, M. Tenenbaum \& W.R. Filho (eds.), A resistência ao golpe de 2016 (pp. 253-255). Bauru: Canal 6.

Barbosa, M. (2010). História cultural da imprensa. Brasil 1800-1900. Rio de Janeiro: Mauad X.

Bentes, I. (2014, March). Respeitosamente vândala. Revista Cult, 188. Available at: https://revistacult.uol.com.br/home/categoria/edicoes/188/

Castells, M. (2013). Redes de indignação e esperança: movimentos sociais na era da interne. Río de Janeiro: Zahar.

Charaudeau, P. (2004). Visadas discursivas, gêneros situacionais e construção textual. In I. Machado \& R. Mello (eds.), Gêneros reflexões em análise do discurso (pp. 13-41). Belo Horizonte: FALE/UFMG. 
Charaudeau, P. (2007). Os estereótipos, muito bem. Os imaginários, ainda melhor. In H. Boyer (ed.), Les stéréotypes, c'est bien. Les imaginaires, c'est mieux (pp. 49-63). Paris: L'Harmattan.

Charaudeau, P. \& Maingueneau, D. (2014). Dicionário de Análise do Discurso. São Paulo: Context.

Jodelet, D. (2001). Representações sociais: Um domínio em expansão. In D. Jodelet (ed.), The social representations (pp. 17-44). Rio de Janeiro: EdUERJ.

Levitsky, S. \& Ziblatt, D. (2018). Como as democracias morrem. Rio de Janeiro: Zahar.

Martins, J. S. (2017). A sociabilidade do homem simples. São Paulo: Context.

Mattos, L. (2014, 13th July). História feita nas ruas em 2013 deixa lições na Copa. O Tempo. Available at https://cutt.ly/ukj6guz

Meneguelli, G. (2015). Eleição 2014 na rede social: cultura remix e os imaginários ideológicos das capas da revista Veja. Fórum Linguístico, 12(2), pp. 689-698.

Meneguelli, G. (2017). Ecos do ethos: um golpe na imagem pública de Dilma Rousseff em Veja on line 2017. [Doctoral dissertation]. Universidade Federal Fluminense, Niterói, Brasil. Available at https://cutt.ly/zkkZgfy

Meneguelli, G. \& Ferré-Pavia, C. (2016). Apología de la polémica como modalidad argumentativa: el conflicto público en Brasil en las protestas de 2015. Culture, Language and Representation, 16, pp. 57-84. doi: 10.6035/CLR.2016.16.4

Miralles, A. M. (2011). Miedo al disenso. Barcelona: Editorial Gedisa.

Moscovici, S. (1989). Des représentations collectives aux représentations sociales. Eléments pour une histoire. In D. Jodelet (ed.), Les Représentations Sociales (pp. 62-86). Paris: Presses Universitaires de France.

Moscovici, S. (2001). Social representations: Investigations in social psychology. Cambridge: Polity Press.

Nogueira, M. A. (2013). As ruas e a democracia - ensaios sobre o Brasil contemporâneo. Brasília: Counterpoint.

Santos, B. S. (2020). La cruel pedagogía del virus. Coimbra: Edições Almedina.

Schutz, A. (1999). On Phenomenology and Social Relations: Selected Writings. Chicago: University of Chicago Press.

Scolari, C. A. (2013). Narrativas transmedia: cuando todos los medios cuentan. Barcelona: Deusto.

Solano Gallego, E. (2016). Brasil. La caída del PT y el ascenso conservador. Nueva Sociedad, 266, pp. 147-155.

Solano Gallego, E. (2018a, May). Crise da democracia e extremismos de direita. Available at https://cutt.ly/Lkj9UAr

Solano Gallego, E. (2018b, 4th October). Por que há ex-eleitores de Lula que votam em Bolsonaro? Entrevista com Esther Solano. IHU online magazine. Available at https://cutt.ly/mkj98yN

Vasconcellos, F. (2014, 12th April). “O sistema educacional não funciona mais”, diz Michel Maffesoli. GZH. Available at https://cutt.ly/bkj5I2w 


\section{Part III}

Hate speech in the social, traditional and community media 

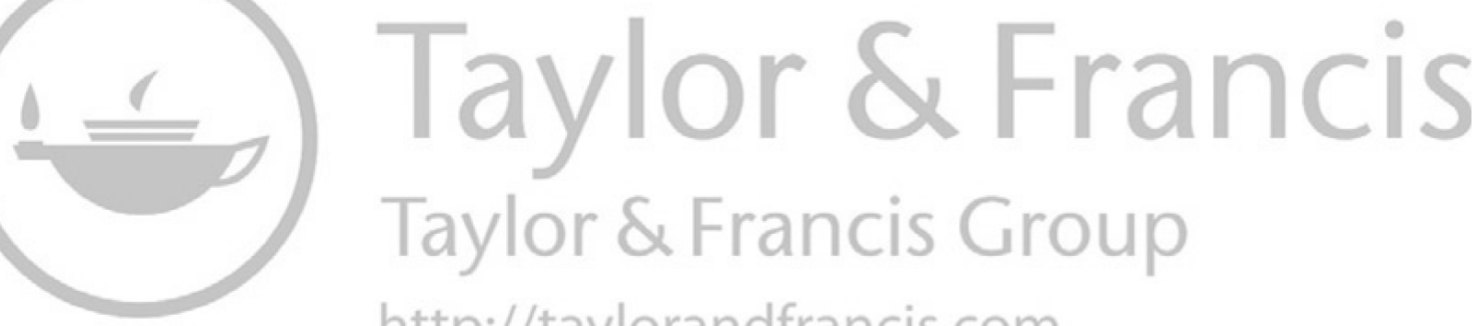
http://taylorandfrancis.com 


\section{Countering the stigma of homeless people}

The Swedish street paper

Situation Sthlm as a counterhegemonic voice for the rehumanisation of homeless people

\section{Nico Carpentier, Vaia Doudaki, Ali İhsan Akbass and Tianyi Wang}

\section{Laclau and Mouffe's discourse theory ${ }^{1}$}

In Hegemony and Socialist Strategy, Laclau and Mouffe (1985) provide an outline of their discourse theory, which is embedded in a post-structuralist and post-Marxist agenda. In contrast to many other approaches in discourse studies, Laclau and Mouffe's (1985) discourse theory uses a macro-textual and macro-contextual (see Carpentier, 2017, pp. 16-17) definition of discourse as frameworks of intelligibility. Discourses thus are seen as necessary instruments that give meaning to the social world, without denying their material dimensions. This also implies that discourses provide subjects with points of identification, which Laclau and Mouffe (1985, p. 115) call subject positions. Similar to Althusser's notion of interpellation, these subject positions offer subjects the building blocks of their subjectivity, as discursive structures for the construction of the self.

Moreover, Laclau and Mouffe (1985) emphasise the structural openness of discourses, which are always vulnerable to re-articulation, avoiding an ultimate and total closure of meaning. Discourses are often coherent entities, gaining their stability from privileged signifiers - or nodal points - but this stability is never to be taken for granted, as discourses can change, become insignificant or disintegrate. This contingency also impacts on subject positions that can never totally saturate the subject, as there are always a multiplicity of subject positions at work, and subjects always construct unique identificatory relationships with these subject positions. But at the same time, subject positions exercise considerable power, by providing frameworks of meaning that structure people's subjectivities, how they see, feel, experience and think about others and themselves, and which subjects and groups they like or dislike, consider friends or enemies or consider even human or not. 
Finally, Laclau and Mouffe (1985) also strongly thematise the political dimensions of the discursive, as discourses engage in struggles with each other, over the establishment of hegemony. Not all discursive struggles result in hegemony, as some struggles simply continue without any discourse achieving victory, but in some cases, a discourse manages to gain a dominant position and transform (itself) into a social imaginary that can benefit from the luxury of taken-for-grantedness, normalisation and eventually sedimentation. But even in this scenario, as our analysis of homelessness will illustrate, counter-hegemonic discourses are able to contest the hegemonic discourse and offer points of resistance, creating the threat that the once victorious discourse could be removed from its (discursive) throne.

\section{Constructions of the homeless and the home}

One area where we can see this discursive struggle at work is in relation to the subject position of the homeless person. The homeless is a subject position, which is - at least potentially - contestable, fluid, contradictory, as well as an object of identification and dis-identification, acceptance and rejection, but still very real in its existence. The homeless subject position is particular, because it is articulated through a series of disempowering signifiers that together form a stigma. Moreover, the vortex of this stigma generates strong absorptive forces through which this state of polarisation between the civilised and the homeless appears permanent and that tend to reduce the individual to this one subject position, ignoring the multiplicity of subject positions that make up a person's subjectivity.

The homeless stigma is simultaneously discursive and material, affective and cognitive, temporal and spatial, dealing with absences and presences, working with selves and others. It is an assemblage of material routines, sleeping places, interactions with companions, social workers, police officers, kind or aggressive passers-by, policies aimed at objectivation, disciplining, invisibility, removal and criminalisation, all structured through the absence of one crucial discursive-material component: the home. This absence of the home - and in particular of its material component, what McCarthy (2013, p. 54 - referring to Swain, 2011) calls "rooflessness" plays a crucial role, both in articulating the subject position and in organising the logics of stigmatisation and othering. Here, we should keep the centrality of the home in Western imaginaries in mind (Felski, 1999). In this imaginary, the home is the house, a material shelter that generates a private sphere for the (bourgeois) nuclear family. The (possession of the) home itself functions as a normative ideal, which is actively imposed as one of the requirements of modern life. Societal groups that are outside this hegemonic discourse (and its materialisation into a home) are, in different degrees, subjected to interventions that aim to align their behaviour with this hegemonic discourse. Powell (2008, p. 88), for instance, describes how 
the nomadic life of Roma and Travellers exposes them to societal pressures to "conform to a sedentary way of life". The sedentarist hegemony - with sedentarism defined as "the system of ideas and practices which serve to normalise and reproduce sedentary modes of existence and pathologise and repress nomadic modes of existence" (McVeigh, 1997, p. 9) - not only affects Roma and Travellers, though, as the subject position of the homeless is also articulated through this anti-nomadist discourse.

The central position of the home in Western imaginaries is not without contestation. Two key contestations are important here, as they also have the potential to impact on the stigma articulated with the subject position of the homeless. Morley's (2000, p. 47) emphasis on the mobile home as symbolic space (and not so much a place) represents one type of contestation. The second contestation focuses more on the problematisation of the home as the site of disciplining interventions, unequal power relations and violence, which allows the questioning of the safety and tranquillity of the (bourgeois) home (see, e.g., Haraway, 1991, pp. 171-172).

\section{Mainstream media and the representation of the homeless}

One main location where the homeless subject position is represented is the field of media. The mainstream media representations of the homeless subject position often support the processes and practices of stigmatisation, which construct them as an outgroup, in a diversity of ways. The absence of the home produces mainly negative stereotypes that stigmatise homeless people, ignoring the structural dimensions of homelessness (Shields, 2001), and using articulations that "largely [exempt] from culpability the social, economic, and political forces that create and perpetuate an unequal distribution of wealth and resources within [...] society and instead [conceptualize] homelessness in terms of personal pathology and failure" (Remillard, 2012, p. 6).

This also implies that mainstream media tend to represent homeless people within the binaries of either "victim" (Whang \& Min, 1999; Schneider, Chamberlain \& Hodgetts, 2010) or "threat" (Whang \& Min, 1999; Shields, 2001; De Melo Resende, 2016), and thus "deserving" or "undeserving" of help and support (Remillard, 2012; Zufferey, 2014). In the latter case, homeless people are articulated as an indirect threat to our health or civilisation (not civilised enough, not clean enough, etc.), and - less frequently - as a threat to our individual safety (as agents of violent behaviour and criminality). Even in more supportive approaches to homelessness, when the need for action is acknowledged, the homelessas-victims representations tend to frame them as "helpless, dependent for their salvation on society's benevolence, while the rest of society is assumed to be healthy and powerful" (Doudaki \& Carpentier, 2019a, p. 10). This articulation removes the homeless people's agency and positions them as an outgroup. 


\section{Counter voices: street papers}

The mainstream media coverage on homeless people, and its alignment with the hegemonic discourse of stigmatisation and sedentarism, is not the only media environment that allows for the circulation of the homeless subject position. Some media publications explicitly resist the hegemonic discourse of homelessness, and engage in a discursive struggle over the construction of this subject position. The most poignant example is the so-called street press. Street papers, circulating most often in the format of magazines or newspapers, demonstrate considerable diversity as to their format, design, content and operational models, but also consistency in regard to their approach and philosophy. They do share a common main purpose, which is to support homeless and other socially excluded people to find their way back into society, through employment (Boukhari, 1999; Howley, 2003; Harter et al., 2004). Homeless and poor people are the sole vendors of these editions, having the opportunity to gain some income and potentially reconnect with society. At the same time, street papers have a strong focus on the coverage of homelessness, poverty and social exclusion, broadening the scope of the latter by bringing inclusive perspectives of their constituents and dimensions, and raising awareness on social inequality and injustice (Harter et al., 2004).

Street papers also foster to varying degrees the voices of their communities, by giving voice to the homeless and the poor, allowing them to share their own "real-life" experiences and perspectives of homelessness, poverty and exclusion (Harter et al., 2004). Given their inclusive logics and their focus on issues of homelessness and social exclusion, which tend to be disregarded by mainstream media, street papers are seen by some scholars as alternative or participatory media. Howley (2003), employing Dorothy Kidd's (1999) definition of alternative media, argues that "in publishing material written by people living in poverty, street papers consciously align themselves with the philosophy and tradition associated with alternative media" (p. 274), since they are "committed to 'altering' prevailing social conditions and do so, in part, by publishing 'native' accounts of economic injustice from the local that they serve" (ibid.). Howley (2003) continues to argue that street papers constitute a unique form of communicative democracy, as, being the voice of the poor, they "seek to engage reading publics in a critically informed dialogue over fundamental issues of economic, social and political justice", addressing "disparities in economic, political and symbolic power" (p. 282).

However, there is a need to be careful with univocally celebrating street papers, especially when considering the actual range of opportunities that is offered to vendors to express themselves. Torck (2001) argues that the space given to the vendors' voices in street papers is generally limited, and restricted to specific writing genres, such as personal narratives, a restriction that in fact perpetuates their stereotypical representations. Also, in many 
cases, street papers' vendors are not part of the management and editorial teams, which raises questions about how participatory and grassrootsbased these publications are.

\section{The case of Situation Sthlm}

Situation Sthlm is one of the two currently active street papers in Sweden, ${ }^{2}$ circulating in the form of a monthly magazine. Its first issue was released in August 1995. It is based in Stockholm, and it is sold in public places by its network of vendors - homeless and socially challenged people - in different parts of, mainly central, Sweden.

Situation Sthlm is a member of the International Network of Street Papers. Its main mission is to support homeless and socially vulnerable individuals to find their way back to society, through employment, and reduce the harm and suffering these individuals are subjected to, due to their living conditions. Situation Sthlm publishes texts about people, events and culture in Stockholm from a street, or community perspective. It also publishes articles about homelessness, the lives of homeless people, about housing policy, psychiatric care and substance abuse care. Each issue of the magazine includes a section written by its vendors.

The number of its vendors varies, but it is estimated at 140 vendors on a monthly basis and at above 300 vendors on a yearly basis. The vendors are not employed by the organisation; they buy the magazine from Situation Sthlm for SEK 30 and sell it for SEK 60. The magazine has a reported circulation of 14,200 copies per month and 99,000 readers per month, and it has been awarded, among others, the Swedish PEN Bern's Prize 2005 and the Publicist Club’s Grand Prize 2006 (www.situationsthlm.se).

For the purposes of the study, we analysed published content over a sixmonth period (July-December 2018), 12 interviews with Situation Sthlm staff members and vendors, and short ethnographic observations (of five days), which were conducted by Ali İhsan Akbaş and Tianyi Wang during the period of November-December 2018. By deploying a discoursetheoretical analysis (Laclau \& Mouffe, 1985; Carpentier, 2017), the study examines how Situation Sthlm articulates a discourse that destigmatises and rehumanises homeless people, through the emphasis on the home as a contingent and affective space, the re-allocation of agency and the reactivation of homeless people's citizenship. At the same time, the analysis points to the limitations in the articulation of this alternative discourse.

\section{Analysis: rehumanising the homeless in Situation Sthlm}

Situation Sthlm counters the hegemonic discourse around homelessness, through its operational model, practices and published content, and articulates an alternative discourse, constructed around three nodal points: the home as a contingent and affective space, the reactivation of the homeless 
individuals' agency and the reinstatement of their citizenship. These nodal points inverse the logics of the hegemonic discourse that constructs the homeless subject position through the absence of house as stigma, the lack of agency for the homeless and the reduction of their political identity to that of the denizen, ${ }^{3}$ which also have been identified in previous studies on the hegemonic construction of homelessness (see Doudaki \& Carpentier, 2019a, 2019b, 2021).

\section{Home as diverse affective space}

Situation Sthlm counters the dominant approach towards homelessness, which focuses on the ideas of the permanent and fixed house as a home, regulated through the principle of ownership, and promotes, in contrast, an alternative articulation of the home that sees it as a contingent, diverse and affective space.

Situation Sthlm's articles show the contingency of the home and the multifacedness of both homelessness and homeness. In the great majority of cases, if not in all, homelessness (and homeness) is not seen as a fixed condition. Finding and maintaining a home is a constant struggle. Most Situation Sthlm vendors are in and out of homes during a big part of their lives. Also, the forms that both roofness and rooflessness take are diverse. Homelessness is about sleeping and living temporarily at friends' and family's houses, at night shelters, temporary residences, on the bus, on the train, in tents, in caravans, in owned or in abandoned cars, under bridges, in public toilets, at benches, in parks, on the pavement. Still, even in these conditions, decency of living is important. For example, Mikael slept for months on the bus and on the train, instead of returning to the "emergency accommodation" offered by the state which he argues is "disgraceful" (issue 251, p. 34) and unsuitable for him, given his medical problems and the fact that he wants his dog to live with him.

Situation Sthlm also broadens the idea of the home, relating it to its affective value. In one of the columns of the magazine, "My place", vendors talk about their favourite place in Sweden. In the vendors' narrations, which often relate to their childhood or to their families, memories from the past emerge. Their favourite place is in all cases an affective place, a place where the vendors found, at some point in their lives, love, safety and happiness. Often this is the place of childhood or of a happy period in their life, a place that they long to return to. Home is a place of privacy and safety, where one can close her/his own door behind her/him. This affective dimension of the home renders it a place that hosts one's passions and dreams, a space for creativity. For example, one of the homeless vendors, Katarina Karlsson, writes about her dream, which is to have a place where she can paint: "It makes such a difference for me to be able to paint for a while and [to say] to hell with all the misery. I don't think as much about my homelessness when I can express myself" (issue 251, p. 35). 
Finally, the affective dimension of the home also has a clear material dimension, as it is seen as a place that contains one's valuables, family photos, art, books, objects of memory that connect people with their past and roots. Situation Sthlm moves away from the home as a bourgeois house, and demonstrates that the home can also be mobile, but at the same time shows the dislocation caused by the absence of access to storage capacity and the struggle to keep one's valuables.

\section{Reactivation of agency}

Contrary to the hegemonic discourse on homelessness, which sees homeless subjects as weak, as victims and as lacking agency, Situation Sthlm articulates a discourse on the homeless people which gives them back, or re-acknowledges, their agency, at a variety of levels.

First, the relationship of Situation Sthlm vendors with the organisation is one space where the vendor's agency becomes enacted, as Situation Sthlm is dependent on the vendors' will and ability to sell the magazine. This approach relates to a broader strategy that Situation Sthlm implements, aimed at supporting the vendors to become more autonomous, which facilitates their empowerment and sense of self-respect. According to the organisation's model, the vendors decide where, when and with what frequency they sell the magazines. There are suggested posts (for example, at the metro or at the train station) but vendors can choose and suggest new posts, in neighbourhoods, even in cities that are initially not in Situation Sthlm's selling network. Also, as vendors develop an expertise in selling the magazine, they come up with ideas on how to improve the distribution of the magazine, which Situation Sthlm's staff listens to.

Agency also becomes enacted through the vendors' authorship. The vendors publish regularly in Situation Sthlm, receiving some financial compensation for publishing in the magazine. The magazine devotes 4-6 pages per issue to the vendors to write their stories, in the section "In their own words". These texts vary both thematically and in terms of genre. They can be short comments, poems, stories about the vendors' everyday lives and the conditions of homelessness, about their struggle with addiction, about their fears, hopes and feelings. The vendors are free to write about what interests them, as long as they stay within the limits of decency, not including foul language or attacks against other people by name, for example, an administrator in the social services that they might be angry with. It is vital for Situation Sthlm that the voice of its vendors is visible in the magazine. Since 1995 when the magazine was first published, its strategy was to have homeless people write about homelessness, on the basis of the argument that homeless individuals should talk about their situation themselves. As editor-in-chief Ulf Stolt, explains:

I encourage them 'tell your story while you're homeless'. They tell it because they are the only ones that can tell it. ... publishing those stories, 
making them publish their stories is what will change people's perception of [the homeless].

The Situation Sthlm staff also writes about homelessness, but for Ulf is important that the journalist takes him/herself "out of the story" and stays invisible, so that the homeless people are not overshadowed by the professional's presence:

When I write about homelessness, I try not to take their story or write about how it is being homeless, because that's their story. And they gonna tell that story, not me, but I can write about things that happen in their lives in their day-to-day business (Ulf).

In that way, "we can also tell their story without being tourists in their reality".

Vendors write not only about the dark sides of life, about homelessness, addiction and suffering, but also about the everyday pleasures of life and about their dreams, which also renders their agency visible. Apart from the pages in which the vendors write themselves, there are also a number of columns and articles in which they are interviewed and their voice is included in topics of homelessness, housing policies and addiction, but also in topics related to their lives and dreams. "My dreams" is one of the columns that contributes to the homeless people's rehumanisation. The vendors are interviewed by Situation Sthlm's journalist Maria Hagström and talk about what they would like to accomplish in life, portrayed as aspiring to a better life, as individuals who have not given up. Through these stories, readers get a multifaceted picture of Situation Sthlm homeless vendors, who are (re-)constructed as intelligent individuals, with a critical mind and a sense of humour, and who regain some control over (the articulation of) their own subject positions.

Throughout their narrations, homeless people appear as able agents, as people with skills, talents, work experience, special knowledge and achievements. They thus become destigmatised and rehumanised through a dual process, as both normal people and people with unique skills and talents. Homeless people are also rehumanised by being presented as both vulnerable and fragile, and strong and resilient, attributed an affective type of agency. Situation Sthlm's aspiration is to portray their vendors in ways that communicate dignity and not pity. As social activities manager and web editor, Jenny Lindroth, explains, “we don't see the victim in our vendors. ... we see strong people and we want to show that image to the readers. They are strong individuals and survivors, and that's how we see them".

Homeless people do struggle with harsh living conditions, with illness, addictions and life tragedies, but rendering this struggle visible again enhances their agency. Situation Sthlm's vendors talk openly about their health problems, their addictions and their battles in dealing with them. 
For example, Eva Nordlander talks about her favourite place, which is the Botanical Garden in Västerås (issue 252, p. 32), a place she sees as an oasis, which was also her hell during a difficult period of her life:

I became homeless and crashed. Had a relapse. I couldn't cope anymore, thinking I would just take a weekend break to get some vacation from myself. It was a long weekend - I was out for two and a half months. I've been sitting here in the garden and drinking, sleeping on the benches, so I'm split about the spot. But I love it and feel at home. Now I am sober and drug-free again, on the first of October it will be six years.

As this recounting of Eva shows, it takes courage to come to terms with one's addictions, and even more so to go back to the place of one's addiction and transform it into a place of hope.

\section{Reinstatement of citizenship}

The discourse on homelessness articulated by the Situation Sthlm assemblage - its organisational model, the practices of its actors and its published content - reinstates the political identity of the homeless people, countering the hegemonic discourse that deprives them of their citizen identity, reducing them to a state of denizenship.

Situation Sthlm's policy contributes to an affective approach towards citizenship, ${ }^{4}$ in which citizens in a difficult situation should not be further stigmatised, but understood and supported. Relatedly, Situation Sthlm points to the right of all citizens to live "a life with dignity and respect" and to the duty of the citizenry to support people in difficulties. As Situation Sthlm CEO, Pia Stolt, argues, it is not very difficult to find yourself on the street, but it is extremely difficult to get back on your feet once you become homeless.

So I hope that we can contribute to tell this story, and to take the side of all the people that try to live their life as good as they can, [and] that we are standing by them. We believe that everyone no matter of the choices, has a right to a life with dignity and respect. We want to lessen the suffering.

Situation Sthlm's operational model helps to reattribute the citizen's identity to the homeless vendors, by following, what they call a harm reduction strategy ${ }^{5}$ through work. The Situation Sthlm team is aware that the organisation cannot solve the vendors' problems; they rather consider Situation Sthlm as "the connection from the streets and onwards to make [the vendors'] life better" (Ulf). This is related to a non-judgemental approach towards the homeless vendors' problems, which is different from the official state policy, 
and which again demonstrates the affective dimension of citizenship. For example, Situation Sthlm does not ban vendors with addictions from selling the magazine, but the latter are not allowed to be under the influence of substances or alcohol while selling the magazine. This logics of tolerance is an example of how the vulnerability of citizens is embraced and not further penalised. Also, vendors are assisted by Situation Sthlm to connect with the authorities, and to get to know their rights and claim them, as it regards, for example, housing and healthcare. This helps homeless people reactivate a sense of entitlement as it regards their rights as citizens.

When it comes to Situation Sthlm's published content, the struggles of the homeless people with the welfare services, to be provided with accommodation, a job or healthcare, become visible. In these interactions with the state, homeless people perform their political identity, through the claiming of their rights. For example, in an article about the quality of housing offered by the social services, we read the story of Mikael, who was provided some housing option, which according to him was not suitable - he has medical problems and needs to be facilitated in accessibility, and he has a dog. He found a suitable, according to him, short-term accommodation, but his application for financial assistance for housing there was rejected, because that residence had no agreement with the state (issue 251, p. 34). At the time that the story was written, he had appealed and his case was being re-examined. Also in the texts that the homeless vendors write themselves, they frequently describe their interactions with the public authorities, evaluating the performance of the state and the quality of services it offers to its citizens. Through the homeless vendors' stories both the support and the exclusions maintained by the welfare system are highlighted. For example, Kjell writes a text about how the social services helped him keep his apartment that he was about to lose. Still, as he explains, one needs to prove that is drug-free, by being subjected to urine tests three times a week and take one's prescribed medication (issue 252, p. 36).

In another example, a vendor signing as Magdalena 407 points to the inefficiency of the welfare system, due to lack of resources, and its rigid logics of offering support to citizens falling within specific recognised categories. As she describes, "I went to the Employment Service to get me a job so I could get financial help, so I can at least sleep in a hostel, instead of a cold caravan" (issue 255, p. 39). She then explains that, after waiting for hours, she was asked to go back the next day, as there was not enough time to be helped. And the story continues:

Talking to people I know, one says: 'Why don't you make sure you get a diagnosis? Everything becomes much easier then, you get help faster'. There is nothing wrong with me. I am not a drug addict, have no mental illness, am not an alcoholic, I am just completely normal, do not think of humiliating myself to get a stamp just to fulfil the social service's wishes so that the Social Insurance Agency pays for my living. 
Apart from their personal encounters with the authorities and the evaluation of the efficiency of the state and its apparatuses, the vendors that write in Situation Sthlm also address a more general critique on the political system, on Swedish leadership, on social inequality, etc. These stories show how the vendors assume again - or have never lost - their identity as members of the polis who have the right to evaluate the performance of the state.

\section{Challenges and limitations in countering the homeless stigma}

Through its organisational model, through its practices and its published content, Situation Sthlm manages to create a rehumanised and repoliticised articulation of the homeless subject position, destigmatising the homeless people, which is however not free of challenges and limitations.

Situation Sthlm is, as it is described by the management team, a low-threshold organisation, open to (all) homeless and socially vulnerable people. Still, there are various restrictions, and exclusions, to this open invitation. According to the organisation, in order for the vendors to be accepted, they should have a Swedish personal identification number, and thus be entitled to support by the state authorities, in relation, for example, to supported housing and healthcare. Situation Sthlm's explanation is that selling the magazine should not be the last resort of people in a desperate situation, as the strategy of the magazine is that they assist vendors to connect with social welfare and get help in finding a place to stay, a job or get treatment for their addiction, so that they are supported in getting back to their feet, in a more structural and multilateral fashion. The requirement to have a Swedish personal identification number excludes a considerable number of people in dire need of help, from becoming vendors, for example, immigrants with no valid (or expired) papers, which also relates to one's perception of who shall be entitled to be regarded as a citizen.

The vendors are treated respectfully, in a non-judgmental manner. Situation Sthlm does not endorse a punitive system, in which if a vendor has misbehaved (for example, by being violent or aggressive) is automatically banned from working as a vendor for the magazine. There is an effort to deal with the problems and differences that arise through discussion about each other's position and feelings, which is called by the Situation Sthlm management team, a strategy of restorative justice. Still, there is a reformative approach in relation to how the vendors shall behave, both in the streets and at the offices of Situation Sthlm.

Also, as it became visible during the short ethnographic observation, the interaction among the staff of Situation Sthlm and the vendors stays within boundaries, mainly restrained to each side's role and position. This is also supported by the arrangement of the Situation Sthlm space, which is organised around one main open space and a set of closed offices, designated for the staff. The two areas are separated by an information desk, and 
the vendors hardly ever access the "office space", as they stay in the open space, where the vendors-staff interactions also take place. Finally, a lot of Situation Sthlm's strength in rehumanising and destigmatising the homeless comes from its commitment to hosting the original voices of the latter. Still, even if the magazine gives more prominence to the homeless people's voice than a number of other street papers, the extent and forms of participation on behalf of the vendors are controlled by Situation Sthlm's management team, in which the vendors are not part of.

\section{Conclusion}

Situation Sthlm manages to articulate a discourse that destigmatises and rehumanises homeless people, through its focus on the contingent and affective home, the reactivation of agency and the reattribution of homeless people's citizenship. This is supported by the magazine's participatory logics, as it concerns the inclusion of its vendors' voices in its published content, giving them space to tell "in their own words" the stories of their lives. Through this practice, Situation Sthlm's homeless vendors are found in the position of taking more control over their identification with, and articulation of, their own subject position. Still, this is not without its limitations as the form and degree of the vendors' involvement is controlled by the managing team.

Also, it should not be neglected that the articulation of the homeless' subject position, as it is constructed in Situation Sthlm - no matter how inclusive and humanising it is - is still context-specific, not representing a universal image of the homeless. It is the product of the actors involved in the Situation Sthlm assemblage, and of their interactions, and it is the product of organisational, cultural, political and economic influences. In particular, the requirements set by the organisation as to who can act as a vendor of the magazine, impacts, among others, on whose signifying practices can appear in the magazine. Also, the logics and the restrictions of the Swedish welfare state, under pressure but still operational, feeds into how the magazine's actors apprehend and experience homeness and homelessness.

Despite the limitations, as the example of Situation Sthlm shows, street papers invite for a reconfiguration of the representation of marginalised and stigmatised social groups, in ways that reverse the state of polarisation that has left the homeless in the position of an outgroup. This invites for a reflection on polarisation, as we should not only focus on processes of polarisation, but also on states of polarisation that have sedimented and hegemonised difference. This also invites for a reflection on the logics of participation, as this case study shows that participation can become a practice of care and a tool for de-polarisation, through the creation of spaces of inclusion, respect, solidarity and affect for the homeless people. 


\section{Acknowledgements and funding information}

This publication was co-funded through research time made available to Vaia Doudaki by Uppsala University's Dept. of Informatics and Media, and by a research internship at the same department, in which Ali İhsan Akbaş and Tianyi Wang participated.

\section{Notes}

1 The parts on discourse theory, the constructions of the home and the street press have already been published; see Doudaki and Carpentier (2021); Carpentier and Doudaki (2019); Doudaki and Carpentier (2019a); Doudaki and Carpentier (2019b).

2 The second one is Faktum, circulating also as a monthly magazine. Faktum was established in 2001 and is based in Gothenburg.

3 For the logics and practices of denizenship, see, for example, Marshall (1992) and Turner (2016).

4 See the academic literature on affective citizenship, for instance, Mookherjee (2005) and Di Gregorio and Merolli (2016).

5 In the interviews, also "the reduction of suffering" is used.

\section{References}

Boukhari, S. (1999). The press takes to the street. Unesco Courier, 52(2), pp. 43-44. Available at https://cutt.ly/RkkViAu

Carpentier, N. (2017). The discursive-material knot: Cyprus in conflict and community media participation. New York: Peter Lang.

Carpentier, N., \& Doudaki, V. (2019). The construction of the homeless as a discursive-political struggle: A discursive-theoretical re-reading of the homeless subject position. Filosofija. Sociologija, 30(1), 71-79.

De Melo Resende, V. (2016). Discursive representation and violation of homeless people's rights: Symbolic violence in Brazilian online journalism. Discourse \& Communication, 10(6), 596-613.

Di Gregorio, M., \& Merolli, J. L. (2016). Introduction: Affective citizenship and the politics of identity, control, resistance. Citizenship Studies, 20(8), 933-942.

Doudaki, V., \& Carpentier, N. (2019a). Critiquing hegemony and fostering alternative ways of thinking homelessness: The articulation of the homeless subject position in the Greek street paper shedia. Communications. Media. Design, 4(1), $5-31$.

Doudaki, V., \& Carpentier, N. (2019b). The construction of the homeless in the Greek street paper shedia. In M. F. Murru, et al. (eds.), Communication as the intersection of the old and the new (pp. 85-103). Bremen: edition lumière.

Doudaki, V., \& Carpentier, N. (2021). The articulation of the homeless subject position as subaltern other: A visual analysis of the Greek street paper shedia. In A. Schober-de Graaf \& B. Hipfl (eds.), Wir und die Anderen: Visuelle Kultur zwischen Aneignung und Ausgrenzung (pp. 222-250). Cologne: Herbert von Halem Verlag.

Felski, R. (1999). The invention of everyday life. New Formations, 39, pp. 13-31. 


\section{Nico Carpentier et al.}

Haraway, D. (1991). Simians, cyborgs, and women: The reinvention of nature. London: Free Association Press.

Harter, L. M., Edwards, A., McClanahan, A., Hopson, M. C., \& Carson-Stern, E. (2004). Organizing for survival and social change: The case of street wise. Communication Studies, 55(2), pp. 407-424.

Howley, K. (2003). A poverty of voices: Street papers as communicative democracy. Journalism, 4(3), pp. 273-292.

Kidd, D. (1999). The value of alternative media. Peace Review, 11(1), pp. 113-119.

Laclau, E., \& Mouffe, C. (1985). Hegemony and socialist strategy: Towards a radical democratic politics. London: Verso.

Marshall, T. H. (1992). Citizenship and social class. In T. H. Marshall \& T. B. Bottomore (eds.), Citizenship and social class (pp. 1-51). London: Pluto Press.

McCarthy, L. (2013). Homelessness and identity: A critical review of the literature and theory. People, Place \& Policy Online, 7(1), pp. 46-58.

McVeigh, R. (1997). Theorising sedentarism: The roots of anti-nomadism. In T. Acton (ed.), Gypsy politics and traveller identity (pp. 7-25). Hertfordshire: University of Hertfordshire Press.

Mookherjee, M. (2005). Affective citizenship: Feminism, postcolonialism and the politics of recognition. Critical Review of International Social and Political Philosophy, 8(1), pp. 31-50.

Morley, D. (2000). Home territories: Media, mobility and identity. New York: Routledge.

Powell, R. (2008). Understanding the stigmatization of gypsies: Power and the dialectics of (dis)identification. Housing, Theory and Society, 25(2), pp. 87-109.

Remillard, C. (2012). Visual representations of homelessness in the Canadian public sphere: An analysis of newspaper and photo voice images. [Doctoral dissertation] University of Calgary, Canada. doi: 10.11575/PRISM/28656

Schneider, B., Chamberlain, K., \& Hodgetts, D. (2010). Representations of homelessness in four Canadian newspapers: Regulation, control, and social order. The Journal of Sociology \& Social Welfare, 37(4), pp. 147-172.

Shields, T. G. (2001). Network news construction of homelessness: 1980-1993. The Communication Review, 4(2), pp. 193-218.

Swain, J. (2011, 25th November). Busting the myth. Inside Housing. Available at https://cutt.ly/nkkNAGv

Turner, B. S. (2016). We are all denizens now: On the erosion of citizenship. Citizenship Studies, 20(6-7), pp. 679-692.

Whang, I., \& Min, E. (1999). Discourse analysis of television news on public antagonism against the homeless. In E. Min (ed.), Reading the homeless: The media's image of homeless culture (pp. 95-107). Westport, CT: Greenwood Publishing Group.

Zufferey, C. (2014). Questioning representations of homelessness in the Australian print media. Australian Social Work, 67(4), 525-536. 


\title{
13 Hate speech as a media practice
}

\author{
The portray of haters and \\ polarization in The Internet \\ Warriors
}

\section{Alejandro Barranquero and Susana Morais}

\section{The Internet Warriors, or who's behind the online hate confrontations}

Who are the people who spend their time debating online and dialectically confronting strangers in anger and rage? Which particular motivations and contexts lie behind their comments? Why do people approach media technologies to spread hate against the Other? These are some of the key questions addressed by The Internet Warriors (2017), a documentary produced by The Guardian and the Bertha Foundation, which was selected as our research object, since it represents an innovative audio-visual strategy to understand why the online world has become a fertile ground for hate speech and political polarization. In particular, the video reveals the faces and stories of the citizens who daily argue online in relation to identity, political beliefs, or religious values, while providing an overview of their social contexts and media practices.

To undertake this ambitious task, his director, Norwegian photojournalist Kyrre Lien, chose the format of a "testimonial documentary", a representation mode that assembles oral histories and witnesses who recount their personal experiences about a particular topic in front of the camera (Nichols, 2010, p. 151). The film is constructed around the first-person testimonials of ten protagonists, the Internet "warriors", who use social networks and news forums to raise their voice and be recognized in the public sphere (Fraser \& Honneth, 2003). As we will see later in this chapter, the warriors of the title are not just the purveyors of prejudice, but also the people with whom this people confront, thus analysing hate speech as a dialectic process that pits one group against an out-group preparing for hate-motivated violence (Waltman \& Haas, 2011).

Following Bruzzi (2006), we will explore The Internet Warriors as an example of "performative documentary", because its protagonists are not just described but put into action when asked to defend themselves and justify their online comments in front of the camera. In this sense, the film reminds previous documentaries -such as "The Act of Killing" (2012) by 
J. Oppenheimer, and "The Thin Blue Line" (1988) by Errol Morris - that tried to unravel the origins of "evil" by exploring the words, body images, contradictions, and silences of their protagonists (Adams \& Vice, 2013; Demaria \& Violi, 2019). With the apparent absence of a narrator and through the portray of ordinary people's performances, the piece eventually becomes a meta-discursive report that connects the online and the offline world in three directions: (a) It contrasts the words limitation of social networks like Twitter with the length and the longer temporality of the video interviews, in which the protagonists are given the opportunity to defend their online activity and explain the circumstances behind their comments; (b) As a consequence, the interviewees confront the impulsive and spontaneous discourse of the social networks with the much more paused and measured enunciation mode of the interviews; (c) Finally, the film gives visibility not only to the authors of the messages, but also to their relatives, couples, friends, and neighbours, who usually appear as secondary characters along the shoot.

Thanks to its "technological affordances", or the potentialities and variety of actions and discourses allowed by the video (Zhang et al., 2011), we will approach the documentary as a powerful tool to unveil the deep roots of online hatred and polarization, exploring its arguments and counterarguments, its (ir)rationalities and the reasons that motivate people to appropriate information and communication technologies to dispute around identities, cultures, and believes. Critical discourse analysis will be used to explore the documentary from the perspective of "media practice", a theoretical framework that has been rarely applied to hate speech despite its capacity to bring and think together actors, discourses, and technologies (Stephansen \& Treré, 2020).

The structure of this chapter is divided into two sections. The first section presents the theoretical and methodological strategy followed to examine the video, and the second develops the results focusing on three basic elements: the identity and context of the protagonists, their argumentative elaborations, and the complex interactions between their online and offline world.

\section{A media practice approach to hate speech}

In recent times, hate speech has gained extraordinary importance in media and communication research (Chetty \& Alathur, 2018). This interest is partly connected to concerns about the potential of ICTs to spread intolerant discourses by enabling boundless, rather inexpensive, and ubiquitous communication for immediate information and opinion-sharing (Schieb \& Preuss, 2016). In this research tradition, excessive academic attention has been given to the analysis of hate speech messages, from the particular issues and frames used to attack vulnerable and "specially protected" groups such as Muslims (Aguilera-Carnerero \& Azeez, 2016; Awan, 2014), immigrants 
(Aslan, 2017; Bliuc et al., 2018), and LGBT communities (Baider, 2018), to the new strategies developed to detect and combat online hatred, either through advanced text mining techniques (Arcila, Blanco-Herrero \& Valdez, 2020; Burnap \& Williams, 2015; Watanabe, Bouazizi \& Ohtsuki, 2018), or by means of regulation, campaigns, training programs, or codes of conduct (De Latour et al., 2017; Gagliardone et al., 2015; Schieb \& Preuss, 2016).

Despite the ambitious efforts to analyse and counteract hate speech, little is known about the particular people who produce threatening or degrading contents online. In fact, academia has often stereotyped and demonized them as if they were just a shapeless mass of trolls, bots, fake news disseminators, and hidden subjectivities (Buckels, Trapnell \& Paulhus, 2014; Jakubowicz, 2017) who confront among them to convince, entertain, or for pure banality (Posselt, 2017; Salikov, 2018). On the other hand, academic efforts have overemphasized the anonymous and fake dimensions behind hate speech (Aro, 2016; Bliuc et al., 2018), its potential as a warfare tool (Aro, 2016), the "echo chambers" and "filter bubble effects" that focus the attention of online users on the contents matching their interests (Pariser, 2011), and the "aggregative capabilities" of the algorithms to disseminate populism and hate (Gerbaudo, 2018).

However, the majority of the approaches have not been able to comprehend hate speech as a complex communication practice involving multifaceted relationships between individuals, texts, technologies, and their social contexts (Treré, 2019). This chapter approaches the phenomenon shifting the focus from the traditional "textualist" views and rather observing it as a "media practice", a notion that helps to decentre media research from the study of media texts or production structures and to redirect onto the study of the open-ended range of practices focused directly or indirectly on media (Couldry, 2004, p. 117).

Understanding online hate speech as a network of multiple and interwoven media layers in which discourses emerge, circulate, and are appropriated by actors and their practices, the media practice approach is also valuable to fight against two fallacies that have historically dominated media studies (Treré, 2019) and, in particular, research on online hate speech. On the one hand, we refer to the "one-medium approach", or the tendency to isolate and separate the analysis of each social network-Facebook, Twitter, Instagram, etc.- -when analysing hate speech (Aslan, 2017; Awan, 2014), what subsequently ignores the multiple media connections in the contemporary "hybrid media systems" (Chadwick, 2017). The other fallacy is "spatial dualism", or the trend to treat the digital/virtual/cyber and the offline/political/real spheres differently, thus forgetting the material conditions where discourses are produced, as well as the complex and dialectic relations that connect the online and the offline spaces (Lim, 2015; Treré, 2019).

By taking practices as a starting point for enquiry, our study will not merely address the production or justification of online hate speech, but 
rather analyse the interplay between the online discourses and the broader social processes of which media practices form part (Stephansen \& Treré, 2020 , p. 4). This preoccupation will lead us to examine The Internet Warriors as a fruitful audio-visual space to wonder about the particular profiles, backgrounds and practices of online opponents, as well as about their positions regarding media and digital technologies.

\section{Research questions and methodological strategy}

The Internet Warriors is so far one of the unique documentaries that have examined the people and social practices behind online hate discourses. This is why we have intentionally selected it as a typical "case study" in order to explore the phenomenon as a dialectic media practice that confronts haters and victims, as well as activates complex identification mechanisms in the audience (Chapman, 2009). Following the principles of case study research (Yin, 2017), we try to capture the holistic and meaningful characteristics of the video by exploring the diverse meta-discourse layers used to present the protagonists, the connections among the testimonies, and the social contexts underlying their online practices.

Discourse analysis is adopted as the main methodological strategy to analyse the documentary, departing from the premise that discourse is a "social practice" that goes beyond the mere description of reality but rather involves the production of complex meanings, imaginaries, and moral senses (Fairclough, 2001). A synthesis of the relation between the internal discursive structure and its contextual interactions with reality (Fairclough, 2001 ) is developed departing from the usual categories of "media practice"; that is, introducing the actors and their contexts, the way their discourse is produced, and, finally, the complex interplay between the online and the offline spheres.

As guiding lines, we take on board two of the questions heard at the beginning of the documentary through a voiceover: "Who are the people who spend their time debating online? and "Are they as angry in person as they are online?" To answer them, two specific areas will be explored: (1) what do the interviewees say about themselves, and how their identities and circumstances are revealed, (2) and which additional information is provided beyond these testimonials, supporting or even contrasting their online belligerent attitudes. Finally, we posed a last question that we called the "argumentative elaboration", or how the participants optimize the "technological affordances" (Shrock, 2015) of the camera to deepen, extend, or change the words they published online.

We will use a multimodal strategy (Jewitt, Bezemer \& O'Halloran, 2016) to underpin how audio-visual discourses are constituted by a variety of combined codes (verbal, pictorial, graphic, kinesics, etc.) that give rise to multiple meanings. In this line, we will pay attention both to the discursive strategies used by the interviewees to read, comment, justify, and nuance 
their online messages, and also to the complementary elements provided by the video. Observing the relation between verbal and visual elements, we will focus on the interplay between the literal/explicit and the symbolic/ implicit meanings. In addition to the 21 minutes length of the documentary, we also consulted the additional transmedia material that accompanies the video: a web, a Facebook site, and a photo-book composed of still images of the protagonists taken when they were being recorded for the documentary.

\section{Findings}

\section{Who they are: identity and contexts}

One of the most noteworthy features of the video is the concern to offer a multiple portrait of the digital warriors. They are different in gender, age, country of residence, education, and professional and family background. Also diverse are the online platforms used to share their opinions as well as the causes they stand for. Table 13.1 systematizes the basic information that defines each of the ten interviewees.

The narrative structure used to present most participants is similar. They are filmed in the intimacy of their homes, neighbourhoods, or places they usually haunt. The interviewees start reading aloud the messages they posted online while the same text is reproduced on screen (in a literal

Table 13.1 Identification of The Internet Warriors

\begin{tabular}{|c|c|c|c|}
\hline Name & Gender & $\begin{array}{l}\text { Country of } \\
\text { Residence }\end{array}$ & Cause \\
\hline Robert Jackson & Male & England & $\begin{array}{l}\text { Anti-immigration } \\
\text { Anti-Islamism }\end{array}$ \\
\hline Imaad Osman & Male & Lebanon & Anti-American \\
\hline Ashleigh Jones/Illusory & $\begin{array}{l}\text { Female (seems } \\
\text { transgender, } \\
\text { although not } \\
\text { declared in } \\
\text { the video) }\end{array}$ & Wales & $\begin{array}{l}\text { Criticizes celebrities } \\
\text { (Lady Gaga, David } \\
\text { Cameron, for example) }\end{array}$ \\
\hline Pete Seville & Male & U.S.A. & $\begin{array}{l}\text { Anti-immigration } \\
\text { U.S. values }\end{array}$ \\
\hline Nick Haynes & Male & U.S.A. & Pro-Trump \\
\hline Alexandra Velichkevich & Female & Russia & Anti-LGBT rights \\
\hline Sina Staes Janevska & Female & Norway & $\begin{array}{l}\text { Anti-immigration } \\
\text { Norwegian values }\end{array}$ \\
\hline Sofia Srour & Female & Norway & Islamic Values \\
\hline Kjell Frode Tislevoll & Male & Norway & $\begin{array}{l}\text { Anti-immigration } \\
\text { Anti-Islamism }\end{array}$ \\
\hline Roger A. Hicks & Male & England & $\begin{array}{l}\text { Anti-immigration } \\
\text { Anti-multiculturalism }\end{array}$ \\
\hline
\end{tabular}

Source: own elaboration. 
way, with misspellings, exclamation points, and case-sensitive distinction), and then explain the reasons behind their opinions. This is why metadiscourse and performativity are two of the main characteristics of the film: instead of just showing the messages and their authors, it impulses the protagonists to speak about their own discourse.

Additionally, the documentary introduces each protagonist through a series of identity attributes: all are revealed indirectly, except for the name or nickname used on social media, which appears on screen. The country of residence can only be deduced from certain symbols (e.g. the English flag painted outside Robert's house or the American diners in which Pete and Nick are filmed); from the interviewees' statements (e.g. Imaad states that he uses Facebook to find out what's going on in Syria); and from the content of their posts (e.g. Sina says: "be a socialist, kill Norway"). Later on, the causes they stand for are disclosed.

The personal circumstances and environments are shown gradually, sometimes using suspense. After presenting the protagonists, the camera moves slowly and includes new people in such a way that we can have a global portray of each participant only when the interview is almost over. Noticeable are also the close-up shots showing, for example, highly symbolic objects like the crucifix on the Alexandra's house wall, or the veil and the Koran on a bookshelf in Sofia's case.

\section{Argumentative elaboration}

The argumentative elaboration is one of the most relevant aspects of the documentary since it offers the interviewees the opportunity to clarify arguments and motivations beyond the limitations and technological "affordances" of the social networks, and also because of the temporary distance between the online posts and the video shooting.

We can distinguish three main types of arguments. First, the ones used by those who write without using abbreviations or misspellings and through the appropriate use of capital letters and punctuation marks. When they speak to the camera, this is the group who gives more extensive and structured explanations. These are the cases of Roger, Sofia, Kjell, and Robert. Roger offers the most developed explanations, trying to separate what he stands for and how it may be interpreted, specifically, racism from his opposition to mixing races: "I don't think it's racist to want to identify with your own race and want to preserve it. [...] A racist is someone who hates other races. I certainly don't hate other races". Additionally, this group includes Sofia, a young woman committed with the defence of Islam and its non-association to terrorism. Her statements are measured and rational: she recognizes legitimacy to those who write prejudiced comments, but also advocates the right to respond critically. Regarding the debate about the veil ban, Sofia argues that "it sounds strange to ban things we 'do not like' because the 'free' and 'open' society should be 'protected"'. 
Kjell's case is unique: unlike the other testimonies, he has changed his mind. After reading aloud two of his online messages - the first claiming that extremist Muslims should live in a separate planet, and the second defending colonialism because "we in the western world are a more civilised version of humanity" - Kjell admits that his prejudices belong to the past. He later explains that the turning point of his change of mind was the opening of a refugee reception centre in his neighbourhood, because it gave him the chance to see that Islamic people were not problematic. Robert is also an unusual case: he makes an effort to let his motivations clear but solely based on his personal experience. The targets of his hate are the European Union ("get rid of it") and Syrians fleeing the war and settled in his country ("the so-called migrants"). However, his reasons are only focused on detailing the difficulties he went through to bring his foreign wife to England.

The second type of argumentative elaboration corresponds to the testimonies which add little to the content of the online messages displayed on screen. Nick is the most representative example. His video shooting takes place during the days of the US presidential election confronting Donald Trump and Hillary Clinton. A relentless defender of Trump, he writes with an aggressive tone, using swearing words, capital letters, abbreviations, and exclamation points: "Fuck you Obama u worthless mutherfucker! And fuck that scumbag lying bitch Hillary! Trump is going to wipe your fucking names out of the U.S. history"; “[Mitt Romney] ur a real scumbag! Thanks for not helping Trump at all! Eat shit!!!! Ur a traitor scumbag!!” When talking to the camera, Nick uses a very similar tone and vocabulary. Alexandra, Sina, Imaad, and Pete show even less structured opinions. Alexandra does not go beyond the argument that LGBTs are "unnatural" and "abnormal" people. Sina fails to explain herself without reading again what she wrote online about Islamic immigration: "It's not just people, you see, It's an ideology. On the same level as Nazism". Imaad also goes little further about the U.S.A.: "The one who waits for democracy from America, is like the one who expects the devil to lift them up to heaven". Finally, Pete claims that the American flag represents something "many men died for". His main argument is undoubtedly his eccentric outfit, more than any verbal explanation: Pete dresses in American-flagged clothes from head to toe.

The third type of argumentative strategy is somewhere in the middle of the previous two. When writing online, Illusory uses capital letters and swearing words, but her explanations are quite detailed. She has thoughtful opinions about many subjects: the impact of online discussions in her life, the difference between online and offline activities, and the concept of hater.

\section{Online and offline dialectics}

If we focus on the statements in front of the camera, there is a clear trend to corroborate the positions expressed online. Robert still thinks that Syrian 
immigrants should all be sent back, and repeats his critical point of view about multiculturalism; nor is there anything suggesting changes in Imaad's explanations; and Nick openly claims to be proud of all he has written before.

Besides their own words, there are also non-verbal elements that confirm The Internet Warriors' profiles: their reaction reading old online messages ("I hope ISIS kill David Cameron" wrote by Illusory makes her smile, and Alexandra laughs loud when she remembers having posted "I don't want bassoons to come from gayropa to smear our ballet Swan Lake!"); the flags we can see outside their houses (the English in Robert's case, the pro-Trump in Nick's and the several American of Pete's clothing); and the above-mentioned Alexandra's crucifix and Sofia's veil and Koran.

The exception to this trend, as already highlighted, is Kjell. He assumes that his prejudices are part of the past and that he would not be able to maintain and write the same anti-Muslim comments again. His arguments range between elaborate and simplistic: on the one hand, he expresses that he would have to argue with his "former self" in an online forum, but, on the other, he expresses: "I work with a Muslim, and he's all right".

The contrasts, or even contradictions, exposed by the video are multiple. Once again, they are recognizable simultaneously by explicit and subtle references. The particular features used in the video filming and editing play a fundamental role in this respect. Camera movements are scarce, and each shot remains fixed for a long time, thus creating images that resemble photography more than video. Additionally, when camera moves, it does slowly, revealing information gradually and highlighting contrasts.

Another feature is the tone of voice, understood in both a literal and symbolic sense. The determined attitude is completely different from the high-pitched tone with which, for example, Robert warmly thanks his wife for bringing a cup of coffee, or exchanges complicit gazes and smiles with her. The same happens to Sina, who speaks to her cat in a loving way and with a tone that reminds the one used with babies. Love for animals is something Roger also shares: he is filmed several times stroking a dog about which he speaks very affectionately. It is not a coincidence but a revealing strategy the presence of pets in the lives of many of the interviewees. Cats, dogs, and birds are frequent protagonists of their domestic environment, allowing us to appreciate the kindest and loving side of their personalities.

The displays of affection are also noticeable in other ways: using a lot of swear words in the presence of his young children, Nick says goodbye to one of them with a warm "I love ya, I'll see you in the morning". Later he speaks affectionately to his youngest daughter while holding her hand. In his first appearance in the film, Roger greets one of his neighbours in a very friendly and polite way. In Pete's case, the contrast appears in his slightly childish image and attitude: his "patriotic clothing" is puerile, just as it is 
to stop in the middle of nowhere to wave a flag. The distorted music coming from his bicycle in that particular moment completes a quite absurd scene.

Other type of contradictions is related to the explanations given to justify their causes. As Sina's interview approaches the end, her husband makes a very interesting revelation: "I'm an immigrant". She answers expressing two ideas that demonstrate how selective her anti-immigration stance can be: "No, you're my husband" and "Yes, you're an immigrant, but you're not a terrorist". The same applies to Pete when he stands out freedom as the supreme value represented by the American flag while advocating for restricting immigrants' rights to move. Something similar happens to Robert, an anti-immigration policy advocate married to a foreign woman. Also contradictory is Imaad's disaffection with the media ("I have a TV, but I don't watch it, because I don't trust it. All of the media are telling lies") while admitting being on Facebook 24 hours in order to be informed about what happens in Syria. Imaad is a clear example of the mistrust traditional media shared by many of the people who use social media actively.

The contrasts can be seen not only when looking at the testimonies separately but also when we analyse the documentary as a whole. It is not an innocent choice to divide each interview or testimonial in several parts and gradually interlace the protagonists, instead of showing them one by one. Between the last shot of one interview and the first of the following there are often obvious and significant contrasts. Anti-immigration Sina precedes the Arab Imaad, Imaad is a declared critic of U.S. policy, and he is followed by the testimony of American patriot Pete. There is also a constant back and forth between anti-LGBT Alexandra and Illusory, who likes to talk about "pop culture, equality and sex". The same happens to Kjell and Sofia, the former an anti-Islamist and the later a young woman wearing a veil who combats prejudices about Islam. The video editing creates a curious dialogue between antagonistic profiles, thus generating a chain of relationships between people who never meet each other, and would not suspect they could be, simultaneously, subjects and objects of each other's hate.

Being an obvious way of guiding the viewer's look, this imprint left by the director's is a counterweight to the prominence given to the interviewees. Except for the voiceover that briefly describes the documentary objectives in its first minutes, it is clear the intention to let the words, gestures, and environments of the interviewees to speak by themselves.

\section{Conclusions}

This chapter has examined The Internet Warriors as a valuable narrative strategy to reflect on hate speech through the testimonials of the people who usually confront online with the out-groups on the basis of ethnicity, political and religious ideologies, or sexual orientation (Waltman \& 


\section{2}

Haas, 2011). The video demonstrates that hate speech cannot be merely approached as an evil or meaningless discourse, but rather adopting a complex regard. In fact, hatred is portrayed as a dialectical process that confronts victims and prosecutors, and in which the usual "submissive" objects of hate-Muslims, immigrant, transgender people, etc.-may also become hatred mongers when they feel challenged and need to defend their identities and ideologies. Besides, the testimonial, performative, and meta-discursive format of the film turns the confessions into a challenging narrative strategy that makes the testimonies speak by themselves and confront the spectators with their own biases and misconceptions. The documentary finally transmits that we are all subject to hate, since hatred is usually introjected from masters to victims, and the latter may paradoxically turn to it if they feel offended or discriminated (Recalcati, 2012).

The Internet Warriors shows that the online discourses cannot be easily separated from the ordinary lives and contexts of the protagonists, what gradually answers our research questions. To answer to "who are the people who debate online", the documentary demonstrates that haters are not just always the "others" but also "ourselves". In other words, hate mongers are not an amorphous mass of trolls and false identities, since hate may also be produced by identified and ordinary people like the spectator. Additionally, the protagonists seem "not as angry in person as they are online": they are able to love their couples, care for their pets, and get along with their friends or neighbours.

Inspired by the emergent literature on the technological "affordances" of the video as an educative tool, we observed that the piece offers an enormous potential for reflecting and discussing about the phenomenon: it uncovers a variety of testimonials and arguments; it proposes an innovative approach to understand an emerging social issue (Ranker, 2015); and it has the capacity to make the spectators confront with themselves, like if they had a mirror placed in their face (Zhang et al., 2011). This research invites further inquiries to keep on exploring the potential of videos and documentaries as powerful educative and investigative tools to deepen and understand the complexity and multiple layers of hate speech as well as counteract its effects.

Besides, the documentary has been analysed from a "media practice" approach that goes beyond discourse, and redirects media analysis onto the question about the relations between actors, contexts, and technologies. These are the three main variables we explored in the chapter: the identities and backgrounds of the online "warriors", their argumentative strategies, and the dialectic interplay between the online and the offline worlds. In this sense, the media practice approach has demonstrated its utility to overcome simplistic textualist approaches and to advance towards a more complex understanding of the multiple interconnections between people, technologies, texts, and social practices. 


\section{References}

Adams, J., \& Vice, S. (2013). Representing perpetrators in Holocaust literature and film. Portland, OR: Vallentine Mitchell.

Aguilera-Carnerero, C., \& Azeez, A. H. (2016). 'Islamonausea, not Islamophobia': The many faces of cyber hate speech. Journal of Arab \& Muslim media research, 9(1), pp. 21-40. doi: 10.1386/jammr.9.1.21_1

Arcila, C., Blanco-Herrero, D., \& Valdez, M. B. (2020). Rejection and hate speech in Twitter: Content analysis of Tweets about migrants and refugees in Spanish. Revista Española de Investigaciones Sociológicas, 172, pp. 21-40. doi: 10.5477/ cis/reis.172.21

Aro, J. (2016). The cyberspace war: Propaganda and trolling as warfare tools. European View, 15(1), pp. 121-132. doi: 10.1007/s12290-016-0395-5

Aslan, A. (2017). Online hate discourse: A study on hatred speech directed against Syrian refugees on YouTube. Journal of Media Critiques, 3(12), pp. 227-256. doi: 10.17349/jmc117413

Awan, I. (2014). Islamophobia and Twitter: A typology of online hate against Muslims on social media. Policy \& Internet, 6(2), pp. 133-150. doi: 10.1002/19442866.POI364

Baider, F. (2018). "Go to hell fucking faggots, may you die!" framing the LGBT subject in online comments. Lodz Papers in Pragmatics, 14(1), pp. 69-92. doi: 10.1515/lpp-2018-0004

Bliuc, A. M., Faulkner, N., Jakubowicz, A., \& McGarty, C. (2018). Online networks of racial hate: A systematic review of 10 years of research on cyberracism. Computers in Human Behavior, 87, pp. 75-86. doi: 10.1016/j.chb. 2018.05.026

Bruzzi, S. (2006). New documentary. Abingdon: Routledge.

Buckels, E., Trapnell, P., \& Paulhus, D. (2014). Trolls just want to have fun. Personality and Individual Difference, 67, pp. 97-102. doi: 10.1016/j.paid.2014.01.016

Burnap, P., \& Williams, M. L. (2015). Cyber hate speech on twitter: An application of machine classification and statistical modeling for policy and decision making. Policy \& Internet, 7(2), pp. 223-242. doi: 10.1002/poi3.85

Chadwick, A. (2017). The hybrid media system: Politics and power. Oxford: Oxford University Press.

Chapman, J. (2009). Issues in contemporary documentary. Cambridge: Polity Press.

Chetty, N., \& Alathur, S. (2018). Hate speech review in the context of online social networks. Aggression and Violent Behavior, 40, pp. 108-118. doi: 10.1016/j. avb.2018.05.003

Couldry, N. (2004). Theorizing media as practice. Social Semiotics, 14(2), pp. 114-132. doi: 10.1080/1035033042000238295

De Latour, A., Perger, N., Salag, R., Tocchi, C., \& Otero, P. V. (2017). We can! Taking action against hate speech through Counter and alternative narratives. Council of Europe. Available at https://bit.ly/3jpAORQ

Demaria, C., \& Violi, P. (2019). The act of documenting: Joshua Oppenheimer's the act of killing. Media, War \& Conflict, 13(1). doi: 10.1177/1750635219871910

Fairclough, N. (2001). Language and power. London: Longman.

Fraser, N., \& Honneth, A. (2003). Redistribution or recognition? A politicalphilosophical exchange. London: Verso. 


\section{Alejandro Barranquero and Susana Morais}

Gagliardone, I, Gal, D., Alves, T., \& Martinez, G. (2015). Countering online hate speech. Paris: UNESCO. Available at https://bit.ly/2YQ1AMm

Gerbaudo, P. (2018). Social media and populism: An elective affinity? Media, Culture \& Society, 40(5), pp. 745-753. doi: 10.1177/0163443718772192

Jakubowicz, A. (2017). Alt_Right White lite: Trolling, hate speech and cyber racism on social media. Cosmopolitan Civil Societies: An Interdisciplinary Journal, 9(3), pp. 41-60. doi: 10.5130/ccs.v9 i3.5655

Jewitt, C., Bezemer, J., \& O’Halloran, K. (2016). Introducing multimodality. London: Routledge.

Lim, M. (2015). A cyberurban space odyssey: The spatiality of contemporary social movements. New Geographies, 7, pp. 117-123.

Nichols, B. (2010). Introduction to documentary. Bloomington: Indiana University Press.

Pariser, E. (2011). The filter bubble: What the Internet is hiding from you. London: Penguin.

Posselt, G. (2017). Can hatred speak? On the linguistic dimensions of hate crime. Linguistik Online, 81(3), pp. 5-25. doi: 10.13092/lo.82.3712

Ranker, J. (2015). The affordances of blogs and digital video: New potentials for exploring topics and representing meaning. Journal of Adolescent \& Adult Literacy, 58(7), pp. 568-578. doi: 10.1002/jaal.405

Recalcati, M. (2012). Hate as a passion of being. Qui Parle: Critical Humanities and Social Sciences, 20(2), pp. 151-182. doi: 10.5250/quiparle.20.2.0151

Salikov, A. (2018). Hannah Arendt, Jürgen Habermas, and rethinking the public sphere in the age of social media. Russian Sociological Review, 17(4), pp. 88-102.

Schieb, C., \& Preuss, M. (2016). Governing hate speech by means of counterspeech on Facebook. Proceedings of the 66th ICA Annual Conference. Fukuoka, ICA.

Shrock, A. (2015). Communicative affordances of mobile media: Portability, availability, locatability, and multimediality. International Journal of Communication, 9, pp. 1229-1246.

Stephansen, H., \& Treré, E. (2020). Citizen media and practice. Currents, connections, challenges. New York: Routledge.

Treré, E. (2019). Hybrid media activism. Ecologies, imaginaries and practices. New York: Routledge.

Waltman, M. S., \& Haas, J. W. (2011). The communication of hate. New York: Peter Lang.

Watanabe, H., Bouazizi, M., \& Ohtsuki, T. (2018). Hate speech on twitter: A pragmatic approach to collect hateful and offensive expressions and perform hate speech detection. IEEE Access, 6, pp. 13825-13835. doi: 10.1109/ ACCESS.2018.2806394

Yin, R. K. (2017). Case study research and applications: Design and methods. London: Sage.

Zhang, M., Lundeberg, M., Koehler, M. J., \& Eberhardt, J. (2011). Understanding affordances and challenges of three types of video for teacher professional development. Teaching and Teacher Education, 27(2), pp. 454-462. doi: 10.1016/j. tate.2010.09.015 


\title{
14 The asylum-seeker discourse fed by political polarization in Turkey
}

\author{
A Twitter-based analysis
}

Nurcan Törenli and Zafer Kıyan

\section{Introduction}

The Syrian civil war that unfolded in March 2011 displaced many people and forced them to seek asylum in other countries. The United Nations High Commissioner for Refugees (UNHCR, 2020) reports that the number of Syrians seeking asylum due to the ongoing civil war has approached 6 million. Within the asylum countries, Turkey is in the lead, accommodating nearly 4 million Syrian asylum-seekers (DGMM, 2020). Currently, Syrian asylum-seekers have not only become one of the essential daily debates in Turkey, but they also have become the main focus of political conflicts and one of the main instruments of domestic politics, which is fed by polarization.

Studies on societies perceiving asylum-seekers as problematic have shown that the indigenous population perception of asylum-seekers is generally polarized at extremes as positive and negative. Authors, such as Boomgaarden and Vliegenthart (2009), Facchini, Mayda and Mendola (2013), Isaksen (2019), Kuntz, Davidov and Semyonov (2017), Lazarev and Sharma (2017), and Otto and Steinhardt (2014), suggest that economic crises, unemployment, high number of refugees, religious and cultural differences, and media discourse are the main dynamics of this polarization. Some studies have shown that party identification is also a polarizing factor. For example, a study by Brooks, Manza and Cohen (2016) conducted in the USA found that individuals' party identification affected their perception of asylumseekers. In their study in which they questioned the extent to which the 2015 Paris terrorist attacks affected the perception of asylum-seekers, Jungkuntz, Helbling and Schwemmer (2019) also reached a similar result, reporting that party identification of individuals was more decisive than terrorist attacks. An experimental study by Druckman, Peterson and Slothuus (2013) conducted in the USA explored the importance of party identification under the conditions of political polarization. The authors found, from a sample of 646 people, of whom $53 \%$ were Democrats and $47 \%$ were Republicans, that individuals formed their thoughts on asylum-seekers by reviewing alternative arguments in the absence of political polarization 
conditions and observing at the discourse of the party that they supported in the presence of such conditions.

This chapter aims to contribute to the existing literature by showing that party identification also affects the discourse on asylum-seekers under political polarization conditions. Studies concerning the local residents' perception of asylum-seekers consist of those that either analyze the mass media discourse (Eberl et al., 2018) or question the extent of the importance of partisanship in mass media discourse. For example, authors, such as Blumell et al. (2020), Don and Lee (2014), Efe (2019), and Tavassoli, Jalilifar and White (2019), found that the ideological and political positioning of mass media outlets together with their stance toward the government had a decisive role in the representation of asylum-seekers. However, since these studies are based on data obtained from the news content of mass media, the results are limited to the corporate media discourse rather than the discourse of the ordinary individual on asylum-seekers. Today, social media platforms, such as Twitter, allow ordinary individuals to create content and thus provide researchers with new possibilities for discourse studies. This chapter concentrates on Twitter to understand the extent to which individuals' proximity to a political party affected their discourse on asylum-seekers. Hence, this chapter focuses on Syrian asylum-seekers and Twitter users in Turkey.

The Turkish political environment, in which polarization has long dominated domestic politics, is well suited for a comprehensive analysis of the polarized discourse toward Syrian asylum-seekers. Furthermore, Twitter is actively used for political interactions in Turkey (Bulut \& Yörük, 2017; Yavuz et al., 2018), and therefore, a significant part of the discussion related to Syrian asylum-seekers takes place through this platform. Considering these two dynamics together, the example of Turkey hosts a highly suitable sample for such research.

The comprehensive dataset for this chapter consists of the tweets produced by a total of 25,000 unique Twitter users under five different hashtags referring to a different incident. Both quantitative and qualitative methods were used for the data analysis. A two-stage study was conducted in the quantitative analysis. In the first stage, Twitter users were grouped according to their political positions. Twitter bios were utilized to clarify the political positions of Twitter users. In the second stage, the tweets produced by users, grouped according to their political positions, were categorized according to their content (positive, negative, neutral, and irrelevant). In the qualitative analysis, the tweets categorized according to their content were analyzed discursively under five headings based on the framework suggested by Wodak $(2008,2016)$ : referential/nomination, prediction, argumentation, perspectivization, and intensification. With this two-sided perspective, the intention was to provide an understanding of the extent to which the users' political party identification affected their discourse on Syrian asylum-seekers. The results showed that the sample of Twitter users 
acted in alignment with the political party that they felt close to. While Twitter users who concurred with the party with a negative attitude toward Syrian asylum-seekers produced a negative discourse, those who sided with the party with a positive attitude generated a positive discourse. These results offer important implications for understanding the role of party identification in forming positive and negative discourse about asylum-seekers.

\section{Polarization in the political life of Turkey: historical-social context}

From the past to the present, political life in Turkey has been the scene of polarizing practices of the ruling classes that prioritize the interests they represent. Mardin (1990) explained this with the center-periphery dynamics in the Ottoman Empire and pointed at two established opposites: statist elements aiming to achieve centralized control throughout the empire and peripheral elements trying to protect their local interests against central powers. Timur (1994, p. 55), who associated polarizing politics with the "divide and rule" principle of the Byzantine and Ottoman states, drew attention to the relocation and settlement policies of statists that fueled the religious and ethnic differences between nomads and locals, which ultimately polarized and weakened the local powers.

With the transition from Empire to Republic, the political field in Turkey has been reduced to the nation-state scale. The main supporters of this transition, which actualized with the victory of the Turkish War of Independence in the early 20th century, were the large merchants and landowners (Uslu, 2015). Thus, centralized powers and interests became represented by these classes and the parties they supported. In practical terms, the TurkishGreek population exchange at the beginning of the 20th century, which coincided with the proclamation of the republic, was an attempt to update the unfinished Turkification project in favor of these classes. The development that dominated the single-party era of 1923-1945 consisted of the attempts of the Republican Peoples' Party (CHP) with its leaders, especially Mustafa Kemal Atatürk, the founder of the Republic, to build a Republic of Turkey citizenship with a Muslim and Turkish identity (Şener, 2015).

Since 1945, polarizing politics have been more evident in the multi-party system. In this new period, the Kemalist CHP became secular and elitist in line with the westernization perspective. Using the polarization between the secular state elite and the religious public (Uslu, 2015), the Democratic Party (DP), which came to power in 1950, became the representative of the politics that blended Islamist-Nationalist ideology with liberalism, contrary to the CHP from which it had emerged. While the Nationalist Movement Party (MHP), founded in 1969, associated nationalist-Islamist ideology with violent practices, the National Salvation Party (MSP), founded in 1972, adapted political Islamism to liberalism with the "national opinion" rhetoric. Meanwhile, left-wing parties (Workers' Party 
of Turkey, Communist Party of Turkey), representing the interests of the working class, which was growing as a result of rapid industrialization and urbanization, became the common "enemy" of the right-wing.

The multi-party system in Turkey was wrecked by two military coups. The Justice Party (AP), which represented all ideologies except communism, stood in for the DP, which had been suppressed by the 1960 coup, while the new liberal version of the AP, the Motherland Party (ANAP), filled in for the AP, which was suppressed by the 1980 coup. These two military coups resulted in 14 elections each of which led the secular and the religious to confront each other, the unstable coalition governments, political and economic crises, political populism that glorifies "us" while discrediting "the other", and increased the electoral threshold to $10 \%$. The Peoples' Labor Party (HEP) joined the political stage to represent Kurdish minorities in the 1990s, preparing the ground for the current representatives of these groups, the Peoples' Democratic Party (HDP).

The period of the Justice and Development Party (AKP) government has special importance for this chapter. AKP was established in the aftermath of the 2001 economic crisis and came to power in 2002 by gathering together all branches of the polarized right-wing. In the early years of its power, AKP sought legitimacy and recognition with a new market-focused, liberal-sensitive outlook, trying to integrate into the European Union, rather than adopting the anti-Western worn-out "national opinion" outlook of the former representatives of the political Islamism. The main theme of AKP's political rhetoric during this period was the expansion of the grounds for democracy, human rights, and freedom. AKP reinforced this theme with short-lived services for the poor and disadvantaged segments in hopes of finding support from left opposition groups, which resulted in success.

The polarizing politics of AKP started to become an election strategy in 2007, and its outline became clear by 2011 (Somer, 2014). The key strategy elements in this period were the emphasis on the failure of the coalition government and the necessity of gathering votes for a strong single party for stable development. During this period, AKP turned to Islamic-conservative rhetoric and practices to create a broad consensus with a Pan-Islamic understanding. The main goal of this rhetoric and these practices, which found support among the center-right voters, was to attack CHP, which was previously criticized by DP, AP, and ANAP for adopting a deprecating manner toward the public. Basically, in this period, AKP pursued the goal of solely representing the national will by equating party, state, and nation using the center-right's animosity toward the secular ideology engraved in the principals of CHP.

From 2007 to 2011, with Recep Tayyip Erdoğan as the leader together with a modest board, AKP restarted the initiative of identifying with Islamicconservative-nationalism, embracing public opinions, and understanding their values, which the CHP first attempted during the single-party era but was unable to actualize due to its secular-elitist board. Meanwhile, CHP 
resorted to mass rallies with the rhetoric of perpetuity of secularism, republic, and regime to eliminate this initiative that was becoming more and more powerful. However, these attempts of CHP and its supporters were defeated by provocative counter-attacks that resulted in favor of AKP, such as the numerous lawsuits involving civil-military elements and long-term imprisonments, the murder of priest Andrea Santoro on 2006, the bombing of the AKP-opponent Cumburiyet Newspaper and the Turkish Council of State shooting the same year, and also the assassination of the chief-editor of Agos Newspaper, Hrant Dink on 2007. Interestingly, these incidents led to an increase in the AKP votes in the July 2007 general elections, and thus prepared the ground for AKP to come to power on its own. Moreover, due to the high electoral threshold, only CHP and MHP managed to enter parliament, but CHP, having ideological conflicts with the MHP, was isolated.

The polarizing politics of AKP started to become more concrete in 2011. In the June 2011 general elections, AKP dominated the judiciary branch through eliminations in the higher judiciary in addition to its existing domination on the legislature and executive branches and increased the dose of Islamist-nationalism, which shifted all the left-secular elements, including the Kurds and Alewives to the opposite pole alongside CHP. In this election, AKP received $50 \%$ of the votes and consolidated its position as the single power. During this period, the polarization discourse regarding Syrian asylum-seekers took its place in politics and daily debates. This process started with the AKP government opening the Turkish border to welcome the people fleeing the civil war in Syria in 2011. Interestingly, as of 2011, although AKP welcomed the Syrian asylum-seekers, the political negotiations with the opposing western-secular segments were unwelcome. The demonstrations that began with the Gezi Park Protest in 2013 and spread to all of Turkey caused the dialogue between the AKP and the opposition to be completely severed.

The main development that put the Syrian asylum-seekers in the center of political polarization was Recep Tayyip Erdoğan's announcement in July 2016, which stated that the efforts for granting citizenship to Syrian asylum-seekers in Turkey had been initiated. The asylum-seekers turned into a political threat in the eyes of the opposition parties and political advantage in the eyes of AKP, as the news broke that they would also be able to vote in the presidential elections. Since then, AKP has managed to remain in power by creating a partisan state and gradually seizing more control (Saraçoğlu \& Yeşilbağ, 2015). With the transition to the Presidential System, the polarization between the westernized-secular segment and the conventional-religious segment reached a new level as the Islamist, nationalist, and conservative President (Recep Tayyip Erdoğan) became incorporated into the state as a central figure above all parties.

Today, Turkey is a country with high polarization to the extent that a political system based on political-ideological alliances was created (Çakır, 2020; Laebens \& Öztürk, 2020). This consists of, on the one hand, the 
Peoples' Alliance, led by AKP, where MHP and the other small center-right parties are located, and, on the other, the Nation Alliance led by the main opposition party, CHP, where some relatively effective parties, such as the Good Party (IP), are located. Although HDP is not ideologically a part of the Nation Alliance, it supports the alliance. Syrian asylum-seekers constitute one of the main themes of the discourses presented by these two opposing alliances in their political fight. While the Nation Alliance adopts an anti-asylum-seeker discourse, the Peoples' Alliance is experiencing a polarization within itself. A pro-asylum-seeker discourse is used in the AKP wing and an anti-asylum-seeker discourse in the MHP wing. Thus, this chapter presents an analysis of the political identities of Twitter users in Turkey and the tweets they generated about Syrian asylum-seekers to understand whether this polarization affects the discourse of the party supporters.

\section{Method}

\section{Collecting data}

Although Syrian asylum-seekers had begun to arrive in Turkey in 2011, they only started to be the subject of discussions on social media in late 2018. The tweets subjected to the data analysis were collected from April-July 2019 when the discussions were the most intense. These tweets, both positive and negative in context, were generated by users in Turkey under five different hashtags referring to a different incident. Hashtag 1 (\#Syrian) was created after Tanju Özkan, the CHP candidate who won the March 2019 local elections to become the mayor of Bolu located in western Turkey, stated that he will cut the aid to Syrian asylum-seekers, while Hashtag 2 (\#SyriansAreGettingTheHellOut) was created after the CHP candidate Ekrem İmamoğlu, who argued that Syrian asylum-seekers should go back to their country, rewon the repeated local elections to become the mayor of Istanbul, the most cosmopolitan city in Turkey. Hashtag 3 (\#syrian) was created after a video showing a young Syrian saying "I want to behead [people]" was shown on YouTube, while Hashtag 4 (\#syrians) was created after a caricature of the Turkish flag, in which the crescent motif was made to look like a mouth with sharp teeth, and the star motif was made to resemble a family with children, drawn by the Syrian caricaturist Moustafa Jacoub, was published on Twitter. Lastly, Hashtag 5 (\#wedontwantsyrians) was created after the Syrians took action to rally following the request of the Governor of Istanbul that undocumented Syrian asylum-seekers leave the city.

We collected the tweets using Netlytic, an open-source tool that uses public APIs to collect data. Since Netlytic allows 1,000 tweets per query, we regularly followed the discussions on these hashtags and made inquiries at 30- or 60-minute intervals. We ended the query when the discussions around the hashtags began to fade, acquiring a total of 25,000 tweets generated by unique users under these five hashtags. ${ }^{1}$ 


\section{Data analysis}

We transferred the 25,000 tweets to five separate Excel sheets and then reviewed the information in the bios of the users who generated them. We found 16,519 users, who had information on their bios that identified them. However, when we looked closely at the bios, we found that 4,127 had a political positioning. ${ }^{2}$ We utilized the results of research by Erdoğan and Uyan Semerci (2018) to determine where the political positioning in the user bios corresponded within the political spectrum in Turkey. Erdoğan and Uyan Semerci (2018) conducted face-to-face interviews with 2,004 people, aged 18 and over, from 16 different cities in Turkey to reveal the extent of the political polarization in Turkey. Two findings from this research were important for our chapter: first, political party supporters used party identification as a way to identify themselves, and second, those close to CHP self-identified as Kemalist-secular, those close to AKP self-identified as conservative, those close to MHP self-identified as nationalist, those close to IP self-identified as educated-modern, and those close to HDP selfidentified as minority-Kurdish. For our chapter, we gathered the users who self-identified as Kemalist-secular in their Twitter bios in the CHP set, those who self-identified as conservative in the AKP set, those who self-identified as nationalist in the MHP set, those who self-identified as educated-modern in the IP set, and those who self-identified as Kurdish in the HDP set. Since the proportion of users in the IP and HDP sets accounted for only $3 \%$ of the sample, and thus did not allow for significant results, these were excluded from the sample pool. Therefore, we had a sample consisting of conservative AKP supporters, Kemalist and secular CHP supporters, and far-right and nationalist MHP supporters, totaling to 4,036 unique users and their tweets.

We divided the 4,036 tweets generated by these users, which were grouped, according to their political positioning, into four sub-categories as positive, negative, neutral, and irrelevant. We placed the tweets emphasizing helping Syrian asylum-seekers or criticizing the aggressive attitudes toward them in the positive category, and the tweets containing aggressive expressions toward the Syrian asylum-seekers and stating that they should return to their country were placed in the negative category. We labeled the tweets that were impartial to Syrian asylum-seekers as neutral and those that were not relevant to the issue as irrelevant. ${ }^{3}$

After dividing the tweets into quantitative categories, we conducted a qualitative analysis to reveal the type of polarization the discourse on Syrian asylum-seekers exhibited. To better see the extent of the polarization, we included only positive and negative tweets in the analysis, which comprised 3,243 unique users and their tweets. Since almost all of the tweets generated by users close to CHP $(97 \%)$ and most of the tweets generated by users close to MHP (83\%) contained negative content, the positive tweets generated by users close to these two 


\section{Nurcan Törenli and Zafer Kıyan}

parties were excluded. We made this decision since the number of positive tweets was not sufficient to reach significant results. For the same reason, we also implemented the same decision for negative tweets generated by users close to AKP. Most users close to this party (84\%) generated positive tweets, and thus, negative tweets were excluded. After all these eliminations, we had 2,940 unique users and their tweets for the qualitative analysis. Of these, $53 \%(1,564)$ were generated by users close to CHP, 24\% by users close to AKP (701), and $23(675) \%$ by users close to MHP.

For the qualitative analysis, we focused on a narrow sample set, in which of the 2,940 tweets, we randomly selected 50 positive or negative tweets from each of the five hashtags, repeating this process for users close to each party. Thus, we obtained 750 tweets generated by users close to CHP, AKP, and MHP, with 250 tweets per party. Following the framework proposed by Wodak $(2008,2016)$, we gathered these under five groups and analyzed them as discourses: Referential/nomination, prediction, argumentation, perspectivization, and intensification.

Wodak $(2008,2016)$ suggests studying the nomenclature used for individuals or actions under referential/nomination strategy, the definitions used for people or events under prediction strategy, and the implicit or explicit arguments used for positive or negative nomenclature and definitions under argumentation strategy. She also recommends observing the perspective of these nomenclature, definitions, and arguments under argumentation strategy, and finally to focus on the ways used to strengthen all these strategies under intensification strategy. The strength of Wodak's framework is that it allows for the analysis of positive and negative discourses on minorities together with the strategies used to generate them. Alongside traditional media content, this framework is also applicable to the content created by social media users (Kreis, 2017). In this chapter, we analyzed the negative tweets generated by users close to CHP and MHP and the positive tweets generated by users close to AKP.

\section{Findings}

\section{Referential/nomination and predication}

How to refer to asylum-seekers has always been a problem (Torkington \& Ribeiro, 2019). In the tweets they generated, the users in the sample referred to Syrian asylum-seekers as refugees, asylum-seekers, or emigrants, although these titles have significant legal and status differences. In this research, the title of asylum-seeker or refugee was preferred by users who were close to CHP and MHP. As shown in Examples 1 and 3 (Table 14.1), these users either explicitly or implicitly emphasized that people who came from Syria were not asylum-seekers or refugees. As seen in Example 5 (Table 14.1), the users who were close to AKP preferred the emigrant title, 
Table 14.1 Tweet Examples (Referential/Nomination)

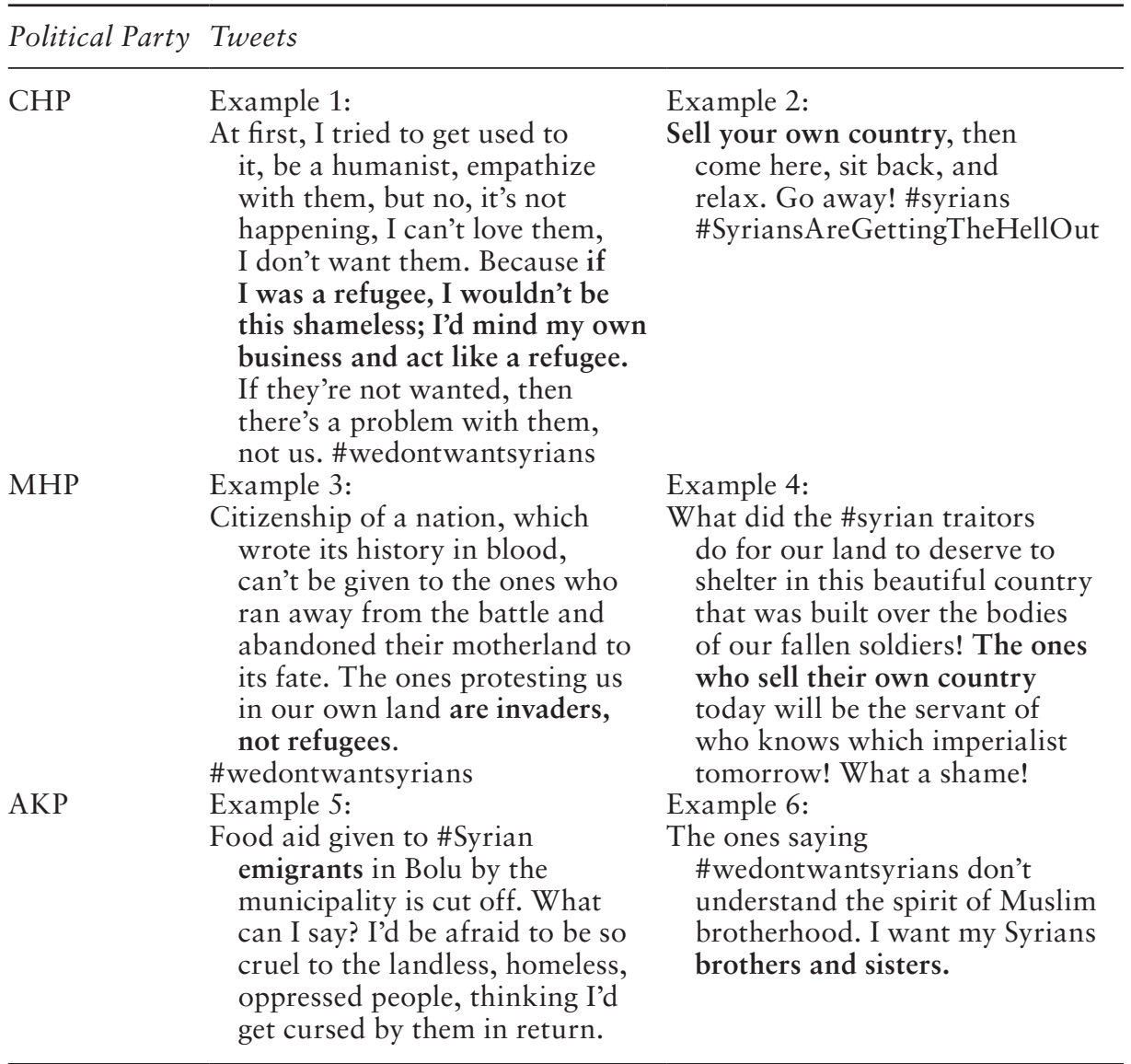

Source: Author's own.

which was used to define Muslims who migrated from Mecca to Medina during the time of the Prophet Muhammad and is very popular in the Islamic discourse.

The users made very different definitions for those coming from Syria. Derogatory descriptions, such as bacteria, parasite, barbaric, creature, desert rat, Arab, and terrorist, were frequently used in negative tweets generated by users close to CHP and MHP. The users close to these two parties were united by describing the men coming from Syria as traitors, war fugitives, and those who sell their own country, as illustrated in Examples 2 and 4 (Table 14.1). Users close to AKP mentioned religious references (oppressed, coreligionist, Muslim, etc.) in their descriptions. As demonstrated in Example 6 (Table 14.1), these users most often referred to the sibling definition. 


\section{Nurcan Törenli and Zafer Kıyan}

\section{Argumentation}

There are two dominant ideas in the tweets we included in the sample. While the users who generated negative tweets usually stated that they did not want Syrian asylum-seekers, the users who generated positive tweets opposed this idea and often criticized the users who generated negative tweets. The users also supported or legitimized their polarized attitudes with opposing arguments. The noticeable concept that was legitimized in negative tweets was the threats thought to be caused by Syrian asylumseekers. As depicted in Examples 7 and 8 (Table 14.2), while the users close to CHP drew attention to the threats posed to public order and health by asylum-seekers, those close to MHP emphasized the threats posed to Turkish identity and culture or the integrity of the demographic structure, as presented in Examples 9 and 10 (Table 14.2). In contrast, the prominent

Table 14.2 Tweet Examples (Argumentation)

\begin{tabular}{|c|c|c|}
\hline Political Party & Tweets & \\
\hline \multirow[t]{2}{*}{$\mathrm{CHP}$} & Example 7: & Example 8: \\
\hline & $\begin{array}{l}\text { Since the \#syrians entered the } \\
\text { country, Bodily Harm Rape } \\
\text { Robbery-Theft Murder has } \\
\text { increased by } 100 \% \text { ! I'd expect } \\
\text { anything from the ones who ran } \\
\text { away from their country instead } \\
\text { of protecting it! }\end{array}$ & $\begin{array}{l}\text { They let the \#syrian s into the } \\
\text { country without any proper } \\
\text { health check, most of the babies } \\
\text { are unvaccinated, diseases that } \\
\text { hadn't been seen for } 50 \text { years have } \\
\text { already started to reappear. This } \\
\text { country got itself into big trouble. }\end{array}$ \\
\hline \multirow[t]{2}{*}{ МHP } & Example 9: & Example 10: \\
\hline & $\begin{array}{l}\text { If they stay, the number of Syrians } \\
\text { in } 2040 \text { will be } 10 \text { million. Lots } \\
\text { of cities in Turkey will lose their } \\
\text { Turkish identity and become } \\
\text { Arabic cities. } \\
\text { \#wedontwantsyrians }\end{array}$ & $\begin{array}{l}\text { The demographic structure of our } \\
\text { country is changing. Our land, } \\
\text { which was built over the bodies of } \\
\text { our fallen soldiers, is being invaded } \\
\text { without firing a single bullet. Our } \\
\text { Muslim brothers! What a rubbish!! } \\
\text { Arabs can't be our brothers...! } \\
\text { Wake up Turkish Nation...! } \\
\text { \#wedontwantsyrians }\end{array}$ \\
\hline \multirow[t]{2}{*}{ AKP } & Example 11: & Example 12: \\
\hline & $\begin{array}{l}\text { An incorrect perception is created } \\
\text { through our \#Syrian Muslim } \\
\text { brothers and sisters. Everyone's } \\
\text { talking, whether they know } \\
\text { something or not. They are a } \\
\text { cultured nation, fond of one } \\
\text { another. They work here, and } \\
\text { the markets and the economy } \\
\text { liven up because of them; lots of } \\
\text { them invest too. They ran away } \\
\text { from the war to save their lives } \\
\text { and honor, but people withheld a } \\
\text { bowl of soup from them. }\end{array}$ & $\begin{array}{l}\text { \#syrians are more useful for } \\
\text { this country than the CHP } \\
\text { supporters. }\end{array}$ \\
\hline
\end{tabular}

Source: Author's own. 
concept that was legitimized in positive tweets generated by the users close to AKP was the benefits of Syrian asylum-seekers to Turkey. These users either associated these benefits with the economy, highlighting the contribution to employment as shown in Example 11, or expressed it with an ironic counter-criticism, as in Example 12 (Table 14.2).

\section{Perspectivization}

The perspective on Syrian asylum-seekers also differs in negative and positive tweets. The negative discourse in tweets generated by users close to CHP was presented either from an ironic perspective as observed in Example 13 or from a problem-oriented perspective as illustrated in Example 14 (Table 14.3). Among the problems raised, those that stood out were the increase in the number of Syrian asylum-seekers, their dispersion to cities across

Table 14.3 Example Tweets (Perspectivization)

\begin{tabular}{|c|c|c|}
\hline Political Party & Tweets & \\
\hline \multirow[t]{9}{*}{ CHP } & Example 13: & Example 14: \\
\hline & If we spent the money that we & \#ImAsking-Which country would \\
\hline & wasted for Syrians to reproduce & take in 4 million refugees? - \\
\hline & on breeding cattle, meat would be & Which country would place the \\
\hline & $\begin{array}{l}\text { 15 Iira/kg. } \\
\text { \#SyriansAreGettingTheHellOut }\end{array}$ & $\begin{array}{l}\text { refugees in the midale of the } \\
\text { cities? - Which country would }\end{array}$ \\
\hline & & spend 37 million dollars on \\
\hline & & refugees while its citizens can't \\
\hline & & get by? - Which country would \\
\hline & & $\begin{array}{l}\text { let the refugees smoke narghile on } \\
\text { beaches?\#wedontwantsyrians }\end{array}$ \\
\hline \multirow[t]{11}{*}{ MHP } & Example 15: & Example 16: \\
\hline & You can't get the Turkishness that & Turkey belongs to Turks! Soon \\
\hline & you do not have in your make & there'll be more Syrians in Turkey \\
\hline & up with a Republic of Turkey & than Turkish people, and no one \\
\hline & identity card. If $24 \mathrm{~K}$ Syrians & seems to be aware of this grave \\
\hline & return to Syria for the Eid, & situation. \#syrians \\
\hline & it means the normal life can & \#SyriansAreGettingTheHellOut \\
\hline & proceed. How long are they going & \#wedontwantsyrians \\
\hline & $\begin{array}{l}\text { to be guests? The ones who don't } \\
\text { send them away have hidden }\end{array}$ & \\
\hline & plans; they hate Turkishness. & \\
\hline & \#syrian \#wedontwantsyrian & \\
\hline \multirow[t]{6}{*}{ AKP } & Example 17: & Example 18: \\
\hline & Send away the ones saying & Saying \#wedontwantsyrians means \\
\hline & \#wedontwantsyrians and give & we are not brothers and sisters \\
\hline & $\begin{array}{l}\text { Syrians citizenship. There's no } \\
\text { border between Syria and us: }\end{array}$ & with Muslim believers. \\
\hline & Syrians are Ottoman subjects, & \\
\hline & $\begin{array}{l}\text { they are people of Turkey, they } \\
\text { can stay here forever. }\end{array}$ & \\
\hline
\end{tabular}

Source: Author's own. 


\section{Nurcan Törenli and Zafer Kıyan}

the country, the money wasted on them, and especially the unemployed Syrian men walking around beaches, swimming and smoking narghile stood out the most. The negative discourse in tweets generated by users close to MHP was presented from a nationalist perspective. These users, as shown in Examples 15 and 16 (Table 14.3), emphasized Turkishness and bravery, and stated that these were innate identities and that Syrian asylum-seekers did not possess and should be deported. The positive discourse in tweets generated by users close to AKP was presented from a religious perspective, referring to the joint history. These users, as shown in Example 17 and 18 (Table 14.3), drew attention to the Syrians being Ottoman subjects, and thus being the religious brothers and sisters of the locals of Turkey.

\section{Intensification}

The users employed different strategies to reinforce the discourse they adopted while expressing their thoughts on Syrian asylum-seekers. All users preferred similar reinforcement strategies in their tweets, whether negative or positive in content, as presented in Examples 19, 20, 21, 22, 23, and 24 (Table 14.4).

Table 14.4 Example Tweets (Intensification)

\begin{tabular}{|c|c|c|}
\hline Political Party & Tweets & \\
\hline CHP & $\begin{array}{l}\text { Example 19: } \\
\text { 'Showing more mercy than needed } \\
\text { means betraying the motherland!' } \\
\text { Marshall Mustafa Kemal Atatü } \\
\text { rkTRTRTRTR\#wedontwantsyrians } \\
\text { Good morning noble supreme } \\
\text { TURKISH NATION. HOW } \\
\text { HAPPY IS THE ONE WHO } \\
\text { SAYS I AM A TURKTR } \\
\text { \#saturday } \\
\text { https://t.co/HzS8k92Sa0 } \\
\text { (The visual shows the founder of } \\
\text { Turkey, Mustafa Kemal Atatürk.) }\end{array}$ & $\begin{array}{l}\text { Example 20: } \\
\text { It's not that \# wedontwantsyrians } \\
\text { due to racism. It's to PROTECT } \\
\text { THE PUBLIC ORDER! }\end{array}$ \\
\hline МHP & $\begin{array}{l}\text { Example 21: } \\
\text { The \#syrians, who disrespect our } \\
\text { FLAG dyed with blood, receive } \\
\text { the aid that our citizens don't get } \\
\text { from the government, sit back and } \\
\text { relax, and return to their country } \\
\text { on holiday, should be sent away. }\end{array}$ & $\begin{array}{l}\text { Example 22: } \\
\text { You come here to MY COUNTRY, } \\
\text { MY LAND, and then carelessly } \\
\text { say that you'll behead people. } \\
\text { What the hell you \#syrian } \\
\text { bastard... }\end{array}$ \\
\hline $\mathrm{AKP}$ & $\begin{array}{l}\text { Example 23: } \\
\text { 'Muslims are brothers and sisters.' } \\
\text { AL-HUJURAT 'Believers, you } \\
\text { should be brothers and sisters.' } \\
\text { Hadith \#wedontwantsyrians }\end{array}$ & $\begin{array}{l}\text { Example 24: } \\
\text { The ones saying "The war ended in } \\
\text { Syria, \#syrians should go back", } \\
\text { please watch this. } \\
\text { https://t.co/WTw4tJXtW2" } \\
\text { (The video in the link shows the } \\
\text { aftermath of an airstrike in Syria.) }\end{array}$ \\
\hline
\end{tabular}

Source: Author's own. 
Usage of quotes, capital letters, emojis, and photos and videos was the most preferred strategy. The users diverged in the references they used. While users close to CHP referenced Atatürk (Example 19), those close to MHP mentioned symbols, such as the motherland, land, and flag (Example 22). The users close to AKP pointed at religious sources, such as Quran and Hadith (Example 23).

\section{Discussion and conclusion}

Asylum-seekers are one of the factors causing political polarization (Mauro \& Verzichelli, 2019). As previous studies have shown, polarization manifests at two different levels as parties and individuals (see Erdoğan \& Uyan Semerci, 2018). Polarization at the political party level occurs when parties are ideologically distanced from each other (Druckman, Peterson \& Slothuus, 2013). Generally speaking, politics can be defined as the basis for political parties aiming to find solutions that will satisfy the needs and demands of the masses by taking these into account in political decision-making mechanisms, but in this process, it is usual, even expected, that ideologically the parties will differ, and under political polarization conditions, the parties will settle to opposing poles, and thus become irreconcilable (Erdoğan \& Uyan Semerci, 2018). So, the negotiation and persuasion efforts between the parties disappear, being replaced by conflict. Under such circumstances, polarizing politics spread from top to bottom, first down to party organizations, then to party supporters, and finally to the whole of society (A ğırdır, 2010). In this case, even the simplest problems can cause polarization and conflict, not only at the party level but also at the individual level.

The presence of Syrian asylum-seekers in Turkey is one of the factors causing polarization, both at the party and individual levels. The findings of this chapter suggest that polarizing politics are feeding on the negative and positive discourse on Syrian asylum-seekers, with the former having a provocative, derogatory, discriminatory, racist, and aggressive language, and the latter having a protective language. More importantly, when the positive discourse is directed at the users at the opposite pole, this protective language is replaced with a provocative, derogatory, and threatening language.

The tweets that we analyzed as discourses within the framework proposed by Wodak $(2008,2016)$ show that concerning asylum-seekers, party supporters act in alignment with the political parties they feel close to. The users close to CHP and MHP, both having negative attitudes toward Syrian asylum-seekers despite being in separate political alliances, generated negative discourses on Syrian asylum-seekers. In contrast, the users close to AKP, which has a positive attitude toward Syrian asylum-seekers, generated positive discourses on Syrian asylum-seekers. These results show that in the case of Syrian asylum-seekers, users close to parties in separate alliances may gather in the same set, and those close to the parties within the same alliance may experience political polarization within themselves. The analyzed 
tweets indicate that in their discourses on asylum-seekers, party supporters adopt the ideological language of the party that they support. Although in terms of generating negative discourses about Syrian asylum-seekers, the users close to CHP and MHP are similar to each other, the expressions they use and the ideological language they adopt are different. While the users close to CHP generally adopt a Kemalist or secular language, those close to MHP use a nationalist language. A similar finding applies to the users close to AKP, who seem to have adopted the Islamist and conservative language of this party, which is seen in their positive discourses about Syrian asylum-seekers.

Particularly, in political polarization circumstances, the hypothesis of political parties playing a big role in generating the negative or positive discourse on Syrian asylum-seekers retains its validity in the example of Turkey. During this period in Turkey, where political polarization has reached the level of political alliances, even for the simplest subjects, everyone from party organizations to party supporters refers to the political language and the adopted discourse of their parties. The tension between the asylumseekers and indigenous population in Turkey is not a new situation since the country has experienced many major population movements throughout history. What is new is that the language of politics is increasingly fed by this tension between the asylum-seekers and local people, escalating the polarization at the individual level. In conclusion, it appears that politics is the source of positive and negative discourses on Syrian asylum-seekers. If this is true, the responsibility of ending the racist and exclusionary discourse against asylum-seekers falls primarily on the actors of institutional politics.

\section{Acknowledgements}

We would like to thank anonymous reviewers and editors for their careful reading and insightful comments.

\section{Notes}

1 Distribution of tweets by hashtags: Hashtag 1 (4,064 tweets), Hashtag 2 (5,352 tweets), Hashtag 3 (3,294 tweets), Hashtag 4 (4,471 tweets), Hashtag 5 (7,819 tweets).

2 Distribution of users by hashtags: Hashtag 1 (878 users), Hashtag 2 (873 users), Hashtag 3 (404 users), Hashtag 4 (728 users), Hashtag 5 (1,244 users).

3 Graduate students Berna Açıkgöz and Halil Saç played an active role in the categorization of tweets.

\section{References}

Ağırdır, B. (2010, 14th June). Siyasette ve toplumda kutuplaşma [Polarization in political and social life]. T24. Available at https://bit.ly/2LrxdWP

Blumell, L. E., Bunce, M., Cooper, G. \& McDowell, C. (2020). Refugee and asylum news coverage in UK print and online media. Journalism Studies, 21(2), pp. 162-179. doi: 10.1080/1461670X.2019.1633243 
Boomgaarden, H. G. \& Vliegenthart, R. (2009). How news content influences antiimmigration attitudes: Germany, 1993-2005. European Journal of Political Research, 48(4), pp. 516-542. doi: 10.1111/j.1475-6765.2009.01831.x

Brooks, C., Manza, J. \& Cohen, E. D. (2016). Political ideology and immigrant acceptance. Socius, 2, pp. 1-12. doi: 10.1177/2378023116668881

Bulut, E. \& Yörük, E. (2017). Mediatized populisms-digital populism: Trolls and political polarization of Twitter in Turkey. International Journal of Communication, 11, pp. 4093-4117.

Çakır, S. (2020). Polarized partisanship, over-stability and partisan bias in Turkey. Turkish Studies, 21(4), pp. 497-523. doi: 10.1080/14683849.2019.1678030

DGMM. (2020, 28th February). Statistics. Available at https://bit.ly/3tDjRba

Don, Z. M. \& Lee, C. (2014). Representing immigrants as illegals, threats and victims in Malaysia: Elite voices in the media. Discourse \& Society, 25(6), pp. 687-705. doi: 10.1177/0957926514536837

Druckman, J. N., Peterson, E. \& Slothuus, R. (2013). How elite partisan polarization affects public opinion formation. American Political Science Review, 107(1), pp. 57-79. doi: 10.1017/S0003055412000500

Eberl, J. M., Meltzer, C. E., Heidenreich, T., Herrero, B., Theorin, N., Lind, F., Berganza, R., Boomgaarden, H. G., Schemer, C. \& Strömbäck, J. (2018). The European media discourse on immigration and its effects: A literature review. Annals of the International Communication Association, 42, pp. 181-206. doi: $10.1080 / 23808985.2018 .1497452$

Efe, İ. (2019). A corpus-driven analysis of representations of Syrian asylum-seekers in the Turkish press 2011-2016. Discourse \& Communication, 13(1), pp. 48-67. doi : $10.1177 / 1750481318801624$

Erdoğan, E. \& Uyan Semerci, P. (2018). Fanusta Diyaloglar: Türkiye'de Kutuplaşmanın Boyutları [Dialogues in the Bell Jar: Dimensions of Polarization in Turkey]. İstanbul: İstanbul Bilgi Üniversitesi Yayınları.

Facchini, G., Mayda, A. M. \& Mendola, M. (2013). What drives individual attitudes towards immigration in South Africa? Review of International Economics, 21(2), pp. 326-341. doi: 10.1111/roie.12039

Isaksen, V. J. (2019). The impact of the financial crisis on European attitudes toward immigration. Comparative Migration Studies, 7(24). doi: 10.1186/ s40878-019-0127-5

Jungkuntz, S., Helbling, M. \& Schwemmer, C. (2019). Xenophobia before and after the Paris 2015 attacks: Evidence from a natural experiment. Ethnicities, 19(2), pp. 271-291. doi: 10.1177/1468796818757264

Kreis, R. (2017). \#refugeesnotwelcome: Anti-refugee discourse on Twitter. Discourse \& Communication, 11(5), pp. 498-514. doi: 10.1177/1750481317714121

Kuntz, A., Davidov, E. \& Semyonov, M. (2017). The dynamic relations between economic conditions and anti-immigrant sentiment: A natural experiment in times of the European economic crisis. International Journal of Comparative Sociology, 58(5), pp. 392-415. doi: 10.1177/0020715217690434

Laebens, M. G. \& Öztürk, A. (2020). Partisanship and autocratization: Polarization, power asymmetry, and partisan social identities in Turkey. Comparative Political Studies. doi: 10.1177/0010414020926199

Lazarev, E. \& Sharma, K. (2017). Brother or burden: An experiment on reducing prejudice toward Syrian refugees in Turkey. Political Science Research and Methods, 5(2), pp. 201-219. doi: 10.1017/psrm.2015.57 
Mardin, Ş. (1990). Türkiye'de Toplum ve Siyaset [Society and politics in Turkey]. İstanbul: Ayrıntı Yayınları.

Mauro, D. D. \& Verzichelli, L. (2019). Political elites and immigration in Italy: party competition, polarization and new cleavages. Contemporary Italian Politics, 11(4), pp. 401-414. doi: 10.1080/23248823.2019.1679960

Otto, A. H. \& Steinhardt, M. F. (2014). Immigration and election outcomesevidence from city districts in Hamburg. Regional Science and Urban Economics, 45, pp. 67-69. doi: 10.1016/j.regsciurbeco.2014.01.004

Saraçoğlu, C. \& Yeşilbağ, M. (2015). AKP döneminde Türkiye: Minare ile inşaat gölgesinde [Turkey during the AKP era. In the shadow of constructions and minarets]. In G. Atılgan, C. Saraçoğlu, \& A. Uslu (Eds.), Osmanlidan günümüze Türkiye'de siyasal hayat [Political life in Turkey from the Ottoman Empire to the present] (pp. 877-963). İstanbul: Yordam Kitap.

Somer, M. (2014). Moderation of religious and secular politics, a country's 'center' and democratization. Democratization, 21(2), pp. 244-267. doi: 10.1080/13510347.2012.732069

Şener, M. (2015). Burjuva uygarlığının peşinde [In pursuit of bourgeois civilization]. In G. Atılgan, C. Saraçoğlu, \& A. Uslu (Eds.), Osmanlidan günümüze Türkiye'de siyasal hayat [Political life in Turkey from the Ottoman Empire to the present] (pp. 201-345). İstanbul: Yordam Kitap.

Tavassoli, F., Jalilifar, A. \& White, P. R. (2019). British newspapers' stance towards the Syrian refugee crisis: An appraisal model study. Discourse \& Society, 30(1), pp. 64-84. doi: 10.1177/0957926518801079

Timur, T. (1994). Osmanlı Toplumsal Düzeni [Ottoman Social System]. Ankara: İmge Kitapevi.

Torkington, K. \& Ribeiro, F. P. (2018). 'What are these people: migrants, immigrants, refugees?': Migration-related terminology and representations in Portuguese digital press headlines. Discourse, Context \& Media, 27, pp. 22-31. doi: 10.1016/j.dcm.2018.03.002

UNHCR. (2020, 1st February). Syria regional refugee response. Available at https://bit.ly/3tDjopq

Uslu, A. (2015). Hür dünyanın saflarında [In the ranks of the free world]. In G. Atılgan, C. Saraçoğlu, \& A. Uslu (Eds.), Osmanlidan günümüze Türkiye'de siyasal hayat [Political life in Turkey from the Ottoman Empire to the present] (pp. 347-392). İstanbul: Yordam Kitap.

Wodak, R. (2008). The contribution of critical linguistics to the analysis of discriminatory prejudices and stereotypes in the language of politics. In R. Wodak \& V. Koller (Eds.), Handbook of communication in the public sphere (pp. 291316). Berlin: De Gruyter.

Wodak, R. (2016). Discrimination via discourse. In N. Bonvillain (Ed.), Routledge handbook of linguistic anthropology (pp. 366-383). London: Routledge.

Yavuz, N., Karkın, N., Parlak, İ. \& Özdeşim Subay, Ö. (2018). Political discourse strategies used in Twitter during Gezi Park protests: A comparison of two rival political parties in Turkey. International Journal of Public Administration in the Digital Age, 5(1), pp. 82-96. doi: 10.4018/IJPADA.2018010105 


\title{
15 Orientalism and the mass media-a study of the representation of Muslims in Southern European TV fiction
}

The case of Spanish prime-time TV series

\author{
Cristina Algaba, Beatriz Tomé-Alonso \\ and Giulia Cimini
}

\section{Introduction}

The mass media in general and television in particular contribute to disseminate distorted images of certain cultures, religions, and ethnic groups by representing them in a stereotypical way (Grovogui, 2013). These TV productions generally reinforce the soft power discourse (Nye, 2005; Martel, 2011) of the supremacy of Western culture over others and reveal a hierarchical structure of the argument/representation (Der Derian \& Shapiro, 1989). For instance, the Orient and its mass media imaginary are constructs based on the representations made by Western writers, journalists, filmmakers, etc. As pointed out by Said (1978), orientalism is constructed as 'otherness' whose features are essentialised: it is exotic, primitive, and inferior. For Western audiences these ideas perpetuate a colonialist view of the Orient.

In Europe, the refugee crisis, the post-colonialist flows, and the strategic geographical location of some of its regions, especially the Mediterranean countries such as Spain, Greece, and Italy, have led to a rise in the immigrant population and to extreme stances towards this socio-political reality. Additionally, major acts of vandalism and terrorism linked to some of these racial or religious minorities, conspicuously linked to the so-called 'Muslim world,' have led to hate speeches in the European media and among their audiences. Indeed, Islamophobia has become pervasive.

This chapter analyses the representation of Muslims in prime-time TV series broadcast in Spain, a country with a large, firmly established Muslim community and a strategic migratory destination. It examines how the narratives chosen are built in order to offer a deliberate image of Muslim characters and certain aspects of their religious beliefs. To this end, the sample is made up of two TV series that have had a particular impact on Spanish 
audiences, namely, El tiempo entre costuras (Antena 3, 2013-2014) and El principe (Telecinco, on 2014-2016), both relevant within the Spanish television industry and internationally broadcast.

\section{A post-structuralist theoretical framework}

The dual theoretical framework and the methodological framework employed to analyse the TV series and their representation of Muslim 'otherness' are described below.

\section{$T V$ series as 'cultural artefacts'}

More than mere entertainment, TV series can be described as "cultural artefacts themselves, [which] embody cultural values and practices" (Algeo, 2007, p. 10). As Hansen (2017) remarks, "[a]ny society includes political, scientific, religious and artistic fields" and TV series (as with comics) "as a (potential) form of culture has a tension-ridden relationship with the latter" (p. 587). So, TV series reflect the tensions of societies and contribute not only to establish 'routinised practices,' but also to serve as indicators of the socio-political debates of concern to them (Moïsi, 2017, p. 21). In this regard, authors such as Shapiro (2009) and Gregg (1999) have emphasised the relevance of visual language for generating stereotypes and for generalising images of 'other' peoples and 'other' places. As noted by Weber (2005) when addressing political issues, popular cultural products help to "get a sense of the everyday connections between 'the popular' and 'the political" and allow spectators to see "how IR [International Relations] myths become everyday myths-because they are circulated, received, and criticized in and through everyday popular forms like films" (p. 9) and TV series. In this way, TV series connect daily practices with global issues and contribute to create imaginaries linked to common values that become familiar and shared by the members of each society (Buonanno, 2007), such as the alleged 'Muslim character,' places of peace, or violence.

TV series, like films and other cultural products, reflect "contemporary anxieties" (Dodds, 2003) about global issues. In their narratives they not only include references to identities, but also provide "information about places" (Dittmer, 2010, p. xvii). "Identity and power are thus invoked in multiple dimensions [...] [and assign] values to places, and it constructs hierarchies of people and places that matter and those that do not" (Dittmer, 2010, p. xvii). In this sense, TV series contribute to create "imagined communities" (Anderson, 1983) in which audiences are encouraged to feel more empathy for some characters and less for others. In this way, they contribute, through the representations that they offer, to construct (at least one of the available) realities. As observed by Der Derian and Shapiro (1989), “[p]ost-structuralist analys[e]s pose a radical 
challenge to both the fact/value distinction and our concept of facticity generally, a concept that post-structuralists claim is conventional and culturally constructed rather than founded in nature" (p. xiv). In this connection, discourses elaborated from positions of (political/social/economic) power manage to define "the world" and to establish "regimes of truth” (Der Derian \& Shapiro, 1989, p. xiv).

\section{Orientalism}

When dealing with the representation of the Middle East and North Africa (hereinafter MENA) region, it is necessary to refer to Said's classic term 'Orientalism.' According to this author, Orientals (or Arabs or Muslims) have been traditionally represented as "exotic, premodern, emotional, and indolent" (Dittmer, 2010, p. 18), as well as "fatalistic" (Said, 1997). 'Orientals' are constructed as the 'other' whose features are essentialised (Tomé-Alonso \& Ferreiro Prado, 2019). Conversely, the so-called 'Westerners' (Huntington, 2011) are perceived as rational, positive, and 'common.'

Although Said published his first essay on orientalism in 1978, the term is still valid. Indeed, orientalism is one of the most long-standing discourses in Western cultural products and "inescapable" for those critically involved in the non-West (Cardeira da Silva, 2016). In the media, "Islamic societies were considered for at least three decades to be in need of 'modernization"” (Said, 1997, p. ii). Similarly, "Islam' has always represented a particular menace to the West" (Said, 1997, p. ii). For AminKhan (2012), orientalism is the "expression in the media in the form of raced and gendered portrayals and demonized cultural representations of Muslims and Islam, with the accompanying assumption of the superiority of Western culture" or, in other words, "the Western media's incendiary racism" (p. 1, 595). These definitions of orientalism refer not only to distant realities, but also to Muslims (or people understood as being Muslims) living in the West.

In cultural industries, this reductionist view has led to multiple representational practices and, consequently, to "stereotyping"1 (Hall, 1997), thus influencing the knowledge and understanding that audiences have of the world (Hesmondhalgh, 2013). Since the turn of the century, these black and white representations have gone from bad to worse, especially as regards the Muslim community. The multiple terrorist attacks perpetrated in many Western cities (New York, Washington, Paris, London, etc.) by the extremist Islamic organisation Al-Qaeda made many Westerners fear Muslims and suspect that they were terrorists and potential agents of chaos in their societies, an idea that the media were largely responsible for fostering. As De Felipe and Gómez (2011, p. 20) note, after the 9/11 terrorist attacks the American television industry soon began to create series and readapt existing ones to include this chapter of American history. The West Wing 
(NBC, 1999-2006), 24 (Fox, 2001-2010), The Shield (FX, 2002-2008), and Homeland (Showtime, 2011-2020), plus many other fiction series, were soon being broadcast to dismayed audiences. Their constant exposure to this negative portrayal of Muslims was publicly decried by members of this community. For instance, Sue Obeidi, the director of the Hollywood bureau of the US Muslim Public Affairs Council (MPAC), reported the negative image of Muslims/Arabs reflected in the TV series Homeland and its inaccurate representation of this collective (Arab characters with Persian names, a US military Muslim convert burying the Qur'an, etc.). Referring to the general media, Obeidi described how the Islamic State used the antithesis of the Muslim characters portrayed in these fictional series, to wit, 'the Muslim hero,' to swell it ranks, thus filling this representational gap in the Western media discourse (Zaheer, 2019). Examples like this highlight the relevance of studying how the concept of orientalism is currently understood, represented, and disseminated in cultural products. In this respect, TV series provide, as has seen in some of the aforementioned post-9/11 fiction offerings, a specific cultural space which serves as a stage "on which political dynamics are represented, imaginaries are shaped, conflicts are interpreted and a consensus is formed" (Iglesias-Turrión, 2013, p. 23).

\section{A framework for analysing orientalist discourses}

In this chapter, three main approaches (Fiske, 2006) are taken to the TV medium, in general, and to TV series, in particular, as texts: (1) Reality or technical codes; (2) Representation or narrative codes; (3) Ideology or ideological codes. By using the term 'code' Fiske (2006) refers to “[...] a rule-governed system of signs, whose rules and conventions are shared amongst members of a culture, and which is used to generate and circulate meanings in and for that culture" (p. 4). To study how the concept of orientalism is represented in the TV series analysed here, recourse is had to the methodological framework proposed by Tomé-Alonso and Ferreiro Prado (2019). These authors state that to analyse orientalism in an audio-visual product the focus should be placed on five key elements: (a) Exoticism; (b) Landscapes and locations; (c) Characters; (d) Music; and (e) Political systems (see Table 15.1).

Concerning the trope 'characters,' it is especially relevant to examine the actantial dimension (Greimas, 1989) of the main characters and how the relationships between Western and Eastern characters are depicted in different scenes. As Iwamura (2011) observes, "[t]he types of identifications the series forged between character and audience more substantively reveal ideological commitments" (p. 135). In this sense, it is relevant to focus on the discourse and representation of the 'other' that these prime-time TV series offered their audiences and on which of the elements described in the orientalist framework (see Table 15.1) contributed to reflect that imaginary on the small screen. 
Table 15.1 Orientalist Framework

\begin{tabular}{|c|c|}
\hline Tropes & Sub-tropes \\
\hline Exoticism & $\begin{array}{l}\text { Sensuality, splendour, passion or romance, bright } \\
\text { colours, music }\end{array}$ \\
\hline Landscapes and locations & $\begin{array}{l}\text { Exotic places, such as the desert (a threatening, } \\
\text { beautiful, and exotic place) } \\
\text { Various locations associated with different moments } \\
\text { or situations versus one location strongly } \\
\text { associated with a specific moment or situation } \\
\text { Duality interior/safe versus exterior/unsafe } \\
\text { Characteristics of one location attributed to the so- } \\
\text { called 'national character' }\end{array}$ \\
\hline Characters & $\begin{array}{l}\text { Hierarchical relations: some countries act, while } \\
\text { others are acted upon (Dittmer, 2010) } \\
\text { One-dimensional or complex? Do characters have } \\
\text { agency? Which characters lack agency? How are } \\
\text { characters depicted? } \\
\bullet \text { Barbarian } \bullet \text { Violent } \bullet \text { Criminal } \bullet \text { Diabolic } \bullet \\
\text { Hateful } \bullet \text { Submissive (women) } \bullet \text { Obsessed with sex } \\
(\text { men) } \bullet \text { Ireful } \bullet \text { Foolish }\end{array}$ \\
\hline Political system & Totalitarian and/or despotic \\
\hline
\end{tabular}

Source: Author's own based on Tomé-Alonso and Ferreiro Prado (2019).

The relevance of space representations and locations has also been stressed in different works (Dodds, 2003; Shapiro, 2009). Cultural products tend to (re)produce landscapes that express "geographic imaginaries and antagonisms" based on "models of identity-difference" between us and them (Shapiro, 2009).

\section{Depicting orientalism in Spanish TV series: exoticism, sensuality, and violence}

As to the concept of orientalism in the cultural industries of Southern Europe, due to the migratory flows existing in countries like Spain and Italy, the representation of the 'other' or the 'foreigner' is frequently associated with African or Maghrebi immigrants. As Rizo observes (as cited in Retis, 2004, p. 127), the most, frequent representations of immigrants are based on two assumptions: (1) Immigrants as a threat or danger to society; and (2) Immigrants as people who have gone through hell and high water to reach 'their promised land.'

The representation of immigration in Spanish TV series is a fairly new line of research. For instance, Biscarrat and Meléndez Malavé (2014, p. 335) analyse the prime-time comedy Aida (Telecinco, 2005-2014), a TV series in which different immigrant collectives (Latin Americans, Asians, Arabs, and Africans) have a noteworthy presence. They conclude that, as TV characters, immigrants tend to be invisible or not to play the same narrative roles as those characters defined as Spanish. In more recent 
studies, the psychosocial dimension of the fictional immigrant has been analysed. As regards this approach, Marcos Ramos and González de Garay (2019) claim that the negative values associated with immigrants (drug problems, violence, untrustworthiness, etc.) surpass the positive aspects in their corpus of 26 Spanish TV series.

Beyond migration and migrant topics, TV fiction allows broad audiences to 'access' distant countries by showing them other 'places' and 'realities.' As stated by Dittmer (2010), "representation makes claims about the way the world is" (p. 49). In this vein, more often than not "the narrative itself denigrates the local, favouring regional and global scales of organization" (p. 67), and dispenses with sophisticated explanations in favour of simple and uniform ones.

Regarding these studies, the aforementioned orientalist framework is employed here to examine the figure of the 'Muslim other.' In order to include diverse representations of the 'other,' two different TV series are analysed: El tiempo entre costuras and El Principe. Both productions have been broadcast in other Southern European regions like Italy, a country that lacks equally relevant domestic prime-time TV series dealing with Muslim culture(s), an issue that is addressed instead in webseries or 'niche' films aim at a smaller and more select target audience. In contrast to Spain, systematic studies on how Muslims and their culture are depicted in mainstream television-and, more importantly, on its implications-have yet to be performed in Italy. As noted above, both Il tempo del coraggio $e$ dell'amore (Canale 5, 2014) and Il principe - Un amore impossibile (Canale 5, 2014; Top Crime, 2017) are Spanish productions broadcast in other Southern European TV industries (for instance, Italian television) as part of a broader 'offering' of Spanish soap operas. So, although they make an equal contribution to reproducing and disseminating 'exotic' imaginaries, the emotional commitment of Spanish audiences to the plot is supposedly higher than that of their Italian counterparts (and their alleged identity) due to the absence of a direct colonial legacy in Maghreb countries like Morocco, Algeria, and Tunisia. In a way, these TV series are 'doubly' exotic for Spaniards.

\section{El tiempo entre costuras: the colonialist conception of Moroccans (the 'Moors')}

As with other cultural products addressing the Spanish Civil War, in El tiempo entre costuras the action takes place in different locations (Madrid, Tangiers, Tetouan, and Lisbon). The main character, the young, unassuming seamstress Sira Quiroga, decides to move from Madrid to Morocco to start a new life with her beau, Ramiro Arribas, a duplicitous man who abandons her in an unknown land and at a dangerous moment in European and Spanish history. Set in the previous century, during and after the Spanish Civil War and at the beginning of the Second World War (the 
series starts in 1934 and ends in 1940), the story involves both real (Juan Luis Beigbeder, Chief of Indigenous Affairs and High Commissioner in the Protectorate of Morocco, and the British aristocrat and spy Rosalinda Fox) and fictional characters such as Sira, whose paths cross due to these historical events.

Based on the best-selling eponymous novel written by María Dueñas on 2009 and translated into approximately 30 languages, this big budget historical TV drama has been just as successful. El tiempo entre costuras has been broadcast on more than 20 international TV channels and streaming platforms (Cabezuelo Lorenzo, Caerols Mateo \& Sotelo González, 2018). This TV series was not only the most-watched fiction series on Antena 3 in the last 12 years (Cabezuelo Lorenzo, Caerols Mateo \& Sotelo González, 2018), but also influenced the consumption habits of its audience. For instance, after the first episodes had been broadcast, travel bookings to Morocco soared as the audience wanted to "follow the steps (or stitches) of character Sira" (Smith, 2014). Regarding audience engagement with this North African country, all the exotic aspects of early-20th-century Morocco are enhanced in order to help viewers to experience (both visually and aurally) the setting: crowded bazaars, men sporting fezzes (typical crimson hats), chilabas and babouches; women in hijabs, boisterous children running after foreign cars and pedestrians, narrow streets, Moorish architecture and ornaments; and the Islamic call to prayer (the Adhan) as a recurrent background sound. All these elements stress the country's exoticism, as it is typically depicted in the books, paintings, and photographs of 19th-century orientalists and disseminated by the film industry in the 20th century (Tomé-Alonso \& Ferreiro Prado, 2019, p. 8). However, these aspects do not evolve during the 11 episodes of the TV series. Instead, they merely serve to create an exotic atmosphere in which the Western characters develop all their plot actions.

In El tiempo entre costuras, the socio-political context in the 1930s and 1940s pervades the tropes of (b) locations and (c) characters to offer a binary opposition (Hall, 1997) between Europeans and Moroccans based on a colonialist view of this North African country. The Spanish Protectorate of Morocco in which Sira starts up her own business as a seamstress was under Spanish control up until 1956. Despite the fact that the Europeans coexisted with the Moroccans, their social relationships were based on inequality and servility, as the latter worked as servants, agents, or assistants for Westerners, personified by the character of Jamila, a Moroccan female servant working at the hostel owned by Doña Candelaria. Jamila is the only native character who interacts with the Spaniards staying at Doña Candelaria's. She also timidly plays the actantial role of the 'helper' (Greimas, 1989) of the story's main character, Sira. Nevertheless, their relationship is never equal due to Jamila's submissive and humble attitude and Sira's gradually improving social status among the upper-class Europeans (mainly Spaniards, Germans, and her British friend Rosalinda Fox) residing 
in Morocco. In this aristocratic and colonialist Morocco, the Arabs are also portrayed through the stereotypical figure of the 'Arab sheik' or 'Arab chief,' in order to reflect the good diplomatic relations between Spain and Morocco. This is superficially achieved by showing these prominent members of Moroccan society shaking hands with some of their counterparts belonging to Franco's political camp. However, this diplomacy with the 'other' boiled down to recruiting 'Moors' for Franco's rebel army. ${ }^{2}$ The artist Félix Aranda, a friend of Sira's, summarises this in a conversation about Beigbeder, the High Commissioner in the Protectorate of Morocco: "He indulges Franco by continuously sending him quarrelsome Moors to the front" [Episode 3. La felicidad de unos cuantos (The happiness of a few)]. Concerning Spanish political interests in this African territory, in Episode 3 Aranda also ironically remarks, "Spain asserts its suzerainty over Morocco to relive the imperial dream. Since Cuba and the Philippines have slipped from Spanish control, Spain's as poor as a church mouse." In line with this idea, Campoy-Cubillo (2016) underscores the underlying ambivalence, beyond Dueñás narrative, combining "the postnational drive towards a normalized Spanish identity and a nostalgic evocation of Francoist imperialism" (p. 257). During this period, the vision of the fearsome and bloodthirsty Moor was rekindled in the Spanish imaginary due to the role played by Moorish troops in the ranks of the rebel forces fighting against the Republican armies during the Civil War. It was precisely "[...] the Republicans of different leanings and the Catalan and Basque nationalists who excelled in the task of presenting the Moroccans as fanatical, bloodthirsty, murderers, rapists, drunkards, kidnappers, etc.” (Martín Corrales, 2004, p. 43).

Notwithstanding the fact that the TV series does not portray these "bloodthirsty' troops or the negative values associated with them, it does indeed contribute to perpetuate other characteristics linked to the stereotypical image of the Moors through Sira's eyes. As Martín Corrales (2004) asserts, since the Muslim invasion of the Iberian Peninsula in the 8th century down to the present day, different historical events (the Reconquista, the Regulars, the 2004 Madrid train bombings, etc.) have favoured a dire perception of this collective, commonly known as the 'Moors,' in Spain. This hegemonic view of Muslim people has traditionally associated them with different negative, stereotypical preconceptions, such as "[...] fanaticism, barbarism, cruelty, lechery, fatalism, laziness, duplicity, etc.” (Martín Corrales, 2004, p. 40). In El tiempo entre costuras, some of these prejudices are introduced in certain dialogues that refer to Africa as a continent of uneducated and shabby people. For instance, this chauvinism emerges in some of Sira's lines [Episode 1. Amor y otras verdades (Love and other realities)]:

SIRA: "But why would the Moors want to learn how to use a typewriter?" RAMIRO: "What ideas you have, Sira! Tangiers is an international city, an open port where citizens from all over Europe arrive. I can assure you that you'll love it." 
The idea of savagery and filthiness is refuted by some characters like Ramiro and Doña Candelaria who, in reply to Sira, remarks, "Maybe they live in Africa, but people there also wash themselves" [Episode 2. El camino más difícil. (The most difficult path)]. Apart from these misconceptions, Sira also discovers that the rigid Spanish morality at the time does not apply in Morocco, mainly witnessing rather than participating in debauchery:

It was a time of discovery. I found that there were substances that, once smoked, could alter the senses; that love did not depend on races or sexes and that there were passions of the flesh that involved other combinations than those of a man and a woman lying on a bed.

[Episode 1. Amor y otras verdades (Love and other realities)]

But these discoveries soon turn sour when Ramiro abandons Sira, who is incapable of finding her bearings in that strange land until Doña Candelaria takes her under her wing and helps her to open her seamstress business. This is when she starts to make the acquaintance of different Europeans and to create a special bond with the British aristocrat Rosalinda Fox, Beigbeder's lover. Fox's British outlook acquaints the audience with the high living standards of other Europeans in the protectorate. The progressive decolonisation of other countries, such as India, is briefly introduced in some of this character's lines: "Maybe India is no longer the paradise it used to be for many English people" [Episode 5. El sol siempre vuelve a salir (The sun always rises again)]. Western nostalgia for the lost Eastern paradise is reflected by this remark.

This nostalgia is also perceived when Sira returns to Madrid (1940) with a double identity: she continues to work as a seamstress while spying on her German clientele for the British government. In this new stage of her life, she masquerades as the Moroccan national Airish Agoriuq (her Spanish name written backwards). In order to attract the attention of upper-class Europeans and the wives of German officials residing in Madrid, she resorts to several clichés associated with the exoticism and sensuality of Morocco: she usually wears a turban and organises a fashion show full of colourful, audacious garments made of exclusive oriental fabrics, among other things. Ultimately, she offers the drab society of post-war Madrid the exoticism of distant, forbidden countries.

By and large, the concept of orientalism is fully developed in the TV adaptation of El tiempo entre costuras. On the one hand, this TV series leverages the exoticism of Moroccan aesthetics to captivate the audience. As "[a]ll the stunning visual excess that it offers, the exotic locations and the wholly absorbing yet restrained melodrama of its narrative, is a welcome tonic to Spain's persistent economic crisis" (Kemp, 2016, p. 171). On the other, it contributes to enhance other aspects linked to the stereotypical image of the Moor, insofar as it does not feature any relevant Moroccan characters, thus excluding the point of view of the 'other.' In fact, these 
characters are more like props employed to flesh out the landscape or play symbolic roles linked to professions at the service of the Westerners living in Morocco.

\section{El Príncipe: terrorism and drug trafficking on the Southern European border}

Set in Ceuta, El Príncipe narrates the investigation of the disappearance of a young Muslim man who is an alleged terrorist. The plot revolves around Javier Morey, a chief inspector working for the Spanish National Intelligence Centre (hereinafter CNI) who travels from Madrid to Ceuta to investigate a terrorist network based in this North African city. Once there, he falls in love with the heroine, Fatima, a young Muslim woman related to a drug trafficker and the missing Muslim man. Police corruption and bad practices and the investigation of the terrorist group Akrab complete the plot. Taking its name from El Príncipe (The Prince), a mainly Muslim neighbourhood in Ceuta, and produced by Mediaset, the series was popular in Spain (21.9\% share), Israel, and a number of Latin American countries. In other Southern European countries like Italy, its share peaked at 17.92 and even $24 \%$ during the second season.

Transporting the audience to the southernmost border of Spain and Europe, in El Principe Ceuta is depicted as a city fraught with danger and immersed in illegal activities. The streets of the Muslim majority neighbourhoods are full of criminals, drug dealers, and would-be terrorists. The Spanish authorities are frequently questioned and the leaders of those neighbourhoods are Muslims who try to control the young in their own interests. These aspects underscore the hazards of living in border localities.

The intertextuality of El Principe should also be highlighted. It contains references to news about Ceuta which often appears in the media, its demographic makeup, its multicultural background, and its problems. Spanish audiences watching the TV series can easily connect with other programmes, such as España mira a La Meca [Spain looks towards Mecca] by Telecinco on 2018, which supposedly offer a 'serious' analysis of Ceuta's Muslim reality. Such allusions include the key role played by the Spanish police in combating crime, the widespread violence among Muslims, and the risk of radicalisation relating to some places of worship. This sense of danger and difference is reflected in the locations and the characters of $E l$ Principe.

Ceuta's peripheral location is highlighted by the fact that Morey travels there from Madrid. It is an 'exotic' place where the Spanish identity mingles with or is even absorbed by the Moroccan one. The visual difference between the skyline of Madrid and Ceuta places the accent on the modern/pre-modern dichotomy (Funnell \& Dodds, 2017). Also, as observed by Funnell and Dodds (2017) when studying James Bond, his journey from Madrid to Ceuta and back again stresses the Spanish 
capital's vulnerability to terrorist attacks and the CNI's battle against terrorist networks. The danger posed by the mainly Muslim neighbourhood, where the action takes places, is succinctly summed up in the following statement, which is often repeated by different characters in the TV series: "In El Principe everything ends in salty water: in tears ... or at the bottom of the sea."

The orientalist content of El Principe can be clearly seen when analysing the male characters, their roles, and their character traits. Muslim males are either terrorists or drug dealers dabbling in crime and murder. These Muslim character traits contrast with the hero role played by an 'authentic' Spaniard. In fact, it is possible to identify a racialised construction of character identity which contributes to the racialisation of the nation-state (Dittmer, 2013, p. 47). The Spanish identity thus seems exclusive to those without a Moroccan background, for in El Principe the Spaniard-Christian and Moroccan-Muslim pairings are self-evident.

The idea of exoticism and tradition is reinforced by the female characters. Besides being stunningly beautiful, the heroine Fatima follows a double logic of submission and rebellion. She has a conflictive relationship with her family who wants her to observe traditional (Muslim) values. Despite her attempts to do so, she ultimately rebels against tradition and, accompanied by Morey, walks to freedom. This journey from tradition to freedom allows for a gendered interpretation of protection by showing a woman who needs to be saved (Dittmer, 2013). The veil that she wears represents her submission to those pre-modern (and oppressive) values.

In the main, as Karzazi (2019) notes, the TV series does not take advantage of its large audience share to raise awareness about the problems of this Spanish region. On the contrary, it offers a monolithic and stereotypical imaginary replete with "mysterious, exotic, dangerous characters, in a way that turns the Muslim residents of this neighbourhood into criminals, drug traffickers or terrorists" (p. 121). In this vein, orientalism allows El Principe to define the Southern border of Spain.

\section{Conclusion}

In sum, this chapter has illustrated the orientalist outlook that Spanish TV series maintain when depicting 'Muslim territories' and 'Muslim peoples.' This stereotypical picture of Muslim difference is a leitmotif in the two prime-time TV fiction series analysed here. First, in the two TV series the Spanish-Western places are contrasted with those identified as mainly Muslim. The dirty and noisy streets of Tangiers and the narrow and suffocating streets of El Príncipe in Ceuta represent those spaces occupied by the 'others.' This difference stresses the "division of wealth between the rich, white foreigners and the poorer locals" (Funnell \& Dodds, 2017, p. 118). It is also an example of what Shapiro (2009) calls 'cartographies of 


\section{Cristina Algaba et al.}

violence': the TV series' narratives draw parallels between Muslim majority countries and insecurity, crime, and terrorism. Therefore, citizens can easily identify 'dangerous,' pre-modern and 'uncivilised' countries or spaces and understand the need to intervene in them. In this regard, another space-related dichotomy can be identified: there are "countries that act and those that are acted upon" (Dittmer, 2010, p. 59). While European intelligence agents are plotting in Tangiers, police officers from Madrid are going about their work in Ceuta, thus creating the idea that these North African territories are no more than a chessboard for Westerners (Dittmer, 2010, p. 59).

Second, the Muslim characters appearing in the two TV series mostly have negative connotations. They are either liars (El tiempo entre costuras) or violent criminals or terrorists (El Principe). The very few 'good' Muslims who appear on screen are closer to the Western characters. Therefore, it is their relationship with the West that defines whether Muslims are 'good' or 'bad,' rather than their own character traits (Alsultany, 2012, p. 15). In contrast, the Western characters possess mainly positive attributes. In the two TV series, the main characters are Spanish. The responsibility of national security thus falls to the national hero or heroine, who tracks down and combats dangers abroad. The national hero thus actively contributes to the "process of territorial differentiation" (Dittmer, 2013, p. 110) between 'our' space and 'theirs' [where] the hero continuously intervenes "[...] not only to produce territorial understandings of the nation-state" (Dittmer, 2013, p. 183), but also those of the relationships with other territories inhabited by Muslims. It is important to stress the representation of Muslim women. Although they can be portrayed as submissive, they also appear in other roles. In El Principe, the female character (Fatima) rebels against family traditions. In this case, the female character is more akin to the Western characters and in conflict with Muslim men. The narrative revolving around this pugnacious woman includes "discourses of liberation or salvation of Muslim women from their dangerous Muslim men" (Aguayo, 2009, p. 47).

Finally, socio-political and economic differences appear in the two TV series. While places associated with the Western characters are represented as free, democratic, and advanced, those mainly occupied by their Muslims counterparts are depicted as more primitive, pre-modern, and authoritarian. This "association of contrasting values with different places enables differentiation based on sociocultural border that relates to the political border but may not be congruent with it" (Dittmer, 2013, p. 111). The modern/pre-modern dichotomy also offers a "visual representation of power" (Funnell \& Dodds, 2017, p. 121) and explicitly stresses the contrast between advanced and backward civilisations.

The orientalist representation of Muslim 'others' contributes to the differentiation between their space and the Spanish/Western one. These 
simplified portrayals of Muslims in Spanish TV series are not new. As some authors have asserted (Flesler, 2008; Campoy-Cubillo, 2016; Vázquez Atochero, 2019), due to its location Northern European countries have historically associated Spain with their conception of North African countries and peoples. As Flesler claims,

Spanish reality entails an old anxiety about Spain's belonging to Europe, and the efforts at overcoming its 'difference' linked in its various historical manifestations to notions of racial impurity, religious fanaticism, underdevelopment, poverty, and a general sense of inferiority in relation to a more-developed Europe.

(2008, pp. 18-19)

Therefore, this stereotypical image is not neutral (Lippmann, 1956). For instance, Campoy-Cubillo (2016) singles out as one of the factors behind the commercial success of El tiempo entre costuras, "the ongoing efforts to normalize discourses of Spanish national identity to make them pliable to the requirements of its integration in the European Union" (p. 257).

This concern has also been shared by other Southern European countries (Italy and Greece) which, as with Spain, are strategically located on the migratory routes from Africa and the Middle East to Europe. They have often been criticised by other EU Member States for the "excessive permeability" of their borders as regards immigration (Triandafyllidou \& Ambrosini, 2011, p. 252). These cultural artefacts help to reinforce national identities and highlight the common traits that these 'peripheral' Southern European societies share with those EU Member States.

\section{Notes}

1 Referring to the difference established by Dyer (1977) between 'typing' and 'stereotyping', Hall states that "'typing' is essential to the production of meaning." On the contrary, 'stereotyping' "[...] is part of the maintenance of social and symbolic order" (Hall, 1997, pp. 257-258) by using binary oppositions and reducing and naturalising the differences between two different cultures.

2 These troops were known as 'the Regulars' or the 'Indigenous Regular Forces.' They were infantry units of the Spanish Army formed by soldiers recruited from Ceuta, Melilla, and the Spanish Protectorate of Morocco, which were officered by Spaniards. These combative units played a major role in the Spanish Civil War.

\section{References}

Aguayo, M. (2009). Representations of Muslim Bodies in The Kingdom: Deconstructing Discourses in Hollywood. Global Media Journal-Canadian Edition, 2(2), pp. 41-56. 


\section{Cristina Algaba et al.}

Algeo, K. (2007). Teaching Cultural Geography with Bend It Like Beckham Teaching Cultural Geography with Bend It Like Beckham. Journal of Geography, 103(3), pp. 133-143.

Alsultany, E. (2012). Arabs and Muslims in the Media: Race and Representation after 9/11. New York: New York University Press.

Amin-Khan, T. (2012). New Orientalism, Securitisation and the Western Media's Incendiary Racism. Third World Quarterly, 33(9), pp. 1595-1610.

Anderson, B. (1983). Imagined Communities. Reflections on the Origin and Spread of Nationalism. London, UK and New York: Verso.

Biscarrat, L. \& Meléndez Malavé, N. (2014). De la exclusión a la heteronomía. Inmigrantes en la ficción televisiva Aída. ICONO14, Revista Científica De Comunicación Y Tecnologías Emergentes, 12(1), pp. 319-346.

Buonanno, M. (2007). The Age of Television: Experiences and Theories. Bristol, UK: Intellect.

Cabezuelo Lorenzo, F., Caerols Mateo, R. \& Sotelo González, J. (2018). La prensa histórica como fuente documental generadora de credibilidad en la ficción: el caso de El tiempo entre costuras. Documentación de las ciencias de la información, 41, pp. 135-145.

Campoy-Cubillo, A. (2016). El tiempo entre costuras: Colonial Nostalgia in the European Cultural Economy. Romance Notes, 56(2), pp. 257-267.

Cardeira da Silva, M. (2016). Southern insights into Orient and Western Orientalisms. Revista de Estudios Internacionales Mediterráneos, 21, pp. 1-11.

De Felipe, F. \& Gómez, I. (2011). Ficciones colaterales. Las huellas del 11-S en las series 'made in USA'. Barcelona, Spain: Editorial UOC.

Der Derian, J. \& Shapiro, M. (1989). International/Intertextual Relations. Postmodern Readings of World Politics. Lexington: Lexington Books.

Dittmer, J. (2010). Popular Culture, Geopolitics, and Identity. Plymouth, UK: Roman \& Littlefield Publishers.

Dittmer, J. (2013). Captain America and the Nationalist Superhero. Metaphors, narratives, and geopolitics. Philadelphia: Temple University Press.

Dodds, K. (2003). Licensed to Stereotype: Geopolitics, James Bond and the Spectre of Balkanism Licensed to Stereotype: Popular Geopolitics, James Bond and the Spectre of Balkanism. Geopolitics, 8(2), pp. 125-156.

Dyer, R. (1977). Stereotyping. In Richard Dyer (ed.), Gays and Film (pp. 27-39). London, UK: British Film Institute.

Fiske, J. (2006). Television Culture. London, UK: Routledge.

Flesler, D. (2008). The Return of the Moor: Spanish Responses to Contemporary Moroccan Immigration. Indiana, West Lafayette: Purdue University Press.

Funnell, L. \& Dodds, K. (2017). Geographies, Genders and Geopolitics of James Bond. London, UK: Palgrave McMillan.

Gregg, R. W. (1999). The Ten Best Films about International Relations. World Policy Journal, 16, pp. 129-134.

Greimas, A. J. (1989). Del sentido II. Ensayos semióticos. Madrid, Spain: Gredos.

Grovogui, S. N. (2013). Deferring difference: a postcolonial critique of the 'race problem' in moral thought. In Sanjay Seth (ed.), Postcolonial Theory and International Relations. A critical introduction (pp. 106-123). Abingdon, UK and New York: Routledge. 
Hall, S. (1997). The Spectacle of 'the Other'. In Stuart Hall (ed.), Representation: Cultural Representations and Signifying Practices (pp. 223-290). London, UK: Sage in association with the Open University.

Hansen, L. (2017). Reading Comics for the Field of International Relations: Theory, Method and the Bosnian War. European Journal of International Relations, 23(3), pp. 581-608.

Hesmondhalgh, D. (2013). The Cultural Industries. London, UK: SAGE Publications Ltd.

Huntington, S. P. (2011). The Clash of Civilizations and the Remaking of World Order. New York: Simon \& Schuster.

Iglesias-Turrión, P. (2013). Maquiavelo frente a la gran pantalla: cine y politica. Madrid, Spain: Akal.

Iwamura, J. N. (2011). Virtual Orientalism. Asian Religions and American Popular Culture. Oxford, UK and New York: Oxford University Press.

Karzazi, K. (2019). La serie televisiva El príncipe; entre mito y realidad. In K. Karzazi, Hassan Arabi \& A. Vázquez Atochero (eds.), Marruecos y España: denominadores comunes (pp. 119-124). Badajoz, Spain: anthropiQa and Lulu Press Inc.

Kemp, L. L. (2016). The re-construal of "La Costurera": A feminist re-interpretation of the role of the seamstress in El tiempo entre costuras/The Time between the Seams (2013). Studies in Spanish \& Latin American Cinemas, 13(2), pp. 159-175.

Lippmann, W. (1956). Public Opinion. New York: Macmillan.

Marcos Ramos, M. \& González de Garay, B. (2019). La caracterización psicosocial de los inmigrantes en las series de televisión españolas de prime time (2016-2017). Communication \& Society, 32(4), pp. 1-15.

Martel, F. (2011). Cultura mainstream. Cómo nacen los fenómenos de masas. Barcelona, Spain: Taurus.

Martín Corrales, E. (2004). Maurofobia/islamofobia y maurofilia/islamofilia en la España del siglo XXI. Revista CIDOB d'Afers Internacionals, 66-67, pp. 39-51.

Moïsi, D. (2017). La geopolítica de las series o el triunfo global del miedo. Madrid, Spain: Errata Naturae.

Nye, J. S. (2005). Soft Power: The Means to Success in World Politics. Nueva York: Public Affairs.

Retis, J. (2004). La imagen del otro: inmigrantes latinoamericanos en la prensa nacional española. Sphera Publica, 4, pp. 119-139.

Said, E. W. (1978). Orientalism. New York: Pantheon Books.

Said, E. W. (1997). Covering Islam. London, UK: Vintage Books.

Shapiro, M. (2009). Cinematic Geopolitics. London, UK: Routledge.

Smith, P. J. (2014, 27th January). Letter from Madrid: Bienvenidos al Lolita and El tiempo Entre Costuras. Mediático. Available at https://bit.ly/3aB40kO

Tomé-Alonso, B. \& Ferreiro Prado, L. (2019). Mapping Orientalist Discourses: Using Waltz with Bashir in the Classroom. International Studies Perspectives, 21(2), pp. 1-18.

Triandafyllidou, A. \& Ambrosini, M. (2011). Irregular Immigration Control in Italy and Greece: Strong Fencing and Weak Gate-Keeping Serving the Labour Market. European Journal of Migration and Law, (13), pp. 251-273.

Vázquez Atochero, A. (2019). A modo de introducción. Repensando el concepto de frontera. In Khadija Karzazi, Hassan Arabi and Alfonso Vázquez Atochero 
236 Cristina Algaba et al.

(eds.), Marruecos y España: denominadores comunes (pp. 11-16). Badajoz, Spain: anthropiQa and Lulu Press Inc.

Weber, C. (2005). International Relations Theory: A Critical Introduction. London, UK: Routledge.

Zaheer, M. (2019, 21th June). How Muslims Became the Good Guys on TV. BBC. Available at https://bbc.in/3tsTrJ5 


\title{
16 Sports and hate speech messages on Instagram \\ The case of Seville FC in the Spanish league
}

\author{
Alberto Monroy-Trujillo, Graciela Padilla- \\ Castillo and Francisco Cabezuelo-Lorenzo
}

\section{Introduction}

Social media is a rising phenomenon that is being covered from many perspectives, and hate speech was never so easy to spread. Twitter, Facebook, WhatsApp and Instagram have grown from simple apps to huge communication channels (Bernárdez, Padilla \& Sosa, 2019; Boczek \& Koppers, 2020; Naderer, Heiss \& Matthes, 2020; Wood, 2020). The opportunities that these new media offer are unlimited for sharing specific content as photographs, thoughts or messages (Gil-de-Zúñiga, Ardèvol-Abreu \& CaseroRipollés, 2019; Apgar, 2020; Budge, 2020; Mazid, 2020; Rui, Cui \& Liu, 2020). The exponential growth of these apps has already presented some challenges to researchers. Furthermore, football is the most popular sport in Spain and the rest of Europe. This research analyses the current situation of sports on Instagram under the context of hate speech. Football popularity claims the attention of those who want to enjoy social media to support their teams and favourite players, to give their opinions and to share information with other fans (López-Medel \& Cabezuelo-Lorenzo, 2018).

Football also claims the attention of those using social media to insult, scorn or vilify other fans and teams. Discovering the motivation behind insults is one of the most difficult purposes that this research wants to unveil. On another note, Seville Football Club (FC) has recently been considered one of the most hated teams in Spain, holding the fourth position only behind Barcelona, Real Madrid and Girona (Statista, 2018). This might explain why their Instagram account is often commented on by hate speakers, usually ready to spread insults and inappropriate expressions with the threat of being read by children.

Therefore, we focus on these main research objectives: (O.1) Overviewing the situation of social media; (O.2) Exploring Instagram's rise to one of the world's top three positions in social media; (O.3) Reflecting on the situation of hate speech and legislation against it; (O.4) Delving into the situation of sports on Instagram and (O.5) Analysing hate speech in the context of the Seville FC Instagram account. 


\section{Alberto Monroy-Trujillo et al.}

The main research questions are the following: Is the legislation regarding hate speech compatible in Spain and the European Union (EU)? Is hate speech a problem on the Seville FC Instagram account? Is there any relation between the tough losses of the team and insults? Are users getting banned when posting insults repeatedly? Do other users report these situations? Are hate speakers using anonymous profiles? Could we find people from other countries posting insults in the Seville FC Instagram account?

The authors consider five hypotheses: (H.1) Instagram users detect hate speech in a great proportion. (H.2) There are great differences between the European and the Spanish laws regarding hate speech. (H.3) Hate speech is present in a great proportion of the Seville FC Instagram account. (H.4) The study of the Seville FC masculine Instagram account will reflect a tendency where the insults towards men or the club will be higher than towards women. (H.5) Insults in the Seville FC Instagram account are not meant to criticise the club's performance but rather to hurt other users.

Concerning the methodology, it is divided into four parts: a longitudinal analysis of the situation of hate speech; the survey, which will lead to some conclusions concerning the behaviour on social media and the detection of hate speech; the classification of the hateful comments in the Seville FC account; and lastly, the creation of a word cloud with the most used insults translated into English. This methodology will clarify the usage of social media in current society in which hate speech takes its part. To this effect, the methodology will be divided into a quantitative and a qualitative analysis. On the one hand, in terms of quantitative procedures, the first method is the analysis of a survey. This survey was launched via Typeform for 17

Table 16.1 List of Questions for the Survey

Analysis Variables

1. Age (under 14, 14-20, 21-30, 31-45, 45-60, over 60).

2. Gender (male, female and other).

3. Do you have an Instagram account? (Yes/No. If not, the survey ends).

4. Do you understand what the meaning of hate speech is? (Yes/No).

5. How would you rate your behaviour on Instagram? (From 1 to 7 ).

6. Have you ever commented on someone's picture in a negative way? (Yes/ No).

6.1. If yes, why did you do it?

6.2. If yes, how offensive do you consider your comment?

7. Have you ever insulted someone/something on Instagram?

7.1. If yes, why did you do it? (Free answer).

7.2. If yes, how offensive do you consider your comment? (Free answer).

8. Have you ever detected hate speech on Instagram? (Yes/No).

8.1. If yes, was it addressed to men, women or other? (Man, woman or group/collective).

8.2. Did you report the situation? (Yes/No).

8.2.1. If no, why did you not do it?

Source: Authors' own. 
days from 3 to 20 April 2019. The platform offered an appealing and agile model to display the survey so it could call the attention of users. Regarding the questions, a total number of 15 were created.

During the creation of the survey, five people were consulted to check the composition and correct any possible mistakes before publishing it. For example, these people developed the logic of ending the survey at question number 3 if the respondent did not have an Instagram account and the additional questions to recover more data from numbers 6,7 and 8 . The resultant questions allowed us to obtain specific data concerning the amount of hate speech detected but also recognised by the respondents. Once the survey was perfectly shaped, it was distributed to the universe of undergraduate students and lecturers at Complutense University in Madrid. They represent a wide variety of ethnic, socioeconomic and age demographics. The final number of people surveyed was 139 . The quantitative procedure is the analysis of the comments on the Seville FC Instagram account. The results of this observation analysis could be combined and compared to the ones obtained from the survey. These comments were studied at the intersection of time from February 1 to May 3, 2019.

We read a total number of 221 comments that could be considered examples of hate speech, and we classified them into three potential categories: (A) Insults to the family; (B) Insults to the other person (Women/Men); and, finally, (C) Insults to clubs. Additionally, these comments were exhaustively analysed to develop a word cloud representing the most used insults. Moreover, we present longitudinal research to cover the concept of hate speech and the legislation concerning this topic in the EU and Spain. This research analyses articles and sentences published between 2011 and 2018. These materials cover the definition, the peculiarities, the legislation, and the differences, as well as the changes in those articles of the Spanish Criminal Code that in 2015 affected this matter.

\section{Instagram and its influence on our lives}

Social media are understood as forms of electronic communication such as websites for social networking and microblogging through which users create online communities to share information, ideas, personal messages and other content such as videos. Social media are at the top of Internet communication today. Nonetheless, there are only a few of them with a considerable audience and enough power to change decisions such as Brexit or the election of Trump in the USA (Bump, 2018). Facebook, Instagram and Twitter are, in this order, the most used social media in the world (Newman, 2018).

Instagram was created in 2010 by Kevin Systrom and Mike Krieger. Their idea was to post a picture with the possibility of getting comments and likes. The particularity of Instagram is that it was one of the first smartphone apps dedicated entirely to photography, as Facebook allowed other features to be combined. This aspect may have been crucial in its exponential growth. 
Since 2014, 100 million active users have joined Instagram each quarter of the year, reaching 1 billion in the last part of 2018 (Statista, 2019a). Nonetheless, the tendency is decreasing since in the last quarter of the same year, the figure was placed in 321 million (Statista, 2019b). The number of Internet users increases each year up to $7 \%$. In 2018 , more than 4 billion people in the world had access to the three main networks, which supposes a rate of $53 \%$ of penetration into the world's population. Moreover, the social media figures are close to this rate as they are $42 \%$ of the penetration rate with 3.196 active social media users (McDonald, 2018).

Considering the data, it is impossible to avoid thinking that social media are already making a great impact on our lives and will continue doing so throughout time. It is commonly said that social media interfere in human relationships, making them unreal and keeping them distant. However, there are some contexts in which social media may help to make humans closer to each other. Social media allows for sharing aspirations and making people feel unique.

Instagram appeared for the very first time in the App Store in 2010 and was meant to be only an iOS application. However, in 2012 it was offered for the first time in an Android version, gaining up to 200 million users in two years. Briefly after that moment, Mark Zuckerberg, CEO, and founder of Facebook decided to buy Instagram for approximately 1 billion dollars (Woods, 2013). Since then, Instagram has raised active users by 800 million, reaching the first billion in June 2018 (Constine, 2018).

Instagram is used by all kinds of people, but according to Omnicore (2018), in the USA, $69 \%$ of Instagram users are females; indeed, $31 \%$ of American women use it while, in the case of men, only $24 \%$ use it. Besides, $59 \%$ of them are people between 18 and 29 years old, $33 \%$ are ages $30-49$ and $8 \%$ remaining are over 50 years old. In business terms, $78 \%$ of influencers prefer this platform over other social media, earning up to $\$ 100.000$ per sponsored post. In business numbers, $71 \%$ of US businesses were on Instagram in 2018, with more than 1 million monthly advertisers and 8 million business profiles. Not in vain, Instagram's Mobile Ad revenue is expected to hit \$7 billion in 2018 (Omnicore, 2018).

In the case of Spain, Instagram is the second most used social media platform in Spain with 15 million users. Facebook has the first position with 25 million users and Twitter is third with 4.9 million users (IAB, 2019). According to the report titled "The Social Media Family 2019", of the 15 million Spanish users, the users from 18 to 39 years old are double the ones aged 40 to $65+$, with $66 \%$ in the first group and $34 \%$ in the second. In terms of gender, it is possible to establish a comparison with the USA as the predominant gender is also the feminine over the masculine, $56 \%-46 \%$, even though the gap is not as significant as in the North American case. The cities with more population and users are the top three: Madrid, Barcelona and Valencia.

In the beginning, the original Instagram app started offering fast uploading of photographs and that was part of the success. Systrom explained that 
"the magic of fast uploads is simply that we're not uploading full resolution" (Riley-Smith, 2013). It might seem simple, but this service started to change the history of social media. Under Zuckerberg's ownership, Instagram has been implementing new critical features, such as new Instagram Stories, which back then was an original idea of Snapchat. It consists of the publication of one photo, sentence or short video lasting a reduced amount of time, and with the advantage that whenever someone tries to capture it, you receive notification of that action.

The positive results obtained by Instagram, at the moment that the Snapchat mechanism was applied and converted to the brand-new Stories, motivated the Facebook team to also export it to their platform. In August 2016, Facebook arrived at Instagram and shortly after the successful experiment in February 2017 to Facebook (Cid, 2017). The mechanisms were as Snapchat created them and even the famous filters were transfused to both Facebook and Instagram. Snapchat succumbed to Facebook. Stories were not the only key features Instagram included in the platform. The projection of the company is to convert the picture of social media into a business and, as it has been referred to in the report, the volume of money in these transactions is very high already. Throughout 2018, Instagram brought under its arm continuous updates, underlining among them Instagram Shopping and IGTV. On the other hand, it incorporated the insertion of links in stories (even though at the moment links are only available for those accounts with more than 10,000 followers). Moreover, it has announced a new change in the algorithm, following Facebook's steps. All these functionalities make Instagram one of the most attractive social media for brands to develop their digital marketing strategy (The Social Media Family, 2019, p. 30).

In the end, Instagram boosted their increase by using the rising interest of people in audio-visual to gain more and more public support. Also, every segment of public opinions such as politicians, football players and football teams started using this app to engage with followers at the expense of other platforms such as Twitter. In the Table 16.2, it is going to be evident that football is a worldwide interest of Instagrammers, while politics is not. The numbers are from May 2019.

Table 16.2 Sample of Some of the Most Popular Teams, Players and Politicians in Spain in 2019 on Instagram

Football Team Followers Football Player Followers Spanish Politician's Followers

\begin{tabular}{lrllll}
\hline Real Madrid & $70.8 \mathrm{M}$ & Lionel Messi & $114 \mathrm{M}$ & Santiago Abascal & $208 \mathrm{~K}$ \\
FC Barcelona & $68.2 \mathrm{M}$ & $\begin{array}{l}\text { Sergio Ramos } \\
\text { Atlético de }\end{array}$ & $\begin{array}{l}31.5 \mathrm{M} \\
\text { Albert Rivera }\end{array}$ & $168 \mathrm{~K}$ \\
$\begin{array}{c}\text { Madrid } \\
\text { Seville FC }\end{array}$ & $603 \mathrm{~K}$ & $\begin{array}{c}\text { Griezmann } \\
\text { Wissam Ben }\end{array}$ & $24.4 \mathrm{M}$ & Pablo Iglesias & $130 \mathrm{~K}$ \\
Valencia CF & $587 \mathrm{~K}$ & $\begin{array}{c}\text { Yedder } \\
\text { Daniel Parejo }\end{array}$ & $197 \mathrm{~K}$ & Pedro Sánchez & $117 \mathrm{~K}$ \\
\hline
\end{tabular}

Source: Authors' own. 


\section{Football and social media}

Nowadays, sports cannot be understood without social media. They both enjoy a synergy that will leave one part orphan in the absence of the other. Clubs are more followed than other actors of public life such as politicians as has been displayed in the previous table, and the most prize-winning teams have more followers than the others. Furthermore, users demand quicker messages, $68 \%$ spend less than one hour on social media each day (AIMC, 2018 , p. 70). In addition, $80 \%$ of users' last use of social media was reported as the day before the survey (AIMC, 2018, p. 69). In response to this interest of people in social media, clubs' presence on social media is $100 \%$ in the first professional football and basketball masculine and feminine leagues (La Liga Santander and Iberdrola in football, Liga Endesa and Liga Día in basketball). Moreover, journalists are fortunate as this opened a great job opportunity as a community manager in charge of these profiles (Vila, 2018).

Every football team posts exclusive content for fans, which is also used by journalists. It is common to see stories with interviews or games between players or the announcement of the line-ups as well as livestreams during warmups and training sessions. Another important use is given to marketing, promoting clothing or products with a model of the players. What is more, every team mentioned in basketball or football has more than 10,000 followers.

In this direction, Lardo (2016) researched the influence or importance of popularity in social media and the expenditure, revenue and market value of football clubs. Repercussion in social media is a key point in professional clubs as the most followed tend to enjoy a better position in terms of market capitalisation (Lardo, 2016). So, social media have a very important role in sports, and success very much depends on them.

Nonetheless, marketing and capitalisation are not the only aims of Instagram's use in sports. Sportsmen and sportswomen show other interests, some of them either more personal or more public but about their own activities and with no profit motives. Pointing out some of the humanitarian aspects, Reichart and Sanderson (2015, pp. 352-353) consider that "athletes were very civic-minded and utilised Instagram to promote their charitable work and community advocacy". They also had time for family, sharing moments with them and showing how cheering these moments were. Additionally, they also posted content related to their workouts and showed some personal characteristics often not shown in the interests of mainstream media coverage.

\section{Hate speech: European and Spanish rules}

Hate speech covers many forms of expression, which spread, incite, promote or justify hatred, violence and discrimination against a person or group of persons for a variety of reasons. It poses grave dangers for the 
cohesion of a democratic society, the protection of human rights and the rule of law. If left unaddressed, it can lead to acts of violence and conflict on a wider scale. In this sense, hate speech is an extreme form of intolerance that contributes to hate crime, according to the Council of Europe. The concept of hate speech emphasises the incitation, promotion or justification of hate, violence or discrimination. For that reason, it covers a lot of angles and rules out the common knowledge that includes only the most severe insults as hate speech. Thus, nowadays social media are full of hatred messages and only a few users report this kind of behaviour as it will appear in the survey results later.

The European Commission against Racism and Intolerance (ECRI) is a competent organisation in the EU to propose politics and actions to treat the problem of hate speech, even though it is under the specific concepts of racism and intolerance. ECRI national members work separately, analysing the situation and proposing new actions and politics, studying the international legal instruments, the civil society, collecting opinions, and organising workgroups around this topic (Cortez-Lobao, 2015). However, it would not be until 2003 when the Court establishes certain limits, leaving the definition in expressions that propagate, incite, promote or justify hate based on intolerance, including religious intolerance (Quesada, 2015, pp. 9-10). Articles 10, 14 and 17 from the European Convention of Human Rights are the main rules concerning the issue of hate speech. Article 10 refers to the action of giving or receiving ideas/information in complete freedom and avoiding the public interference of any institution to restrict this expression.

However, this is not precluding states to require the necessary licenses for broadcasting. Besides, the second part of the article digresses about the importance of understanding the duties and responsibilities of the freedom of expression that finds its limit in the harm to the reputation or rights of others. The other important article in this sense is article 14, referring to the prohibition of discrimination. It establishes that the right to freedom of expression and all freedoms related to it is granted to everyone. There should not be any distinction between sex, race, colour, language, religion, politics or another opinion, or national or social origin. On the other hand, article 17 , referring to the prohibition of abuse of rights, compensates for both articles 10 and 14 by reinforcing the second point of article 10 . For example, acting or giving speeches against a particular denomination, religion or any kind of belief violates article 9 of the convention. In this sense, the object of analysis of this thesis could be framed under this fault as insults against supporters of Seville FC and might be considered as hate speech and not as freedom of expression.

In the Spanish case, hate speech is considered a penal process and for that, it is treated in the Spanish Criminal Code. The current legislation in this kind of criminal attitude appears in article 510. This article is part of the Law 1/2015 March 30th and substituted the former articles 607.2 and 510.1 of the Ley Orgánica 10/1995 Nov. 23 also known as the Spanish 


\section{Alberto Monroy-Truillo et al.}

Código Penal. Moreover, article 578 is also important as it includes the ennoblement or praise of terrorism as a criminal attitude, naming sentences from one to three years of prison.

\section{Results and analysis}

\section{Survey}

Concerning the survey, the profile of participants is $74.1 \%$ women compared to $25.9 \%$ men. The majority of Instagram's users are also women. When it comes to age, the results are also conditioned by the place where the survey has been done. University students are mainly between the ages of 18 and 22 in Spain, although it is possible to find older students. In this case, the results are eloquent with this, as $97.9 \%$ of respondents are between 14 and 30 years old. The $2.1 \%$ remaining refer to teachers of the groups surveyed. Instagram's penetration is very high. From the 139 respondents, $94.9 \%$ answered as having an Instagram account, 132 in terms of numbers. That means that only $5.1 \%$ do not have an account. The high usage of Instagram made this survey easier in terms of finding users to participate. It is important to remember that in all the research, Instagram was, at least, in the top three. When rating user's own behaviour in the usage of their Instagram account, they showed a very good perception about themselves. On the one hand, $30 \%$ of them reported that their behaviour was as good as seven out of seven; $40 \%$ said that it was worthy of a six; $21 \%$ selected five out of seven and $6 \%$ selected the exact middle point between good and not so good behaviour. On the other hand, not a great number of polled selected the second half of the possibilities. Only $1 \%$ evaluated their performance as three out of seven, while $2 \%$ considered themselves as bad as two. However, none of the respondents classified their behaviour as one.

The users' behaviour was reported as generally positive, so two questions have only had the contribution of a few of them. The first question referring to negative behaviour on Instagram is where we find more users willing to admit their comments, up to nine people (7\%). None of them considered that their comment was especially offensive, and most of them rated their comments as three out of seven. In respect to insults, it is understood a bit different compared with negative comments. In this case, the percentage of hate speakers descends a percentile point: only $6 \%$ acknowledge to have insulted someone via Instagram. Besides, one of them answered that the comment was as hard as six out of seven, a rating not used in the previous question.

Moving forward, the hate speech detection rate, which has been displayed, is very outstanding. The $88.6 \%$, at some point in their social media usage, have detected hate speech. One of the most important findings will be shown in the next part of the thesis. Only $11.4 \%$ reported not to have detected any situation involving hate speech. In today's society, the importance of good behaviour on social media is crucial as it is used by underage teenagers. 
Insulting is never the right decision, yet we coexist with insults everywhere in our daily life. On Instagram, the respondents reported that the primary target was women at $56.8 \%$ while men were only $7.6 \%$. The gender problem is still a really important matter. However, it is important for the object of this thesis study that $32.2 \%$ is related to insults towards groups or collectives, such as Seville FC.

Nonetheless, when it comes to reporting the situation, the action protocol is not shared among the respondents. Only $50.4 \%$ reported the situation when detecting hate speech while $49.6 \%$ did not. It is important to underline that it is very important to report those situations. As has been mentioned, more and more children have access to social media, so a report is basic.

\section{Content analysis}

Concerning the Seville FC Instagram account, made from February 1 to May 3, 2019, 221 comments were analysed. Comments were classified into three different categories: insults to the family of the other; issues concerning sex and gender; and lastly, about sport club and associations.

To set the context, in the last 15 years Seville FC has raised their trophy room considerably: five UEFA Europa League trophies and one Super Cup in Europe and one Spanish Super Cup and two Spanish King's Cup in Spain. Seville Football Club fans are very much accustomed to the flavour of victory and that is, usually, not completely positive.

On the other hand, during the last three years, when the trophy room has not received any visits, the figures have been completely different. In 2017 Seville FC was eliminated from UEFA by Leicester City, an apparently minor club. In 2018, it was eliminated in the semi-finals by Bayern Munich and in 2019 by Sportovní Klub Slavia Praha, a team with less budget and trophies.

This last elimination from the UEFA Europa League is one of the critical days in the Seville FC Instagram account as the insults and negative comments were very numerous. The defeat against Barcelona in the Spanish King's Cup was also a hurtful moment for its fans. However, the recent defeat against Getafe or Leganés in their battle for a spot in the UEFA has

Table 16.3 Categories in Comments and Insults

\begin{tabular}{lc}
\hline Insult Category & Number of Insults \\
\hline 1. Family & 71 \\
2. The other person & 94 \\
2.1. Woman & 43 \\
2.2. Man & 51 \\
3. Clubs & 56 \\
TOTAL & 221 \\
\hline
\end{tabular}

Source: Authors' own. 
enraged Seville FC supporters. These two days were considered critical, and a great number of the comments compiled refer to these two particular moments this year.

The content analysis results are partially opposed to the ones obtained throughout the survey. On the questionnaire the respondents answered "who was the insult addressed to"? with a clear target represented by women $(56.8 \%)$. In this case, hate speech against men represents more cases than women, although this might be understandable as the Instagram account is from the masculine section of Seville FC. However, the other big target detected in the survey was hate speech directed to groups or collectives $(32.2 \%)$. The comments against the club consisted of criticising the bad procedures developed in the member composition of the team. In some of the cases, the insults were addressed to the club members themselves and in other cases, the insults were addressed to other fans but referring to the club. Nevertheless, the terms used by users are not justifiable.

The last part of the classification is the most controversial hence it created some major disputes and fights: the family. It is barely understandable that during the process of commenting on a picture of a team, any user could end up fighting with the other addressing their families. However, from the 221 hate speech comments, 71 were concerned with insulting a member of the family either from a player or from the other user. It represents $32.12 \%$ of the total.

Moreover, this block was especially hard to read. The insults were addressed to the mothers of the other users or players, as will be visible in the next graph where the most used insult was motherfucker. Besides, it was particularly cruel some of the ways users insulted the dead members of the family of others. Some examples are "your mum is death" (04/04/2019), "we are a shit team, motherfuckers" (03/04/2019) and "your fucking mother is going to come in the draft, with all your dead relatives, sucking all your fucking life" (14/03/2019).

As said before, the comments are clearly not directed to discuss any of the events in the current development of the football activity. They are meant to hurt and insult without any kind of doubt. The incredible characteristic of all these situations is the possibility to compile them several weeks after. Thus, the community manager is not trying to intercede by erasing or reporting these comments. It is certainly interesting that some fans from the Andalusian club use the level of the rivals to discredit their merits. In the cases above, the negative comments are focused on the potential of the squad: Leganés, a low budget team from the South of Madrid with whom Seville FC lost 0-3 on May 3 in La Liga Santander, and Slavia Prague, a Czech team that eliminated them from the UEFA Europa League.

The cases of users that repeatedly insult others are very often seen. Here we can see how this Instagrammer starts using a very harmful insult as it is referring to the mother of the other in pejorative terms and evolves with insults addressed to the players and coach. However, the most peculiar fact 
about these insults is that the user is a re-offender, and he is not banned. Here are four of these comments, but it is possible to find several from him in different posts on the Sevilla Football Club Instagram account. The motivations are unknown.

The international projection of the club is also possible to analyse from the offenses. The first comment at the left is from an Italian fan, a supporter of AS Roma with some hate developed towards José Ramón Verdejo, wellknown as "Monchi", former sports director of the Rome team, now developing his job in Seville. The second one is from a Brazilian fan of Seville FC trying to express his anger aggressively.

However, if we talk about Seville FC, we have to mention their rivalry with Real Betis Balompié, the other team from Seville. This tense relationship in football terms is also evident from the point of view of insults. These two users are making fun of the defeats of Seville FC, although their team is performing worse this season. It is important to mention that only hard insults have been selected. If the criteria had been to include all the negative comments displayed in the critical publications, the results would have ended with a considerably greater number. Moreover, the period of time taken was only two and a half months.

The next step of this research development is the analysis of the insults in a strict sense. The procedure has been noting down the insults in Table 16.4 , and from that, making a word cloud with them. Some insults have been approximated to the concept remarked in the table as, for example, "son of a bitch" was approached to "motherfucker".

The most recurrent insult is "motherfucker" (71 times) with a huge difference from the second, which is "asshole" (32). Most of the attacks

Table 16.4 Most Repeated Insults

\begin{tabular}{ll}
\hline Insult & Repetitions \\
\hline Motherfucker & 71 \\
Asshole & 32 \\
Sucker & 29 \\
Drunk & 23 \\
Shit & 17 \\
Mercenary & 15 \\
Bold & 10 \\
Bastard & 8 \\
Silly & 5 \\
Wretch & 3 \\
Shit team & 2 \\
Dogs & 2 \\
Shit referee & 2 \\
Rat & 1 \\
Dumb & 1 \\
\hline
\end{tabular}

Source: Authors' own. 
started with a simple comment referring to the fans of Seville FC making fun of the defeat or elimination from some competition, and the answer was insulting the mother of the first one. As well, some fans from other clubs with a historical rivalry, such as Betis or Valencia, posted comments in the Seville FC account in such terms to avenge the recent results. Seville won the most recent derby against Betis, and their fans took advantage of every opportunity to compensate for it.

\section{Conclusions}

This research provides reasons to understand the place of hate speech in current digital societies, where the most important channels of communication are social media. This study also underlines the differences between the concepts of hate speech and their limits among European and Spanish rules. This chapter shows the huge detection rate of hate speech reported in the survey. It is important to underline that $88 \%$ of users have detected this behaviour. It is something really worrying.

Coming closer to the more concrete point of the research, the Seville FC Instagram account, hate speech has been found clearly. It is present in a huge proportion in the publications of the Andalusian club, validating the detection rate given by the respondents of the survey. However, the conflicting point between both methods comes when the insults are referred to as the final target of the action. While the respondents detected a clear objective represented by women, in the Instagram account of Seville FC, the target is more often identified as men.

However, we could also consider insults to women the ones embraced in the insult of "motherfucker", as it is addressed to the mother of the other. The saddest finding is the motivation of the insults. It is considered that if the club loses a great goal the fans would charge against the club and try to point out what is not going in the right direction in their opinion. Nonetheless, insulting the family is very recurrent, and it is not related to the club's performance. The most unkind and unpleasant comments are related to insults directed to members of the family. Also, these comments have usually nothing to do with the legitimate use of opinion in sports terms. The starting point is often the malice of hurting the other and creating a conflict where a lot of users feel entitled to keep motivating each other with other insults.

The hate speech situation on Instagram has become worrying. In the current society, there are sufficient mechanisms to control and track a lot of different situations, and we really think that Instagram should do something about this problem. The public consumers of Instagram are young and in some cases underage. A society where social media contains hate will reflect hate. This study shows really harsh comments from publications one month after their original post. This is something that needs to be changed. 
Users are often insulting others, but they do not get banned from Instagram. This situation really needs to change. Indeed, they do not use anonymous profiles, which makes insults and verbal attacks much easier. Users do not report these attacks, and this is unfortunately a common situation. The degree of connivance and coexistence between users and insults is so advanced that nobody cares about them. They read them, but they act as if they were not there. This is without any kind of doubt one of the biggest problems that should be treated and campaigned against to change. These negative comments contribute to deteriorating the education level of the users, as well as failing to create a good and positive community in social media. It is our duty to use our time to report and condemn these situations. Social media is a public space, and it lies in our responsibility to build the best of it.

\section{References}

AIMC. (2018). $20^{\circ}$ Navegantes en la Red. Available at https://bit.ly/3rY8UPA

Apgar, D. (2020). The Use of Group Text Messaging to Enhance the Social Support of Social Work Students. Social Work Education, 39(4), pp. 1-18. doi: 10.1080/02615479.2020.1736022

Bernárdez, A., Padilla, G. \& Sosa, R. P. (2019). From Action Art to Artivism on Instagram. Relocation and Instantaneity for a New Geography of Protest. Catalan Journal of Communication \& Cultural Studies, 11(1), pp. 23-37. doi: https:// doi.org/10.1386/cjcs.11.1.23_1

Boczek, K. \& Koppers, L. (2020). What's New about Whatsapp for News? A Mixed-Method Study on News Outlets' Strategies for Using WhatsApp. Digital Journalism, 8(1), pp. 126-144. doi: 10.1080/21670811.2019.1692685

Budge, K. (2020). Visually Imagining Place: Museum Visitors, Instagram, and the City. Journal of Urban Technology, 27(1), pp. 1-19. doi: 10.1080/10630732.2020.1731672

Bump, P. (2018). All the Ways Trump's Campaign Was Aided by Facebook, Ranked by Importance. Available at https://wapo.st/3fRy $8 \mathrm{fV}$

Cid, M. (2017). Facebook Stories: qué son y cómo funcionan las historias efímeras de Facebook. Available at https://bit.ly/3usXtRC

Constine, J. (2018). Instagram Hits 1 Billion Monthly Users, Up from $800 \mathrm{M}$ in September. Available at https://tcrn.ch/3dHkFou

Cortez-Lobao, T. (2015). El papel del Consejo de Europa en la lucha contra el racismo y la intolerancia. Available at https://bit.ly/3rX8MzT

Gil-de-Zúñiga, H., Ardèvol-Abreu, A. \& Casero-Ripollés, A. (2019). WhatsApp Political Discussion, Conventional Participation and Activism: Exploring Direct, Indirect and Generational Effects. Information, Communication \& Society, 23(2), pp. 1-18. doi: 10.1080/1369118X.2019.1642933

IAB. (2019). Estudio Anual de Redes Sociales. Available at https://bit.ly /31U8yyS

Lardo, A. (2016). Social Media Networks as Drivers for Intellectual Capital Disclosure: Evidence from Professional Football Clubs. Journal of Intellectual Capital, 18(1), pp. 63-80. doi: 10.1108/JIC-09-2016-0093 
López-Medel, I. \& Cabezuelo-Lorenzo, F. (2018). A Digital Communication Strategy for Global Domination: The Real Madrid Case. In A. V. Laskin (ed.), Social, Mobile, and Emerging Media Around the World: Communication Case Studies (pp. 121-134). New York: Lexington Books.

Mazid, I. (2020). The Virality of Social Change Messages on Facebook: A Study of Advocacy and Relationship Building Strategies of LGBTQ Advocacy Organizations. International Journal of Strategic Communication, 14(1), pp. 1-17. doi: 10.1080/1553118X.2020.1730377

McDonald, N. (2018). Digital in 2018: World's Internet Users Pass the 4 Billion Mark. Available at https://bit.ly/3t2rbfV

Naderer, B., Heiss, R. \& Matthes, J. (2020). The Skilled and the Interested: How Personal Curation Skills Increase or Decrease Exposure to Political Information on Social Media. Journal of Information Technology \& Politics, 17(3), pp. 1-9. doi: 10.1080/19331681.2020.1742843

Newman, N. (2018). Journalism, Media, and Technology Trends and Predictions 2018. Oxford, UK: Reuters Institute and the University of Oxford.

Omnicore. (2018). Instagram by the Numbers: Stats, Demographics \& Fun Facts. Available at https://bit.ly/3uwIxSo

Quesada, C. (2015). La labor del Tribunal Europeo de Derechos Humanos en torno al discurso de odio en los partidos políticos: coincidencias y contradicciones con la jurisprudencia española. Revista Electrónica de Estudios Internacionales, 30, pp. 1-33. doi: 10.17103/reei.30.04

Reichart, L. \& Sanderson, J. (2015). I'm Going to Instagram! An Analysis of Athlete Self-Presentation on Instagram. Journal of Broadcasting \& Electronic Media, 59(2), pp. 342-358. doi: 10.1080/08838151.2015.1029125

Riley-Smith, B. (2013). How Instagram Took Over the World in Just Three Years. Available at https://bit.ly/31WaAhO

Rui, J. R., Cui, X. \& Liu, Y. (2020). They Are Watching Me: A Self-Presentational Approach to Political Expression on Facebook. Mass Communication and Society, 23(2). doi: 10.1080/15205436.2020.1740741

Statista. (2018). El Barça, Real Madrid y Girona, los clubs más impopulares de La Liga. Retrieved from https://es.statista.com/grafico/16209/ clubs-mas-odiados-la-liga/

Statista. (2019a). The Number of Monthly Active Instagram Users from January 2013 to June 2018 (in Millions). Available at https://bit.ly/31ULmAI

Statista. (2019b). The Number of Monthly Active Twitter Users Worldwide from 1st Quarter 2010 to 4th Quarter 2018 (in Millions). Available at https://bit. ly/2PIEvrp

The Social Media Family. (2019). V Estudio sobre los usuarios de Facebook, Twitter e Instagram en España. Available at https://bit.ly/3uvtRD3

Vila, L. (2018). La esperanza laboral de los periodistas: el marketing digital. Available at https://bit.ly/327HTyR

Wood, E. (2020). Libraries Full Circle: The Cross-Section of Community, The Public Sphere, and Third Place. Public Library Quarterly, 39(3), pp. 1-23. doi: 10.1080/01616846.2020.1737491

Woods, B. (2013). Instagram. Brief History. Available at https://bit.ly/3fQBfVB 


\section{Index}

Abascal, Santiago 120, 124, 145, 150, 152-3, 162, 241

activists 5, 85-6, 93-4, 134

Al-Qaeda 223

algorithm 4, 33-5, 41, 43-5, 46, 60,

113, 195, 241; see also algorithmic

filtering

algorithmic filtering 17

Amazon 3, 36

apartheid 5, 67-8, 71, 73, 76, 78-9,

$81-2$

Arab Spring 49

Bolsonaro, Jair 7, 163, 165-6, 172-6

borderline content 17

Bush, George W. 34, 47

Cameron, David 103, 105, 110, 197, 200

Casado, Pablo 120, 125, 241

citizenship $3,7,10,73,85,118,183-4$, 187-8, 190-2, 207, 209, 213, 215

Clinton, Hillary 88, 93, 148-9, 199

cultural: artefacts 222, 233; industries $223,225,235$

critical thinking 16,30

cyberbalkanization 1

cyber-ghettos $1,3,10,26$

cyber utopianism 118

Daily Me (Negroponte) 34

deliberative models 50

democratic debate 16

dichotomization 102, 165

digital: communication 17, 54, 250;

conversation 4, 49, 51, 54-6, 58-61;

objects 4, 49, 54, 59-61; society 18

discourse: analysis $67,70-1,80-1$, 95-6, 99, 110, 112, 130-1, 135,
163-4, 192, 194, 196; counterhegemonic 7, 180; critical 80, 81, 95, 96, 99, 110, 112, 194; studies 99, $112,179,206$; theory $70,71,81,82$, 179,191

disinformation 1-3, 16-20, 25-6, 30-1 diversification of polarization (PérezEscolar \& Noguera-Vivo) 3-4, 26-7

emotions 21, 26, 29, 32, 55, 75, 86, 93-4, 99, 107, 110, 149

End of Ideology (Dalton) 16, 28

extremism 47, 56, 94, 118, 147

fact-checking 2, 18-21, 23, 29-30

fake: content 18 ; news $16-9,23-4$, 28-32, 86, 113, 118, 127, 161, 165, 174,195

false information 18, 26, 28

Farage, Nigel 100-1, 104-110

far-left 143

far-right 23, 26, 57, 94, 96, 116, 119 , $163,166,211$

framing 100, 150-1, 154, 156, 160-2, 203

Geography of Hate Map project 61

Google: Chrome 120; News 36-7, 46; Play 3; Search 36

Gore, $\mathrm{Al} 34,47$

hateful 53, 64, 204, 225, 238; see also hateful speech

hateful speech 4, 5, 55-62, 94

Iglesias, Pablo 120, 124, 127, 241

immigrant 6, 23, 26, 52, 89, 96, 112 , 131, 145, 148-51, 154-61, 189, 194, 200-2, 219-21, 225-6 


\section{Index}

impeachment 7, 47, 163, 165-7, 174

information: disorder 2, 11, 15, 18, 25, 26, 32; pollution 18

Johnson, Boris 100-1, 103-4, 106-7 journalism 18-20, 29-30, 31, 46, 47, $71,81,126,128-9,171,191-2,218$, 249-50

leftist $23,26,79,122,124,134$, 156,159

Los Indignados (social movement) 49

malinformation 19, 26, 45

Mandela, Nelson 67

media: alternative 140, 182, 192;

mainstream 20, 34, 37, 42, 64, 140, $147,181-2,242$; mass $8,10,16,25$, $63,130,163,206,221$

media consumption 17-8

metadiscourse 198

metaphors 3, 4, 33, 34, 35, 36, 37, 38, 40, 41, 43, 44, 45, 77, 136, 234

misinformation 2-3, 16-21, 26, 28, 31-2

Muslim 23, 58, 63, 137, 194, 199-200, 202-3, 207, 213-6, 221-4, 226, 228, 230-4, 236

Myanmar 59, 63, 70

Obama, Barack 147, 199

occupy (social movement) 49, 132, 144

online deliberation 4, 49-50, 54-5, 57,61

online disinhibition $69,81,82$

orientalism 221, 223-5, 229, 231, 234-5

otherness 150-1, 221-2

participatory society $1-3$

polarizing 5-6, 21, 26, 115, 118-9, 121, 124-5, 205, 207-9, 217

politicians 5-6, 15-6, 18, 20, 22-3, 25, $27,33,58,61,88,99,100,103,109$, $117,120,122-6,128,130,132-3$,
135-9, 141, 145, 147, 150, 152, 154, $156,159,241-2$

populism $6,64,87,95-7,114,127-8$, 130-4, 136-7, 139, 142-4, 195, 204, 208, 219

post-truth $96,114,129,149$

problematisation 181

propaganda $7,145-8,150,152-6$, $159-62,171,203$

private messaging networks 18

public sphere $19,37,45,46,64,115$, 192, 193, 204, 220, 250

racism $63,67-71,73-4,76-82,101$, 118, 198, 203-4, 216, 223, 234, 243, 249

radicalism $6,47,115,118-9,127,143$

Reagan, Ronald 20, 28, 84

Sánchez, Pedro 15, 21-2, 26, 117, 120, 124,241

selective exposure theory (Festinger) 2, 9-11, 29-31, 46, 113, 128

sexism 87,89

social networks 18, 23-4, 29, 32,

$113-5,118,174,193-4$,

198,203

spiral of silence (Noelle-Neumann) 40, 47,62

stereotyping 98, 110, 223, 233-4

Tea Party (political movement) 132 technological affordances 194, 196 television 83, 85-6, 93, 117, 159, 161, $192,221-3,226,234-5$

user-distributed content 17, 31

verification $18,20-1,29$

viral $18,25,31,68,88,139,141$

visual style analysis $85-9$

WhatsApp 18, 237, 249

Zuckerberg, Mark 17 